\title{
PROCESAMIENTO DE SEÑALES DE TOMOGRAFÍA DE IMPEDANCIA ELÉCTRICA PARA EL ESTUDIO DE LA ACTIVIDAD CEREBRAL
}

Tesis de Doctorado

\section{Mariano FERNÁNDEZ CORAZZA}

Presentada ante la Facultad de Ingeniería de la Universidad Nacional de La Plata como requisito para la obtención del grado académico de

\section{DOCTOR EN INGENIERÍA}

Directores: Dr. Nicolás von Ellenrieder

Dr. Carlos Horacio Muravchik

Jurado de tesis: Dr. Máximo Eugenio Valentinuzzi

Dr. Raúl González Lima

Dr. Hugo Leonardo Rufiner

Laboratorio de Electrónica Industrial, Control e Instrumentación

Departamento de Electrotecnia, Facultad de Ingeniería, UNLP

Fecha de defensa oral y pública: 18 de marzo de 2015 


\section{Dedicada a}

mi esposa Vanesa

y a mis padres Silvia y Jorge. 
Quienes descubrieron las corrientes electromagnéticas nunca llegaron a tener conciencia del nuevo universo apenas generado, desde la misma muerte hasta la cuasi-resurrección, desde 'mágicas' curaciones hasta la exploración de los espacios, pequeños y aparentemente insondables de la mente humana, inmensos y aún desconocidos como las galaxias.

Dr. Ing. Máximo Eugenio Valentinuzzi 


\section{Resumen}

La tomografía de impedancia eléctrica (EIT) permite estimar la conductividad eléctrica interna de un cuerpo. Consiste en aplicar una corriente eléctrica sobre su frontera y medir el potencial eléctrico resultante mediante un arreglo de sensores. Es considerada como una potencial herramienta de diagnóstico médico, caracterizada principalmente por su portabilidad y relativo bajo costo. Si bien se encuentra aún en etapa de desarrollo, está comenzando a ser utilizada en centros de salud para la caracterización del aparato cardio-respiratorio y existe un creciente interés en su aplicación a las neurociencias. Por ejemplo, es posible utilizar la EIT para construir modelos virtuales de la cabeza más precisos mediante la estimación de la conductividad eléctrica de los principales tejidos de la cabeza como un conjunto de parámetros relativamente pequeño, modalidad denominada EIT paramétrico. También se puede utilizar la EIT para generar un mapa de la distribución de conductividad eléctrica interna de un objeto, llamado problema de reconstrucción en EIT. Los cambios de la conductividad eléctrica en la cabeza pueden estar asociados a la actividad neuronal, a focos epilépticos, a accidentes cerebro-vasculares o a tumores. Ambas modalidades de EIT requieren la resolución del problema directo (PD), que consiste en el cálculo de la distribución de potencial eléctrico en el objeto originada por la inyección de corriente sobre su superficie, suponiendo que la conductividad interna es conocida.

La estimulación de corriente continua transcraneal (tDCS) es físicamente muy similar a la EIT, pero la corriente eléctrica es aplicada sobre el cuero cabelludo de modo de alterar la tasa de disparos de poblaciones de neuronas en una región de interés. Es una potencial alternativa al empleo de psicofármacos para tratar desórdenes como epilepsia o depresiones.

En esta tesis se desarrollan y analizan nuevos métodos para distintos problemas de EIT, centrándose mayormente en aplicaciones a la cabeza humana, y de tDCS. En primer lugar, se describen soluciones analíticas y numéricas para el PD en EIT, 
estas últimas basadas en el método de los elementos finitos. Luego, se desarrolla un nuevo procedimiento para resolver el PD con bajo costo computacional basado en la formulación del PD en electroencefalografía (EEG).

Se propone un nuevo método para determinar la forma de onda de la fuente de corriente que permite desafectar la actividad propia del cerebro con un bajo número de muestras temporales. En EIT paramétrico, se utiliza la cota de CramérRao (CRB) para determinar pares de electrodos convenientes para la inyección de corriente y para analizar límites teóricos en la estimación de las conductividades del cráneo y del cuero cabelludo, modelizándolos como tejidos isótropos y anisótropos. A su vez, se propone el estimador de máxima verosimilitud (MLE) como herramienta para realizar las estimaciones. El MLE se aplica a mediciones simuladas y reales de EIT mostrando un desempeño muy cercano a los límites teóricos.

Para el problema de reconstrucción en EIT se adapta el algoritmo sLORETA, muy utilizado en el problema de localización de fuentes de actividad neuronal en EEG. Además, se lo modifica levemente para incorporar la regularización espacial de Laplace. Por otro lado, se introduce la utilización de filtros espaciales adaptivos para localizar cambios de conductividad de pequeño tamaño y estimar su variación temporal. Los resultados muestran mejoras en sesgo y resolución, en comparación con algoritmos de reconstrucción típicos en EIT. Estas mejoras son potencialmente ventajosas en la detección de accidentes cerebro-vasculares y en la localización indirecta de fuentes de actividad neuronal.

En tDCS, se desarrolla un nuevo algoritmo para la determinación de patrones de inyección de corriente basado en el principio de reciprocidad y que considera restricciones de seguridad y de hardware. Los resultados obtenidos a partir de simulaciones muestran que el desempeño de dicho algoritmo es comparable al desempeño de algoritmos de optimización tradicionales cuyas soluciones implicarían un equipamiento comparativamente más complejo y costoso.

Los métodos desarrollados en la tesis son comparados con métodos pre-existentes y validados a través de simulaciones numéricas por computadora, mediciones sobre maquetas experimentales (ó 'fantomas') y, de acuerdo con las posibilidades experimentales y respetando los principios de la bioética, mediciones reales sobre humanos. 


\section{Abstract}

Electrical impedance tomography (EIT) is a technique to estimate the electrical conductivity of an object. It consists in the application of an electric current on its boundary and the measurement of the resulting electric potential with a sensor array. In clinical practise, it is considered as a potential diagnostic tool characterized by its portability and relatively low cost. While it is still in a development stage, it is starting to be used in health centers to characterize the cardio-respiratory system. In turn, there is an increasing interest of EIT in neuroscience. For example, EIT can be used to estimate the electrical conductivity of the main tissues of the head as a set of a relatively low number of parameters, which is known as bounded or parametric EIT. This is useful for several medical imaging techniques that require realistic and accurate virtual models of the head. EIT can also be used to generate a map of the internal distribution of the electrical conductivity, known as the reconstruction problem. Tracking conductivity changes inside the head is of great interest as they may be related to neuronal activity, epileptic foci, acute stroke, or tumors. Both modalities of EIT require the solution of the EIT forward problem (FP), i.e., the computation of the electric potential distribution due to current injection on the scalp assuming that the electrical conductivity is known.

The transcranial direct current stimulation (tDCS) is another technique which is physically very similar to EIT. It consists in injecting a small electric current in a convenient way such that it stimulates specific neuronal populations, increasing or decreasing their firing rate. It is considered as an alternative to psychoactive drugs in the treatment of brain disorders such as epilepsy or depression.

This thesis describes the development and analysis of new methods for EIT FP, parametric EIT, reconstruction in EIT, and tDCS, focusing primarily (although not exclusively) in applications to human head. We first describe analytical and numerical approaches for the EIT FP, where the numerical approach is based on 
the finite element method. Then, we develop a new procedure to solve the EIT FP based on the electroencephalography (EEG) FP formulation, which results in computational advantages.

We propose a new method to determine the waveform of the electric current source such that the neuronal activity of the brain can be neglected with the smallest possible number of time samples. In parametric EIT, we use the Cramér-Rao bound (CRB) to determine convenient electrode pairs for the current injection and theoretical limits in the estimation of the electrical conductivity of the main tissues of the head, which we model as isotropic and anisotropic. We propose the maximum likelihood estimator (MLE) to estimate these conductivities and we test it with simulated and real EIT measurements, showing that the MLE performs close to the CRB.

We adapt the sLORETA algorithm to the reconstruction problem in EIT. This algorithm is being widely used in the source localization problem in EEG. We also slightly modify it to include the Laplace smoothing prior in the solution. Likewise, we introduce the use of adaptive spatial filters in the localization of conductivity changes and the estimation of its time courses from EIT measurements. The results show improvements over typical EIT algorithms. These improvements may benefit the early detection of acute strokes and the localization of neuronal activity using EIT.

In tDCS, we develop a new algorithm to determine convenient current injection patterns. It is based on the reciprocity principle and considers hardware and safety constraints. Our simulation results show that this method performs similarly to other commonly used algorithms that require more complex and costly equipments.

The methods we develop and study in this thesis are compared with pre-existing methods and are validated through numerical simulations, measurements on phantoms and, according to the experimental possibilities and bioethical principles, humans. 


\section{Agradecimientos}

A las instituciones que financiaron la realización de esta tesis: el Consejo Nacional de Investigaciones Científicas y Técnicas, la Universidad Nacional de La Plata, la Comisión de Investigaciones Científicas de la Provincia de Buenos Aires y la Agencia Nacional de Promoción Científica y Tecnológica. Al Instituto LEICI por proporcionar el lugar y el material de trabajo.

A los Dres. Sergei Turovets y Don Tucker del NeuroInformatics Center, University of Oregon, Eugene, OR, USA y de Electrical Geodesics Inc., Eugene, OR, USA por avalar mi estadía en dichas instituciones, por brindarme una invaluable cantidad de datos experimentales y por propiciar un enriquecedor intercambio de ideas. Además, a la Fundación Bunge \& Born y a la Comisión Fulbright por su apoyo económico y logístico en esa experiencia.

Al Ing. Eduardo Santos y al Dr. Franco Simini del Núcleo de Ingeniería Biomédica de la Universidad de la República, Montevideo, Uruguay por brindar datos reales de tomografía de impedancia eléctrica sobre tanques experimentales y al Dr. Jean Gotman de McGill University, Canadá por proporcionar registros de electroencefalografía.

Al Dr. Alejandro Blenkmann y a la Dra. Silvia Kochen, del Centro de Epilepsia del Hospital Ramos Mejía y del Instituto de Biología Celular y Neurociencias "Prof. E. de Robertis" de la UBA, por su colaboración y constante intercambio de ideas para evacuar dudas referentes a la neurología.

A mis directores Nicolás von Ellenrieder y Carlos Muravchik, a quienes no sólo agradezco la dirección de mi doctorado, sino también su confianza, su invaluable apoyo en mi formación científica y académica, su gran predisposición ante todo tipo 
de dudas y consultas, y su amistad. También agradezco al Dr. Leandro Beltrachini por su gran colaboración y ayuda en el aprendizaje de diversos temas relacionados con la tesis.

A los miembros del jurado, Dr. Máximo Eugenio Valentinuzzi, Dr. Raúl González Lima y Dr. Hugo Leonardo Rufiner, por haber aceptado evaluar la presente tesis doctoral y por sus valiosas y atinadas correcciones y sugerencias.

A todos los integrantes del Laboratorio LEICI por proporcionar un ambiente de trabajo cómodo y propicio para la realización del doctorado, en especial a Juan Pablo Pascual y Sebastián Pazos por su ayuda y constante intercambio de charlas e ideas. Al Dr. Hernán De Battista por propiciar mi llegada al laboratorio y mi dedicación a la investigación. También agradezco a los integrantes de la Cátedra Matemática B por su apoyo en mi formación académica y científica.

En especial agradezco a mi esposa Vanesa por su amor, apoyo y compañía constante durante todo el período del doctorado, por haber alentado mi iniciación en la investigación y, en general, por compartir su enorme corazón y calidad humana conmigo. Además, agradezco especialmente a mis padres, Silvia y Jorge, por su gran ayuda, apoyo incondicional y cariño durante el doctorado y, más aún, durante toda mi vida. También, agradezco a demás miembros de mi familia y a mis amigos. 


\section{Índice general}

Índice general $\quad x i$

Índice de figuras $\quad x v$

Índice de tablas $\quad$ xix

Lista de abreviaturas $\quad$ xxi

1. Introducción 1

1.1. Resultados preexistentes . . . . . . . . . . . . . . 6

1.2. Contribuciones originales . . . . . . . . . . . . . . 11

1.3. Trabajos completos provenientes de la tesis . . . . . . . . . . . 14

1.3.1. Trabajos completos en revistas internacionales reconocidas . . 14

1.3.2. Trabajos completos aceptados . . . . . . . . . . . . 14

1.3.3. Trabajos en congresos internacionales . . . . . . . . . . 15

1.3.4. Trabajos en congresos nacionales . . . . . . . . . 15

1.3.5. Trabajos en preparación . . . . . . . . . . . . 16

1.4. Organización de la tesis $\ldots \ldots \ldots \ldots \ldots$

2. Tomografía de impedancia eléctrica $\quad 19$

2.1. Introducción . . . . . . . . . . . . . . . . . . . . . . . 19

2.2. Planteo del problema . . . . . . . . . . . . . . . . . . 20

2.3. Aproximaciones y modelos . . . . . . . . . . . . . . . . 22

2.3.1. Aproximación cuasi-estática . . . . . . . . . . . . . 22 
2.3.2. Modelo eléctrico de la cabeza . . . . . . . . . . . . . 22

2.3.3. Intensidad de corriente en EIT . . . . . . . . . . . . . . . . 24

2.3.4. Ruido en EIT . . . . . . . . . . . . . . . . . . . 25

2.3.5. Equipamiento en EIT . . . . . . . . . . . . . . 25

2.4. Problema directo . . . . . . . . . . . . . . . 26

2.4.1. Solución analítica . . . . . . . . . . . . . . . 27

2.4.2. Solución numérica . . . . . . . . . . . . . . . . . 31

2.4.3. Validación . . . . . . . . . . . . . . . 36

2.5. Modelo de señal . . . . . . . . . . . . . . . . . . . . . . . . . . . . 38

2.6. Paralelismo entre EIT y EEG . . . . . . . . . . . . . . . . . 39

2.6.1. Alternativa para el problema directo en EIT . . . . . . . . . . 41

2.6.2. Verificación numérica . . . . . . . . . . . . . . . . . 42

2.7. Conclusiones . . . . . . . . . . . . . . . . . . . . . . . 43

3. EIT paramétrico $\quad 45$

3.1. Introducción . . . . . . . . . . . . . . . . . . 45

3.2. Estimador de máxima verosimilitud (MLE) . . . . . . . . . . . . . 47

3.3. Cota de Cramér-Rao (CRB) . . . . . . . . . . . . . . . . 48

3.3.1. CRB para la formulación numérica . . . . . . . . . . . . . . . 48

3.4. Algoritmos de optimización . . . . . . . . . . . . . . . . . . . . . . 49

3.5. Experimentos con datos simulados . . . . . . . . . . . . . . . 50

3.5.1. Modelo esférico de tres capas . . . . . . . . . . . . . . 50

3.5.2. Modelos de geometrías realistas . . . . . . . . . . . . . 53

3.6. Experimentos con datos reales . . . . . . . . . . . . . . . . 59

3.6.1. Modelo eléctrico de la cabeza . . . . . . . . . . . . . . . 61

3.6.2. Resultados . . . . . . . . . . . . . . . 62

3.7. Discusión y conclusiones . . . . . . . . . . . . . . . . 64

$\begin{array}{ll}\text { 4. Forma de onda de corriente } & 69\end{array}$

4.1. Introducción . . . . . . . . . . . . . . . . . . . . . . 69

4.2. Modelo de señal . . . . . . . . . . . . . . . . . . . . . 70

4.3. Estimador de máxima verosimilitud (MLE) . . . . . . . . . . . . 71 
4.4. Forma de onda óptima . . . . . . . . . . . . . . . . . . . . 73

4.5. Resultados . . . . . . . . . . . . . . . . . . . 75

4.6. Conclusiones . . . . . . . . . . . . . . . . . . 78

5. Reconstrucción en EIT $\quad 81$

5.1. Introducción . . . . . . . . . . . . . . . . . . . . 81

5.2. Algoritmos . . . . . . . . . . . . . . . . . . 83

5.2.1. Algoritmos Tikhonov . . . . . . . . . . . . . . . 83

5.2.2. Algoritmos sLORETA ................ 84

5.3. Resultados . . . . . . . . . . . . . . . . 86

5.3.1. Simulaciones numéricas . . . . . . . . . . . . . 86

5.3.2. Mediciones en una maqueta experimental . . . . . . . . . . 88

5.4. Discusión y conclusiones . . . . . . . . . . . . . . . . . . . . 89

6. Filtrado espacial en EIT (EIT-SF) 93

6.1. Introducción . . . . . . . . . . . . . . . . . . . . . 93

6.2. Principios del filtrado espacial . . . . . . . . . . . . . . . . 95

6.2.1. Formulación . . . . . . . . . . . . . . . . 95

6.2.2. Matrices de covarianza y parámetro de regularización . . . . . 97

6.2.3. Variantes del filtro LCMV . . . . . . . . . . . . . . . . . . 99

6.3. Resultados generales . . . . . . . . . . . . . . . . . 100

6.3.1. Filtro espacial bidimensional en simulaciones . . . . . . . . . . 103

6.3.2. Filtro espacial bidimensional en mediciones reales . . . . . . . 107

6.3.3. Filtro espacial tridimensional en simulaciones . . . . . . . . . 109

6.3.4. Filtro espacial tridimensional en mediciones reales . . . . . . 114

6.4. Resultados particulares con aplicaciones en el cerebro . . . . . . . . . 118

6.4.1. Análisis de ruido y número de sensores . . . . . . . . . . . . . 120

6.4.2. Análisis de la dinámica y la geometría . . . . . . . . . . . . . 122

6.5. Discusión . . . . . . . . . . . . . . . . . 125

6.5.1. Sesgo y resolución . . . . . . . . . . . . . . . . . . . . 125

6.5.2. Estimación de la forma de onda . . . . . . . . . . . . . . . . . 128

6.5.3. Variantes del filtro LCMV . . . . . . . . . . . . . . . . . . 128 
6.5.4. Error en la posición de los sensores . . . . . . . . . . . . . . 129

6.5.5. Potenciales aplicaciones de EIT-SF en el cerebro . . . . . . . . 130

6.6. Conclusiones . . . . . . . . . . . . . . . . . . . . . . . 131

7. Optimización en tDCS 133

7.1. Introducción . . . . . . . . . . . . . . . . . . 133

7.2. Problema directo . . . . . . . . . . . . . . . 134

7.3. Algoritmos de optimización . . . . . . . . . . . . . . . . . . 135

7.3.1. Mínimos cuadrados (LS) . . . . . . . . . . . . . . 136

7.3.2. LCMV . . . . . . . . . . . . . . . . 136

7.4. Principio de reciprocidad . . . . . . . . . . . . . . . 137

7.5. Patrones basados en reciprocidad . . . . . . . . . . . . . . 139

7.6. Experimentos simulados . . . . . . . . . . . . . . . . 141

7.6.1. Resultados . . . . . . . . . . . . . . . . . . . . 142

7.7. Discusión . . . . . . . . . . . . . . . . . . . 144

7.8. Conclusiones . . . . . . . . . . . . . . . . . . . . . 149

$\begin{array}{ll}\text { 8. Conclusiones } & 151\end{array}$

Apéndice A. Resultados en EIT paramétrico detallados 155

Apéndice B. Parámetro de regularización 159

$\begin{array}{ll}\text { Bibliografía } & 161\end{array}$ 


\section{Índice de figuras}

2.1. Electrodos . . . . . . . . . . . . . . . . . . . . 24

2.2. Sensibilidad del potencial eléctrico . . . . . . . . . . . 30

2.3. Potencial eléctrico analítico y numérico . . . . . . . . . . . . 37

2.4. Potencial eléctrico modelos realista y esférico . . . . . . . . . . . 37

2.5. Flujo de corriente en un corte coronal . . . . . . . . . . . . . . 38

2.6. Alternativa para la matriz de sensibilidad en EIT - 1 . . . . . . . 43

2.7. Alternativa para la matriz de sensibilidad en EIT - $2 \ldots \ldots$. . . . 44

3.1. Promedio de las estimaciones para 64 electrodos . . . . . . . . . . 51

3.2. Promedio de las estimaciones para 32 electrodos . . . . . . . . . . . 52

3.3. Promedio de las estimaciones para 16 electrodos . . . . . . . . . 52

3.4. Varianza de las estimaciones . . . . . . . . . . . . . . . . 53

3.5. Modelo para las simulaciones en geometrías realistas. . . . . . . . 55

3.6. CVB para el modelo isótropo . . . . . . . . . . . . . 59

3.7. CVB para los modelos parcialmente isótropo y anisótropo . . . . . 60

3.8. CVB y ECV para los tres modelos . . . . . . . . . . . . . 60

3.9. Red de 128 electrodos . . . . . . . . . . . . . . . . . . . . . 61

3.10. Modelo eléctrico detallado de la cabeza . . . . . . . . . . . . . 63

3.11. Estimaciones con bEIT usando datos reales . . . . . . . . . . . . . 64

4.1. Formas de onda óptimas . . . . . . . . . . . . . 76

4.2. Varianza total del estimador $-1 \ldots \ldots \ldots$. . . . . . . 77

4.3. Varianza total del estimador $-2 \ldots \ldots \ldots \ldots$ 
5.1. Mejores reconstrucciones de ambos fantomas . . . . . . . . . . 86

5.2. Error y desviación estándar de las reconstrucciones . . . . . . . . . . 87

5.3. Error de reconstrucción del primer fantoma . . . . . . . . . . . . 88

5.4. Error de reconstrucción del segundo fantoma . . . . . . . . . . . . 90

5.5. Sesgo para el segundo fantoma . . . . . . . . . . . . . . . . 90

5.6. Reconstrucciones del fantoma real . . . . . . . . . . . . . . . 92

6.1. Modelo para generar las señales . . . . . . . . . . . . . . . . . 102

6.2. Simulación de un sólo cambio de conductividad: CCI . . . . . . . . 103

6.3. Simulación de un sólo cambio de conductividad: salida . . . . . . . . 104

6.4. Simulación de dos cambios de conductividad simultáneos: CCI . . . . 105

6.5. Simulación de dos cambios de conductividad simultáneos: salidas . . . 106

6.6. Fotos del globo . . . . . . . . . . . . . . . . . . 107

6.7. Mapas de CCI bidimensionales obtenidos con datos reales . . . . . . . 108

6.8. Salidas del filtro espacial bidimensional con datos reales . . . . . . . 109

6.9. Modelo de tanque cilíndrico . . . . . . . . . . . . . . . . . . . 110

6.10. Mapas de CCI tridimensionales obtenidos con datos simulados . . . . 111

6.11. Salidas del filtro tridimensional con datos simulados . . . . . . . . . . 111

6.12. Simulaciones con ruido en la ubicación de los sensores . . . . . . . . . 113

6.13. Variantes del filtro LCMV para datos simulados . . . . . . . . . . . . 113

6.14. Fotos del experimento en tanque cilíndrico . . . . . . . . . . . . . 114

6.15. Mapas de CCI tridimensionales obtenidos con datos reales . . . . . . 116

6.16. Salidas del filtro espacial tridimensional con datos reales . . . . . . 116

6.17. Simulación con dos objetos en simultáneo . . . . . . . . . . . . . . . 119

6.18. Variantes del filtro LCMV para datos reales . . . . . . . . . . . . . 119

6.19. Mapas de CCI con geometría realista . . . . . . . . . . . . 121

6.20. Error de posición en geometría realista . . . . . . . . . . . . . . 122

6.21. Modelo realista y formas de onda simuladas . . . . . . . . . . . 123

6.22. Mapas de CCI obtenidos para el decrecimiento lineal . . . . . . . . 124

6.23. Centros de gravedad para geometrías realistas . . . . . . . . . . . 124

6.24. Salidas del filtro para geometrías realistas . . . . . . . . . . . 126

6.25. Localización utilizando un modelo de cabeza diferente . . . . . . . . . 127 
7.1. Objetivos o blancos analizados en el estudio de tDCS . . . . . . . 139

7.2. Potencial eléctrico para 128 electrodos . . . . . . . . . . . . . 141

7.3. Potencial eléctrico para 256 electrodos . . . . . . . . . . . . . 142

7.4. Densidad de corriente para 128 electrodos . . . . . . . . . . . . 143

7.5. Densidad de corriente para 256 electrodos . . . . . . . . . . . 144

7.6. Densidad de corriente normal para 256 electrodos . . . . . . . . . 145

7.7. Densidad de corriente tangencial para 256 electrodos . . . . . . . 146

7.8. Densidad de corriente en los objetivos . . . . . . . . . . . . 147

7.9. Direccionalidad y error de posición en los objetivos . . . . . . . 148

7.10. Focalidad o dispersión en los objetivos . . . . . . . . . . . 149 


\section{Índice de tablas}

3.1. Combinaciones de pares utilizados . . . . . . . . . . . . 51

3.2. Valores de conductividad estimados . . . . . . . . . . . 56

3.3. Valores de conductividad de referencia $\ldots \ldots \ldots \ldots$

6.1. Error de posición en fantoma bidimensional . . . . . . . . . 106

6.2. Resolución en fantoma bidimnsional . . . . . . . . . . . . 107

6.3. Error de posición en fantoma tridimensional . . . . . . . . . . . 115

6.4. Resolución en fantoma tridimensional . . . . . . . . . . . . . . 117

6.5. Error de posición en geometrías realistas . . . . . . . . . . . . 125

6.6. Resolución en geometrías realistas . . . . . . . . . . . . . . 125

A.1. EIT paramétrico con datos reales $\ldots \ldots \ldots \ldots \ldots$ 
XX

Índice de tablas 


\section{Lista de abreviaturas}

ACV Accidente Cerebro-Vascular, p.3

bEIT bounded Electrical Impedance Tomography - Tomografía de Impedancia Eléctrica paramétrica, p.2

BEM Boundary Element Method - Método de los Elementos de Contorno, p.31

CCI Conductivity Change Index - Índice de Cambio de Conductividad, p.97

CEM Complete Electrode Model - Modelo de Electrodos Completo, p.39

CoG Center of Gravity - Centro de Gravedad, p.101

CRB Cramér-Rao Bound - Cota de Cramér-Rao, p.48

CSF Cerebro-Spinal Fluid - Líquido Cefalorraquídeo, p.3

CT Computed Tomography - Tomografía Computada, p.1

CVB Coefficient of Variation Bound - Cota del Coeficiente de Variación, p.49

DTI Diffusion Tensor Imaging - Imágenes por Tensor de Difusión, p.20

ECV Estimador del Coeficiente Variacional, p.57

EEG Electroencefalografía, p.1

EIT Electrical Impedance Tomography - Tomografía de Impedancia Eléctrica, p.1

FEM Finite Element Method - Método de los Elementos Finitos, p.31

GN Gauss-Newton, p.97

LCMV Linearly Constrained Minimum Variance - Lineal de Mínima Varianza con Restricciones, p.93

LS Least Squares - Mínimos Cuadrados, p.10

MEG Magnetoencefalografía, p.1

MLE Maximum Likelihood Estimator - Estimador de Máxima Verosimilitud, p.47

MR Magnetic Resonance - Resonancia Magnética, p.1 
PD Problema Directo, p.134

PE Position Error - Error de Posición, p.101

PET Positron Emission Tomography - Tomografía de Emisión de Positrones, p.1

RES Resolución, p.101

RMS Root Mean of the Squares - Valor Cuadrático Medio, p.101

SD Standard Deviation - Desviación Estándar, p.120

SF Spatial Filtering - Filtrado Espacial, p.4

SNR Signal to Noise Ratio - Relación Señal a Ruido, p.98

tDCS transcranial Direct Current Stimulation - Estimulación de Corriente Continua transcraneal, p.1

WGN White Gaussian Noise - Ruido Blanco Gaussiano, p.95 


\section{Capítulo 1}

\section{Introducción}

El cerebro humano es seguramente el objeto conocido más complejo que cabe en un volumen de aproximadamente $1000 \mathrm{~cm}^{3}$. El funcionamiento conjunto de miles de millones de neuronas de un cerebro trabajando presenta aún grandes misterios. Si bien existen algunos documentos de la historia antigua que relacionan el cerebro con el habla o funciones motrices, la gran mayoría de lo que hoy sabemos de él fue develado en los últimos 150 años. El conocimiento actual del funcionamiento del cerebro y de las enfermedades o patologías que lo pueden afectar ha sido mayormente descubierto gracias a distintas herramientas desarrolladas especialmente para su estudio. Entre ellas encontramos la electroencefalografía (EEG), la magnetoencefalografía (MEG), la tomografía computada (CT), la tomografía de emisión por positrones (PET) y la resonancia magnética (MR). La tomografía de impedancia eléctrica (EIT) aparece como otra herramienta para el estudio de la cabeza humana,

incluyendo el cerebro, aunque esta aplicación se encuentra en fase de desarrollo y no es comúnmente utilizada en la práctica clínica. En tanto, la estimulación de corriente continua transcraneal (tDCS) es técnicamente muy similar a la EIT pero difiere en el propósito, ya que en tDCS se busca influir en el funcionamiento del cerebro, constituyendo una herramienta de tratamiento en lugar de ser de diagnóstico como lo es la EIT.

La EIT consiste en estimar la conductividad eléctrica interna de un objeto a partir de aplicarle una corriente eléctrica y medir el potencial eléctrico resultante 
con un arreglo de sensores, generalmente electrodos. Las aplicaciones de EIT para la salud humana son de lo más variadas, entre las que se destacan el estudio del funcionamiento pulmonar, el control del ciclo cardíaco y la detección de tumores. En aplicaciones a la salud humana, la corriente a inyectar es inocua, por lo que se la considera como una técnica mínimamente invasiva. Frente a otras técnicas de imágenes médicas como la MR funcional, la EIT es considerada una técnica de bajo costo, cuyo equipamiento es portable, pero que genera imágenes de relativa baja resolución.

Una aplicación particular de la EIT es la determinación de la conductividad eléctrica de los principales tejidos de la cabeza como un conjunto de parámetros relativamente pequeño. Esta modalidad se basa en modelos de la cabeza humana segmentados, es decir, suponiendo que las superficies que delimitan los distintos tejidos son conocidas, y se conoce generalmente como EIT paramétrico (bEIT, por bounded Electrical Impedance Tomography). Es considerada de gran interés para determinar la conductividad eléctrica del cráneo y del cuero cabelludo, donde EIT presenta una mayor sensibilidad. Un conocimiento preciso de la conductividad de estos tejidos permite mejorar la calidad de los modelos de la cabeza humana, relevantes en el estudio de fenómenos que ocurren dentro del cráneo (como ser la localización de fuentes de actividad neuronal a partir de mediciones de EEG, MEG o EIT, la detección de accidentes cerebro-vasculares utilizando mediciones de EIT, o la precisión en la planificación de tratamientos con tDCS). Otra aplicación de la EIT, más general que EIT paramétrico, es la estimación de la distribución o mapa de la conductividad eléctrica interna de un objeto. En este caso, el número de parámetros a estimar es elevado en relación al número de mediciones disponibles, ya que corresponde al número de píxeles si se utilizan dos dimensiones o vóxeles en el caso de tres dimensiones. Los algoritmos utilizados para estimar estos mapas de conductividad son denominados algoritmos de reconstrucción en EIT. Si se busca reconstruir cambios de conductividad teniendo en cuenta un mapa de conductividad base, se lo llama también EIT en diferencias. Tanto para EIT paramétrico como para reconstrucción en EIT es necesario calcular o predecir el potencial eléctrico esperado en los sensores suponiendo conductividades conocidas, lo que se conoce 
como el problema directo en EIT y está gobernado por las ecuaciones de Maxwell.

Ciertos fenómenos que ocurren dentro de la cabeza humana pueden asociarse a cambios de conductividad, y por ende, pueden ser potencialmente detectados y estudiados por EIT. Entre ellos se encuentran los accidentes cerebrovasculares (ACV), que en el caso de ser hemorrágicos generan un incremento en la conductividad eléctrica por un aumento de concentración de sangre en la zona afectada, y que en el caso de ser isquémicos, presentan un decrecimiento en la conductividad eléctrica debido al efecto de la inflamación celular ante la ausencia de sangre. La activación neuronal también puede asociarse a cambios de conductividad, debido principalmente a un mayor consumo de oxígeno en las zonas más activas y en menor medida a la depolarización neuronal. La posibilidad de detectar actividad neuronal con EIT, permitiría estudiar el funcionamiento normal del cerebro (EIT funcional), como así también, estudiar y diagnosticar ciertas patologías como es el caso de la epilepsia, ayudando en la localización de focos epilépticos y en el estudio de la propagación de las crisis. La EIT presenta una baja sensibilidad para detectar cambios de conductividad interiores al cráneo, debido principalmente a que el cráneo en conjunto con el líquido encefalolorraquídeo (CSF) actúan como un blindaje para la corriente eléctrica cuando la misma es aplicada sobre el cuero cabelludo. Sin embargo, las ventajas mencionadas anteriormente junto con su relativamente buena resolución temporal y la creciente mejora en la tecnología disponible, hacen que la EIT sea considerada como una prometedora técnica para estas aplicaciones. En el caso de la detección de actividad neuronal, la EIT presenta la ventaja adicional de tener la capacidad de detectar activaciones en regiones donde no necesariamente exista un potencial resultante neto de la actividad eléctrica neuronal, condición que es necesaria en EEG y en MEG. Este hecho se debe a que la activación, es decir, la aparición de potenciales de acción, se acompaña de cambios temporales de conductividad.

Existe un paralelismo entre la formulación matemática del problema de localización de fuentes de actividad neuronal mediante mediciones de EEG y la del problema de localización de cambios de conductividad mediante mediciones de EIT. Este paralelismo permite adaptar herramientas y técnicas desarrolladas en el ámbito de EEG o MEG para ser utilizadas en EIT. Una de estas herramientas es la del filtrado 
espacial (SF) o beamforming, cuyo planteo y formulación matemática difiere significativamente de los algoritmos de reconstrucción tomográfica comúnmente utilizados en EIT.

La estimulación de corriente continua transcraneal (tDCS) también consiste en la aplicación de corriente eléctrica, en este caso continua, sobre el cuero cabelludo. A diferencia de la EIT, se busca que la corriente afecte a poblaciones de neuronas de una región de interés, aumentando o disminuyendo la excitabilidad de las neuronas. Este efecto de la corriente continua sobre las neuronas hace de la tDCS una potencial alternativa a la utilización de psicofármacos para el tratamiento de ciertas patologías asociadas al cerebro como las epilepsias o las depresiones. La tDCS es técnica y matemáticamente muy similar a la EIT, ya que también se basa en las ecuaciones de Maxwell para describir la distribución de la corriente en la cabeza humana. El objetivo en la determinación de patrones de inyección de corriente en tDCS es concentrar la densidad de corriente sobre una región de interés y reducir la corriente en el resto del cerebro. Ésta es la principal ventaja frente a los psicofármacos, que indefectiblemente afectan a todo el cerebro por igual. Para lograr que el patrón de inyección de corriente a través de un arreglo de electrodos en el cuero cabelludo produzca una densidad de corriente lo más cercana posible a la deseada, se utilizan distintos algoritmos de optimización. Sin embargo, las soluciones obtenidas con estos algoritmos generalmente suponen que el equipamiento posee una fuente de corriente independiente para cada electrodo, lo que implica equipamientos complejos y costosos. El principio de reciprocidad relaciona el potencial eléctrico sobre el cuero cabelludo debido a una fuente dipolar en algún lugar del cerebro, y el gradiente del potencial eléctrico generado en el mismo punto espacial debido a una distribución de corriente aplicada sobre el cuero cabelludo. Este principio puede ser utilizado como guía para determinar patrones de inyección de corriente adecuados en tDCS.

Esta tesis estudia la aplicabilidad de EIT paramétrico para estimar la conductividad del cráneo y del cuero cabelludo, modelizando ambos tejidos como isòtropos y anisòtropos, y determinando pares de inyección de corriente convenientes. Se realiza un análisis teórico de los límites de desempeño para distintos niveles de ruido de manera independiente al estimador que se utilice, a través del cálculo de la CRB. 
Además, se desarrolla un método para determinar la forma de onda óptima de la corriente a inyectar en EIT de manera que se requiera un menor número de muestras temporales para desafectar las señales eléctricas generadas por el propio funcionamiento del cerebro, que actúan como ruido indeseado en las mediciones de EIT.

Se adaptan algunos algoritmos de reconstrucción utilizados en EEG, para su aplicación a la EIT, como ser sLORETA ${ }^{1}$ y sLORETA con regularización espacial de Laplace ${ }^{2}$. También se muestra y analiza detalladamente la adaptación de técnicas de filtrado espacial a EIT para localizar cambios de conductividad y estimar su evolución temporal, estudiando su desempeño y aplicabilidad a fenómenos que ocurren dentro de la cabeza humana. Para estos propósitos de desarrolla, a su vez, una alternativa computacionalmente ventajosa para resolver el problema directo de EIT en diferencias basándose en el paralelismo con el problema de localización de fuentes en EEG.

Por último, se estudian algoritmos de optimización para la aplicación de corriente en la tDCS basados en el principio de reciprocidad, que tienen en cuenta restricciones de equipamientos más simples y que, además, consideran las restricciones de seguridad propias de la tDCS. Se analiza y compara el desempeño de las soluciones obtenidas con estos métodos frente a soluciones óptimas que consideran restricciones de hardware menores.

Desde un punto de vista general, los análisis presentados en esta tesis permiten ampliar la disponibilidad de métodos y herramientas para la EIT y tDCS, centrándose fundamentalmente, pero no exclusivamente, en aplicaciones de la cabeza humana.

${ }^{1}$ sLORETA (standarized Low Resolution Electromagnetic Tomography) es un algoritmo desarrollado por Pascual-Marqui (2002) muy utilizado en el problema de localización de fuentes de actividad neuronal en Electroencefalografia (EEG) y Mgnetoencefalografia (MEG).

${ }^{2}$ La regularización espacial de Laplace es una condición que impone suavidad en la solución considerando cierta relación entre los elementos vecinos 


\subsection{Resultados preexistentes}

Si bien la EIT tiene sus inicios en la medición de propiedades geológicas hace aproximadamente 85 años, la EIT aplicada a la práctica clínica es considerada relativamente moderna, desarrollada en los últimos 35 años. Aplicada a la medicina, es una técnica mínimamente invasiva y de bajo costo que permite la detección de tumores de mama, el monitoreo del funcionamiento pulmonar, el estudio del ciclo cardíaco y la obtención de imágenes de actividad cerebral, entre otras aplicaciones (Bayford, 2006). Su aplicación en la cabeza humana ha sido explorada en los últimos 20 años, con resultados aún no completamente satisfactorios en la generación de imágenes internas a la cavidad craneal (Holder, 2008).

Las ecuaciones de Maxwell son la base del electromagnetismo, y tanto el problema directo de la EIT como de tDCS encuadran dentro de un problema de electromagnetismo sobre un sólido con condiciones de frontera de Neumann ${ }^{3}$. Una de las primeras soluciones analíticas sobre una esfera homogénea cuando existen dos fuentes de corriente puntuales y opuestas fue desarrollada por Frank (1952), y más tarde Rush y Driscoll (1968) publicaron la solución con las fuentes de corriente colocadas sobre la superficie. En la literatura se pueden encontrar diversos ejemplos de soluciones analíticas sobre geometrías regulares como círculos (Calderón, 1980; Isaacson et al., 2004), esferas (Gonçalves et al., 2000) y cilindros (Kleinermann et al., 2000), como así también de soluciones numéricas utilizando el método de elementos de contorno (BEM) (de Munck et al., 2002), el método de elementos finitos (FEM) (Abascal et al., 2007) o el método de diferencias finitas (FDM) (Turovets et al., 2014).

EIT paramétrico surge como una técnica para estimar la conductividad eléctrica de los principales tejidos de la cabeza, previa segmentación de ella, especialmente para el cráneo y el cuero cabelludo. Las mediciones in-vitro no han sido conclusivas y no siempre se extrapolan a los valores in-vivo. La conductividad de estos tejidos varía mucho según la literatura, fundamentalmente debido a la dispersión entre distintos sujetos y a la inhomogeneidad dentro de un mismo sujeto (Geddes y Baker, 1967;

\footnotetext{
${ }^{3}$ Las condiciones de Neumann se refieren a conocer la derivada del potencial eléctrico en la frontera. Por otro lado, las condiciones de borde de Dirichlet se refieren a conocer directamente el potencial sobre la frontera.
} 
Oostendorp et al., 2000; Hoekema et al., 2003; Lai et al., 2005; Sadleir y Argibay, 2007; Tang et al., 2008). Una buena recopilación de las propiedades eléctricas de los tejidos de la cabeza pueden encontrarse en Horesh (2006).

El cráneo es altamente resistivo comparado con los tejidos que lo rodean, actuando como un escudo eléctrico entre el cuero cabelludo y el cerebro. Si bien generalmente se lo supone como un tejido homogéneo e isótropo, se conoce que está compuesto mayormente por dos capas de hueso compacto y una capa de hueso esponjoso en el medio por lo que también se lo ha modelado como dos tejidos diferentes, aunque el costo computacional es mayor (Dannhauer et al., 2011). Otro modelo utilizado es suponer al cráneo como un tejido homogéneo pero anisótropo (Wolters et al., 2006), aunque la relación de anisotropía radial:tangencial (relación entre las componentes radial y tangencial de la conductividad) varía desde 1:10 (Rush y Driscoll, 1968) hasta 1:1.6 (Sadleir y Argibay, 2007). Algo similar ocurre con su conductividad, que varía entre $0,04 \mathrm{~S} / \mathrm{m}$ y $0,004 \mathrm{~S} / \mathrm{m}$, discutiéndose incluso valores fuera de este rango (Geddes y Baker, 1967; Rush y Driscoll, 1968; Oostendorp et al., 2000; Hoekema et al., 2003; Horesh, 2006).

El cuero cabelludo presenta un rol muy importante en las distintas modalidades de EIT ya que es el tejido que se encuentra en contacto directo con la corriente aplicada. Aunque está compuesto por una mezcla de distintos tipos de piel, grasa y músculo, la diferencia de conductividad entre estos tejidos no es tan grande y por otro lado subdividir al cuero cabelludo es muy dificultoso, por lo que generalmente se lo modela como homogéneo e isótropo. Sin embargo, debido principalmente a la conductividad de los músculos, también se lo ha modelado como un tejido homogéneo pero anisótropo con una relación radial:tangencial de 1:1.5. Si bien pocos estudios han medido su conductividad, es aceptado suponer un valor de conductividad entre 0.3 y $0.5 \mathrm{~S} / \mathrm{m}$ (Horesh, 2006).

EIT paramétrico ha sido utilizado anteriormente para estimar las conductividades de los principales tejidos de la cabeza. Eriksen (1990) propuso el método utilizando electrodos sólo en el cuero cabelludo, y realizó las primeras mediciones in-vivo utilizando un modelo de cabeza de tres capas esférico. Luego Ferree et al. (2000) desarrollaron un método para la estimación de las conductividades de los teji- 
dos de la cabeza basándose en la solución analítica del modelo esférico de tres capas. Por otro lado, De Munck et al. (1999) formalizaron el método y lo generalizaron para un número arbitrario de parámetros aunque menor a los necesarios en el problema de reconstrucción de EIT, y fueron quienes lo bautizaron como EIT paramétrico. Del mismo grupo, en Gonçalves et al. (2000, 2003) se continuó desarrollando esta idea obteniendo mediciones reales y se incorporó el uso de modelos de la cabeza geométricamente realistas. Sin embargo, ninguno de estos estudios propuso estimar la conductividad eléctrica del cráneo y del cuero cabelludo suponiéndolos tejidos anisótropos.

El problema de reconstrucción en EIT, es decir, el problema de estimar un mapa o distribución de conductividad interna, es generalmente subdeterminado o al menos mal condicionado. La subdeterminación proviene del hecho que en general el problema posee más incógnitas que datos, es decir, el número de píxeles o vóxeles de la imagen o mapa a reconstruir es mayor que el número de mediciones. En EIT, pueden utilizarse distintos pares de inyección de corriente lo que aumenta el número de mediciones independientes dado un número fijo de electrodos. El mal condicionamiento es debido principalmente a la baja sensibilidad del método para distinguir cambios de conductividad alejados de los sensores debido al efecto conjunto del cráneo y del CSF. Con estas características, el problema generalmente se linealiza y se busca la solución de mínima norma con algún tipo de regularización. Un excelente resumen de los algoritmos de reconstrucción de EIT se encuentra en Lionheart et al. (2004). Sin embargo, otros algoritmos de reconstrucción muy utilizados y ampliamente aceptados en EEG no han sido analizados para EIT linealizado, aunque la formulación matemática de ambas técnicas es equivalente.

La temprana detección y caracterización de ACVs es una de las más prometedoras entre las potenciales aplicaciones de EIT (Clay y Ferree, 2002; Horesh, 2006; Abascal et al., 2008). Los ACVs pueden clasificarse en hemorrágicos, generalmente causados por la ruptura de una vena o arteria lo que implica un derrame sanguíneo, e isquémicos, generalmente causados por el bloqueo de alguna arteria, lo que significa la no irrigación a una parte del cerebro. Si el ACV es isquémico, se puede administrar una droga, el activador de plasminógeno tisular recombinante (r-tPA, 
por recombinant tissue plasminogen activator), dentro de las 4 horas luego de iniciado el ACV, con pronósticos favorables (Kunst y Schaefer, 2011; Nentwich y Veloz, 2012). El problema es que esta misma droga es contraindicada en el caso de ACVs hemorrágicos, de ahí la importancia de detectar y caracterizar el tipo de ACV rápidamente. En los ACVs isquémicos la ausencia de sangre hace que las células se inflamen, reduciendo la conductividad eléctrica en hasta un $30 \%$ (Horesh, 2006), mientras que en los ACVs hemorrágicos, la conductividad eléctrica aumenta debido a que la sangre es más conductora que el tejido cerebral, aunque este aumento de conductividad es más difícil de determinar ya que depende de la cantidad de sangre derramada que varía considerablemente en cada caso. El problema de utilizar EIT para detectar ACVs es que necesita alguna medición previa para usar como referencia o base de comparación, la cual generalmente no estaría disponible. Para esto se propuso EIT de múltiples frecuencias (MF-EIT), aunque la complejidad del equipo aumenta considerablemente (Horesh, 2006).

EIT es una técnica prometedora para detectar y caracterizar también otros cambios de conductividad que pueden ocurrir dentro del cerebro. Un pequeño incremento de la conductividad, entre 1 y $10 \%$, es de esperar que ocurra en una región con alta actividad neuronal (Holder, 2008), como puede ocurrir en tejido epileptogénico durante una crisis en una epilepsia focal (Fabrizi et al., 2006), o en la actividad producida por potenciales evocados, es decir, activación frente a un estímulo controlado y conocido. Cambios de conductividad aún más pequeños son producidos por la rápida depolarización neuronal (Gilad et al., 2009; Holder, 2008). Poder detectar actividad neuronal, métodos como EEG o MEG requieren que exista un alineamiento predominante en las poblaciones de neuronas, o lo que es lo mismo, que se genere un potencial resultante neto (Gilad et al., 2009). Sin embargo, la EIT tiene la potencial capacidad de detectar activaciones en regiones donde no necesariamente se cumpla esa condición.

El filtrado espacial (SF) ha sido muy utilizado en el área de las comunicaciones para arreglos de antenas (van Been et al., 1997) (también llamado beamforming en este contexto), y fue satisfactoriamente introducido en el problema de localización de fuentes de actividad neuronal con mediciones de EEG en los años 90 (Robin- 
son y Rose, 1992). Un filtro espacial se diseña de manera de orientar la ganancia de un arreglo de sensores hacia algún punto particular del espacio. La orientación está controlada por una combinación lineal adecuada de las señales individuales de cada sensor. Esta manera de combinar las señales es completamente distinta a los algoritmos de reconstrucción generalmente utilizados en EIT. En estos últimos todos los píxeles o vóxeles se resuelven en un mismo paso, y se obtiene una imagen o mapa para cada instante de tiempo. Por el contrario, el filtrado espacial realiza un barrido virtual de la región de interés, que puede ser menor al objeto bajo estudio, estimando cada píxel o vóxel por separado teniendo en cuenta la variación temporal y generando un solo índice de activación para todos los instantes de tiempo (Sekihara y Nagarajan, 2008). A pesar del paralelismo matemático entre el potencial producido por un dipolo en EEG y las mediciones esperables en EIT para un cambio de conductividad en el mismo lugar (Lionheart et al., 2004), no se encuentran antecedentes de la aplicación de técnicas de filtrado espacial en EIT. La localización de cambios de conductividad de pequeño tamaño, como ocurre en ACVs isquémicos y en la EIT funcional, es una potencial aplicación del las técnicas de filtrado espacial en EIT que presenta ventajas similares a su uso en EEG.

La tDCS también consiste en inyectar corriente en la cabeza humana a través de un par o de un arreglo de electrodos apropiados. La corriente a inyectar es continua ya que se espera de algún modo polarizar a las neuronas para aumentar o disminuir su umbral de activación (Priori, 2003; Lang et al., 2005). Este tipo de terapias surge como una alternativa a los psicofármacos en el tratamiento de desórdenes del comportamiento, enfermedad de Parkinson o aún en epilepsia (Boggio et al., 2006; Yook et al., 2011; Kalu et al., 2012). La ventaja de tDCS es que mediante patrones de inyección adecuados es posible direccionar la corriente eléctrica buscando afectar sólo una región de interés en lugar de afectar a todo el cerebro, lo que la convierte en una técnica de creciente interés. Para la optimización de patrones de inyección que permitan aprovechar la direccionalidad de la tDCS, se han explorando principalmente dos métodos: mínimos cuadrados (LS) y beamforming (o LCMV) con restricciones de tipo norma L1, lo cual implica que los algoritmos de optimización deben ser iterativos y computacionalmente costosos (Dmochowski et al., 2011; Sadleir et al., 2012). 
A su vez, implican la inyección de corriente con distintas intensidades en cada uno de los electrodos, lo que incrementa la complejidad del hardware.

\subsection{Contribuciones originales}

Las principales contribuciones de esta tesis están relacionadas con métodos para la estimación de la conductividad eléctrica o cambios de conductividad en la cabeza humana a partir de mediciones de EIT tomadas sobre el cuero cabelludo. Se incorpora también el estudio de métodos de optimización de patrones de corriente en tDCS.

Por un lado se desarrolló una nueva manera de resolver el problema directo de EIT en diferencias basándose en el paralelismo matemático entre EIT en diferencias y el problema de localización de fuentes en EEG. Esta alternativa posee grandes ventajas computacionales tanto en uso de memoria como en tiempo de cálculo. Puede ser utilizada para obtener la matriz de sensibilidad necesaria tanto para los algoritmos de reconstrucción en EIT tradicionales como para los algoritmos desarrollados en esta tesis, incluyendo las técnicas de filtrado espacial aplicadas a EIT. Los detalles de esta alternativa para resolver el problema directo fueron publicados en el trabajo Fernández-Corazza et al. (2015c).

Para EIT paramétrico se analizó el impacto de utilizar un número diferente de electrodos para la estimación de las relaciones entre la conductividad eléctrica del cráneo, cuero cabelludo y cerebro con un modelo esférico de tres capas y se estudiaron todas las posibles combinaciones para 16, 32 y 64 electrodos, determinando los pares de inyección de corriente de menor varianza (Fernández-Corazza et al., 2011b). En el mismo trabajo, se cuantificó la mejora al desafectar el ruido producido por la propia activación neuronal. En Fernández-Corazza et al. (2011a) se desarrolló la idea de EIT paramétrico sobre un modelo de geometría realista con la novedad de modelar tanto al cráneo como al cuero cabelludo de manera anisótropa, es decir, se estimaron las conductividades tangenciales y radiales de cada tejido. En FernándezCorazza et al. (2013a) se continuó este trabajo utilizando el método de Newton para resolver el problema de mínimos cuadrados en la estimación paramétrica, en lugar 
del método de Nelder-Mead utilizado en los trabajos anteriores. La principal diferencia entre ambos es que el método de Newton requiere el cálculo de las primeras y segundas derivadas de la solución del problema directo respecto a los parámetros a estimar. En ese mismo trabajo se incorporó un análisis teórico utilizando la cota de Cramér-Rao para determinar pares de inyección de corriente convenientes y para cuantificar el desempeño del método para distintos niveles de ruido y distintos valores de conductividad dentro de los rangos encontrados en la literatura. Además, se aplicaron los métodos propuestos a mediciones reales de EIT paramétrico y se lograron estimar satisfactoriamente valores de conductividad del cráneo y del cuero cabelludo utilizando un modelo virtual de la cabeza humana detallado con dos modelizaciones distintas para los electrodos. En esta tesis sólo se muestran los resultados con un sujeto, pero para una futura publicación está previsto adquirir y analizar datos de más sujetos no disponibles al momento de la escritura de esta tesis.

Como se ha mencionado anteriormente, la actividad electromagnética propia del cerebro actúa como ruido indeseado en la EIT. Se desarrolló entonces un modelo de señal a partir del cual se determina el estimador de máxima verosimilitud de los coeficientes de atenuación que contienen la información útil en EIT. Para ese estimador se determinó la forma de onda óptima (de mínima varianza) dada una cierta actividad neuronal (Fernández-Corazza et al., 2013b) y se desarrolló un procedimiento para determinar el mínimo número de muestras necesarias para desafectar la actividad normal del cerebro de las mediciones, que sirve para reducir la duración de un estudio de EIT.

En relación a algoritmos de reconstrucción en EIT, se realizó la adaptación del algoritmo sLORETA, ampliamente utilizado en EEG, al problema de reconstrucción en EIT. Además, se realizó una modificación del mismo para poder incorporarle condiciones de suavidad espacial. Se realizaron simulaciones y se analizaron datos reales sobre tanques experimentales para determinar el desempeño de estos algoritmos comparándolos con otros algoritmos de reconstrucción típicamente utilizados 
en EIT, como son la solución de mínima norma con regularización de Tikhonov ${ }^{4}$ y la solución de mínima norma con regularización de Laplace. El desarrollo de estas ideas y los resultados fueron presentados en Fernández-Corazza et al. (2013c)

Otro aporte de la tesis es la adaptación de técnicas de filtrado espacial, en particular del filtro de restricciones lineales de mínima varianza (LCMV) y algunas de sus variantes, a la localización de cambios de conductividad y estimación de su evolución temporal a partir de mediciones de EIT. Se mostró la viabilidad del método analizando su desempeño en simulaciones sobre modelos de cabeza realistas para el caso de EIT estático, es decir, simulando sólo mediciones antes y después de un cambio de conductividad (Fernández-Corazza et al., 2012). En Fernández-Corazza et al. (2015c) se desarrolló un análisis más exhaustivo y más general del método para el caso de EIT dinámico, considerando varias muestras temporales. Se incorporaron otras características de los filtros espaciales como ser la utilización de condiciones de ganancia nula para eliminar la influencia de cambios de conductividad que no son de interés, y el aprovechamiento del conocimiento a priori de la forma de onda. Se realizaron simulaciones bidimensionales y tridimensionales, y se analizaron mediciones tomadas sobre tanques experimentales comparando su desempeño con otros métodos de reconstrucción tradicionales en EIT, pero sin restringirse a las aplicaciones de EIT en la cabeza humana. Luego, en Fernández-Corazza et al. (2014) se realizaron simulaciones particulares sobre diferentes modelos de cabeza realistas analizando el desempeño del método ya aplicado específicamente a la detección de ACVs isquémicos y a la localización de fuentes de actividad neuronal.

Para tDCS, se estudiaron algoritmos de optimización y se desarrollaron nuevas soluciones basándose en el principio de reciprocidad, que tienen en cuenta restricciones de hardware y de seguridad haciéndolas más viables para su utilización práctica. Además, se realizó un análisis comparativo del desempeño de los distintos algoritmos para distintas regiones de interés. Algunos resultados parciales fueron presentados en un congreso internacional (Fernández-Corazza et al., 2015b), mientras que se encuentra en preparación un trabajo más completo para ser presentado en una revista

\footnotetext{
${ }^{4}$ La regularización de Tikhonov es el método de regularización más utilizado para resolver sistemas de ecuaciones mal determinados
} 
internacional de alto impacto (Fernández-Corazza et al., 2015a).

\subsection{Trabajos completos provenientes de la tesis}

\subsubsection{Trabajos completos en revistas internacionales recono- cidas}

- FERnÁnDEZ-CORAZZA, M., L. Beltrachini, N. von Ellenrieder, y C. H. Muravchik. Analysis of parametric estimation of head tissue conductivities using electrical impedance tomography. Biomed Signal Proces (ISSN: 1746-8094, FI scimago: 2,071), Vol 8, Número 6, pp. 830-837, 2013. doi: 10.1016/j.bspc.2013.08.003.

- FERnÁnDEZ-CORAZZA, M., L. Beltrachini, N. von Ellenrieder y C. H. Muravchik. Waveform Selection for Electrical Impedance Tomography. IEEE Latin America Transactions (ISSN: 1548-0992, FI scimago: 0,330), Vol 1, Número 1, pp. 402-407, 2013. doi: 10.1109/TLA.2013.6502837.

- FERNÁNDEZ-CORAZZA, M., N. von Ellenrieder, y C. H. Muravchik. Spatial filtering in electrical impedance tomography. J Phys Conf Ser (ISSN: 17426596, FI scimago: 0,265), Vol 407, Número 1, pp. 012023, 2012. doi:10.1088/1742$6596 / 407 / 1 / 012023$.

- FERNÁNDEZ-CORAZZA, M., N. von Ellenrieder, y C. H. Muravchik. Estimation of electrical conductivity of a layered spherical head model using electrical impedance tomography. J Phys Conf Ser(ISSN: 1742-6596, FI scimago: 0,265), Vol 332, Número 1, pp. 012022, 2011. doi:10.1088/1742-6596/332/1/012022.

\subsubsection{Trabajos completos aceptados}

- FERnÁnDEZ-CORAZZA, M., N. von Ellenrieder, y C. H. Muravchik. Linearly constrained minimum variance spatial filtering for localization of conductivity changes in electrical impedance tomography. Int J Numer Method 
Biomed Eng (ISSN: 2040-7947, FI scimago: 1,806), Vol 31, Número 2, pp. n/a-n/a, 2015. doi: 10.1002/cnm.2703.

\subsubsection{Trabajos en congresos internacionales}

- FERnÁndeZ-CORAZZA, M., S. Turovets, P. Luu, D. Tucker. Optimization in transcranial electrical neuromodulation based on the reciprocity principle. En Brain Stimulation: 1st International Brain Stimulation Conference, Singapur, Vol 8, Número 2, pp. 403, 2015. doi: 10.1016/j.brs.2015.01.286.

- FERNÁNDEZ-CORAZZA, M., N. von Ellenrieder, y C. H. Muravchik. EIT spatial filtering in realistically shaped head models. En 15th Int. Conf. on Biomed. App. of Electrical Impedance Tomography (ISBN 978-0-7709-0577-4), Ontario, Canadá , pp. 31, 2014. url: https://cudo.carleton.ca/eit2014/3380.

- von Ellenrieder, N., L. Beltrachini, A. Blenkmann, M. FERNÁNDEZ-CORAZZA, S. Kochen, y C. Muravchik. A low-cost and robust photogrammetry method for determining electrode positions. En 30th International Epilepsy Congress (ISSN 1528-1167), Montreal, Canadá, Vol. 54, pp. 358-358, 2013. doi:10.1111/epi.12248.

\subsubsection{Trabajos en congresos nacionales}

- FERNÁNDEZ-CORAZZA, M., N. von Ellenrieder, y C. H. Muravchik. sLORETA vs regularización de Tikhonov en reconstrucción de tomografía de impedancia eléctrica. En XV Reunión de Trabajo Procesamiento de la Información y Control RPIC 2013 (ISBN: 978-987-27739-7-7), Bariloche, Argentina, pp. 283-288, 2013.

- FERnÁndEZ-CORAZZA, M., L. Beltrachini, N. von Ellenrieder, y C. H. Muravchik. Tomografía de impedancia eléctrica y resonancia magnética como herramientas conjuntas para la estimación paramétrica de la conductividad eléctrica del cráneo y del cuero cabelludo. En XIV Reunión de Trabajo Procesamiento de la Información y Control RPIC 2011 (ISBN: 978-950-698-279-9), Oro Verde, Argentina, pp. 845-850, 2011. 


\subsubsection{Trabajos en preparación}

- FernándeZ-CORAZZA, M., S. Turovets, P. Luu, y D. Tucker. Current pattern optimization in transcranial direct current stimulation based on the reciprocity principle.

\subsection{Organización de la tesis}

El capítulo 2 constituye una introducción a los problemas relacionados con la tomografía de impedancia eléctrica (EIT) y a las herramientas existentes que se utilizan en el desarrollo de la tesis. Se describen los modelos físicos y matemáticos usualmente empleados en EIT. Además, se presenta la formulación matemática de los métodos para resolver el problema directo de manera analítica cuando se supone una geometría esférica y de manera numérica utilizando el método de elementos finitos (FEM) cuando la geometría es arbitraria. Se muestran también algunos ejemplos resueltos de ambas maneras para validar el método FEM en el problema directo de EIT. Además, se describe el paralelismo matemático entre EIT en diferencias y EEG, y se desarrolla la nueva manera de resolver el PD en EIT basándose en dicho paralelismo.

En el capítulo 3 se presentan los aportes para la técnica de EIT paramétrico. Se describen y desarrollan los métodos propuestos para estimar los valores de conductividad de los principales tejidos de la cabeza tanto para geometrías esféricas basándose en fórmulas analíticas, como para geometrías realistas basándose en la formulación FEM. Además se describe la cota de Cramér-Rao como herramienta para evaluar el desempeño del problema de EIT paramétrico, y se la utiliza para determinar pares de inyección de corriente convenientes. También se presentan valores de conductividad estimados al aplicar el estimador de máxima verosimilitud a mediciones simuladas y reales obtenidas sobre seres humanos.

En el cuarto capítulo se describe una manera de determinar la forma de onda óptima para la corriente aplicada en EIT. La misma minimiza la cantidad de muestras temporales necesarias para desafectar las señales generadas por la propia actividad 
cerebral, que en aplicaciones de EIT, actúa como una perturbación indeseada y se la puede modelar con una distribución normal matricial. Este desarrollo está basado en utilizar un estimador de máxima verosimilitud para los coeficientes que relacionan la intensidad de la onda aplicada y la intensidad de los potenciales medidos en los sensores, que son los que contienen la información útil en EIT. Se muestran los resultados obtenidos utilizando señales reales de EEG para ejemplificar posibles condiciones de ruido reales.

En el quinto capítulo se describen los algoritmos de mínima norma y sLORETA con regularización de Tikhonov y con regularización de Laplace, mostrando su adaptación al problema de reconstrucción en EIT. Se muestran resultados comparativos obtenidos a través de simulaciones y a través de mediciones reales sobre tanques experimentales o fantomas.

En el capítulo 6 se describen los principios del filtrado espacial y se desarrolla su formulación cuando la técnica es adaptada a mediciones de EIT. Se lo compara y diferencia de otros algoritmos de reconstrucción y se lo aplica a los casos de EIT estático, es decir, sólo dos mediciones, una antes y otra después de un cambio de conductividad, y de EIT dinámico, con varias mediciones temporales en donde es posible además estimar la variación temporal de los cambios de conductividad. Se muestran resultados al realizar simulaciones y mediciones reales sobre tanques experimentales.

En el capítulo 7 se describen las formulaciones de la tDCS y del principio de reciprocidad. Se analizan los algoritmos más utilizados para la optimización de los patrones de inyección de corriente, dada una determinada región de interés del cerebro que se quiere estimular. A su vez, se desarrollan nuevas alternativas para resolver el mismo problema basadas en el principio de reciprocidad y suponiendo una sola fuente de corriente en el hardware. Se analizan y comparan los desempeños de las distintas soluciones.

Por último, en el octavo capítulo se presentan las conclusiones generales de la tesis, así como posibles líneas de investigación a seguir. 


\section{Capítulo 2}

\section{Tomografía de impedancia eléctrica}

\subsection{Introducción}

En este capítulo se describe el contexto general de la tomografía de impedancia eléctrica (EIT). Este contexto consiste en modelos físicos, modelos eléctricos de la cabeza, modelos de señal, ruido, etc., que se utilizan en el resto de la tesis para evaluar y analizar el desempeño de las distintas metodologías propuestas.

La EIT es una técnica que se basa en inyectar una pequeña corriente en un cuerpo y medir el potencial eléctrico resultante sobre la superficie mediante un arreglo de sensores (Bayford, 2006). Entre sus diversas aplicaciones, se encuentra la estimación de la distribución de conductividad eléctrica de los principales tejidos de la cabeza. En esta aplicación, su mayor desventaja es la baja resolución espacial si no se la combina con otras modalidades de imágenes.

En EIT paramétrico o "bounded EIT”(bEIT) se combina la información anatómica estructural de imágenes de resonancia magnética (MR), con la técnica de EIT. A partir de las imágenes de MR se segmenta la cabeza en diferentes tejidos, en los que se supone una conductividad eléctrica generalmente homogénea. Se utiliza entonces la técnica de EIT para realizar una estimación paramétrica de la conductividad del cuero cabelludo y del cráneo. La sensibilidad de esta técnica para estimar la conductividad de tejidos internos al cráneo es muy baja por el efecto conjunto del cráneo (baja conductividad) y el CSF (alta conductividad). Es por ello que para estimarlas 
se puede utilizar la técnica de imágenes de MR de tensor de difusión ( $\mathrm{DTI}^{1}$ ), aunque es de una complejidad muy superior a la EIT.

El problema de reconstrucción en EIT consiste en estimar un mapa o distribución de conductividad interno del objeto bajo estudio. Este problema es no lineal y mal condicionado, y generalmente se resuelve mediante una aproximación lineal. Una completa revisión de los algoritmos de reconstrucción comúnmente utilizados en EIT puede encontrarse en Lionheart et al. (2004). Los mismos se basan generalmente en la solución de mínimos cuadrados utilizando alguna regularización de Tikhonov.

En lo que sigue, denominamos EIT estático cuando se tienen datos correspondientes a dos instantes de tiempo, uno antes y otro después de un determinado cambio de conductividad. En cambio, denominamos EIT dinámico cuando se tiene una mayor cantidad de muestras temporales permitiendo conocer la evolución o dinámica temporal de los cambios de conductividad.

\subsection{Planteo del problema}

Existen dos problemas principales asociados a la EIT y que se enuncian a continuación, el problema directo y el problema inverso. El problema directo de EIT es el cálculo de la distribución de potencial eléctrico generado por la corriente aplicada suponiendo que la distribución de conductividad eléctrica es conocida. Las ecuaciones que gobiernan los fenómenos electromagnéticos son las ecuaciones de Maxwell (Jackson, 1975), y basadas en ellas se resuelve el problema directo. Las ecuaciones de Maxwell están dadas por:

\footnotetext{
${ }^{1}$ DTI, o imágenes de tensor de difusión es una secuencia especial de las resonancias magnéticas que permite mapear el proceso de difusión de las moléculas (generalmente de agua) en tejidos biológicos, in-vivo. Este proceso de difusión se puede utilizar para mapear el tensor de conductividad eléctrica (Tuch et al., 2001)
} 


$$
\begin{aligned}
& \vec{\nabla} \times \vec{E}(\vec{x}, t)+\frac{\partial \vec{B}(\vec{x}, t)}{\partial t}=0 \\
& \vec{\nabla} \times \vec{H}(\vec{x}, t)=\vec{J}(\vec{x}, t)+\frac{\partial \vec{D}(\vec{x}, t)}{\partial t} \\
& \vec{\nabla} \cdot \vec{D}(\vec{x}, t)=\rho(\vec{x}, t) \\
& \vec{\nabla} \cdot \vec{B}(\vec{x}, t)=0
\end{aligned}
$$

donde $\vec{x}$ es un punto arbitrario del espacio y $t$ es el índice del tiempo, $\vec{E}$ y $\vec{H}$ son los campos eléctrico y magnético respectivamente, $\vec{J}$ y $\rho$ son la densidad de corriente y la densidad de carga, $\vec{D}$ y $\vec{B}$ son las densidades de flujo eléctrico y magnético, y $\vec{\nabla}$ es el operador gradiente. A partir de estas ecuaciones, y una vez determinada la geometría del problema, se pueden formular las ecuaciones diferenciales parciales a resolver para plantear el problema directo de EIT.

El problema inverso depende de si estamos en el contexto de EIT paramétrico o en el contexto de reconstrucción de EIT, y en consecuencia las metodologías para resolverlo difieren según el contexto. En el caso de EIT paramétrico, el problema inverso consiste en estimar un número pequeño de parámetros, como pueden ser los valores de conductividad equivalente de los principales tejidos de la cabeza. Este problema generalmente se resuelve como una estimación o ajuste de mínimos cuadrados donde se busca minimizar la diferencia entre las mediciones y las soluciones al problema directo sobre un modelo virtual. La búsqueda de los valores de conductividad que minimizan esta diferencia se encuadra dentro de lo que se denomina optimización convexa, por lo que se espera que exista una única solución mínima.

En el contexto de reconstrucción en EIT, el número de incógnitas, que pasa a ser la conductividad de cada píxel o vóxel de la imagen a reconstruir, es generalmente mayor al número de mediciones. Esto hace que el problema sea subdeterminado, es decir, más incógnitas que ecuaciones. La solución más común es entonces la solución de mínima norma con algún tipo de regularización. 


\subsection{Aproximaciones y modelos}

\subsubsection{Aproximación cuasi-estática}

De acuerdo a las ecuaciones de Maxwell (2.1), la intensidad de los campos eléctrico y magnético en el tiempo pueden producir ondas electromagnéticas. En particular, para bajas frecuencias, puede utilizarse la aproximación cuasi-estática (Geselowitz, 1967). Esto es usual en la mayoría de los estudios ya que reduce la complejidad del problema (Bayford, 2006). La limitación es que el modelo es válido solo para frecuencias menores a $\sim 100 \mathrm{kHz}$, para las cuales la longitud de onda es mucho mayor que las dimensiones de la cabeza. Las ecuaciones de Maxwell con esta aproximación son las siguientes:

$$
\begin{aligned}
& \vec{\nabla} \times \vec{E}(\vec{x}, t)=0 \\
& \vec{\nabla} \times \vec{H}(\vec{x}, t)=\vec{J}(\vec{x}, t) \\
& \vec{\nabla} \cdot \vec{D}(\vec{x}, t)=\rho(\vec{x}, t) \\
& \vec{\nabla} \cdot \vec{B}(\vec{x}, t)=0
\end{aligned}
$$

\subsubsection{Modelo eléctrico de la cabeza}

Un modelo eléctrico de la cabeza es una representación del mapa o distribución de conductividad eléctrica en la misma. Para su construcción se necesitan definir la geometría de la cabeza, la forma de las superficies interiores que separan los principales tejidos, las conductividades eléctricas (isótropas o anisótropas) globales (homogéneas) o distribuidas (no homogéneas) y la ubicación de los electrodos o sensores. Generalmente se plantea un modelo tridimensional de tres a siete capas que representan los principales tejidos de la cabeza.

En cuanto a la geometría, una primera aproximación es utilizar modelos esféricos, que consisten en esferas concéntricas representando los distintos tejidos. Para construir modelos de geometría realista, las superficies que delimitan los tejidos se 
obtienen generalmente a partir de imágenes de MR y/o de CT. Esto permite obtener geometrías personalizadas para cada individuo, aunque también se pueden utilizar modelos de cabeza promedio (atlas) y de esta forma los resultados que se obtienen pueden considerarse más generales. En la aplicación de la EIT a la detección temprana de ACVs, es esperable no contar con la geometría particular del individuo, por lo que utilizar modelos de atlas es una alternativa práctica, rápida y económica a costa de una menor precisión.

La conductividad del cerebro podría suponerse isótropa ya que sólo una pequeña cantidad de corriente llega a esa zona. Al cerebro (incluyendo CSF) se le puede asignar un valor de conductividad de aproximadamente 0,3S/m (Bayford, 2006). $\mathrm{Si}$ el cerebro es subdividido en materia gris y materia blanca, son generalmente aceptadas conductividades equivalentes de aproximadamente $0,3 S / m$ y $0,2 S / m$ respectivamente (Horesh, 2006). Para el líquido cefalorraquídeo, la conductividad no varía sustancialmente entre individuos y se acepta generalmente un valor de 1,79 S/m (Horesh, 2006). Otra posibilidad es construir modelos más realistas en los cuales la distribución de la conductividad del cerebro (incluyendo materia gris, blanca y líquido cefalorraquídeo se modela como heterogénea y anisótropa, y se estima a partir de mediciones de DTI (Tuch et al., 2001).

Tanto para el cráneo como para el cuero cabelludo la literatura muestra un amplio rango en los valores de conductividad, ya sean resultados de mediciones reales o bien valores utilizados para armar los modelos. Para el cráneo los valores van desde $0,004 \mathrm{~S} / \mathrm{m}$ hasta $0,04 \mathrm{~S} / \mathrm{m}$, mientras que para el cuero cabelludo van de $0,25 \mathrm{~S} / \mathrm{m}$ a 0,45S/m (e.g. Eriksen (1990); Horesh (2006); Abascal et al. (2008)). En cuanto a la anisotropía del cráneo $(c r)$, una relación tangencial:normal de 10 : 1 ha sido lo más utilizado (Rush y Driscoll, 1968; Abascal et al., 2008), aunque últimamente se la considera como un límite superior (Horesh, 2006). Para el cuero cabelludo (cc) la relación es menor, aproximadamente $1,5: 1$, por lo que generalmente se lo modela como isótropo (Horesh, 2006).

Los arreglos de electrodos comprenden generalmente 16, 32, 64, 128 o 256 electrodos, y se colocan sobre el cuero cabelludo, aunque la técnica sigue siendo válida para electrodos colocados sobre la corteza cerebral o para electrodos profundos. En la Fig. 

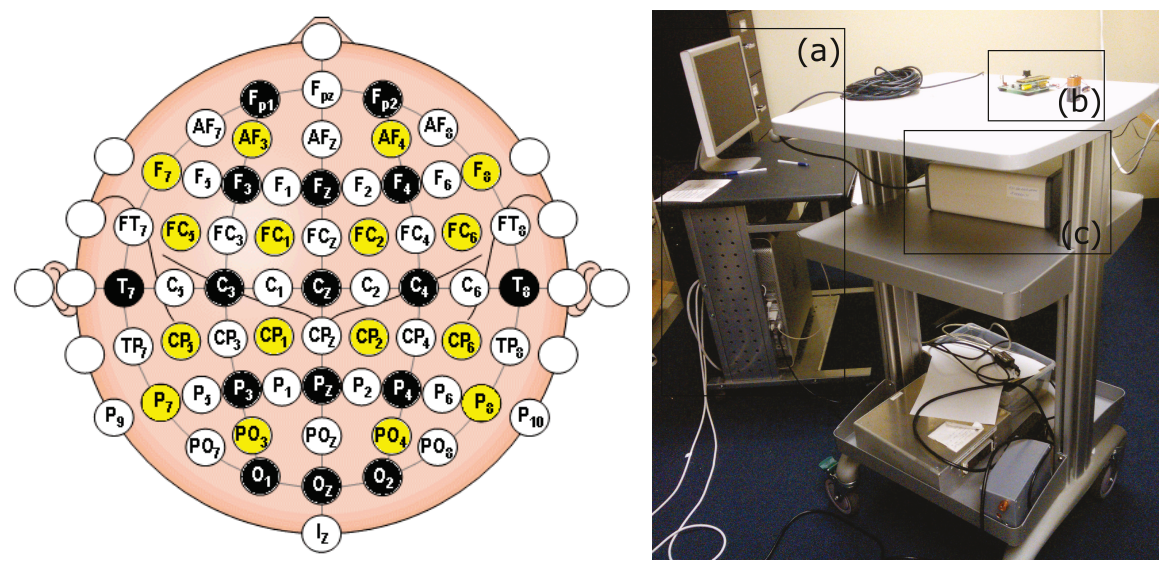

Figura 2.1: Izquierda: posicionamiento de 64 electrodos basado en el sistema 10-10. Los electrodos amarillos y negros conforman el sistema de 32 electrodos mientras que sólo los negros conforman el arreglo de 16 electrodos. Derecha: tomógrafo de EIT experimental AMP300, de Electrical Geodesics Inc, Eugene, Oregon, Estados Unidos: (a) unidad de procesamiento e interfaz con el usuario, (b) fuente de corriente externa y (c) unidad de amplificación y selección de canales.

2.1 se muestra como ejemplo la distribución de 64,32 y 16 electrodos siguiendo el sistema estándar 10-10.

\subsubsection{Intensidad de corriente en EIT}

La elección del valor de corriente eléctrica a inyectar no es trivial, ya que se desea que se encuentre dentro de los niveles limitados por la sensibilidad fisiológica, tanto en intensidad como en frecuencia. En el estudio de Ahadzi et al. (2004), se analiza específicamente la máxima corriente admitida para EIT. En el mismo se concluye que lo importante es limitar la densidad de corriente, y que para electrodos estándar de EEG, el umbral de percepción ronda entre los 100 y $200 \mu A$, volviéndose apenas incómodo a los $400 \mu \mathrm{A}$. Estos valores de densidad de corriente se aproximan a otro estudio (Dalziel, 1972) en donde se mide la sensación de la corriente al tomar un cable con la mano. Por otro lado, la norma IEC60601 (2005) determina 100 $\mu$ A como valor de corriente máximo como corriente auxiliar que puede pasar por un paciente. 


\subsubsection{Ruido en EIT}

Las mediciones de potencial eléctrico en EIT se encuentran contaminadas principalmente por dos fuentes de ruido electromagnético: el ruido del conjunto elecrodoamplificador, incluyendo el producido por el contacto electrodo-piel, y la actividad eléctrica propia del cerebro, que actúa como una interferencia indeseada en EIT. Esta última puede tener una amplitud mayor significando una mayor varianza en los parámetros estimados en el caso de EIT paramétrico (Fernández-Corazza et al., 2011b). Sin embargo, como es espacial y temporalmente correlacionado, una selección apropiada de la forma de onda de la corriente a inyectar junto con un adecuado procesamiento de los datos puede mitigar su efecto con un número suficiente de muestras temporales (Gonçalves et al., 2003; Poolman et al., 2008; Fernández-Corazza et al., 2013b).

\subsubsection{Equipamiento en EIT}

El equipamiento de EIT tiene la ventaja de ser portable. Está conformado por una fuente de corriente, llaves selectoras, y un equipo de amplificación con conversores A/D. Para este último componente es posible utilizar un equipo de medición de EEG, siempre que la fuente de corriente sea de una frecuencia menor a la de la frecuencia de corte del equipo de EEG.

La variedad de diseños y características de los equipos de EIT es amplia, ya que la mayoría son equipos experimentales y sólo unos pocos son comerciales. En los trabajos de revisión de Bayford (2006) y Holder (2008) hay buenas, aunque no necesariamente completas, revisiones de los equipos de EIT.

Dos equipos experimentales se utilizaron para obtener mediciones reales en esta tesis. El primero es el IMPETOM C, un equipo de EIT desarrollado por el Núcleo de Ingeniería Biomédica de la Universidad de Montevideo, Uruguay. El mismo consiste en 16 canales de medición paralelos, permite una corriente máxima de $5 \mathrm{~mA}$ a $50 \mathrm{kHz}$, y una tasa de muestreo de 15 muestras por segundo (Santos y Simini, 2012). Este equipo sólo se utilizó para obtener mediciones sobre un tanque experimental asociado, orientado originalmente a estudiar el sistema cardio-respiratorio. En ese 
tanque experimental, los 16 electrodos están dispuestos a la misma altura y equiespaciados a lo largo de su borde. El segundo equipo es el AMP300 (Fig. 2.1), de Electrical Geodesics Inc (EGI) que fue utilizado para obtener mediciones sobre otro tanque experimental y sobre humanos. El equipo tiene la capacidad de adquirir 128 ó 256 canales, puede utilizar una fuente de corriente externa o interna de frecuencia y amplitud arbitraria, y utiliza un sólo amplificador con un conversor A/D de 24 bits. Permite muestrear las señales crudas a una tasa máxima de $1000 \mathrm{~Hz}$, y posee además un sistema de lazo de enganche de fase para extraer la relación entre las amplitudes de las señales correspondientes a la corriente inyectada y a los valores de potencial eléctrico medidos, que es la información útil de EIT (Poolman et al., 2008).

\subsection{Problema directo}

El problema directo de EIT consiste en calcular la distribución del potencial eléctrico sobre el volumen, y en particular en los sensores, resultado de aplicar la corriente sobre un par de electrodos, y suponiendo que la conductividad eléctrica es conocida. Este problema posee solución analítica involucrando desarrollos en series cuando se trabaja con modelos esféricos, pero debe ser resuelto de manera numérica para geometrías arbitrarias.

De la aproximación cuasi-estática en (2.2) tenemos:

$$
\vec{\nabla} \times \vec{E}=0
$$

donde $\vec{E}$ es el campo eléctrico. De la Eq. (2.3), el campo eléctrico $\vec{E}$ se puede expresar como el gradiente de un campo potencial $\Phi$

$$
\vec{E}=-\vec{\nabla} \Phi
$$

Es sabido que la densidad de corriente $\vec{J}$ es proporcional a $\vec{E}$ (Jackson, 1975), entonces:

$$
\vec{J}=\boldsymbol{\sigma} \vec{E}
$$


donde, $\boldsymbol{\sigma}$ es el tensor de conductividad eléctrica del medio.

La ley de conservación de la corriente dice que la divergencia de la densidad de corriente es cero en todos lados excepto en los puntos de inyección de corriente. Como las corrientes en EIT se aplican sobre la frontera, el campo eléctrico $\Phi$ debe satisfacer la ecuación de Laplace en el sólido $\Omega$, con condiciones de Neumann en su frontera $\delta \Omega$, es decir, conociendo su derivada en $\delta \Omega$ :

$$
\begin{cases}\vec{\nabla} \cdot(\boldsymbol{\sigma}(\vec{x}) \vec{\nabla} \Phi(\vec{x}))=0, & \text { en } \Omega \\ \boldsymbol{\sigma}(\vec{x}) \vec{\nabla} \Phi(\vec{x}) \cdot \hat{n}=j(\vec{x}), & \text { en } \delta \Omega\end{cases}
$$

donde $j$ es la componente normal de la densidad de corriente en la frontera, y si se suponen electrodos de inyección puntuales, viene dada por:

$$
j(\vec{x})=I \delta\left(\vec{x}-\overrightarrow{x^{+}}\right)-I \delta\left(\vec{x}-\overrightarrow{x^{-}}\right),
$$

donde $\overrightarrow{x^{+}}$y $\overrightarrow{x^{-}}$son los puntos de inyección y toma de corriente respectivamente, $I$ es la intensidad de corriente, y $\delta$ es la delta de Dirac.

\subsubsection{Solución analítica}

A continuación se plantea el desarrollo para encontrar la solución analítica al problema directo de EIT para un modelo esférico de $N$ capas isótropas, homogéneas y concéntricas centradas en el origen $\vec{O}$, y se muestra el desarrollo completo para el caso de tres capas.

Gracias a la simetría del problema, para cada capa $i$, la solución del potencial eléctrico $\Phi$ en cada punto del espacio descripto en coordenadas esféricas $(r, \theta, \phi)$, puede ser expresada como una combinación lineal de los polinomios de Legendre 
(Frank, 1952; Jackson, 1975):

$$
\begin{aligned}
\Phi^{(i)}(r, \beta, \gamma) & =\sum_{l=0}^{\infty}\left(A_{l}^{(+)(i)} r^{l}+B_{l}^{(+)(i)} r^{-l-1}\right) P_{l}(\cos \beta) \\
& -\sum_{l=0}^{\infty}\left(A_{l}^{(-)(i)} r^{l}+B_{l}^{(-)(i)} r^{-l-1}\right) P_{l}(\cos \gamma) \\
\Phi^{(i)}(r, \beta, \gamma) & =\sum_{l=1}^{\infty}\left(A_{l}^{(i)} r^{l}+B_{l}^{(i)} r^{-l-1}\right)\left(P_{l}(\cos \beta)-P_{l}(\cos \gamma)\right)
\end{aligned}
$$

donde las constantes $A_{l}^{(i)}, B_{l}^{(i)}$ dependen de las condiciones de borde, $P_{l}(x)$ es el polinomio de Legendre de orden $l\left(P_{0}(x)=1\right), \beta(\theta, \phi)$ es el ángulo entre el semieje z positivo y el segmento $\overline{O x^{+}}$, y $\gamma(\theta, \phi)$ es el ángulo entre el semieje z positivo y el segmento $\overline{O x^{-}}$. En la capa más exterior $N$, el potencial eléctrico no es exactamente igual a la expresión de la Ec. (2.8)) ya que los puntos de inyección de corriente se encuentran en esta capa y su efecto debe considerarse. Aplicando la propiedad de linealidad, el potencial en esta capa puede ser expresado como la suma del potencial en un medio infinito $\left(\Phi_{\infty}\right)$ y de un potencial con la forma de la Ec. $(2.8)\left(\Phi^{(N)}\right)$ tal que el potencial suma $\left(\Phi_{t o t}^{(N)}\right)$ satisfaga las condiciones de frontera. Luego,

$$
\Phi_{\text {tot }}^{(N)}=\Phi_{\infty}+\Phi^{(N)}
$$

donde,

$$
\Phi_{\infty}=\frac{I}{4 \pi \sigma_{N}}\left(\frac{1}{\sqrt{r^{2}+r_{N}^{2}-2 r r_{N} \cdot \cos (\beta)}}-\frac{1}{\sqrt{r^{2}+r_{N}^{2}-2 r r_{N} \cdot \cos (\gamma)}}\right)
$$

siendo $r_{N}$ el radio la superficie exterior de la esfera y $\sigma_{N}$ su valor de conductividad. Para tener continuidad en el origen, $B_{l}^{(1)}$ debe ser cero, por lo que para cada orden $l$, se deben determinar $2 N-1$ constantes $A_{l}^{(1)}, A_{l}^{(2)}, B_{l}^{(2)}, \ldots, A_{l}^{(N)}, B_{l}^{(N)}$. En cada superficie que divide las capas, dos condiciones deben cumplirse: la continuidad de las componentes normales de la densidad de corriente, y la continuidad del campo 
eléctrico. Esto determina una misma cantidad $(2 N-1)$ de ecuaciones:

$$
\begin{aligned}
\left.\sigma_{1} \frac{\partial \Phi^{(1)}}{\partial r}\right|_{r=r_{1}} & =\left.\sigma_{2} \frac{\partial \Phi^{(2)}}{\partial r}\right|_{r=r_{1}} \\
\left.\sigma_{N-1} \frac{\partial \Phi^{(N-1)}}{\partial r}\right|_{r=r_{N-1}} & =\left.\sigma_{N} \frac{\partial \Phi_{t o t}^{(N)}}{\partial r}\right|_{r=r_{N-1}} \\
\left.\Phi^{(1)}\right|_{r=r_{1}} & =\left.\Phi^{(2)}\right|_{r=r_{1}} \\
\ldots & \\
\left.\Phi^{(N-1)}\right|_{r=r_{N-1}} & =\left.\Phi_{t o t}^{(N)}\right|_{r=r_{N-1}} \\
\left.\sigma_{N} \frac{\partial \Phi_{t o t}^{(N)}}{\partial r}\right|_{r=r_{N}} & =0
\end{aligned}
$$

donde $r_{i}$ es el radio de la superficie esférica que delimita las capas $i$ e $i+1$. Las constantes $A_{l}^{(i)}, B_{l}^{(i)}$ se pueden determinar resolviendo el sistema de ecuaciones (2.11).

Para el caso particular de $N=3$, el potencial sobre la capa exterior resulta:

$$
\begin{aligned}
\Phi_{\text {tot }}^{(3)} & =\frac{k}{r_{3}} \Phi_{\infty}+ \\
& +\frac{k}{r_{3}}\left(\sum_{l=1}^{\infty}\left(\frac{K_{1} \sigma_{1} / \sigma_{2}+K_{2} \sigma_{1} / \sigma_{3}+K_{3} \sigma_{2} / \sigma_{3}+K_{4}}{K_{5} \sigma_{1} / \sigma_{2}+K_{6} \sigma_{1} / \sigma_{3}+K_{7} \sigma_{2} / \sigma_{3}+K_{8}}-1\right)\left(P_{l}(\cos \beta)-P_{l}(\cos \gamma)\right)\right),
\end{aligned}
$$




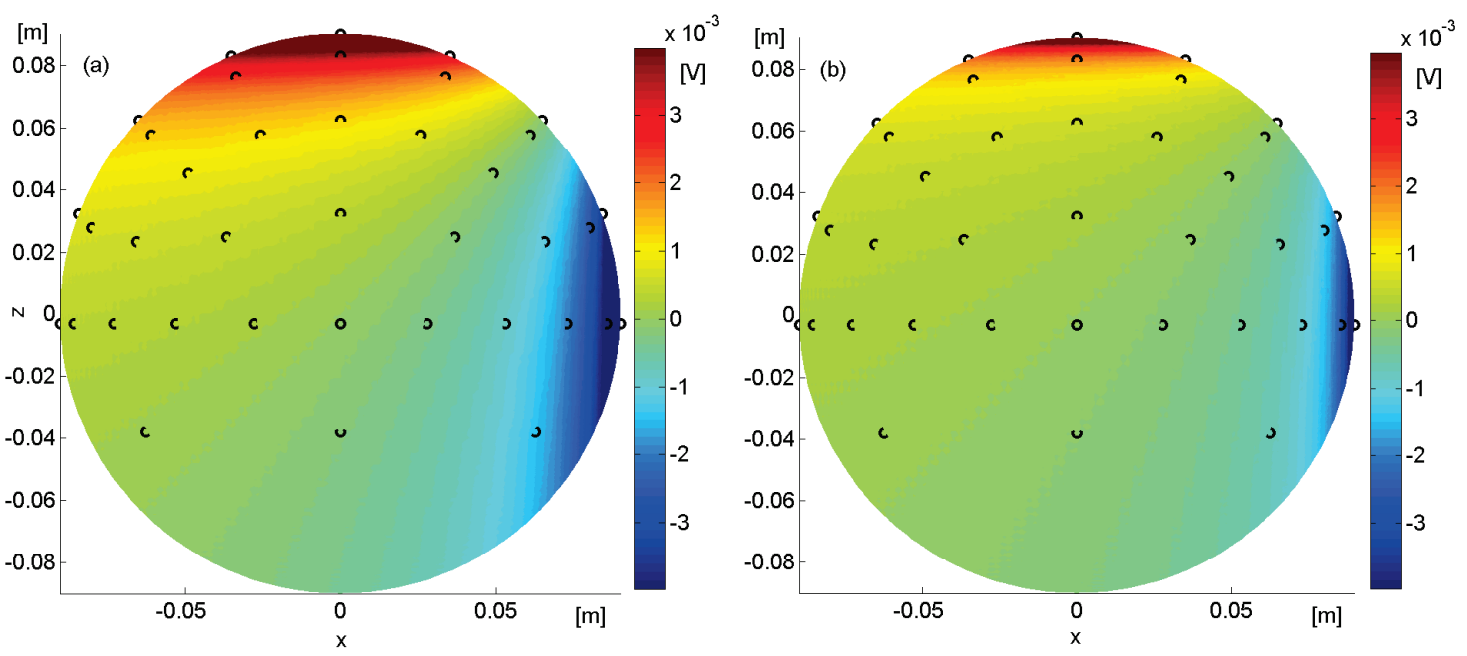

Figura 2.2: (a) Potencial eléctrico sobre la superficie para $\sigma_{2}=0,008 \mathrm{~S} / \mathrm{m}$, vista posterior. (b) Potencial eléctrico sobre la superficie para $\sigma_{2}=0,04 S / m$, vista posterior.

donde,

$$
\begin{aligned}
k & =\frac{I}{4 \pi \sigma_{3}}, \\
\Phi_{\infty}(\beta, \gamma) & =\frac{1}{\sqrt{|2-2 \cos (\beta)|}}-\frac{1}{\sqrt{|2-2 \cos (\gamma)|}}, \\
K_{1} & =\left(l+1+l{\overline{r_{2}}}^{2 l+1}\right) l\left(1-\left(\overline{r_{1}} / \overline{r_{2}}\right)^{2 l+1}\right), \\
K_{2} & =\left(1-{\overline{r_{2}}}^{2 l+1}\right) l\left(l+(l+1)\left(\overline{r_{1}} / \overline{r_{2}}\right)^{2 l+1}\right), \\
K_{3} & =\left(1-{\overline{r_{2}}}^{2 l+1}\right) l(l+1)\left(1-\left(\overline{r_{1}} /{\overline{r_{2}}}^{2 l+1}\right),\right. \\
K_{4} & =\left(l+1+l{\overline{r_{2}}}^{2 l+1}\right)\left(l+1+l\left(\overline{r_{1}} / \bar{r}_{2}\right)^{2 l+1}\right), \\
K_{5} & =l^{2}(l+1)\left(1-\left(\overline{r_{1}} / \overline{r_{2}}\right)^{2 l+1}\right)\left(1-\bar{r}_{2}^{2 l+1}\right), \\
K_{6} & =\left(l+(l+1)\left(\overline{r_{1}} / \overline{r_{2}}\right)^{2 l+1}\right)\left(l^{2}+\left(l^{2}+l\right){\overline{r_{2}}}^{2 l+1}\right), \\
K_{7} & =(l+1) l\left(1-\left(\overline{r_{1}} / \overline{r_{2}}\right)^{2 l+1}\right)\left(l+(l+1){\overline{r_{2}}}^{2 l+1}\right), \\
K_{8} & =(l+1) l\left((l+1)+l\left(\overline{r_{1}} / \overline{r_{2}}\right)^{2 l+1}\right)\left(1-{\overline{r_{2}}}^{2 l+1}\right),
\end{aligned}
$$

y donde $\overline{r_{1}}$ y $\overline{r_{2}}$ son $r_{1}$ y $r_{2}$ relativos a una esfera de radio 1 , es decir, $\overline{r_{1}}=r_{1} / r_{3} \mathrm{y}$ $\overline{r_{2}}=r_{2} / r_{3}$.

La Fig. 2.2 muestra la solución del problema directo sobre la superficie exterior 
para dos valores diferentes de la conductividad de la capa del medio (equivalente al cráneo), y se puede observar la sensibilidad del potencial eléctrico respecto a dicho parámetro.

\subsubsection{Solución numérica}

Para resolver el problema directo de EIT en una geometría arbitraria se recurre al método de los elementos finitos (FEM) que, a diferencia del método de elementos de contorno (BEM), permite incluir conductividades anisótropas en el modelo. A continuación se explica brevemente como puede resolverse el problema numérico mediante el método de residuos pesados y la formulación de Galerkin, basándose principalmente en Silvester y Ferrari (1994); Kwon y Bang (2000) y Beltrachini et al. (2008).

Como se busca cumplir con la primera condición de (2.6), se propone una función de peso $\omega$ que satisfaga

$$
\int_{\Omega} \omega \vec{\nabla}(\boldsymbol{\sigma}(\vec{x}) \cdot \vec{\nabla} \Phi(\vec{x})) d \Omega=0
$$

lo que se conoce como el método de residuos pesados, en donde $\Phi$ es el potencial que se quiere calcular. Aplicando propiedades del gradiente y de la divergencia, la expresión (2.23) puede escribirse como

$$
\int_{\Omega} \vec{\nabla}(\omega \boldsymbol{\sigma} \cdot \vec{\nabla} \Phi) d \Omega-\int_{\Omega} \vec{\nabla} \omega \cdot \boldsymbol{\sigma} \cdot \vec{\nabla} \Phi d \Omega=0
$$

conocida como la formulación débil del problema. Luego, aplicando el Teorema de Green al primer término, se obtiene

$$
\int_{\Omega} \vec{\nabla} \omega \cdot \boldsymbol{\sigma} \cdot \vec{\nabla} \Phi d \Omega=\int_{\delta \Omega} \omega \underbrace{\boldsymbol{\sigma} \cdot \vec{\nabla} \Phi \cdot \hat{n}}_{j} d(\delta \Omega) .
$$

Para resolver estas integrales, se discretiza el volumen en elementos, en este caso 
tetraedros ${ }^{2}$, y se aplica una interpolación lineal dentro de cada uno de ellos (FEM de primer orden). Una discretización conveniente es aquella en la que la posición de los electrodos coincide con vértices de tetraedros ya que FEM posee una mejor convergencia en los nodos. La integral de volumen de (2.25) se resuelve para cada elemento $k$ de la discretización:

$$
\sum_{k=1}^{K} \int_{\Omega^{(k)}} \vec{\nabla} \omega^{(k)} \cdot \boldsymbol{\sigma}^{(k)} \cdot \vec{\nabla} \Phi^{(k)} d \Omega^{(k)}
$$

donde $K$ es el número de tetraedros. El FEM de primer orden consiste en suponer al potencial $\Phi$ como una combinación lineal de cuatro funciones lineales $\psi_{i}$ las cuales valen 1 en el nodo $i$ y 0 en los otros nodos, para $i=1,2,3,4$ :

$$
\Phi^{(k)}=u_{1}^{(k)} \psi_{1}^{(k)}+u_{2}^{(k)} \psi_{2}^{(k)}+u_{3}^{(k)} \psi_{3}^{(k)}+u_{4}^{(k)} \psi_{4}^{(k)}
$$

donde $u_{i}$ son constantes a determinar. Para la elección de la función de peso se utiliza el método de Galerkin, el cual propone que dicha función sea la misma que la utilizada para aproximar la solución, es decir

$$
\omega_{i}^{(k)}=\psi_{i}^{(k)}
$$

Como lo anterior vale para los cuatro nodos de cada tetraedro, la integral de (2.26) sobre cada elemento queda definida como

$$
\int_{\Omega^{(k)}} \nabla \boldsymbol{\Psi}^{(k)} \cdot \boldsymbol{\sigma}^{(k)} \cdot \nabla \boldsymbol{\Psi}^{(k)^{T}} d \Omega^{(k)} \cdot \mathbf{u}^{(k)}
$$

donde $\mathbf{u}^{(k)}$ es el vector cuyas componentes son los $u_{i}^{(k)}$ y $\nabla \Psi^{(k)}$ es la matriz confor-

\footnotetext{
${ }^{2}$ La utilización de tetraedros en lugar de otro tipo de elementos permite obtener fórmulas explícitas simples de integración con cambios de coordenadas sencillos, reduciendo la carga computacional.
} 
mada por las derivadas de las funciones lineales $\psi^{(k)}$ (el índice $k$ es omitido)

$$
\nabla \Psi^{(k)}=\left(\begin{array}{lll}
\frac{\partial \psi_{1}}{\partial x} & \frac{\partial \psi_{1}}{\partial y} & \frac{\partial \psi_{1}}{\partial z} \\
\frac{\partial \psi_{2}}{\partial x} & \frac{\partial \psi_{2}}{\partial y} & \frac{\partial \psi_{2}}{\partial z} \\
\frac{\partial \psi_{3}}{\partial x} & \frac{\partial \psi_{3}}{\partial y} & \frac{\partial \psi_{3}}{\partial z} \\
\frac{\partial \psi_{4}}{\partial x} & \frac{\partial \psi_{4}}{\partial y} & \frac{\partial \psi_{4}}{\partial z}
\end{array}\right)
$$

De (2.29) se obtiene una matriz $\mathbf{K}_{e}$ de $4 \times 4$ (llamada matriz elemental) para cada tetraedro, que involucra una transformación a un sistema de coordenadas volumétricas. Para un punto $(x, y, z)$ del interior del tetraedro se definen las coordenadas $\xi_{i}$ como la relación entre dos volúmenes $V_{i}$ y $V$. El primero, es el volumen del sub-tetraedro formado el punto $(x, y, z)$ y tres de los cuatro vértices del tetraedro original, mientras que el volumen $V$ es el volumen total del tetraedro original. Los detalles de la resolución de la integral de volumen pueden encontrarse en Beltrachini et al. (2008). Allí se deduce que la matriz elemental queda expresada según la formulación matricial

$$
\mathbf{K}_{e}=\frac{\mathbf{B}^{T} \boldsymbol{\sigma} \mathbf{B}}{36 V}
$$

donde $\mathbf{B}$ es una matriz de transformación de $3 \times 4$ que depende de la ubicación de los vértices del tetraedro, $V$ es el volumen del mismo, y $\boldsymbol{\sigma}$ es el tensor de conductividad eléctrica, representado por una matriz de $3 \times 3$, con 6 elementos independientes.

En el caso isótropo, el tensor de conductividad viene dado por

$$
\boldsymbol{\sigma}=\sigma_{i s o} \mathbf{I}_{3}
$$

donde $\mathbf{I}_{\mathbf{3}}$ es la matriz identidad de $3 \times 3$. El tensor de conductividad es diferente para el caso anisótropo. Como ya se mencionó es posible modelizar al cráneo y al cuero cabelludo con dos conductividades diferentes, una en dirección radial o perpendicular $\sigma_{r}$ y otra en dirección tangencial o paralela a sus superficies $\sigma_{t}$. Para 
poder expresarlo como

$$
\boldsymbol{\sigma}=\left(\begin{array}{ccc}
\sigma_{t} & 0 & 0 \\
0 & \sigma_{t} & 0 \\
0 & 0 & \sigma_{r}
\end{array}\right)
$$

es necesario un cambio de base de la canónica $\left(B_{c}\right)$ a una que tenga dos elementos en dirección tangencial a la superficie y el otro en dirección radial $\left(B_{t r}\right)$. Para encontrar una base adecuada, se tomó el centroide de cada elemento y se lo proyectó perpendicularmente hasta el punto de la superficie más cercano. Este punto forma parte de un triángulo del cual dos lados del mismo pueden tomarse como los vectores tangenciales de la superficie mientras que el producto vectorial entre ellos resulta en un vector normal a ella. Esos tres elementos $\left\{\mathbf{v}_{\mathbf{1}}, \mathbf{v}_{\mathbf{2}}, \mathbf{v}_{\mathbf{3}}\right\}$ conforman una base $B_{t r}$ orientada de acuerdo a lo buscado. Luego, la matriz cambio de base $[\mathbf{M}]_{B_{c}, B_{t r}}$ queda definida por

$$
\mathbf{M}=[\mathbf{M}]_{B_{c}, B_{t r}}=\left(\left[\mathbf{v}_{\mathbf{1}}\right]_{B_{c}},\left[\mathbf{v}_{\mathbf{2}}\right]_{B_{c}},\left[\mathbf{v}_{\mathbf{3}}\right]_{B c}\right)
$$

mientras que $[\mathbf{M}]_{B_{t r}, B_{c}}=[\mathbf{M}]_{B_{c}, B_{t r}}^{-1}=\mathbf{M}^{-1}$. Resultando entonces:

$$
\mathbf{K}_{e}=\frac{1}{36 V} \mathbf{B}^{T} \mathbf{M} \boldsymbol{\sigma} \mathbf{M}^{-1} \mathbf{B}
$$

Para trabajar con modelos equivalentes, es práctica usual que las trazas del tensor isótropo y anisótropo sean iguales $\left(\operatorname{tr}(\boldsymbol{\sigma})=2 \sigma_{t}+\sigma_{r}=3 \sigma_{i s o}\right)$, lo cual debe tenerse en cuenta al escoger los valores de conductividad en el caso de construir datos sintéticos.

En el caso anisótropo, la matriz elemental se puede dividir en dos submatrices $K_{\text {et }} \mathrm{y} K_{e r}$ :

$$
\begin{aligned}
\mathbf{K}_{e} & =\frac{1}{36 V} \mathbf{B}^{T} \mathbf{M}\left(\begin{array}{ccc}
\sigma_{t} & 0 & 0 \\
0 & \sigma_{t} & 0 \\
0 & 0 & \sigma_{r}
\end{array}\right) \mathbf{M}^{-1} \mathbf{B}= \\
& =\frac{\mathbf{B}^{T} \mathbf{M}}{36 V}\left(\sigma_{t}\left(\begin{array}{lll}
1 & 0 & 0 \\
0 & 1 & 0 \\
0 & 0 & 0
\end{array}\right)+\sigma_{r}\left(\begin{array}{lll}
0 & 0 & 0 \\
0 & 0 & 0 \\
0 & 0 & 1
\end{array}\right)\right) \mathbf{M}^{-1} \mathbf{B}=
\end{aligned}
$$




$$
=\sigma_{t} \mathbf{K}_{e t}+\sigma_{r} \mathbf{K}_{e r}
$$

Luego, el conjunto ensamblado de todas las $\mathbf{K}_{e}$ forma la llamada matriz de rigidez K del problema, de tamaño $N_{p} \times N_{p}$ siendo $N_{p}$ el número total de puntos del mallado o discretización.

Se logra así linealizar el problema quedando de la forma

$$
\mathbf{K u}=\mathbf{f}
$$

donde $\mathbf{u}$ es el vector potencial incógnita (de $N_{p} \times 1$ ) y f es el vector independiente que se obtiene de resolver la integral de superficie de la Ec. (2.25).

Si consideramos a la densidad de corriente como una fuente y un sumidero puntuales ubicados en la posición de los electrodos de inyección $\left(\vec{x}^{+}\right.$y $\left.\vec{x}^{-}\right)$, y teniendo en cuenta que la función $\omega$ es igual a 1 en esos puntos,

$$
\int_{\delta \Omega} \omega \vec{J} d(\delta \Omega)=\left\{\begin{array}{cc}
+I & \text { si } \vec{x}=\vec{x}^{+} \\
-I & \text { si } \vec{x}=\vec{x}^{-} \\
0 & \text { cc }
\end{array} .\right.
$$

Por lo tanto el vector independiente $\mathbf{f}$ está formado por todos ceros salvo $+I \mathrm{y}-I$ en la ubicación correspondiente a los puntos de inyección. Luego del ensamblado de todos los elementos, quedan definidos los sistemas de ecuaciones lineales tanto para el modelo isótropo

$$
\mathbf{K u}=\left(\sum_{i=1}^{n} \sigma^{(i)} \mathbf{K}^{(i)}\right) \mathbf{u}=\mathbf{f}
$$

como para el anisótropo

$$
\mathbf{K u}=\left(\sum_{i=1}^{n} \sigma_{t}^{(i)} \mathbf{K}_{t}^{(i)}+\sigma_{r}^{(i)} \mathbf{K}_{r}^{(i)}\right) \mathbf{u}=\mathbf{f}
$$

donde $\mathbf{K}^{(i)}, \mathbf{K}_{t}^{(i)}, \mathbf{K}_{r}^{(i)}$ son las matrices de correspondientes al tejido o capa $i$, isótropas, tangenciales o radiales respectivamente.

De acuerdo a la cantidad de elementos de la discretización del volumen, el número 
de puntos $N_{p}$ puede ser muy elevado, por lo que debe aprovecharse el carácter ralo de la matriz de rigidez de FEM. Para resolver el sistema de (2.39) y (2.40) se puede utilizar por ejemplo el algoritmo de gradientes biconjugados estabilizado (van der Vorst, 1992), o el algoritmo de gradientes conjugados precondicionado (Barrett et al., 1994), especialmente aptos para trabajar con este tipo de matrices.

De esta forma se puede calcular la solución al problema directo, ya sea de manera analítica o numérica, la cual permite obtener el potencial eléctrico en cualquier punto del objeto y en particular, en la ubicación de los sensores.

\subsubsection{Validación}

Para validar el método utilizado se realizaron dos experimentos de simulación. Por un lado, se resolvió el problema de EIT de manera analítica y mediante FEM con gradientes biconjugados para una esfera unitaria, homogénea e isótropa $(0,33 \mathrm{~S} / \mathrm{m}$ de conductividad). Por otro lado, se resolvió el problema directo de manera analítica para un modelo esférico de tres capas y de manera numérica para un modelo de geometría realista, de dimensiones similares y también de tres capas.

Para el primer experimento, se utilizó una esfera compuesta por 23345 tetraedros, haciendo coincidir la ubicación de los 64 electrodos con nodos del mallado. En la Fig. 2.3 se grafica el potencial eléctrico de ambas soluciones tomando como nodos de inyección de corriente a los electrodos $\mathrm{Cz}$ y T8 de la Fig. 2.1 para un valor de corriente de $100 \mu \mathrm{A}$.

Con esta cantidad de elementos y disposición de electrodos la diferencia entre la solución analítica calculada como un desarrollo en serie de 100000 términos y la solución numérica del método FEM, presentó un error relativo de 0,01 , calculado como la norma de la diferencia dividida por la norma de la solución analítica. Es decir, un error global del $1 \%$.

Para el segundo experimento, se discretizó el modelo de cabeza realista en 494450 tetraedros, con 137072, 42580 y 314798 correspondiendo al cuero cabelludo, cráneo y cerebro respectivamente (mallado no regular, con los elementos más pequeños en las interfaces entre tejidos; volumen de los elementos entre 0,45 y $71 \mathrm{~mm}^{3}$ ). La Fig. 2.4(a) muestra el potencial sobre un corte coronal de la cabeza para el caso 

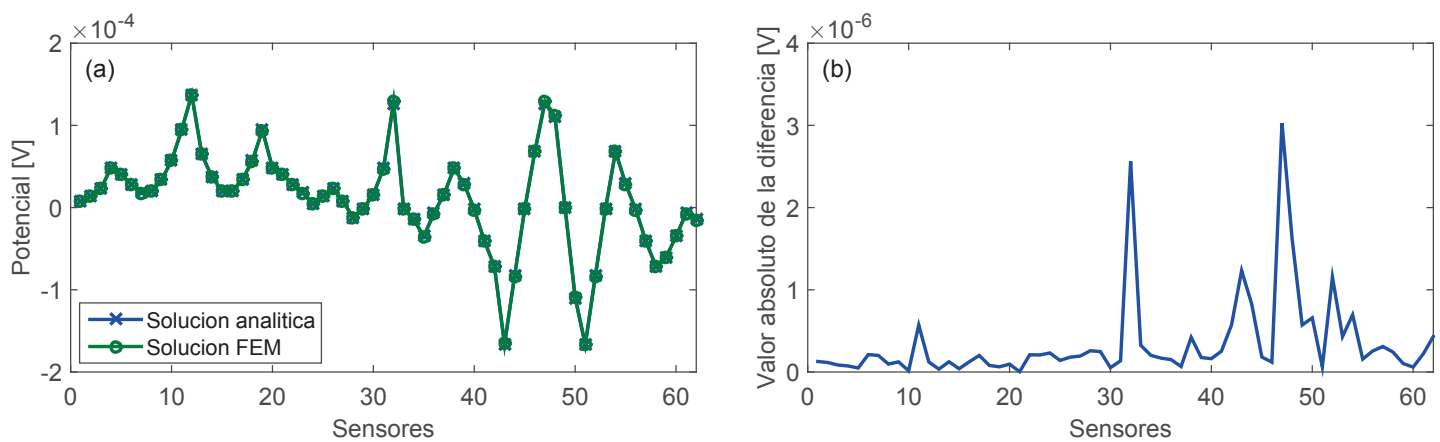

Figura 2.3: (a) Potencial sobre los sensores en el modelo esférico homogéneo e isótropo tanto para la solución analítica y como para la solución mediante FEM. (b) Diferencia del potencial entre ambas soluciones.
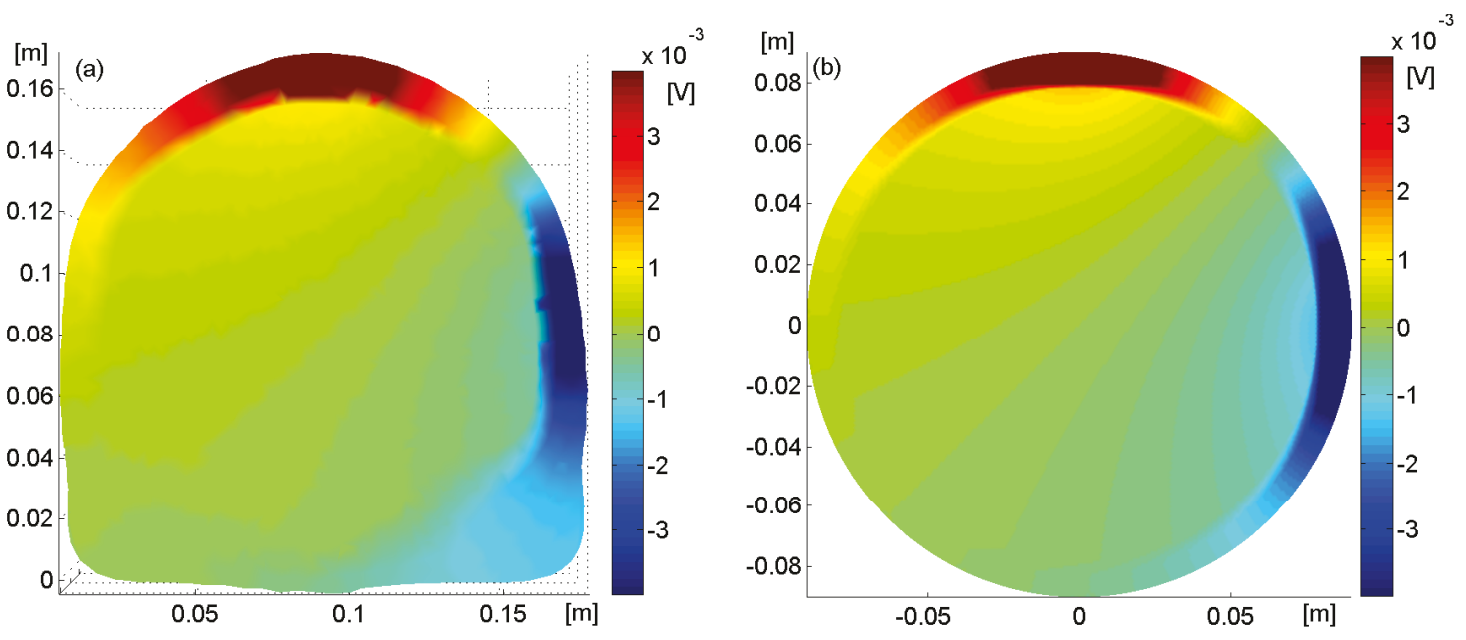

Figura 2.4: Potencial eléctrico sobre un corte coronal: (a) del modelo realista y (b) del modelo esférico.

isótropo mientras que la Fig. 2.4(b) lo hace para el modelo esférico de tres capas con los mismos valores de conductividad, puntos de inyección y sobre el mismo corte.

En la Fig. 2.5 se muestra un ejemplo del flujo de corriente y de la densidad de corriente en un corte coronal, con los electrodos C3-C4 como par de inyección de corriente y para un modelo que incluye inhomogeneidad y anisotropía en la conductividad correspondiente a la cavidad interior al cráneo obtenida a partir de imágenes de DTI. Se observa que la corriente se distribuye mayormente por el cuero cabelludo y que dentro de la cavidad intracraneal, se concentra mayormente en el líquido 


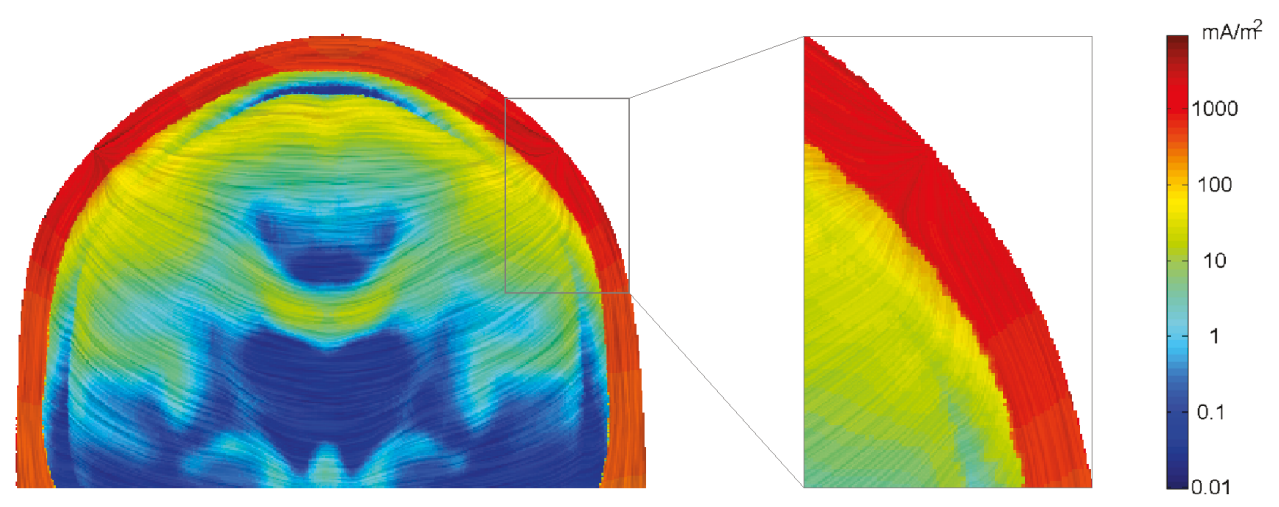

Figura 2.5: Flujo de corriente en un corte coronal con el par de inyección de corriente C3-C4. Las líneas grises muestran la dirección de la corriente mientras que la intensidad indica la amplitud de la densidad de corriente.

cefalorraquídeo.

\subsection{Modelo de señal}

Si se tienen $L$ electrodos, generalmente 2 se utilizan para la inyección de corriente y $L-2$ para medir. Es usual suponer que el par de inyección cambia a una frecuencia mayor que la dinámica de la conductividad interna, obteniendo $M$ conjuntos de $L-2$ mediciones para una misma instantánea, donde $M$ es la cantidad de pares de inyección utilizados. $M=L(L-1) / 2$ es el máximo número de pares posibles no redundantes para $L$ electrodos. En ausencia de ruido, sólo $M=L$ es suficiente para generar el resto de las mediciones que faltan para obtener las $L(L-1) / 2$ mediciones (Lionheart et al., 2004). El protocolo Sheffield descripto en Lionheart et al. (2004) es una manera comúnmente utilizada en EIT que utiliza los $M=L$ posibles pares adyacentes para la inyección de corriente.

El potencial sobre los electrodos $\mathbf{m}_{t}$ para un cierto instante de tiempo $t$ es una función no lineal del mapa de conductividad $\boldsymbol{\sigma}_{t}$, como se observa por ejemplo en la Ec. (2.12), más un término de ruido $\mathbf{n}_{t}$, es decir:

$$
\mathbf{m}_{t}=f\left(\boldsymbol{\sigma}_{t}\right)+\mathbf{n}_{t} .
$$


El término de ruido tiene en cuenta principalmente el efecto del ruido electrónico de los amplificadores y el producido por impedancia de contacto de los sensores, pero también considera otras contribuciones no incluidas en el modelo. Se lo modeliza generalmente como ruido blanco gaussiano de media nula. La conductividad eléctrica puede ser modelada como un tensor continuo, pero en la práctica, el volumen es subdividido en un dominio discreto con $K$ elementos. Si se supone homogeneidad e isotropía dentro de cada elemento, la conductividad puede modelizarse como un vector de $K$ valores escalares, uno por elemento de la discretización. Una aproximación a la Ec. (2.41) es linealizar el problema alrededor de una conductividad de referencia o conductividad base $\boldsymbol{\sigma}_{i}$ :

$$
\mathbf{m}_{t}=f\left(\boldsymbol{\sigma}_{i}\right)+\mathbf{J}\left(\boldsymbol{\sigma}_{t}-\boldsymbol{\sigma}_{i}\right)+\mathbf{n}_{t}
$$

donde $\mathbf{J}=\left[\mathbf{j}_{1} \mathbf{j}_{2} \ldots \mathbf{j}_{K}\right]$ es la matriz de sensibilidad o Jacobiano de tamaño $M(L-$ $2) \times K, y \mathbf{j}_{k}$ es llamado el vector de sensibilidad del elemento $k$. EIT permite la reconstrucción absoluta del mapa de conductividad, o la detección de diferencias de conductividad $\delta \boldsymbol{\sigma}_{t}=\boldsymbol{\sigma}_{t}-\boldsymbol{\sigma}_{i}$. Esta última opción permite desafectar varios errores sistemáticos y es más usual (Lionheart et al., 2004), y se tiene:

$$
\mathbf{m}_{t}-\mathbf{m}_{i}=\mathbf{y}_{t}=\mathbf{J} \delta \boldsymbol{\sigma}_{t}+\delta \mathbf{n}_{t}
$$

donde $\mathbf{m}_{i}=f\left(\boldsymbol{\sigma}_{i}\right)$. Es importante destacar que la geometría u otro modelo de electrodos como el modelo de electrodos completo (CEM) (Vauhkonen et al., 1998) sólo modifican la matriz de rigidez $\mathbf{J}$, por lo que los métodos que se desarrollan en esta tesis son compatibles con otras modelizaciones simplemente modificando $\mathbf{J}$.

\subsection{Paralelismo entre EIT y EEG}

Sea $\boldsymbol{\sigma}(\vec{x})$ el tensor de conductividad en un punto del espacio $\vec{x}$ de un sólido $\Omega$, y sea $\Phi(\vec{x})$ el potencial eléctrico producido por la corriente aplicada. Un cambio de conductividad $\delta \boldsymbol{\sigma}(\vec{x})$ produce un cambio en la distribución del potencial eléctrico $\delta \Phi(\vec{x})$. Para frecuencias lo suficientemente bajas como para que valga la aproxima- 
ción cuasi-estática de las ecuaciones de Maxwell, la ecuación que gobierna la física del problema es:

$$
\nabla \cdot(\boldsymbol{\sigma}(\vec{x}) \nabla \Phi(\vec{x}))=0
$$

en todo $\vec{x}$ excepto en los puntos de inyección de corriente. La Ec. (2.44) se satisface también cuando el cambio de conductividad está presente:

$$
\nabla \cdot((\boldsymbol{\sigma}(\vec{x})+\delta \boldsymbol{\sigma}(\vec{x})) \nabla(\Phi(\vec{x})+\delta \Phi(\vec{x})))=0 .
$$

Aplicando propiedades del operador gradiente, la Ec. (2.45) puede escribirse como:

$$
\nabla \cdot(\boldsymbol{\sigma} \nabla \Phi)+\nabla \cdot(\boldsymbol{\sigma} \nabla \delta \Phi)+\nabla \cdot(\delta \boldsymbol{\sigma} \nabla \Phi)+\nabla \cdot(\delta \boldsymbol{\sigma} \nabla \delta \Phi)=0
$$

donde la dependencia espacial $\vec{x}$ se omite por claridad.

El primer término de la Ec. (2.46) es cero debido a que cumple con la Ec. (2.44), y el último término de la Ec. (2.46) puede ser despreciado para cambios de conductividad pequeños ya que es aproximadamente $\mathcal{O}\left(\delta \boldsymbol{\sigma}^{2}\right)$ (Lionheart et al., 2004). Luego, la Ec. (2.45) se puede aproximar por:

$$
\nabla \cdot(\boldsymbol{\sigma} \nabla \delta \Phi) \approx-\nabla \cdot(\delta \boldsymbol{\sigma} \nabla \Phi)
$$

Esta aproximación es equivalente a la ecuación:

$$
\nabla \cdot\left(\boldsymbol{\sigma} \nabla \Phi_{\mathrm{EEG}}\right)=\nabla \cdot \overrightarrow{J_{\mathrm{p}}}
$$

que gobierna el problema directo de EEG, donde $\overrightarrow{J_{p}}$ es la densidad de corriente primaria debido a una fuente dipolar y $\Phi_{\mathrm{EEG}}$ es el potencial eléctrico resultante. El problema directo en EEG consiste en estimar el potencial eléctrico en los $L$ electrodos producido por una fuente eléctrica dipolar en una cierta ubicación $k$. Si se comparan las Ecs. (2.47) y (2.48), se observa el paralelismo entre el problema directo de EIT en diferencias y el problema directo en $\mathrm{EEG}^{3}$. La diferencia de potencial en EIT

\footnotetext{
${ }^{3}$ Debido a que en realidad es una aproximación, es que hablamos de paralelismo y no estrictamente de equivalencia. La equivalencia se da cuando se desprecia el último término de la Ec. (2.46), es decir, para EIT en diferencias linealizado.
} 
$\delta \Phi$ es equivalente al potencial $\Phi_{\mathrm{EEG}}$, y la fuente en EIT es menos el cambio de conductividad multiplicado por el gradiente del potencial en el punto donde ocurre el cambio de conductividad, es decir, $-\delta \boldsymbol{\sigma} \nabla \Phi$.

\subsubsection{Alternativa para el problema directo en EIT}

Basándose en el paralelismo matemático entre el problema directo en EEG y el problema directo de EIT en diferencias, en esta sección desarrollamos un método novedoso para calcular el cambio de potencial en los electrodos que se produce en EIT debido a un cambio de conductividad interno en la ubicación $k$. Para un cambio de conductividad unitario, el cambio de potencial en los electrodos se denomina vector de sensibilidad y se lo denota $\mathbf{j}_{k}$. El conjunto de los vectores de sensibilidad obtenidos con distintos pares de inyección y para todas las posibles ubicaciones $k$ puede agruparse en una matriz de sensibilidad J. Como se verá en los Capítulos 5 y 6, esta matriz es necesaria tanto para los algoritmos de reconstrucción en EIT como en filtrado espacial en EIT (EIT-SF).

En EEG, el modelo de señal para una fuente dipolar con momento q y ubicada en el elemento $k$ involucra una matriz de sensibilidad $\mathbf{L F}_{k}$, que contiene el potencial eléctrico esperado en los sensores generado por la fuente dipolar. Esta matriz es de dos o tres columnas dependiendo de si el problema se formula en dos o tres dimensiones. Cada columna o vector de sensibilidad de EEG se corresponde a una orientación canónica de q. El modelo de señal para una fuente dipolar ubicada en $k$ es:

$$
\mathbf{y}_{\mathrm{EEG}}=\mathbf{L F}_{k} \mathbf{q}+\mathbf{n}(\mathbf{t})
$$

donde $\mathbf{y}_{\mathrm{EEG}}$ es el vector de mediciones de largo $L$ ( $L$ es el número total de electrodos), si es que se supone referencia de potencial eléctrico de media nula. Si se tomara como referencia para el potencial a uno de los electrodos, el vector $\mathbf{y}_{\mathrm{EEG}}$ sería de largo $L-1$.

Existen algunas diferencias entre el modelo de señal para EEG (2.49) y el modelo de señal de EIT en diferencias (2.43). El vector de mediciones de EIT y tiene 
$(L-2) M$ elementos, donde $M$ es la cantidad de pares de inyección utilizados, mientras que $\mathbf{y}_{\mathrm{EEG}}$ tiene $L$ elementos. A partir de la matriz de sensibilidad de EEG $\mathbf{L} \mathbf{F}_{k}$, es posible armar una nueva matriz $\overline{\boldsymbol{L F}}_{k}^{m}$ para cada par de inyección $m$ de la siguiente manera: las filas de $\mathbf{L F}_{\mathbf{k}}$ correspondientes a los electrodos de inyección son eliminadas, y luego el promedio de cada columna es restado a cada columna para mantener el sistema de referencia de media nula. El potencial esperado en los electrodos $\delta \Phi$ debido a un cambio de conductividad en $k$, es decir, el vector de sensibilidad en EIT en diferencias para el par de inyección $m$, es $\overline{\boldsymbol{L F}}_{k}^{m} \nabla \Phi_{k}^{m} V_{k} . \nabla \Phi_{k}^{m}$ es el gradiente del potencial eléctrico en la ubicación $k$ cuando el par de inyección es $m$ y $V_{k}$ es el volumen (o área) del elemento $k$. Los vectores $\overline{\boldsymbol{L F}}_{k}^{m} \nabla \Phi_{k}^{m} V_{k}$ obtenidos para los $M$ pares de inyección pueden agruparse uno a continuación del otro formando un vector de tamaño $M(L-2) \times 1$, que es el vector de sensibilidad de EIT en diferencias $\mathbf{j}_{k}$. Por último los distintos $\mathbf{j}_{k}$ obtenidos para las $K$ posibles ubicaciones pueden agruparse cada uno en una columna distinta formando la matriz de sensibilidad $\mathbf{J}$ de tamaño $M(L-2) \times K$.

Esta forma alternativa de computar la matriz de rigidez presenta como principal ventaja que sólo se necesitan guardar en memoria la matriz de rigidez de EEG que es de tamaño $L \times D K$ y el gradiente del potencial eléctrico para cada par de inyección que es de tamaño $M \times D K$, donde $D$ es el número de dimensiones geométricas, generalmente 2 o 3 . Nótese que la matriz de rigidez de EIT posee un tamaño mucho mayor: $M(L-2) \times K$.

\subsubsection{Verificación numérica}

Se realizó una verificación numérica en un caso simple de simulación, de un tanque circular bidimensional de radio $10 \mathrm{~cm}$, discretizado en 1092 elementos triangulares, con 16 electrodos, $M=105$ pares de inyección y $1 \mathrm{~mA}$ de corriente inyectada. Se simuló un cambio de conductividad de $0,01 \mathrm{~S} / \mathrm{m}$ sobre una conductividad base de $1 S / m$ y se computó la matriz de rigidez de EIT de manera directa, es decir, simulando el cambio de conductividad, y de la manera alternativa basándose en el problema directo en EEG. En la Fig. 2.6(a) pueden verse los valores de todos los elementos de ambas matrices de rigidez, en la Fig. 2.6(b) se muestra el valor absoluto de la 

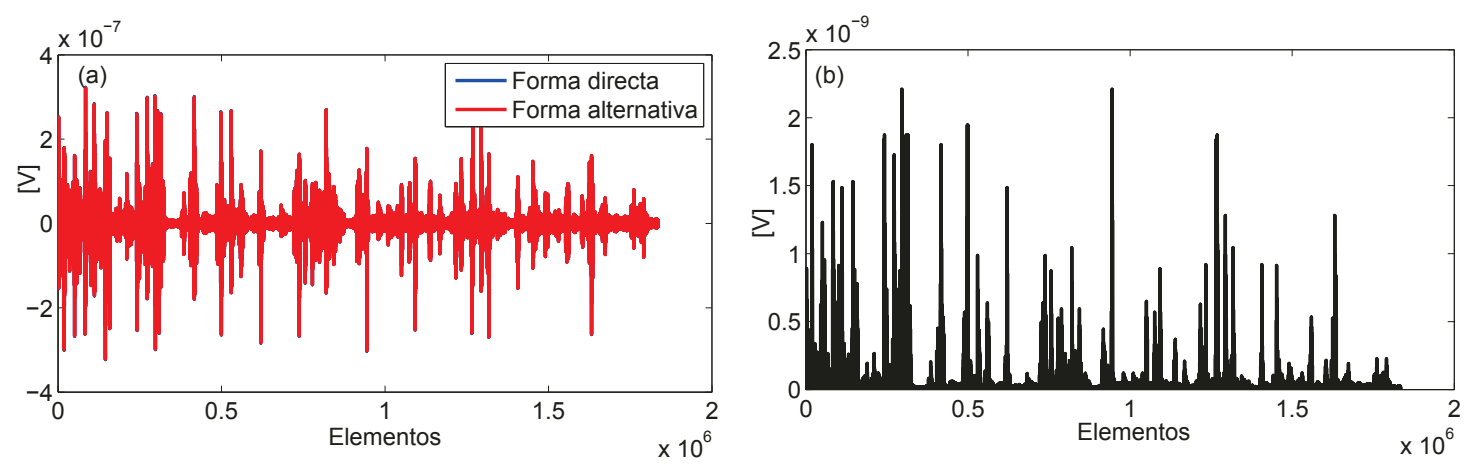

Figura 2.6: (a) Todos los elementos de la matriz de sensibilidad de EIT obtenidos de manera directa y de manera alternativa basándose en el problema de EEG. En esta imagen los elementos se encuentran prácticamente superpuestos. (b) Valor absoluto de la diferencia de los elementos de las matrices de sensibilidad calculadas de ambas maneras.

diferencia y en la Fig. 2.7 se muestra la norma de la diferencia para cada vector de sensibilidad. En esta última figura se puede observar que la diferencia es máxima en los elementos con electrodos en alguno de sus nodos.

Cabe destacar que para este simple ejemplo, el tiempo computacional para calcular la matriz de sensibilidad J de manera directa fue de 284 segundos, mientras que la manera alternativa tardó sólo 15 segundos. Esto indica que la ventaja computacional al utilizar esta formulación alternativa es no sólo en memoria sino además en tiempo.

\subsection{Conclusiones}

En este capítulo se desarrollaron las soluciones para el problema directo en EIT, tanto para modelos esféricos de manera analítica, como para modelos realistas utilizando FEM. Para el modelo esférico, se desarrolló por completo el caso particular de un modelo esférico, isótropo, de tres capas. Para la solución con FEM, se mostró además cómo incluir en el modelo tensores de conductividad no necesariamente isótropos.

La comparación entre la solución analítica y la obtenida mediante FEM para el caso de esfera unitaria permitió validar empíricamente el uso de algoritmos FEM 


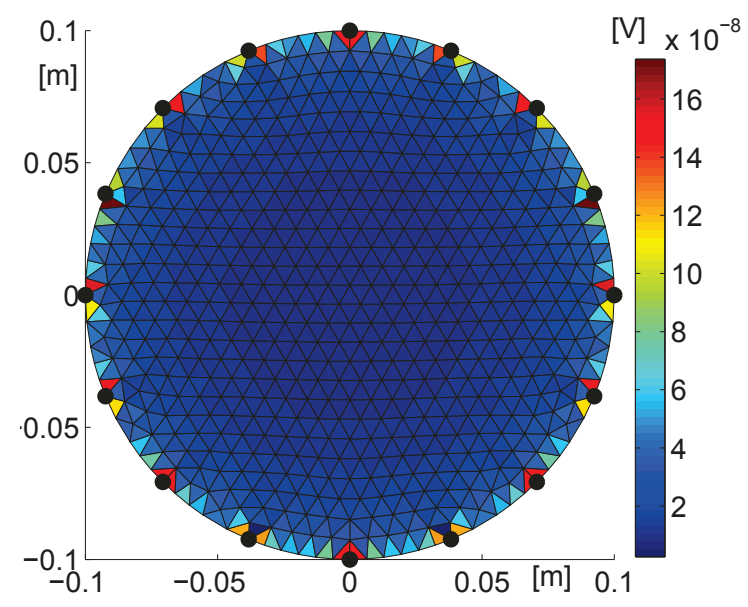

Figura 2.7: Norma de la diferencia de cada vector de sensibilidad. Los puntos "•" indican las ubicaciones de los electrodos.

propios para resolver el problema directo de EIT. La utilización de FEM en EIT es muy común y ya ha sido validada en la literatura, como por ejemplo en Bagshaw et al. (2003); Abascal et al. (2007). Haciendo coincidir las ubicaciones de los electrodos con nodos del mallado se lograron diferencias entre la solución analítica y la numérica que se encuentran dentro de los valores típicos para este tipo de problemas con una cantidad de tetraedros relativamente baja. A mayor cantidad de elementos, estas medidas del error incluso tienden a mejorar. A su vez, en la Fig. 2.4 se observa una marcada correlación entre la resolución del problema directo en geometría realista utilizando FEM y la solución analítica en el modelo esférico de tres capas.

También se describieron y desarrollaron los modelos de que serán utilizados y referidos en los siguientes capítulos de la tesis, y se mostraron las principales características de los equipos experimentales utilizados en esta tesis para obtener mediciones reales de EIT.

Por último, se desarrolló una novedosa alternativa para resolver el problema directo de EIT en diferencias basándose en el paralelismo con el problema de localización de fuentes en EEG. Esta alternativa presenta grandes ventajas desde el punto de vista computacional, tanto en memoria como en tiempo de cálculo, lo que resulta altamente ventajoso en el caso de complejos modelos de cabeza realistas que pueden estar compuestos por millones de elementos. 


\section{Capítulo 3}

\section{EIT paramétrico}

\subsection{Introducción}

Conocer los valores de conductividad eléctrica de los tejidos que conforman la cabeza humana es necesario para poder construir modelos confiables que permitan una mayor precisión en el análisis de datos y en la planificación de experimentos. Por ejemplo en EEG, mejores modelos permiten una mejor precisión en la localización de fuentes de actividad neuronal. Lograr mayor precisión es de extrema importancia en aplicaciones médicas como ser el caso de epilepsias focales, en donde la ubicación de fuentes anómalas está generalmente asociada con algún tipo de lesión en la región. En los casos en que la epilepsia se torna refractaria a los medicamentos, la solución es la resección de la zona epileptógena, lo que obviamente requiere conocer su ubicación y extensión lo más precisamente posible. Otra aplicación en la que se requiere precisión es en la planificación de experimentos de tDCS, ya que el objetivo es estimular sólo la región de interés. Por último, conocer con precisión la conductividad eléctrica de los tejidos, fundamentalmente del cráneo y del cuero cabelludo, es fundamental en la aplicación de EIT para detectar cambios de conductividad interiores al cráneo, ya que la técnica es altamente sensible a variaciones de estos valores.

En Horesh (2006) se realiza una completa descripción de las propiedades eléctricas de los tejidos de la cabeza y en particular del cráneo y del cuero cabelludo, cuyas principales características se replican a continuación. El cráneo es altamente 
resistivo con respecto a los tejidos que lo circundan, lo que produce un efecto de blindaje eléctrico entre las zonas exterior e interior a él. Por otro lado, la conductividad del cuero cabelludo afecta significativamente las mediciones de EIT ya que es la primera capa con la que se encuentra la corriente, la cual tiende a distribuirse más sobre este tejido que a ingresar al cráneo, por tener este último menor conductividad. Las conductividades de estas dos capas suelen modelizarse como homogéneas e isótropas, es decir, con un valor equivalente constante y sin una dirección preferencial. Sin embargo esto puede ser una sobresimplificación. En efecto, el cráneo está mayormente conformado por dos subcapas externas de hueso compacto y una interna de hueso esponjoso que no poseen un espesor uniforme a lo largo del mismo por lo que la conductividad pierde homogeneidad. A su vez existe anisotropía ya que la conductividad tangencial a través de la capa esponjosa es mayor que la transversal o radial (Rush y Driscoll, 1968). Un fenómeno similar ocurre en el cuero cabelludo donde existen zonas con músculos, los cuales presentan una mayor conductividad en la misma dirección que la de las fibras que los componen.

EIT paramétrico (bEIT) es una modalidad de EIT que permite estimar valores de conductividad eléctrica equivalentes de los principales tejidos de la cabeza, en particular, del cráneo y el cuero cabelludo. El principal interés es utilizar bEIT para estimar la conductividad del cráneo mayormente por dos motivos: por un lado, a diferencia de los tejidos blandos de la cabeza, su conductividad no puede ser obtenida a partir de la técnica de DTI; y por el otro, EIT paramétrico permite una estimación in-vivo y específica de cada individuo de manera mínimamente invasiva, a diferencia de otras mediciones de la conductividad del cráneo que han sido realizadas post-mortem, o de manera invasiva. Los principios de EIT paramétrico pueden encontrarse en Eriksen (1990); De Munck et al. (1999); Ferree et al. (2000) y mediciones in-vivo utilizando esta técnica pueden encontrarse en Eriksen (1990); Oostendorp et al. (2000); Gonçalves et al. (2003); Clerc et al. (2005); Zhang et al. (2006); Ouypornkochagorn et al. (2014). Sin embargo en la mayoría de estos experimentos se utilizan modelos de tres capas, se estiman sólo uno o dos parámetros y no se tiene en cuenta la anisotropía.

En el presente capítulo primero se plantea el estimador de máxima verosimi- 
litud (MLE) para las conductividades, adoptando un modelo de ruido Gaussiano y suponiendo isotropía y anisotropía en los tejidos. El estimador se aplica tanto a problemas de geometrías esféricas, utilizando soluciones analíticas para el problema directo, como a geometrías realistas, donde se utiliza FEM para hallar las soluciones al problema directo. A su vez, se calcula la Cota de Cramér-Rao para el problema de estimación, y se obtienen límites de desempeño teóricos y se determinan pares de inyección de corriente convenientes. Por último, se obtienen los valores de conductividad equivalentes del cráneo y del cuero cabelludo aplicando las mismas técnicas a mediciones reales de EIT sobre humanos.

\subsection{Estimador de máxima verosimilitud (MLE)}

El problema inverso de EIT paramétrico involucra estimar los valores de conductividad eléctrica equivalentes de cada tejido basándose en mediciones de potencial eléctrico. En la presente sección se describe la obtención del MLE bajo un modelo Gaussiano del ruido (Kay, 1993).

Si a los valores de conductividad los agrupamos en un vector de parámetros $\boldsymbol{\theta}$, la Ec. (2.41) se puede reescribir como:

$$
\mathbf{m}=f(\boldsymbol{\theta})+\mathbf{n},
$$

donde $\mathbf{m}$ es de tamaño $L-2 \times 1$ si se supone referencia promedio para un sólo par de inyección de corriente. Nótese que $\mathbf{n}$ es el término de ruido que se modeliza como WGN no correlacionado de media nula y varianza $\sigma_{w}^{2}$. Como la dependencia de las mediciones con los parámetros de interés no es lineal, se debe adoptar una solución a un problema de minimización. Para el modelo de señal de la Ec. (3.1), la formulación del estimador MLE para el vector de parámetros $\boldsymbol{\theta}$ viene dada por (Kay, 1993):

$$
\boldsymbol{\theta}^{M L}=\underset{\boldsymbol{\theta}}{\operatorname{argmin}}\left\{(\hat{\mathbf{m}}-f(\boldsymbol{\theta}))^{T}(\hat{\mathbf{m}}-f(\boldsymbol{\theta}))\right\},
$$

donde el vector $\hat{\mathbf{m}}$ es el promedio de $S$ mediciones y $f(\boldsymbol{\theta})$ es el potencial eléctrico en los sensores que se determina a partir de la soluciones al problema directo planteadas 
en el capítulo 2. El problema de minimización es convexo, por lo que se espera una única solución, pero a su vez es mal-condicionado ya que la solución es muy sensible a pequeños cambios en las mediciones.

\subsection{Cota de Cramér-Rao (CRB)}

La cota de Cramér-Rao (CRB) es útil para cuantificar el desempeño teórico de una estimación paramétrica, ya que permite encontrar una cota inferior para la varianza del error de cualquier estimador insesgado. En este capítulo, se la utiliza para determinar la calidad de las estimaciones de la conductividad los tejidos con EIT paramétrico y para determinar pares de inyección convenientes.

Si $\hat{\boldsymbol{\theta}}$ es un estimador insesgado de $\boldsymbol{\theta}$,

$$
\operatorname{Cov}\{\hat{\boldsymbol{\theta}}\} \geq \operatorname{CRB}(\boldsymbol{\theta})=\mathbf{F}^{-1}(\boldsymbol{\theta}),
$$

donde la desigualdad matricial implica que la diferencia es positiva semidefinida, F es la matriz de información de Fisher, CRB es la matriz de Cramér-Rao y Cov significa covarianza. Para señales con ruido blanco Gaussiano, como se adoptó en el modelo de (3.1), F viene dada por

$$
[\mathbf{F}(\boldsymbol{\theta})]_{i j}=\frac{S}{\sigma_{w}^{2}}\left(\frac{\partial \boldsymbol{\mu}(\boldsymbol{\theta})}{\partial \theta_{i}}\right)^{T}\left(\frac{\partial \boldsymbol{\mu}(\boldsymbol{\theta})}{\partial \theta_{j}}\right)
$$

donde $\boldsymbol{\mu}(\boldsymbol{\theta})$ es la esperanza de $\mathbf{m}$ y $S$ es el número total de muestras supuestas independientes (Kay, 1993). De la Ec. (3.1), la esperanza de m viene dada por:

$$
\boldsymbol{\mu}(\boldsymbol{\theta})=f(\boldsymbol{\theta}) .
$$

\subsubsection{CRB para la formulación numérica}

En la Ec.(3.4) es necesario obtener $\frac{\partial \boldsymbol{\mu}(\boldsymbol{\theta})}{\partial \theta_{i}}$ para cada uno de los parámetros $\theta_{i}$. De las Ecs. (2.39) y (2.40) se puede particularizar el modelo de señal para la formulación 
FEM como:

$$
\mathbf{m}=\mathrm{MK}^{-1}(\boldsymbol{\theta}) \mathbf{f}+\mathbf{n},
$$

donde $\mathbf{M}$ es una matriz rala de selección de tamaño $(L-2) \times N_{p}$ que elige los elementos de $\mathbf{u}$ correspondientes a los nodos ubicados en la posición de los electrodos. La derivadas parciales resultan:

$$
\frac{\partial \boldsymbol{\mu}(\boldsymbol{\theta})}{\partial \theta_{i}}=\mathbf{M}\left(-\mathbf{K}^{-1} \frac{\partial \mathbf{K}}{\partial \theta_{i}} \mathbf{K}^{-1}\right) \mathbf{f}=-\mathbf{M K}^{-1} \frac{\partial \mathbf{K}}{\partial \theta_{i}} \mathbf{u} .
$$

Para comparar la varianza relativa de cada parámetro $\theta_{i}$, definimos una cota del coeficiente de variación, (CVB) como

$$
C V B_{i}=\frac{\sqrt{C R B_{i i}}}{\theta_{i}}
$$

donde $\theta_{i}$ es un valor referencia del parámetro, y $C R B_{i i}$ es el i-ésimo elemento de la diagonal de la matriz CRB. Este coeficiente representa una cota en la desviación estándar relativa de cada parámetro.

\subsection{Algoritmos de optimización}

Existen distintos métodos numéricos para resolver el problema de minimización (3.2), entre los cuales se encuentran el algoritmo Nelder-Mead (Lagarias et al., 1998), basado en los métodos del tipo "simplex", y el método clásico de Newton (Fletcher, 1987), el cual requiere conocer las expresiones del Gradiente y del Hessiano de la función a minimizar en (3.2).

El método de Nelder-Mead presenta la ventaja que evalúa la función a optimizar sin la necesidad de tener que proveer derivadas de ningún orden. Si los valores a estimar no son del mismo orden, es conveniente realizar un cambio de escala para ayudar a la convergencia del método. En tanto, el método de Newton requiere del Gradiente y del Hessiano de la función a minimizar, pero la cantidad de iteraciones 
es menor. Básicamente, cada iteración del método de Newton viene dada por

$$
\hat{\boldsymbol{\theta}}_{j+1}=\hat{\boldsymbol{\theta}}_{j}-\mathbf{H}^{-1} \mathbf{G},
$$

donde $\mathbf{G}$ y $\mathbf{H}$ son el Gradiente y el Hessiano de la función a minimizar con respecto a los parámetros a estimar. Para el caso de resolución numérica con FEM es posible encontrar el conjunto de derivadas que se requieren para construir el Gradiente y el Hessiano de una manera similar a la expresión (3.7).

\subsection{Experimentos con datos simulados}

\subsubsection{Modelo esférico de tres capas}

Se construyó un modelo esférico de tres capas, para estimar las relaciones entre las conductividades del cráneo, cuero cabelludo y cerebro. Estimar relaciones en lugar de las conductividades absolutas es conveniente si analizamos la solución analítica del problema directo de la Ec. (2.12). Sólo dos de las tres relaciones son independientes, por lo que se adoptó $\theta_{1}=\sigma_{1} / \sigma_{2}$ y $\theta_{2}=\sigma_{1} / \sigma_{3}$ como variables independientes quedando $\sigma_{2} / \sigma_{3}=\theta_{2} / \theta_{1}$. En el estimador MLE de la Ec. (3.2), $f$ se determina a partir de calcular el potencial $\Phi_{t o t}^{(3)}$ de la Ec. (2.12) en la ubicación de los electrodos. El problema de minimización bidimensional (2 parámetros) se resolvió utilizando el algoritmo de Nelder-Mead sin restricciones descripto en la sección anterior. En la formulación de la Ec. (3.2) existe la restricción de que las incógnitas deben ser positivas, pero es posible comenzar con valores iniciales relativamente cercanos a los valores verdaderos evitando así que el algoritmo converja a valores negativos sin la necesidad de utilizar un algoritmo de optimización con restricciones más complejo.

Las mediciones se simularon suponiendo ruido blanco gaussiano, que se adicionó a la solución del problema directo, de media cero y desviación estándar $1 \mu V$. El problema de estimación se resolvió para 16, 32 and 64 electrodos según la configuración 10 - 10 estándar de EEG de la Fig 2.1. Se puede observar que existe una simetría en la distribución de los electrodos entre los lados derecho e izquierdo, por ejemplo entre los pares C4-F4 y C3-F3. Esta simetría no ocurre entre las caras frontales y 

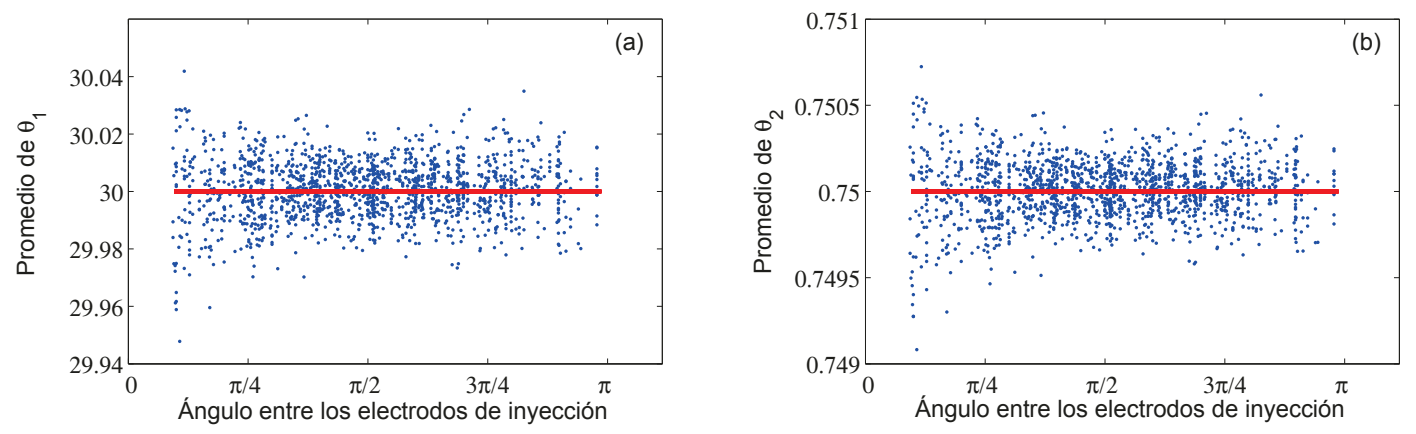

Figura 3.1: Cada punto azul es el promedio de las 100 estimaciones para cada par de inyección de (a) $\theta_{1}=\sigma_{1} / \sigma_{2}$ y (b) $\theta_{2}=\sigma_{1} / \sigma_{3}$, para 64 electrodos. La línea roja muestra el promedio de los promedios.

posteriores debido a la existencia de los electrodos occipitales Iz, P9 y P10 para 64 electrodos, y debido al electrodo Oz para 16 y 32 electrodos. Entonces, se consideraron todos los pares de electrodos sin una configuración simétrica exacta, resultando un número menor al máximo de $L(L-1) / 2$. El número de combinaciones utilizadas se muestra en la Tabla 3.1.

Tabla 3.1: Combinaciones de pares utilizados

\begin{tabular}{ccc}
\hline Electrodos $(\mathrm{L})$ & Combinaciones & $L(L-1) / 2$ \\
\hline 64 & 1551 & 2016 \\
32 & 391 & 496 \\
16 & 99 & 120 \\
\hline
\end{tabular}

Para cada combinación, se simularon 100 realizaciones de ruido diferentes y se estimaron la media y varianza de $\hat{\theta}_{1}$ y $\hat{\theta}_{2}$. Las Figs. 3.1(a) y 3.2(a) muestran la variabilidad de $\hat{\theta}_{1}$ en función del ángulo entre los electrodos de inyección, para los casos de 64 y 32 electrodos respectivamente. El promedio también se muestra con una línea horizontal. Las Figs. 3.1(b) y 3.2(b) muestran lo mismo pero para la variable $\theta_{2}$.

La Fig. 3.3(a) muestra la media y la media más/menos la varianza de la estimación de $\theta_{1}$ para los distintos pares de inyección usando 16 electrodos. Un par de inyección particular, T7-T8, presentó una varianza muy alta. Esto es esperable ya 

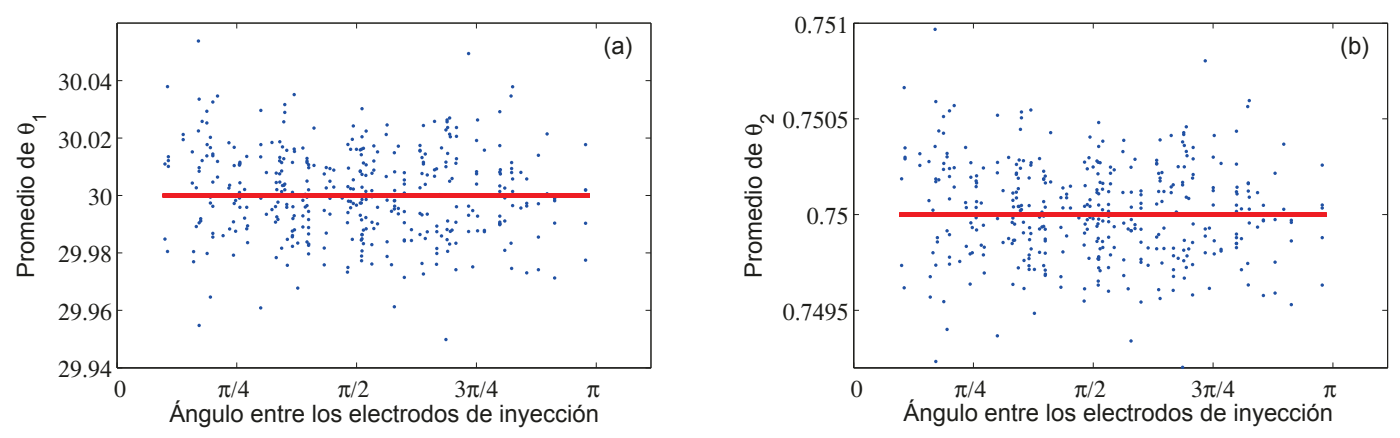

Figura 3.2: Cada punto azul es el promedio de las 100 estimaciones para cada par de inyección de (a) $\theta_{1}=\sigma_{1} / \sigma_{2}$ y (b) $\theta_{2}=\sigma_{1} / \sigma_{3}$, para 32 electrodos. La línea roja muestra el promedio de los promedios.
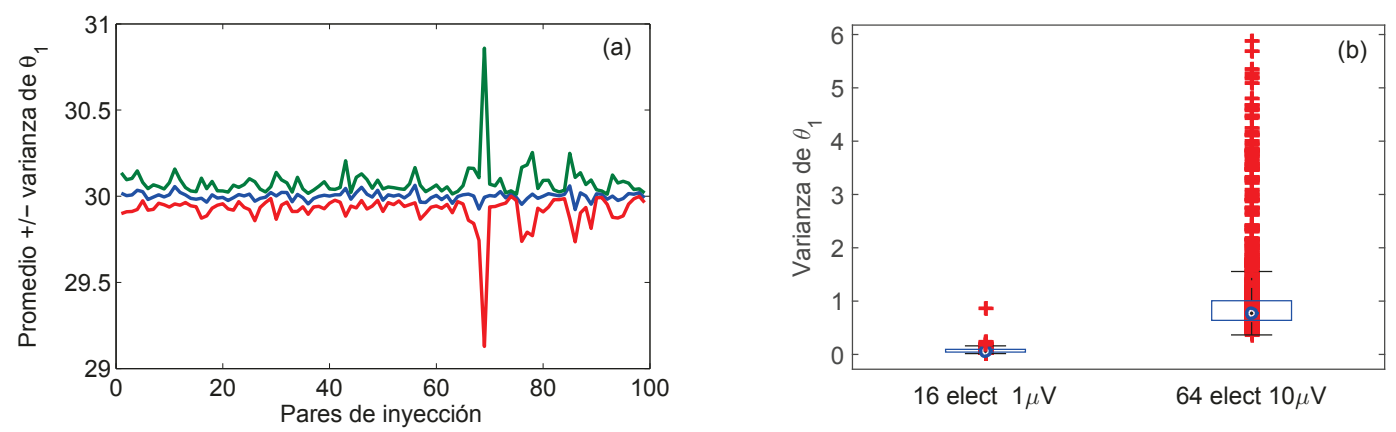

Figura 3.3: (a) Promedio más/menos la varianza para las estimaciones de $\theta_{1}$ con 16 electrodos en función de los pares de inyección. (b) Gráfico de cajas para la varianza de las estimaciones de $\theta_{1}$ para 16 electrodos con SD de ruido de $1 \mu V$ y para 64 electrodos con SD de ruido de $10 \mu \mathrm{V}$. La marca central es la mediana, los bordes son los percentiles 25 y 75 , y los bigotes se extienden hasta los valores más extremos no considerados anómalos.

que en este caso, los electrodos de medición se encuentran mayormente concentrados cerca del plano central entre los dos electrodos de inyección, donde el potencial eléctrico es insensible a variaciones en las variables $\theta_{1}$ y $\theta_{2}$.

La Fig. 3.4(a) muestra la varianza de $\hat{\theta}_{1}$ obtenida para diferentes simulaciones donde cada cruz representa la varianza media para cada par de inyección, y la Fig. 3.4(b) muestra el mismo resultado para $\theta_{2}$. La combinación T7-T8 fue excluida de ambos gráficos para una mayor claridad.

Otro conjunto de simulaciones fue realizado para estudiar el impacto de la va- 

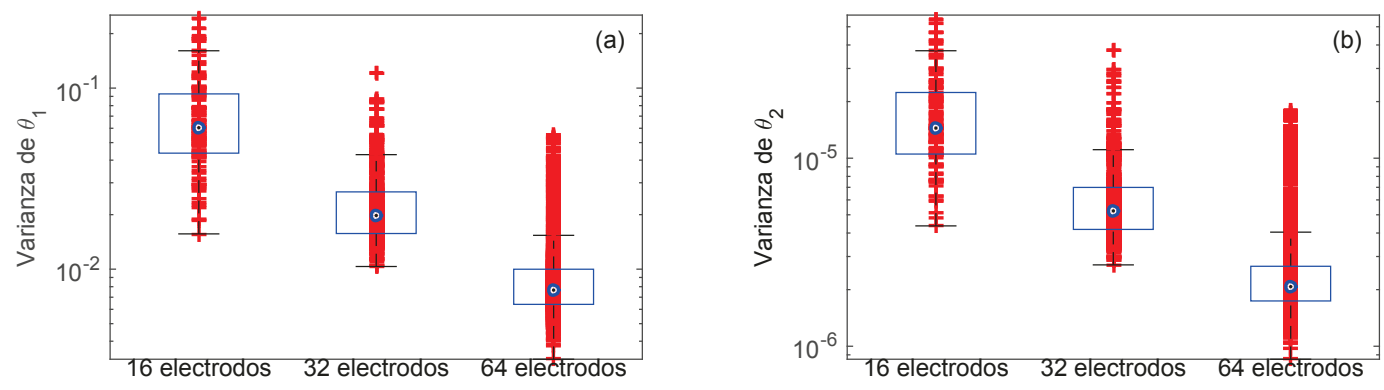

Figura 3.4: Gráfico de cajas para la varianza de las estimaciones de (a) $\theta_{1}$ y (b) $\theta_{2}$ para cada par de inyección (cada cruz representa a cada par). La marca central es la mediana, los bordes son los percentiles 25 y 75, y los bigotes se extienden hasta los valores más extremos no considerados anómalos.

rianza del ruido. Es esperable que la actividad normal del cerebro alcance picos de alrededor de $20 \mu V$ (Niedermeyer y da Silva, 2004). Si bien este ruido puede ser desafectado con alguna técnica apropiada como en Gonçalves et al. (2003) o como la que se desarrolla en el capítulo 4, teniendo en cuenta que la forma de onda de la corriente inyectada es bien conocida, es de interés conocer cuál sería el efecto de no desafectar dicho ruido. Entonces, se realizó la misma simulación para 64 electrodos, pero con un ruido de desviación estándar más alta, de $10 \mu V$. En la Fig. 3.3(b) se compara el desempeño de la estimación con $1 \mu \mathrm{V}$ y $10 \mu \mathrm{V}$ de desviación estándar para 16 y 64 electrodos respectivamente, donde la caja izquierda es la misma que la derecha de la Fig. 3.4(a).

\subsubsection{Modelos de geometrías realistas}

En esta sección se muestran los resultados obtenidos sobre un modelo de cabeza realista de tres capas, considerando isotropía y anisotropía en el cráneo y en el cuero cabelludo. La geometría del modelo está basada en el atlas ICBM 152 (Mazziotta et al., 2001). Se realizó una discretización del modelo de la cabeza subdividiendo el dominio en 494450 tetraedros con 79725 nodos o vértices, donde 137072, 42580 y 314798 elementos corresponden al cuero cabelludo, cráneo y cerebro respectivamente, como puede verse en la Fig. 3.5(a). Para ello se utilizó el programa de distribución 
gratuita iso2mesh (Fang y Boas, 2009). En la Fig. 3.5(b) se muestran las superficies que dividen las capas y la ubicación de los 64 electrodos utilizados.

Se estudiaron tres tipos de conductividad eléctrica para los tejidos:

Modelo isótropo: Las tres capas se consideran homogéneas e isótropas, y los parámetros de interés son las conductividades de los tejidos: cuero cabelludo $\left(\sigma^{c c}\right)$, cráneo $\left(\sigma^{c r}\right)$ y cerebro o cavidad intracraneal $\left(\sigma^{c e r}\right)$.

Modelo parcialmente isótropo: El cráneo y el cuero cabelludo se consideran isótropos y homogéneos, al igual que en el modelo anterior. Pero el mapa de conductividad intracraneal se considera anisótropo y no homogéneo y se obtiene de imágenes de tensor de difusión (DTI) del atlas ICBM-DTI-81 (Mori et al., 2008), como se puede observar en la Fig. 3.5(c). Para este modelo entonces hay sólo dós parámetros: $\sigma^{c c}$ y $\sigma^{c r}$.

Modelo anisótropo: El cráneo y el cuero cabelludo se consideran homogéneos, pero anisótropos, con una componente tangencial o paralela a las superficies, y otra radial o perpendicular. Para la conductividad intracraneal se utiliza la misma distribución obtenida con DTI del modelo anterior. Se buscan estimar cuatro parámetros o valores equivalentes de conductividad: cuero cabelludo tangencial $\left(\sigma_{t}^{c c}\right)$, cuero cabelludo radial $\left(\sigma_{r}^{c c}\right)$, cráneo tangencial $\left.\sigma_{t}^{c r}\right)$ y cráneo radial $\left(\sigma_{r}^{c r}\right)$.

Se simularon distintas mediciones con ruido blanco Gaussiano y se utilizó el estimador MLE de la Ec. (3.2) para la estimación de los parámetros, donde $f$ se determinó a partir de calcular el vector de potencial eléctrico u usando FEM según la Ec. (2.39) o la Ec. (2.40) dependiendo del modelo. Se eligió un valor típico para la desviación estándar del ruido de $1 \mu V$, que tiene en cuenta el ruido electrónico de los amplificadores e incertezas no incluidas en el modelo. Se adoptó un valor de corriente de $100 \mu A$ pico para todas las simulaciones, de acuerdo al máximo permitido por la norma IEC60601 (2005). Se realizó un primer estudio donde se simularon mediciones sobre los modelos parcialmente isótropo y anisótropo, y se estimaron los parámetros de conductividad del cráneo y cuero cabelludo utilizando el MLE con el método de Nelder-Mead, para un par en particular, el C3-C4 del sistema 10-10 de 64 electrodos de la Fig. 2.1, el cual se considera apropiado de acuerdo a los resultados obtenidos en las simulaciones con el modelo esférico. Luego se realizó un segundo estudio 

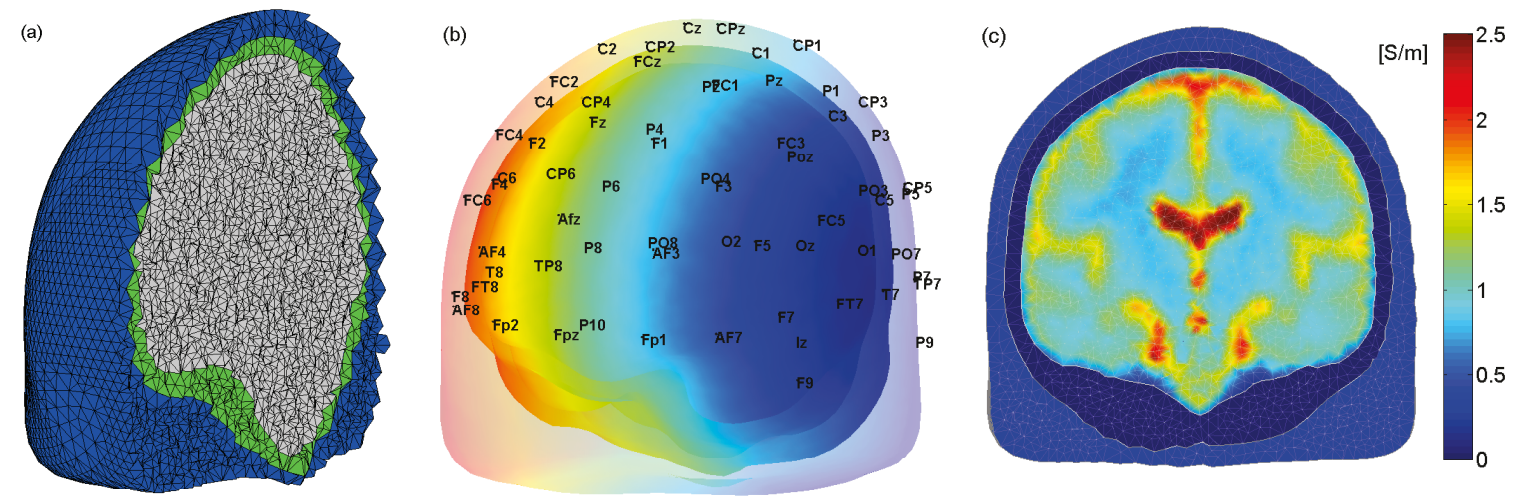

Figura 3.5: Modelo utilizado para los experimentos de simulación en geometrías realistas. (a) Segmentación y discretización. (b) Superficies entre tejidos y ubicación de los electrodos. (c) Mapa de conductividad interno obtenido con DTI.

más general sobre los tres modelos, con 16 pares para la inyección de corriente. Se tuvieron en cuenta distintos valores para la conductividad y el factor de anisotropía del cráneo, y se comparó la calidad de las estimaciones con la cota teórica CRB. En este caso se utilizó el MLE con el método de Newton. La CRB fue utilizada además, para comparar la calidad de la estimación entre los distintos pares de inyección.

Para el primer estudio, se simularon 100 conjuntos de mediciones con distintas realizaciones de ruido, estimando las conductividades tanto del problema isótropo como del anisótropo para cada conjunto. Como puntos iniciales para el algoritmo se eligieron valores aleatorios con distribución uniforme entre 0.95 y 1.05 del valor esperado. El resultado de la estimación se muestra en la Tabla 3.2, en donde la primer columna muestra la media, la segunda la desviación estándar y la tercera el coeficiente variacional (CV) que consiste en dividir la desviación estándar por la media. La última columna muestra los valores de referencia utilizados en este primer estudio. Las primeras dos filas corresponden a las estimaciones del modelo parcialmente isótropo y las últimas cuatro a las del modelo anisótropo.

Para el segundo estudio, además estimar los valores de conductividad usando el MLE con el método de Newton, se computó el CVB sobre los tres modelos de conductividad, para estudiar el desempeño del método y para determinar pares de inyección convenientes. En esta oportunidad, se analizaron 16 pares diferentes para 
Tabla 3.2: Valores de conductividad estimados con el par C3-C4: media, desviación estándar, coeficiente variacional $(\mathrm{CV})$ y valores de referencia.

\begin{tabular}{lcccc}
\hline$\sigma$ & Media $[\mathrm{S} / \mathrm{m}]$ & Desv. Est. $[\mathrm{S} / \mathrm{m}]$ & CV & Referencia $[\mathrm{S} / \mathrm{m}]$ \\
\hline$\sigma^{c c}$ & $3,9998 \times 10^{-1}$ & $2,06 \times 10^{-4}$ & $5,16 \times 10^{-4}$ & $4 \times 10^{-1}$ \\
$\sigma^{c r}$ & $1,0000 \times 10^{-2}$ & $8,20 \times 10^{-6}$ & $8,40 \times 10^{-4}$ & $1 \times 10^{-2}$ \\
$\sigma_{t}^{c c}$ & $4,4993 \times 10^{-1}$ & $2,74 \times 10^{-4}$ & $6,09 \times 10^{-4}$ & $4,5 \times 10^{-1}$ \\
$\sigma_{r}^{c c}$ & $3,0561 \times 10^{-1}$ & $1,40 \times 10^{-2}$ & $4,57 \times 10^{-2}$ & $3 \times 10^{-1}$ \\
$\sigma_{t}^{c r}$ & $1,5140 \times 10^{-2}$ & $6,13 \times 10^{-4}$ & $4,04 \times 10^{-2}$ & $1,5 \times 10^{-2}$ \\
$\sigma_{r}^{c r}$ & $1,4993 \times 10^{-3}$ & $4,74 \times 10^{-6}$ & $3,16 \times 10^{-3}$ & $1,5 \times 10^{-3}$ \\
\hline
\end{tabular}

la inyección de corriente, un subconjunto representativo de los 2016 posibles pares de inyección. La elección de los pares se realizó de manera tal de abarcar situaciones favorables y desfavorables, de acuerdo a lo estudiado en la sección anterior sobre el modelo esférico. Para resolver el sistema lineal de FEM (Ec. 2.37) y calcular las derivadas de la Ec. (3.7), del Gradiente y del Hessiano se utilizó el algoritmo de gradiente biconjugado estabilizado de van der Vorst (1992), que puede manejar matrices ralas.

Para los modelos isótropo y parcialmente isótropo, se seleccionaron valores de referencia del cuero cabelludo y de la cavidad intracraneal comúnmente encontrados en la bibliografía: $\sigma^{c c}=0,4 S / m$ y $\sigma^{c e r}=0,3 S / m$ (Bayford, 2006). En vista del rango de valores encontrados para el cráneo, se analizaron diferentes situaciones con valores variando desde $0,004 \mathrm{~S} / \mathrm{m}$ a $0,04 \mathrm{~S} / \mathrm{m}$. Para el modelo anisótropo, se eligió 1 : 1,5 como relación radial:tangencial de la conductividad del cuero cabelludo, de acuerdo a un estudio existente (Horesh, 2006). Para el cráneo, existe un amplio rango de valores para esta relación, por lo que se analizaron valores variando desde $1: 1$ (isótropo) hasta 1 : 10. En cada caso, se eligieron valores de manera que la traza de los tensores de conductividad $\boldsymbol{\sigma}(\vec{x})$ sean iguales a la traza del tensor isótropo del mismo tejido, es decir, $\operatorname{Tr}\{\boldsymbol{\sigma}(\vec{x})\}=3 \times \sigma^{c c}$ si $\vec{x}$ es un punto interior al cuero cabelludo, y $\operatorname{Tr}\{\boldsymbol{\sigma}(\vec{x})\}=3 \times \sigma^{c r}$ si $\vec{x}$ es un punto del cráneo. Los valores adoptados fueron entonces: $\sigma_{t}^{c c}=0,45 S / m, \sigma_{r}^{c c}=0,3 S / m, \sigma_{t}^{c r}$ entre $0,01 S / m$ y $0,014 S / m$, y $\sigma_{r}^{c r}$ entre $0,01 S / m$ y $0,0014 S / m$. En la Tabla 3.3 se resumen los valores de referencia utilizados para cada tejido.

Para el cómputo de la CBV, se supusieron 50 muestras temporales independien- 
Tabla 3.3: Valores de conductividad de referencia elegidos para el segundo estudio $[S / m]$

\begin{tabular}{|c|c|c|c|}
\hline Modelo & cuero cabelludo & cráneo & intracraneal \\
\hline Isótropo & 0,4 & $0,004-0,04$ & 0,3 \\
\hline Parc. isótropo & 0,4 & $0,004-0,04$ & DTI \\
\hline Anisótropo & $\begin{array}{cc}\text { tangencial } & \text { radial } \\
0,45 & 0,3\end{array}$ & $\begin{array}{cc}\text { tangencial } & \text { radial } \\
0,01-0,014 & 0,01-0,0014\end{array}$ & DTI \\
\hline (relación rad:tan) & $1: 1,5$ & $1: 1-1: 10$ & \\
\hline
\end{tabular}

tes. Para la minimización de Newton en el MLE, se eligieron valores iniciales más bajos que los valores de referencia, y se definió que termine luego de seis iteraciones. Se encontró empíricamente que la estabilidad numérica y la velocidad de convergencia es mejor para valores iniciales más bajos que los valores de referencia, y que el método se estanca usualmente luego de seis iteraciones.

El cálculo de la CRB permite determinar pares de inyección convenientes. Las Figs. 3.6 y 3.7 muestran el CVB de los pares de inyección analizados para los tres modelos de cabeza adoptando los siguientes valores para la conductividad del cráneo: $\sigma^{c r}=0,01 S / m$ para el modelo isótropo, y $\sigma_{t}^{c r}=0,014 S / m$ y $\sigma_{r}^{c r}=0,0014 S / m$ para los otros modelos. Para cada parámetro, el color de la línea de conexión entre los electrodos del par de inyección es proporcional al CVB obtenido con ese par. Los pares con menor CVB (mejores) presentan en general una mayor distancia entre los electrodos de inyección y éstos se encuentran rodeados de varios electrodos de medición en concordancia con los resultados obtenidos con el modelo esférico. Obsérvese que en la Fig. 2.2, el mayor cambio en el potencial de la superficie, por ende la mayor sensibilidad, ocurre en los electrodos de medición cercanos a los electrodos de inyección.

Para cada par de inyección de corriente se simularon 20 conjuntos de $S=50$ mediciones cada uno, con realizaciones de ruido independientes. La estimación paramétrica se realizó para cada conjunto con el MLE de la Ec. (3.1), donde $\hat{\mathbf{m}}$ es el promedio de las 50 mediciones. Los diferentes conjuntos fueron utilizados para encontrar la varianza del MLE y compararla con la CRB. En realidad para comparar con la CVB, se definió el Estimador del Coeficiente Variacional (ECV) para cada 
parámetro $\theta_{i}$ como:

$$
E C V_{i}=\frac{\sqrt{\operatorname{Var}\left(\theta_{i}^{M L}\right)}}{\theta_{i}},
$$

donde Var significa varianza. Para analizar el desempeño del MLE en todo el rango de conductividad del cráneo se muestran los resultados sólo para el par 'P3-Fc4', el cual se considera un ejemplo representativo. Los valores de CVB y ECV se muestran para los modelos isótropo y parcialmente isótropo en función del valor de conductividad del cráneo en las Figs. 3.8(a) y 3.8(b), y para el modelo anisótropo, como función de la relación de anisotropía del cráneo en la Fig. 3.8(c). Puede observarse que en la Fig. 3.8(b) también se muestra el CVB para el modelo isótropo con la finalidad de cuantificar los beneficios de conocer a-priori la conductividad del cerebro.

En el caso del modelo anisótropo (Figs. 3.7(c-f) y 3.8(a)), las conductividades tangencial del cuero cabelludo y perpendicular o radial del cráneo presentan un menor CVB comparadas con las conductividades radial del cuero cabelludo y tangencial del cráneo. Esto se debe a que el potencial eléctrico medido es más sensible a las conductividades tangencial del cuero cabelludo y radial del cráneo, que son las más importantes en el problema de localización de EEG. Obsérvese que las líneas grises de la Fig. 2.5 indican que el flujo de la corriente es mayormente tangencial en el cuero cabelludo y perpendicular en el cráneo.

La Fig. 3.8(b) muestra que el conocimiento a priori del mapa de conductividad intracraneal lleva a una reducción de tres veces en el CVB relativo de la conductividad del cuero cabelludo y en una reducción del $\sim 40 \%$ del CVB relativo del cráneo. Estos resultados pueden interpretarse como una reducción del número total del mediciones que deben realizarse para lograr un desempeño dado.

Al comparar el MLE con la CRB puede observarse en la Fig. 3.8 que el valor de ECV fue estimado a partir de sólo 20 muestras, por lo que estos resultados pueden ser un poco ruidosos. El MLE es asintóticamente eficiente, es decir, alcanza a la CRLB para un número infinito de muestras. Igualmente, incluso con este bajo número de muestras es evidente que el MLE se acerca notablemente al CVB para $S=50$ mediciones independientes. Este comportamiento fue observado en todos los pares de inyección analizados. 

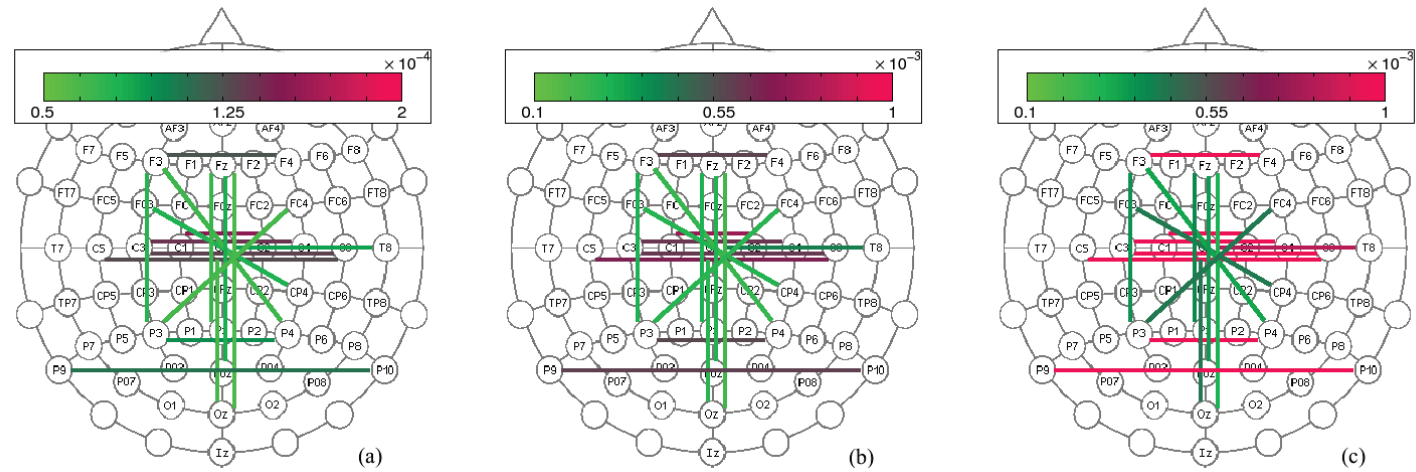

Figura 3.6: CVB para el modelo isótropo: (a) conductividad del cuero cabelludo, (b) conductividad del cráneo y (c) conductividad del cerebro o cavidad intracraneal. El color de cada línea indica el CVB obtenido cuando el par de inyección está formado por los electrodos que conecta esa línea. Obsérvese que cada diagrama tiene su propia escala.

\subsection{Experimentos con datos reales}

En esta sección se presentan los resultados que se obtuvieron al aplicar el estimador de máxima verosimilitud, con el método de Newton a un conjunto de datos reales de EIT paramétrico que fueron provistos por Electrical Geodesics Inc. y el NeuroInformatics Center de la Universidad de Oregon, Estados Unidos, quienes cuentan además con todos los permisos y habilitaciones necesarios para realizar estos experimentos. Los datos se obtuvieron sobre un sujeto masculino de 40 años, y de origen asiático. Se utilizó un arreglo de 128 electrodos como se muestra en la Fig. 3.9(a) y una corriente de $22 \mu \mathrm{A}$ a $24 H z$. Para cada par de inyección se midió el potencial en el resto de los electrodos con respecto al electrodo de referencia $\mathrm{Cz}$. Se estimaron valores de conductividad del cráneo y del cuero cabelludo modelizándolos como tejidos isótropos y homogéneos. Para ello se utilizó un protocolo de 62 pares de inyección de corriente, que se muestra en las primeras dos columnas de la Tabla A.1 del Apéndice A junto con los resultados de las estimaciones. 

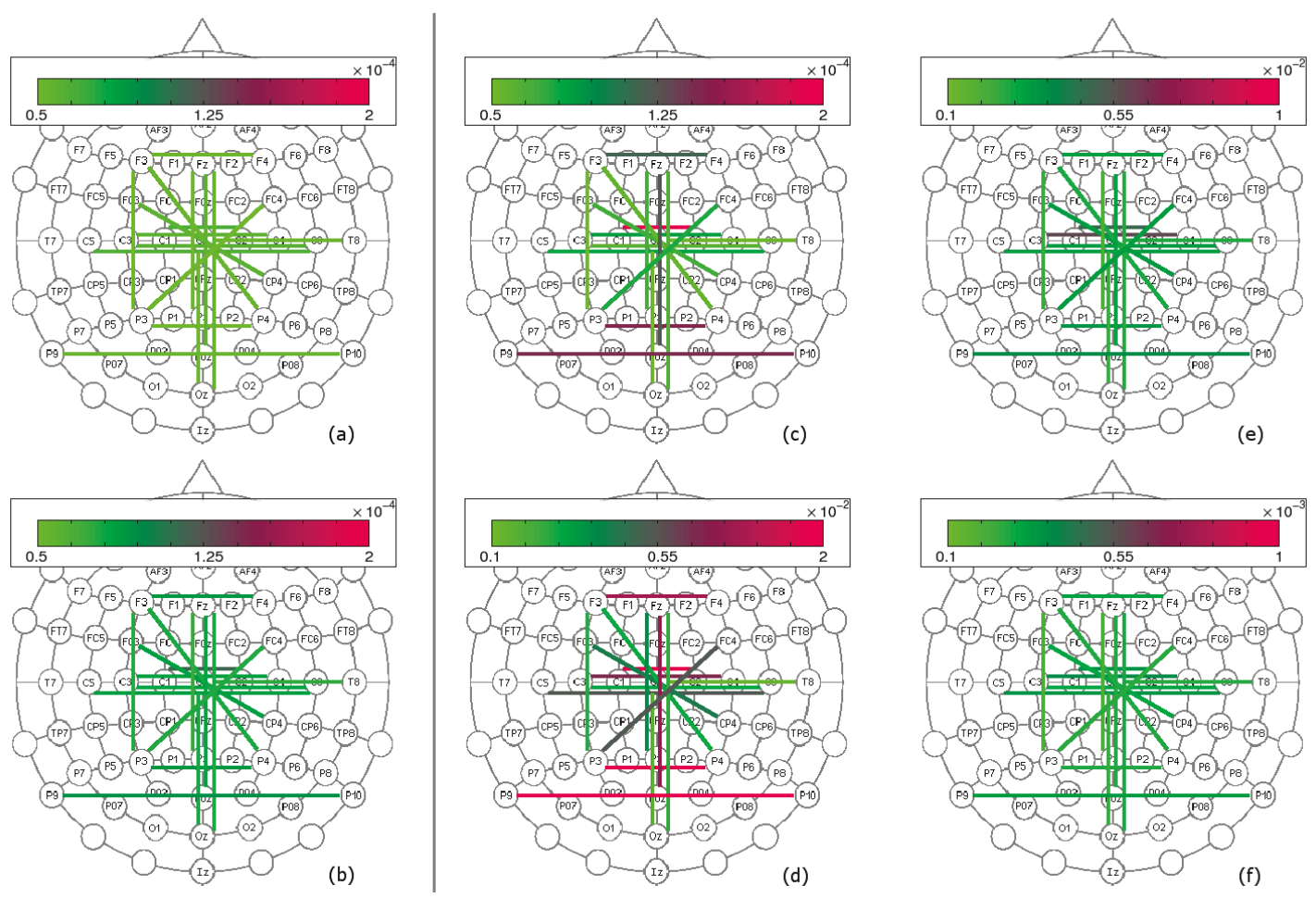

Figura 3.7: CVB para el modelo parcialmente isótropo: (a) conductividad del cuero cabelludo y (b) conductividad del cráneo; y para el modelo anisótropo: (c) conductividad del cuero cabelludo tangencial, (e) conductividad del cuero cabelludo radial, (d) conductividad del cráneo tangencial y (f) conductividad del cráneo radial. El color de cada línea indica el CVB obtenido cuando el par de inyección está formado por los electrodos que conecta esa línea. Obsérvese que cada diagrama tiene su propia escala.
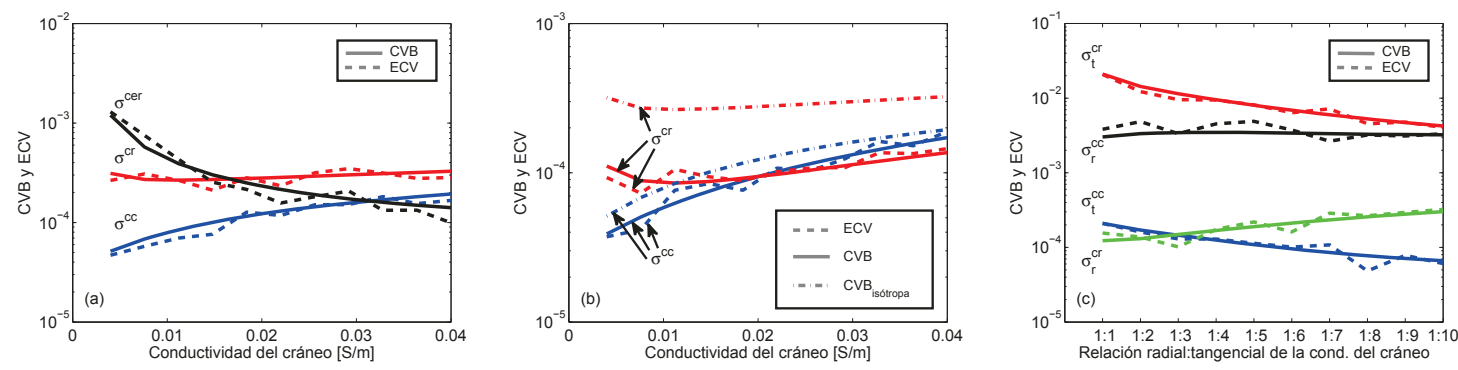

Figura 3.8: CVB y ECV como función de la conductividad del cráneo para el par 'P3-Fc4' y para los modelos (a) isótropo, (b) parcialmente isótropo y (c) anisótropo. En (b) también se muestra el CVB para el modelo isótropo. 

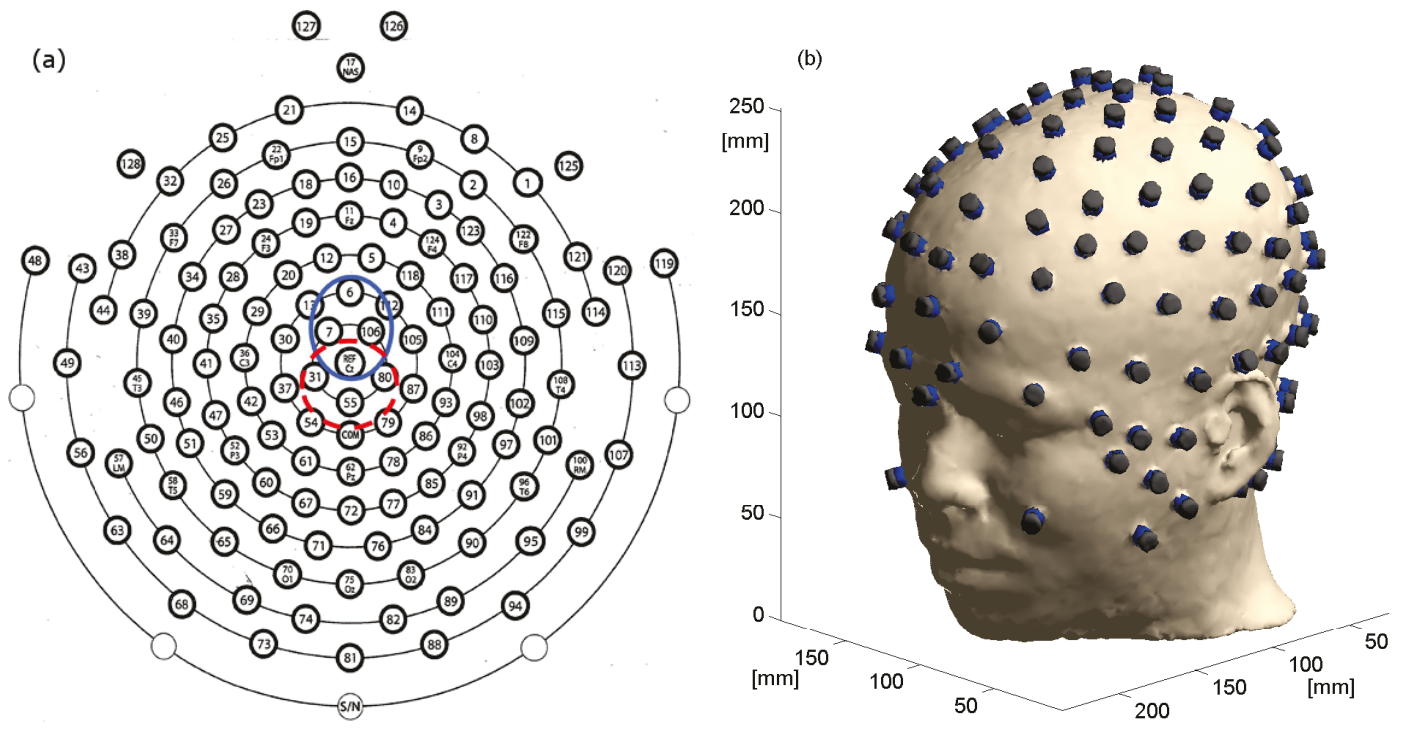

Figura 3.9: (a) Diagrama de red de electrodos de alta densidad para 128 electrodos (EGI). (b) Modelo virtual de cabeza con modelo realista de los electrodos incluyendo gel (azul) y metal (gris oscuro).

\subsubsection{Modelo eléctrico de la cabeza}

Se construyó un modelo detallado de cabeza de un sujeto particular, del cual se cuenta con imágenes de resonancia magnética (MRI) del tipo T1 pesadas y de tomografía computada (CT). La resonancia fue adquirida con un escáner 3T Allegra (Siemmens Healthcare) y la tomografía con un escáner GE (General Electrics). La matriz de adquisición fue de tamaño $256 \times 256 \times 256$ con tamaño de vóxel $1 \mathrm{~mm} \times$ $1 \mathrm{~mm} \times 1 \mathrm{~mm}$ para ambas imágenes. Las imágenes de CT fueron corregistradas a las imágenes de MRI y luego la cabeza fue segmentada en siete tejidos (materia blanca, materia gris, CSF, cuero cabelludo, ojos, aire y cráneo) utilizando el paquete de segmentación y procesamiento de imágenes BrainK, de Electrical Geodesics Inc. (EGI), Eugene, OR, US (Li et al., 2006). La ubicación de los 128 electrodos fue provista por el sistema geodésico de fotogrametría (GPS) de EGI (Russell et al., 2005). Se asignaron valores de conductividad isótropos para cada tejido de acuerdo a lo más utilizado en la literatura: $0,2 S / \mathrm{m}$ para la materia blanca, $0,33 \mathrm{~S} / \mathrm{m}$ para la materia gris, $1,79 S / m$ para el CSF y $0,4 S / m$ para los ojos (Horesh, 2006).

Se construyeron dos versiones del modelo virtual de cabeza variando la modeli- 
zación de los electrodos. En una versión se modelizaron los electrodos como puntos colocados sobre el cuero cabelludo (modelo puntual). En la segunda versión, se generó un modelo volumétrico más realista, donde cada electrodo de modelizó como un cilindro de eje perpendicular a la superficie exterior del cuero cabelludo, de $1 \mathrm{~cm}$ de diámetro y de $1 \mathrm{~cm}$ de altura (modelo realista). A cada electrodo se lo dividió en tres discos de altura $2 \mathrm{~mm}, 4 \mathrm{~mm}$ y $4 \mathrm{~mm}$ representando cuero cabelludo, gel conductor y metal respectivamente. Al gel se le asignó una conductividad de $1,5 \mathrm{~S} / \mathrm{m}$ de acuerdo a lo informado por el fabricante y al metal una conductividad de $1000 \mathrm{~S} / \mathrm{m}$. Si bien el metal en general tiene una conductividad superior, valores por encima de $1000 \mathrm{~S} / \mathrm{m}$ afectaron a la estabilidad numérica de los algoritmos utilizados y a su vez $1000 \mathrm{~S} / \mathrm{m}$ es un valor suficientemente alto comparado con los valores de conductividad del resto de los medios del modelo.

A partir de la segmentación y de la incorporación de los electrodos, se construyeron dos mallas de tetraedros de aproximadamente 1,4 millones de elementos a partir de la segmentación utilizando el paquete iso2mesh (Fang y Boas, 2009), donde los elementos correspondientes al aire fueron directamente removidos del modelo. Para medir la calidad de las mallas se calcularon el factor de stretch (o factor de forma) definido en Tizzard et al. (2005) y el volumen de cada uno de los elementos. Para ambas mallas, se obtuvo que aproximadamente el 0,08\% de los elementos presentan un factor de stretch menor que 0,05 y que todos los elementos presentan un volumen superior a $1 \times 10^{-11}$ cuando hemos detectado que recién elementos de volumen inferior a $5 \times 10^{-12}$ pueden producir errores numéricos. El modelo con electrodos realistas se muestra en la Fig. 3.9(b), mientras que en la Fig. 3.10 se muestra la malla de tetraedros, junto con la segmentación y la ubicación de los electrodos para la red de alta densidad de 128 electrodos para el modelo de electrodo puntual.

\subsubsection{Resultados}

Se utilizaron las mismas mediciones para realizar las estimaciones tanto para el modelo con electrodos puntuales como para el modelo con electrodos realistas. Para cada par de inyección se utilizaron 10 iteraciones del método de Newton arrancando con valores aleatorios distribuidos normalmente, centrados en $0,2 \mathrm{~S} / \mathrm{m}$ y $0,001 \mathrm{~S} / \mathrm{m}$ 

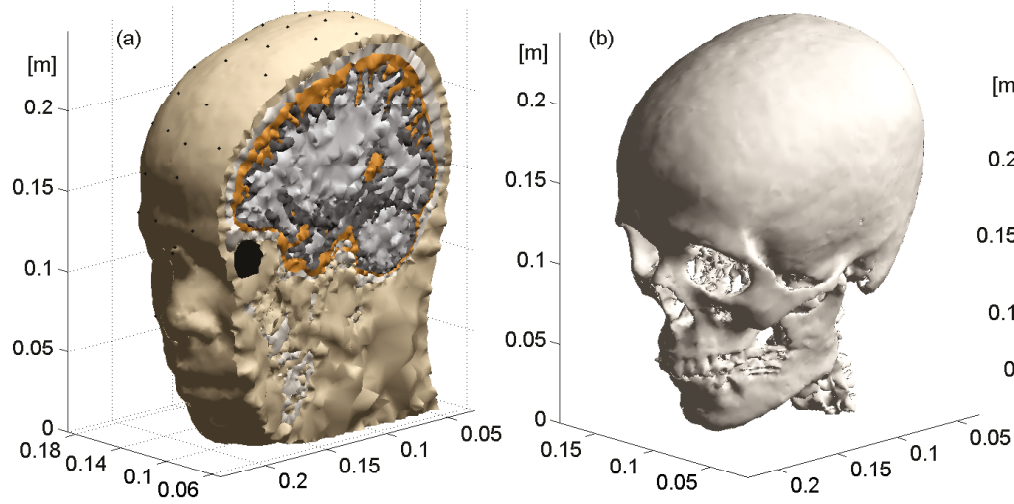

(c)

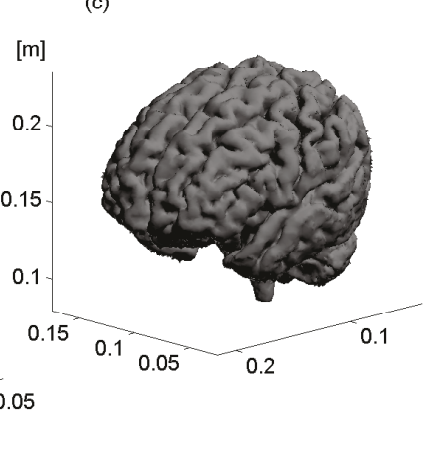

Figura 3.10: Modelo eléctrico de cabeza. (a) Corte sagital mostrando los diferentes tejidos de la segmentación, la malla de tetraedros y las ubicaciones de los electrodos. (b) Modelo virtual del cráneo. (c) Modelo virtual de la materia gris.

para el cuero cabelludo y para el cráneo respectivamente, y con desviación estándar de $5 \%$. Nótese que, como se ha mencionado anteriormente, para los valores iniciales se eligieron valores inferiores a los que se esperan estimar para facilitar la convergencia del método de Newton. Se utilizaron más iteraciones que en el caso de mediciones simuladas ya que se encontró empíricamente que con datos reales el método se estabilizaba entre la octava y la novena iteración con al menos 4 dígitos significativos.

En la Tabla A.1 del Apéndice A se muestran todos los resultados para ambos modelos de los electrodos. Las estimaciones señaladas como " $\mathrm{N} / \mathrm{C}$ " indican que el método no convergió adecuadamente, ya sea porque convergió a valores negativos o porque después de la décima iteración los valores no se estabilizaron con al menos cuatro decimales significativos. Analizando los resultados junto con la Fig. 3.9(a) se puede observar que para el modelo de electrodos realistas, los pares de inyección que involucraron algún electrodo vecino al $\mathrm{Cz}$ no convergieron. Por otro lado se puede observar un mayor número de pares que convergieron con el modelo de electrodo realista que con el modelo de electrodo puntual y que en 42 pares el modelo con electrodos realistas presentó un error menor que el modelo puntual, el cual fue menor sólo en 3 casos. En la Fig. 3.11 se puede ver condensada la información de la tabla, es 

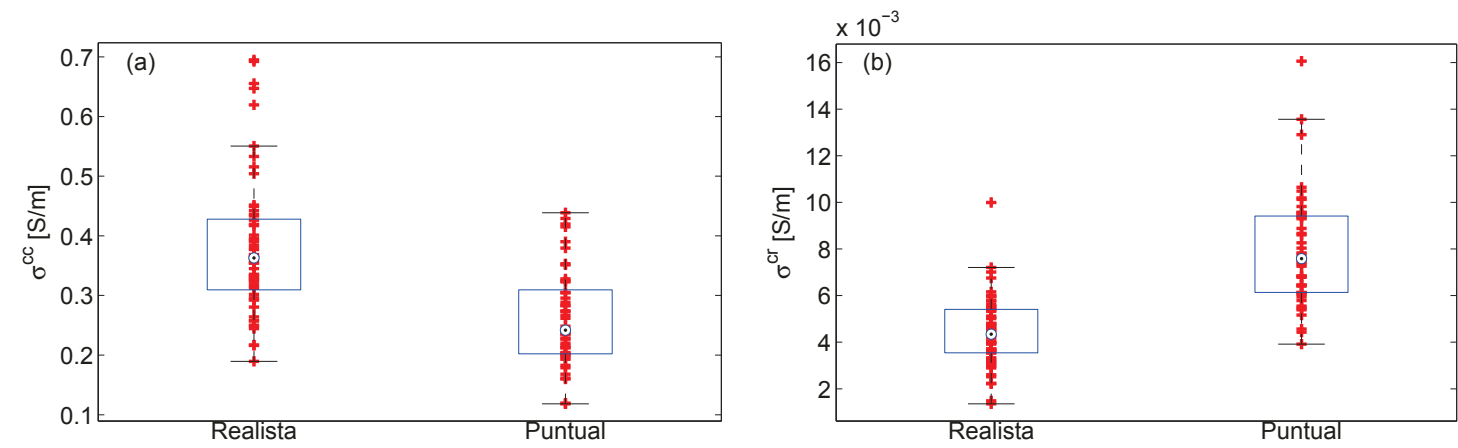

Figura 3.11: Estimaciones con datos reales. (a) Estimaciones para la conductividad del cuero cabelludo para ambos modelos de electrodos. (b) Estimaciones para la conductividad del cráneo para ambos modelos de electrodos.

decir, los valores de conductividad estimados para los distintos pares. Para el modelo de electrodo realista, el valor promedio de la conductividad del cuero cabelludo fue de $0,38 S / m$ y de $0,0045 S / m$ para el cráneo. Para el modelo de electrodo puntual los valores promedio fueron $0,26 S / m$ para el cuero cabelludo y $0,0079 S / m$ para el cráneo.

\subsection{Discusión y conclusiones}

Los parámetros de relaciones de conductividades del modelo esférico se pudieron estimar satisfactoriamente con el estimador MLE para el método de EIT paramétrico para 16, 32 y 64 electrodos, considerando además que se utilizó un nivel de corriente adecuado y una desviación estándar típica para el ruido. La combinación de imágenes de MR junto con EIT permitió la estimación paramétrica de las conductividades en vez de la obtención de un mapa de conductividades que se podría obtener utilizando sólo EIT, el cual presentaría una muy baja resolución espacial.

En general, se obtuvieron mejores resultados utilizando pares de inyección con mayor ángulo entre los electrodos activos, aunque el desempeño mejoró también con un mayor número de electrodos de medición cerca de los electrodos de inyección ya que esos electrodos presentan una mayor sensibilidad frente a variaciones en las conductividades de los tejidos. Por ejemplo, el par C3-C4 presentó menor varianza 
que el par T7-Cz aunque el ángulo entre los electrodos activos es similar en ambos casos. En síntesis, es conveniente utilizar pares de inyección con más sensores de medición cerca de los electrodos activos y con un ángulo grande entre las ubicaciones de los dos electrodos activos. Luego, y en términos generales, pares como F3-P4, P3-FC4, F3-P3 o Fz-Pz son convenientes. Utilizar estos pares de inyección implica menos mediciones (menor tiempo de medición) para tener errores relativos similares si se utilizan otros pares. Obsérvese que para igual intensidad de corriente y un mayor ángulo, es decir, mayor separación entre los electrodos de inyección de corriente, la potencia inyectada al sistema aumenta porque aumenta la "carga" conectada a la fuente. Una observación particular de la Fig. 3.6(a) es que para el modelo isótropo, pares fronto-occipitales presentaron menor CVB que pares laterales. Esto puede deberse a la geometría más bien elíptica y no esférica de la cabeza. Los resultados también mostraron una dependencia aproximadamente exponencial decreciente de la varianza de estimación con respecto al número de electrodos. De los resultados sobre geometrías realistas también se desprende la importancia de desafectar la actividad eléctrica normal del cerebro, y en el siguiente capítulo se mostrará una manera adecuada de realizarlo.

Teniendo en cuenta el objetivo de estimar los valores de conductividad equivalentes en modelos realistas, hay que separar los resultados obtenidos para el modelo isótropo del parcialmente isótropo. Para el primer modelo, los resultados de la Tabla 3.2 muestran que se logró el objetivo con una desviación estándar entre 3 y 4 órdenes de magnitud menores que la media, con coeficientes de variación de similar dispersión para ambos parámetros. Para el caso parcialmente isótropo la calidad de la estimación (dada por el CV) de la conductividad tangencial del cuero cabelludo y radial del cráneo fue similar al caso isótropo, pero la estimación de la conductividad tangencial del cráneo y radial del cuero cabelludo fue peor. Esto se puede observar en la Tabla 3.2 y en la Fig. 3.8(c). La razón es que el potencial sobre la superficie es comparativamente más sensible a las variaciones de las conductividades tangencial en el cuero cabelludo y radial en el cráneo que a las otras. Sin embargo, esto coincide con el grado de influencia de las conductividades para la estimación de la localización de fuentes de actividad cerebral en EEG, por lo que los resultados del método 
propuesto siguen siendo válidos para ser utilizado con ese propósito. Igualmente los resultados que se muestran en las Fig. 3.8 indican que, bajo las condiciones propuestas y para 50 muestras, la estimación con EIT paramétrico presentó en general una baja varianza relativa (menor a 0,1 ) para todos los parámetros estudiados. Más aún, esto se mantuvo para todos los rangos de conductividad y factor de anisotropía del cráneo analizados. Nótese que de las Ecs. (3.3), (3.4) y (3.8), los valores de CVB son inversamente proporcionales a la raíz cuadrada del número de repeticiones $S$. Luego, los resultados podrían extrapolarse fácilmente a cualquier número de mediciones independientes. Para los modelos isótropo y parcialmente isótropo, la conductividad del cuero cabelludo presentó la menor CRB relativa. Una baja CRB indica alta sensibilidad lo que significa que el cuero cabelludo es el tejido con mayor influencia en EIT, en concordancia con lo expresado por Horesh (2006). La Fig. 3.8(a) muestra que para valores de la conductividad del cráneo altos, la influencia de la conductividad del cerebro aumenta considerablemente.

Por último, fue posible aplicar el MLE para estimar la conductividad del cráneo y del cuero cabelludo con mediciones reales de bEIT sobre humanos utilizando una gran cantidad de pares de inyección de corriente y un modelo detallado de siete capas. Se obtuvieron valores plausibles tanto para el cráneo como para el cuero cabelludo, aunque cercanos a los valores más bajos reportados por la literatura. Particularmente con el modelo de electrodo puntual se obtuvo una baja conductividad del cuero cabelludo y una conductividad del cráneo en el rango medio, mientras que para el modelo de electrodo realista se obtuvo un valor bajo para el cráneo y un valor de rango medio para el cuero cabelludo, aunque el modelo de electrodo realista presentó un mejor ajuste a las mediciones y el proceso de estimación resultó ser más estable. En Eriksen (1990) los valores reportados están en aproximadamente 0,5 y 0,004 para el cráneo, aunque son resultados antiguos, con un modelo esférico de tres capas. En Clerc et al. (2005) y en Zhang et al. (2006) se estima un sólo parámetro (relación cráneo - cuero cabelludo) resultando una conductividad del cráneo cercana a 0,01 suponiendo una conductividad del cuero cabelludo de 0,3. Sin embargo usan modelos de tres capas, y fijan la conductividad del cuero cabelludo igual a la del cerebro. Además en Zhang et al. (2006) sólo miden en sujetos pediátricos. En 
Oostendorp et al. (2000) se encuentran valores del cuero cabelludo bajos, cercanos a $0,2 S / m$ y del cráneo cercanos a $0,01 S / m$. Allí se utilizan modelos de electrodos puntuales y los resultados son similares a los nuestros también suponiendo electrodos puntuales. Las últimas mediciones de Gonçalves et al. (2003) y Ouypornkochagorn et al. (2014) muestran resultados del cráneo alrededor de 0,08S/m y varían en el cuero cabelludo: alrededor de 0,33 y 0,6S/m respectivamente. En Gonçalves et al. (2003) no se usaron electrodos puntuales pero se utilizó un modelo de tres capas mientras que en Ouypornkochagorn et al. (2014) se utilizaron modelos que contemplan el CSF pero no se menciona qué modelización se utilizó para los electrodos. En nuestros resultados un valor bajo en la conductividad del cráneo puede deberse a que el sujeto presenta un cráneo más delgado que la media que deriva en una menor conductividad por tener una mayor proporción de hueso compacto que de hueso esponjoso (Sadleir y Argibay, 2007). Por eso, este análisis debería realizarse en más sujetos. La comparación con otros estudios se hace dificultosa porque brindan muy poca información acerca del grosor del cráneo de los sujetos analizados.

El valor de conductividad del cráneo se mantiene aún indefinido en la literatura por lo que EIT paramétrico se perfila como un método simple y de bajo costo para estimar su conductividad para cada sujeto en particular in-vivo. La combinación con DTI mejora el desempeño de EIT paramétrico (ver Fig.3.8(b)), y se complementan, ya que con EIT paramétrico es posible estimar la conductividad del cráneo, la cual no puede ser obtenida mediante DTI. EIT paramétrico podría ser utilizado para estimar un mayor número de parámetros en modelos del cráneo que lo consideren un tejido no-homogéneo y que, por ejemplo, incluyan las suturas o sub-dividan al cráneo en hueso compacto y hueso esponjoso. Otras posibilidades son relacionar la conductividad del cráneo con el valor de intensidad de las imágenes de CT, o descomponer a la distribución de la conductividad en armónicos esféricos lo que resultaría en una conductividad no homogénea pero suave.

Los resultados presentados en este capítulo refuerzan la idea de utilizar EIT paramétrico como una rutina junto a otras modalidades de diagnóstico o tratamiento que requieran de modelos eléctricos virtuales precisos, como es el caso del problema de localización de fuentes en EEG/MEG, o en la planificación de tDCS. 


\section{Capítulo 4}

\section{Forma de onda de corriente}

\subsection{Introducción}

En aplicaciones de EIT sobre la cabeza humana es posible utilizar el mismo equipamiento de EEG para medir el potencial eléctrico producido por la corriente aplicada. La EEG es una técnica no-invasiva que permite estudiar la actividad cerebral, basándose en registros de potencial eléctrico medidos con electrodos aplicados sobre el cuero cabelludo. El equipamiento de medición de EEG filtra las señales, dejando pasar solamente las bajas frecuencias (generalmente menores a los $100 \mathrm{~Hz}$ ), que es el rango en donde se concentra mayoritariamente la energía de la actividad cerebral. Cuando se mide el potencial eléctrico en EIT, la actividad cerebral también está presente en las señales medidas, y debe ser tratada como ruido de fondo. Estas señales no deseadas se suman al ruido electrónico debido al contacto electrodo-piel y a los amplificadores. Como la forma de onda a inyectar es conocida y su propagación por el medio (a bajas frecuencias) es lineal, el potencial eléctrico debido al paso de corriente tiene la misma forma de onda pero afectada, en cada electrodo, por un coeficiente de atenuación. Esto hace que sea posible desafectar la actividad cerebral en la estimación de los coeficientes, los cuales son necesarios para luego estimar la conductividad eléctrica de la cabeza. Diversos estudios destacan la importancia de realizar un post-procesamiento de las señales de EIT para eliminar este ruido de fondo (Gonçalves et al., 2003; Fernández-Corazza et al., 2011b). Este 
pre-procesamiento de las señales es conveniente tanto para EIT paramétrico como para reconstrucción en EIT.

En el presente capítulo se obtiene el estimador de máxima verosimilitud (MLE) para los coeficientes de atenuación y se propone una metodología para encontrar el mínimo número de muestras necesarias para desafectar el ruido debido a la actividad cerebral, cuando la matriz de covarianza del ruido total es conocida. Como la forma de onda de la fuente de corriente es en principio arbitraria, el método implica emplear una forma de onda particular, que es óptima en el sentido de minimizar la varianza del estimador. En este capítulo se describe cómo obtener esta forma de onda óptima o de mínima varianza. El método se aplica sobre dos ejemplos de pacientes reales analizando también el impacto de reemplazar la forma de onda óptima por sinusoides de distintas fases y frecuencias.

\subsection{Modelo de señal}

En EIT, se inyecta una señal corriente $\mathbf{i}(t)$ por un par de electrodos, y se mide el potencial eléctrico resultante en los restantes. Las mediciones son muestreadas y pueden ordenarse formando una matriz de mediciones $\mathbf{Y}$ de $L-2$ filas y $T$ columnas, siendo $L$ el número de electrodos y $T$ el número de muestras temporales. Cada fila corresponde a las mediciones realizadas por un canal o electrodo, y cada columna corresponde a un distinto instante de tiempo. En ausencia de ruido, la señal medida tendrá la misma variación temporal o forma de onda que la señal inyectada, pero cada canal se verá afectado por un coeficiente de atenuación diferente, por lo que se define un vector de coeficientes de atenuación a, de $L-2$ elementos. En estas condiciones el modelo de las mediciones será

$$
\mathbf{Y}=\left(\mathbf{a} \otimes \mathbf{i}^{T}\right)+\mathbf{Q}
$$

donde $\mathbf{i}$ es un vector de $T$ elementos formado por las muestras de la señal de corriente aplicada, la operación $\otimes$ es el producto de Kronecker, y Q es una matriz de tamaño $L-2 \times T$ que corresponde al ruido de las mediciones. 
El término de ruido $\mathbf{Q}$ incluye tanto al ruido asociado al sistema de adquisición, debido a los amplificadores y a la impedancia de contacto entre los electrodos y la piel, como a la actividad eléctrica del cerebro. El primero puede modelizarse como ruido blanco independiente entre canales, mientras que el segundo corresponde al EEG y está correlacionado temporal y espacialmente. En el rango de frecuencias de interés la amplitud del EEG es sustancialmente mayor que el ruido electrónico, y un modelo apropiado para el ruido total $\mathbf{Q}$ es considerarlo normal matricial (de Munck et al., 2002; Beltrachini et al., 2013), es decir $\mathbf{Q} \sim \mathcal{N}_{L-2 \times T}(0, \mathbf{X}, \mathbf{T})$ con covarianza temporal $\mathbf{T}=\mathbb{E}\left\{\mathbf{Q}^{T} \mathbf{Q}\right\}$ y covarianza espacial $\mathbf{X}=\mathbb{E}\left\{C \mathbf{Q Q}^{T}\right\}$, siendo $C$ una constante que permite una adecuada normalización de la potencia. La distribución normal matricial es un caso particular de una distribución normal multivariada; se dice que una matriz $\mathbf{Z}$ tiene distribución normal matricial $\mathbf{Z} \sim \mathcal{N}_{(L-2) \times T}(\mathbf{M}, \mathbf{X}, \mathbf{T})$ cuando el vector $\mathbf{z}=\operatorname{vec}\{\mathbf{Z}\}$ tiene distribución normal $\mathbf{z} \sim \mathcal{N}(\operatorname{vec}\{\mathbf{M}\}, \mathbf{X} \otimes \mathbf{T})$. La operación vec $\{\cdot\}$ forma un vector a partir de reacomodar las columnas de una matriz una a continuación de otra. En consecuencia el modelo de medición establece que

$$
\mathbf{Y} \sim \mathcal{N}_{(L-2) \times T}\left(\mathbf{a} \otimes \mathbf{i}^{T}, \mathbf{X}, \mathbf{T}\right)
$$

o bien, definiendo $\mathbf{y}=\operatorname{vec}\left\{\mathbf{Y}^{T}\right\}$

$$
\mathbf{y} \sim \mathcal{N}(\mathbf{a} \otimes \mathbf{i}, \mathbf{X} \otimes \mathbf{T})
$$

\subsection{Estimador de máxima verosimilitud (MLE)}

Supongamos un vector aleatorio con distribución normal $\mathbf{z} \sim \mathcal{N}(\boldsymbol{\mu}(\boldsymbol{\theta}), \mathbf{C})$, donde el vector de parámetros $\boldsymbol{\theta}$ afecta la media $\boldsymbol{\mu}$ de la distribución $f_{\mathbf{z}}$ pero no su varianza C. Se sabe que el estimador de máxima verosimilitud de ese vector $\boldsymbol{\theta}$ se obtiene 
al minimizar la función de verosimilitud $\mathcal{L}(\boldsymbol{\theta})=-\ln f_{\mathbf{z}}(\mathbf{z} ; \boldsymbol{\theta})$ (Kay, 1993), es decir

$$
\begin{aligned}
\left.\frac{\partial \mathcal{L}(\boldsymbol{\theta})}{\partial \boldsymbol{\theta}}\right|_{\boldsymbol{\theta}=\hat{\boldsymbol{\theta}}} & =\left.\left(\frac{\partial \boldsymbol{\mu}}{\partial \boldsymbol{\theta}}\right)^{T} \frac{\mathcal{L}(\boldsymbol{\theta})}{\partial \boldsymbol{\theta}}\right|_{\boldsymbol{\theta}=\hat{\boldsymbol{\theta}}} \\
& =\left.\left(\frac{\partial \mu}{\partial \boldsymbol{\theta}}\right)^{T} \mathbf{C}^{-1}(\boldsymbol{\mu}(\boldsymbol{\theta})-\mathbf{z})\right|_{\boldsymbol{\theta}=\hat{\boldsymbol{\theta}}}=0 .
\end{aligned}
$$

Para el caso bajo estudio, la distribución del vector de mediciones y es la dada en (4.3). Dado que $(\partial(\mathbf{a} \otimes \mathbf{i}) / \partial \mathbf{a})^{T}=\mathbf{I}_{L-2} \otimes \mathbf{i}^{T}$, donde $\mathbf{I}_{L-2}$ es la matriz identidad de tamaño $L-2 \times L-2$, reemplazando en (4.4) se obtiene

$$
\frac{\partial \mathcal{L}(\mathbf{a})}{\partial \mathbf{a}}=\left(\mathbf{I}_{L-2} \otimes \mathbf{i}^{T}\right)\left(\mathbf{X}^{-1} \otimes \mathbf{T}^{-1}\right)(\mathbf{a} \otimes \mathbf{i}-\mathbf{y}),
$$

donde se hizo uso de la propiedad del producto de Kronecker $(\mathbf{A} \otimes \mathbf{B})^{-1}=\mathbf{A}^{-1} \otimes \mathbf{B}^{-1}$. Igualando la ecuación anterior a cero se debe despejar el estimador de máxima verosimilitud â de

$$
\left(\mathbf{I}_{L-2} \otimes \mathbf{i}^{T}\right)\left(\mathbf{X}^{-1} \otimes \mathbf{T}^{-1}\right)(\hat{\mathbf{a}} \otimes \mathbf{i})=\left(\mathbf{I}_{L-2} \otimes \mathbf{i}^{T}\right)\left(\mathbf{X}^{-1} \otimes \mathbf{T}^{-1}\right) \mathbf{y} .
$$

Para lograrlo se utiliza la siguiente propiedad del producto de Kronecker

$$
(\mathbf{A} \otimes \mathbf{B})(\mathbf{C} \otimes \mathbf{D})=\mathbf{A C} \otimes \mathbf{B D},
$$

válida si los tamaños de las matrices permiten realizar los productos matriciales del lado derecho. Aplicando esta propiedad dos veces en el término de la izquierda de (4.6), y una vez en el término de la derecha, se obtiene

$$
\mathbf{X}^{-1} \hat{\mathbf{a}} \otimes \mathbf{i}^{T} \mathbf{T}^{-1} \mathbf{i}=\left(\mathbf{i}^{T} \mathbf{T}^{-1} \mathbf{i}\right) \mathbf{X}^{-1} \hat{\mathbf{a}}=\left(\mathbf{X}^{-1} \otimes \mathbf{i}^{T} \mathbf{T}^{-1}\right) \mathbf{y},
$$

donde la primera igualdad se debe a que $\mathbf{i}^{T} \mathbf{T}^{-1} \mathbf{i}$ es escalar. En consecuencia

$$
\hat{\mathbf{a}}=\frac{\mathbf{X}}{\mathbf{i}^{T} \mathbf{T}^{-1} \mathbf{i}}\left(\mathbf{X}^{-1} \otimes \mathbf{i}^{T} \mathbf{T}^{-1}\right) y,
$$


como $\mathbf{X} /\left(\mathbf{i}^{T} \mathbf{T}^{-1} \mathbf{i}\right)=\mathbf{X} \otimes\left(\mathbf{i}^{T} \mathbf{T}^{-1} \mathbf{i}\right)^{-1}$, reemplazando en (4.9) y aplicando nuevamente la propiedad (4.7) se obtiene

$$
\hat{\mathbf{a}}=\left(\mathbf{I}_{L-2} \otimes \frac{\mathbf{i}^{T} \mathbf{T}^{-1}}{\mathbf{i}^{T} \mathbf{T}^{-1} \mathbf{i}}\right) \mathbf{y}
$$

Esta última expresión puede reacomodarse reensamblando la matriz de datos $\mathbf{Y}$, resultando el estimador de máxima verosimilitud de los parámetros

$$
\hat{\mathbf{a}}=\frac{\mathbf{Y} \mathbf{T}^{-1} \mathbf{i}}{\mathbf{i}^{T} \mathbf{T}^{-1} \mathbf{i}}
$$

Se observa que el estimador no depende de la matriz de covarianza espacial del ruido, sólo depende de la matriz de covarianza temporal y de la señal inyectada. Dado que esta última puede elegirse arbitrariamente, en la próxima sección se describe cómo hacerlo de manera óptima.

\subsection{Forma de onda óptima}

Para elegir de manera óptima la forma de onda observemos que el estimador de máxima verosimilitud â se puede escribir como

$$
\hat{\mathbf{a}}=\left(\mathbf{a} \otimes \mathbf{i}^{T}+\mathbf{Q}\right) \frac{\mathbf{T}^{-1} \mathbf{i}}{\mathbf{i}^{T} \mathbf{T}^{-1} \mathbf{i}}=\mathbf{a}+\frac{\mathbf{Q} \mathbf{T}^{-1} \mathbf{i}}{\mathbf{i}^{T} \mathbf{T}^{-1} \mathbf{i}} .
$$

Dado que la esperanza del ruido $\mathbf{Q}$ es nula, es evidente que el estimador â es insesgado. Definimos la varianza total del estimador VarT $\{\hat{\mathbf{a}}\}$ como la suma de las varianzas de cada electrodo, es decir

$$
\operatorname{VarT}\{\hat{\mathbf{a}}\}=\sum_{i=1}^{L-2} \operatorname{Var}\left\{a_{i}\right\}
$$

y puede calcularse de mediante

$$
\operatorname{VarT}\{\hat{\mathbf{a}}\}=\mathbb{E}\left\{(\hat{\mathbf{a}}-\mathbf{a})^{T}(\hat{\mathbf{a}}-\mathbf{a})\right\}=\frac{\mathbf{i}^{T} \mathbf{T}^{-1} \mathbb{E}\left\{\mathbf{Q}^{T} \mathbf{Q}\right\} \mathbf{T}^{-1} \mathbf{i}}{\left(\mathbf{i}^{T} \mathbf{T}^{-1} \mathbf{i}\right)^{2}}
$$


resultando

$$
\operatorname{VarT}\{\hat{\mathbf{a}}\}=\left(\mathbf{i}^{T} \mathbf{T}^{-1} \mathbf{i}\right)^{-1}
$$

En este trabajo se propone elegir como forma de onda óptima de la señal de corriente a inyectar a aquella que minimiza la varianza total del estimador de los coeficientes de atenuación. Es decir que debemos encontrar el vector i que minimice (4.15), para una dada energía de la señal. Es decir que para encontrar la forma de onda óptima se deberá encontrar el máximo del funcional

$$
J(\mathbf{i})=\mathbf{i}^{T} \mathbf{T}^{-1} \mathbf{i}+\lambda\left(E-\mathbf{i}^{T} \mathbf{i}\right),
$$

donde $\lambda$ es un multiplicador de Lagrange, y $E$ es la energía de la señal i. El resultado se obtiene con

$$
\left.\frac{\partial J(\mathbf{i})}{\partial \mathbf{i}}\right|_{\mathbf{i}=\mathbf{i}_{o p t}}=\left.\left(2 \mathbf{T}^{-1} \mathbf{i}-2 \lambda \mathbf{i}\right)\right|_{\mathbf{i}=\mathbf{i}_{o p t}}=0 .
$$

De donde se desprende que

$$
\mathbf{T}^{-1} \mathbf{i}_{\text {opt }}=\lambda \mathbf{i}_{\text {opt }}
$$

Para que cumpla (4.18), $\mathbf{i}_{\text {opt }}$ debe ser un autovector de $\mathbf{T}^{-1}$, en particular al reemplazar (4.18) en (4.16) se obtiene $J\left(\mathbf{i}_{\text {opt }}\right)=\lambda E$. Como se desea que $J\left(\mathbf{i}_{\text {opt }}\right)$ sea máximo, $\lambda E$ debe ser máximo lo que ocurre si $\lambda$ es el máximo autovalor de $\mathbf{T}^{-1}$. Entonces $\mathbf{i}_{\text {opt }}$ es el autovector asociado al máximo autovalor de $\mathbf{T}^{-1}$, o lo que es lo mismo, el autovector asociado al mínimo autovalor de $\mathbf{T}$. Este autovector $\mathbf{i}_{\text {opt }}$ puede obtenerse también como el autovector asociado al mínimo valor singular de la descomposición en valores singulares de $\mathbf{Q}^{T}$, lo que resulta conveniente desde el punto de vista de la implementación dado que el rango dinámico involucrado será menor (Van Trees, 2002).

En consecuencia, para obtener una estimación de los parámetros de atenuación del problema de EIT con mínima varianza, las muestras de la forma de onda de la corriente inyectada se deben obtener a partir del ruido o actividad de fondo de EEG. La forma de onda queda determinada por el autovector asociado al mínimo autovalor de la matriz de covarianza temporal del ruido. De esta forma se maximiza la diferencia entre la forma de onda inyectada y las realizaciones de ruido más 
probables.

\subsection{Resultados}

La expresión (4.15) permite comparar el desempeño al utilizar sinusoides de distintas frecuencias y fase en lugar de la forma de onda óptima. La matriz de covarianza temporal $\mathbf{T}$ puede ser diferente, de acuerdo a la actividad cerebral en cada individuo y en distintas situaciones, por lo que la forma de onda óptima también es relativa a cada individuo y cada conjunto de mediciones. Dos matrices de covarianza fueron estimadas a partir de un conjunto de mediciones existente sobre dos pacientes con epilepsia durante sueño no REM. Las mediciones de EEG fueron tomadas sobre 29 canales, filtradas a $100 \mathrm{~Hz}$ y muestreadas a $200 \mathrm{~Hz}$. Para ambos pacientes el tiempo de medición fue de aproximadamente 30 minutos. Estos datos fueron proporcionados por el EEG lab del Montreal Neurological Institute.

Si la señal i es una sinusoide de una determinada frecuencia y fase, la varianza del estimador esperada para esa señal se puede determinar a partir de (4.15) y compararla con el valor que toma cuando i es la forma de onda óptima. Es posible entonces barrer rangos de frecuencia y fase para determinar si el uso de sinusoides empeora significativamente la estimación, y en caso de que eso no ocurra, determinar las frecuencias más favorables.

En base a las matrices de covarianza temporal de ambos pacientes se computaron las formas de onda óptima para cada uno de ellos. Las Fig. 4.1 muestra las formas de onda óptimas obtenidas para el paciente 1 y el paciente 2. La amplitud de la señal óptima se adaptó de manera que su valor cuadrático medio sea de $100 \mu A$, que es el valor máximo permitido según la norma IEC60601 (2005).

Para determinar el mínimo número de muestras necesario para desafectar el ruido del cerebro se puede comparar la varianza total para distintos números de muestras con la varianza total esperada en el caso de que sólo haya ruido blanco. A menor cantidad de muestras, será menor el tiempo que el paciente esté expuesto a la aplicación de la corriente y la duración del estudio de EIT.

Se calculó entonces el valor de la varianza total para cada paciente en función 

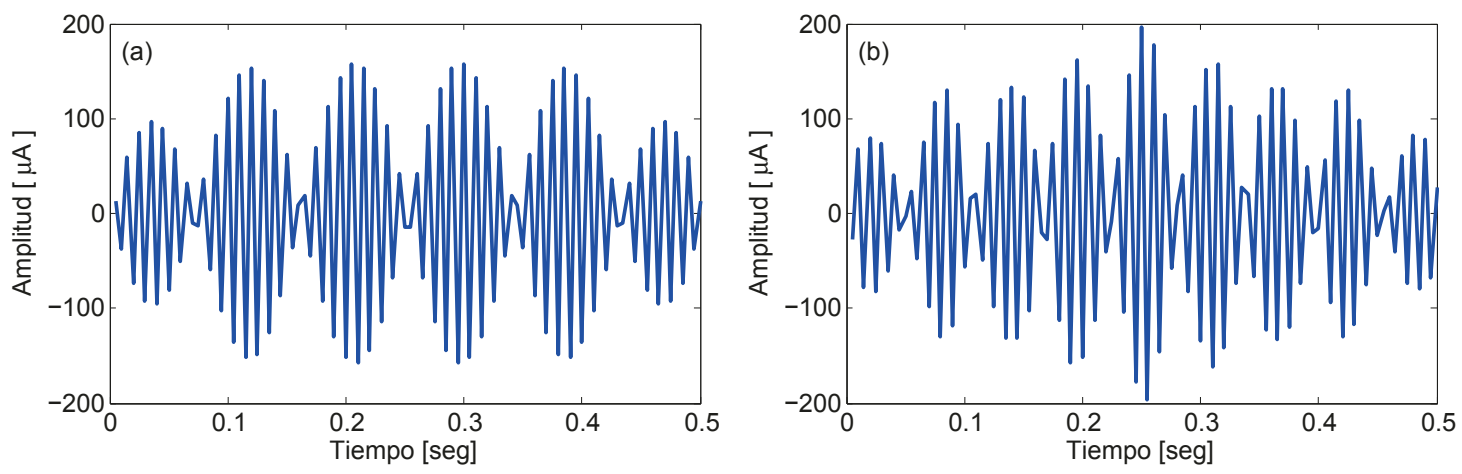

Figura 4.1: Formas de onda óptimas para (a) el paciente 1 y (b) el paciente 2.

del número de muestras. La Fig. 4.2(a) muestra los resultados para ambos pacientes cuando la cantidad de muestras varía entre 2 y 100. También se grafica la varianza total esperada en el caso que sólo se estuviera midiendo ruido blanco. En el caso de los ejemplos de mediciones que se analizaron, se puede observar que a mayor cantidad de muestras, la varianza total del estimador se acercó al caso de sólo ruido blanco. Para el paciente 1, considerando aproximadamente 15 muestras la diferencia entre las varianzas totales fue de $0,01 \mu V^{2}$ por lo que se puede suponer que para mayor cantidad de muestras la actividad propia del cerebro ya fue desafectada. En tanto que para el paciente 2 esto ocurrió con aproximadamente 40 muestras.

El resultado del uso de sinusoides en reemplazo de la forma de onda óptima se muestra en la Fig. 4.2(b) para el paciente 1 y en la Fig. 4.3(a) para el paciente 2. El barrido de frecuencias se realizó entre 10 y $100 \mathrm{~Hz}$ y el de la fase entre 0 y $2 \pi$. Para cada valor de frecuencia se realizó el barrido de la fase quedándose sólo con los valores máximo y mínimo de la varianza total. Las curvas se encuentran normalizadas respecto de la varianza total de â al utilizar la forma de onda óptima, por lo que valores cercanos a 1 representan sinusoides que se comportan de manera similar a la forma de onda óptima. En el caso del paciente 1, se puede observar un decrecimiento de la varianza total relativa en función de la frecuencia. Sólo para frecuencias mayores a $95 \mathrm{~Hz}$ la varianza al emplear sinusoides creció nuevamente y se hizo dependiente de la fase, debido a la poca cantidad de muestras por ciclo. Se puede observar que aproximadamente a $94 \mathrm{~Hz}$ se alcanzó un desempeño muy 

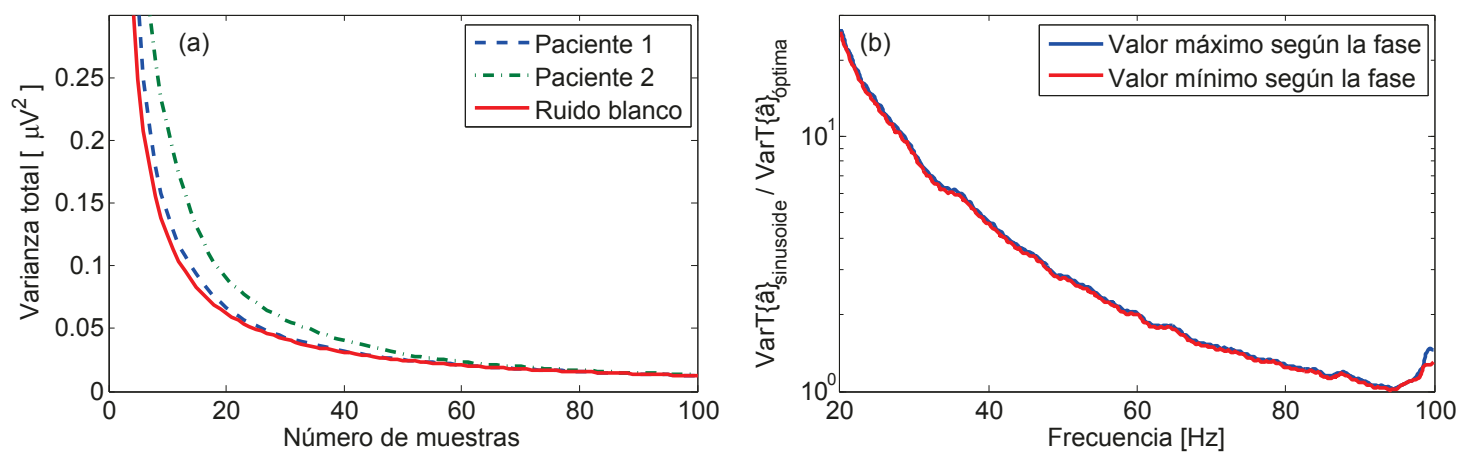

Figura 4.2: (a) Varianza total utilizando la forma de onda óptima en función del número de muestras para ambos pacientes y varianza total esperada en el caso que sólo exista ruido blanco. (b) Varianza total del estimador en función de la frecuencia de la sinusoide para el paciente 1, normalizada por la varianza total obtenida con la forma de onda óptima. Las dos curvas representan los valores máximo y mínimo que para cada frecuencia se obtienen al variar la fase. El eje vertical se encuentra en escala logarítmica.

similar al de utilizar la forma de onda óptima y que a aproximadamente $60 \mathrm{~Hz}$ lo duplicó. El paciente 2, en cambio, presentó un comportamiento diferente. Se sabe que el conjunto de datos de este paciente tiene una importante actividad cerebral de alta frecuencia. Esto también se ve reflejado en las curvas de la Fig. 4.3(a), donde para frecuencias mayores a $30 \mathrm{~Hz}$, la varianza no siempre decreció a medida que la frecuencia aumentó. En ciertos intervalos de frecuencia se pueden observar "picos" indicando que utilizar una sinusoide en dichos intervalos produciría un desempeño significativamente peor que al de utilizar la forma de onda óptima. Para este paciente los mejores desempeños se encontraron al utilizar sinusoides de aproximadamente 79 ó $91 \mathrm{~Hz}$.

Para el paciente 2 se analizó además el barrido en frecuencia y fase para distinto número de muestras a fin de estudiar el desempeño de las sinusoides de acuerdo al número de muestras. En la Fig. 4.3(b) cada curva representa el valor máximo de la varianza total (peor elección de la fase) en función de la frecuencia para distintos números de muestras. Se puede observar que la varianza total mantuvo este comportamiento de frecuencias favorables y desfavorables sin importar la cantidad de muestras que se tomen para la estimación. 

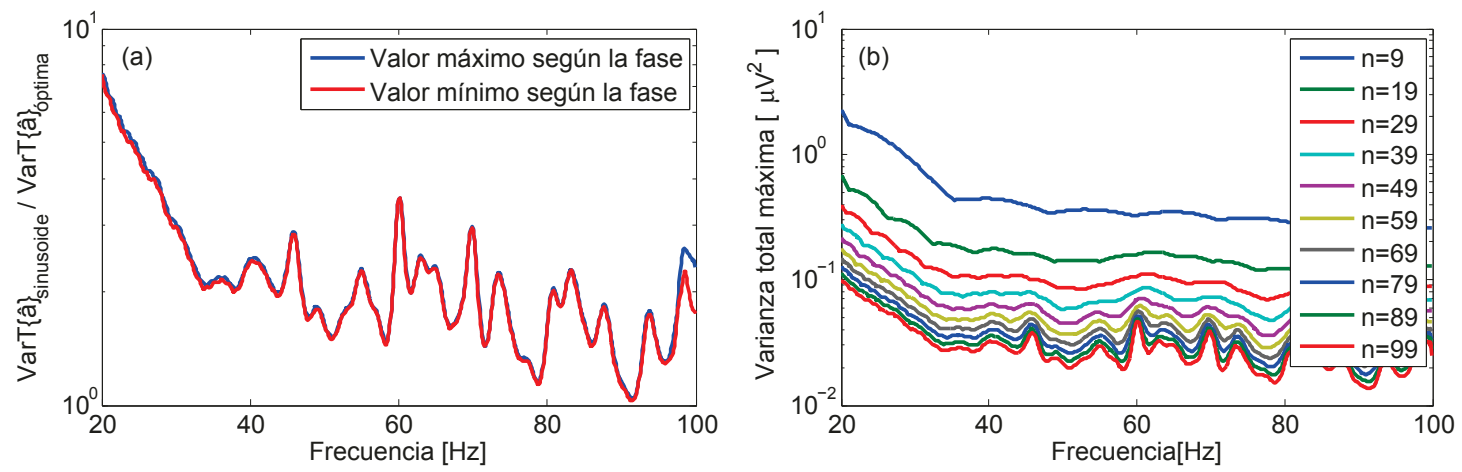

Figura 4.3: (a) Varianza total relativa del estimador en función de la frecuencia de la sinusoide para el paciente 2, normalizada por la varianza total obtenida con la forma de onda óptima. Las dos curvas representan los valores máximo y mínimo que para cada frecuencia se obtienen al variar la fase. El eje vertical se encuentra en escala logarítmica.(b) Varianza total máxima (peor elección de la fase) en función de la frecuencia de la sinusoide para el paciente 2. Las distintas curvas representan los valores obtenidos para distintos números de muestras. El eje vertical se encuentra en escala logarítmica.

\subsection{Conclusiones}

En el presente capítulo se mostró un procedimiento para obtener el mínimo número de muestras necesarias para desafectar el ruido del cerebro, que involucra la obtención de la forma de onda óptima. Esto implica una mejora para la comodidad del paciente ya que reduce la duración del estudio de EIT, que puede involucrar la medición del potencial generado por la inyección de corriente a través de un gran número de pares de electrodos.

Muchos de los resultados del presente trabajo están relacionados con que la actividad del cerebro concentra su energía mayormente a bajas frecuencias, y la misma tiende a disminuir a medida que la frecuencia aumenta. Entonces se espera que las formas de onda óptima presenten oscilaciones de alta frecuencia, hecho que se puede verificar observando en la Fig. 4.1 las formas de onda que se obtuvieron. También se puede observar que se asemejaron a sinusoides de alta frecuencia. Es por eso que se buscó determinar la influencia de utilizar una u otra forma de onda. En las Figs. 4.2(b) y 4.3(a) se puede observar que utilizando una sinusoide de alta 
frecuencia fue posible alcanzar desempeños cercanos al de utilizar la forma de onda óptima, y que la fase prácticamente no afecta la calidad de la estimación.

Los resultados de este capítulo muestran cómo la actividad cerebral de cada paciente influye en la estimación de los coeficientes de atenuación necesarios para la estimación de conductividades usando EIT. La obtención de la forma de onda óptima resultó ser de importancia ya que permitió determinar para cada ejemplo el mínimo número de muestras necesario para desafectar el ruido propio del cerebro. Para las mediciones estudiadas, se mostró que el error introducido en la estimación de los coeficientes de atenuación al reemplazar dicha forma de onda por una sinusoide de una frecuencia adecuada es despreciable. Por otro lado, un análisis espectral permitió determinar frecuencias convenientes para cada conjunto de datos. En general, las frecuencias altas presentaron menor varianza total del estimador, pero pueden existir frecuencias altas que afectan negativamente en la estimación, como en el caso excepcional del paciente 2. Además se mostró que este comportamiento espectral se mantiene si se disminuye el número de muestras para realizar la estimación. 


\section{Capítulo 5}

\section{Reconstrucción en EIT}

\subsection{Introducción}

En el problema de reconstrucción en EIT, generalmente se utiliza la solución de mínimos cuadrados (LS) con alguna matriz de regularización para construir una imagen de la distribución de conductividad interna del objeto (Lionheart et al., 2004). En cambio, en el problema de localización de fuentes de actividad neuronal a partir de registros de electroencefalografía (EEG) o magnetoencefalografía (MEG), el algoritmo más utilizado es sLORETA. Esto se debe principalmente a su ventaja de ser teóricamente no sesgado, además de poseer otras ventajas como su simpleza y su baja complejidad computacional (Rullmann et al., 2009; Beltrachini et al., 2011a). Sin embargo, en EIT apenas unos pocos trabajos utilizan alguna variante de sLORETA para la reconstrucción de conductividad (Dong et al., 2005, 2006), lo cual es cuanto menos curioso ya que, bajo ciertas condiciones, el problema de estimar la distribución de la actividad neuronal en EEG o MEG es matemáticamente equivalente al problema de reconstrucción de cambios de conductividad en EIT (EIT en diferencias) (Lionheart et al., 2004). En el presente capítulo se adapta el algoritmo sLORETA a EIT y se evalúa su desempeño frente a algoritmos clásicos de EIT. A su vez, se modifica el algoritmo sLORETA para incorporar la condición de suavidad espacial de Laplace.

El problema de reconstrucción en EIT es no lineal y mal condicionado, aunque 
generalmente se resuelve mediante una aproximación lineal. Una completa revisión de los algoritmos de reconstrucción comúnmente utilizados en EIT puede encontrarse en Lionheart et al. (2004). Los mismos se basan generalmente en la solución de LS utilizando alguna regularización de Tikhonov. La más sencilla, que en el presente capítulo llamamos Tikhonov Clásica o simplemente Tikhonov, consiste en utilizar la matriz identidad más un factor de escala, y es también conocida como carga diagonal. Una alternativa muy utilizada es agregar una matriz diferente a la matriz identidad, que constituye una condición de suavidad en la solución a través de restricciones sobre las regiones vecinas. Esta condición de suavidad se puede implementar, por ejemplo, utilizando el filtro de Laplace o utilizando un filtro Gaussiano. A la solución de Tikhonov con el filtro de Laplace lo llamamos Tikhonov-Laplace

El algoritmo sLORETA, ampliamente utilizado en EEG y MEG, fue introducido por Pascual-Marqui (2002) y tiene la ventaja de ser teóricamente no sesgado. Es decir que, en ausencia de ruido y en el caso de una sola fuente puntual, la ubicación del máximo de la imagen reconstruida coincide con la posición de la fuente. Esto no ocurre con Tikhonov, en donde se puede mostrar teóricamente que existe un sesgo hacia la ubicación de los sensores (Sekihara y Nagarajan, 2008). En este capítulo analizamos la aplicabilidad de sLORETA al problema de reconstrucción en EIT y comparamos su desempeño con los algoritmos Tikhonov. A su vez, presentamos una alternativa a sLORETA en donde se incorpora la condición de suavidad de Laplace, y que llamamos sLORETA-Laplace.

Principalmente nos interesa analizar cuál de los algoritmos estudiados presenta una solución de mejor calidad. Para eso realizamos simulaciones sobre fantomas o maquetas virtuales y calculamos el error cuadrático medio y el error absoluto de la diferencia entre las soluciones y el mapa de conductividad verdadero, para distintos niveles de ruido. Esto nos permite investigar además si algún algoritmo es más robusto frente a la varianza del ruido. Analizamos también si algún algoritmo presenta una menor sensibilidad al llamado parámetro de regularización, lo que sería una ventaja adicional ya que en estos algoritmos la calidad de las reconstrucciones depende enormemente de ese parámetro de elección arbitraria. Otra característica que estudiamos para evaluar el desempeño de los algoritmos de reconstrucción es el 
sesgo. También, se aplican los algoritmos de reconstrucción a mediciones reales de EIT, adquiridas con el IMPETOM C de la Universidad de la República, Montevideo, Uruguay sobre un tanque cilíndrico experimental. Las características del equipo se encuentran descriptas en el capítulo 2. Según nuestro conocimiento, en esta tesis se aplica por primera vez el algoritmo sLORETA a mediciones reales de EIT.

\subsection{Algoritmos}

\subsubsection{Algoritmos Tikhonov}

El problema linealizado de reconstrucción en EIT, planteado en la ecuación (2.43), es un modelo lineal estocástico cuya solución de mínimos cuadrados (LS) es:

$$
\widehat{\delta \boldsymbol{\sigma}}=\left(\mathbf{J}^{T} \mathbf{J}\right)^{-1} \mathbf{J}^{T} \mathbf{y}
$$

siempre que exista la inversa de $\mathbf{J}^{T} \mathbf{J}$, o su solución de mínima norma es

$$
\widehat{\delta \boldsymbol{\sigma}}=\mathbf{J}^{T}\left(\mathbf{J J}^{T}\right)^{-1} \mathbf{y}
$$

si $\mathbf{J J}^{T}$ es invertible. Mínimos cuadrados se aplica cuando el sistema es sobredeterminado, es decir, que no existe solución, o lo que es lo mismo, que existen más ecuaciones independientes que incógnitas. Por otro lado, las soluciones de mínima norma se refieren a problemas subdeterminados, donde existen infinitas soluciones por haber menos ecuaciones que incógnitas o variables independientes, como ocurre generalmente en los problemas de reconstrucción. Si a su vez el problema es mal condicionado o singular, una alternativa es aplicar la regularización de Tikhonov, que consiste en resolver el problema de minimización con una restricción adicional:

$$
\widehat{\delta \boldsymbol{\sigma}}=\underset{\delta \boldsymbol{\sigma}}{\operatorname{argmin}}\left\{\|\mathbf{y}-\mathbf{J} \delta \boldsymbol{\sigma}\|^{2}+\|\alpha \boldsymbol{\Gamma} \delta \boldsymbol{\sigma}\|^{2}\right\}
$$


en donde $\boldsymbol{\Gamma}$ es la matriz de Tikhonov y $\alpha$ es el parámetro de regularización. La solución a este problema es:

$$
\widehat{\delta \boldsymbol{\sigma}}=\left(\mathbf{J}^{T} \mathbf{J}+\alpha^{2} \boldsymbol{\Gamma}^{T} \boldsymbol{\Gamma}\right)^{-1} \mathbf{J}^{T} \mathbf{y}
$$

Aplicando la identidad de matrices de Woodbury a la expresión anterior se obtiene:

$$
\widehat{\delta \boldsymbol{\sigma}}=\left(\left(\alpha^{2} \boldsymbol{\Gamma}^{T} \boldsymbol{\Gamma}\right)^{-1}-\left(\alpha^{2} \boldsymbol{\Gamma}^{T} \boldsymbol{\Gamma}\right)^{-1} \mathbf{J}^{T}\left(\mathbf{J}\left(\alpha^{2} \boldsymbol{\Gamma}^{T} \boldsymbol{\Gamma}\right)^{-1} \mathbf{J}^{T}+\mathbf{I}\right)^{-1} \mathbf{J}\left(\alpha^{2} \boldsymbol{\Gamma}^{T} \boldsymbol{\Gamma}\right)^{-1}\right) \mathbf{J}^{T} \mathbf{y} .
$$

Luego multiplicando el primer término por $\left(\mathbf{J}\left(\alpha^{2} \boldsymbol{\Gamma}^{T} \boldsymbol{\Gamma}\right)^{-1} \mathbf{J}^{T}+\mathbf{I}\right)^{-1}\left(\mathbf{J}\left(\alpha^{2} \boldsymbol{\Gamma}^{T} \boldsymbol{\Gamma}\right)^{-1} \mathbf{J}^{T}+\mathbf{I}\right)$ y realizando algunas operaciones algebraicas se llega a la formulación equivalente:

$$
\widehat{\delta \boldsymbol{\sigma}}=\left(\boldsymbol{\Gamma}^{T} \boldsymbol{\Gamma}\right)^{-1} \mathbf{J}^{T}\left(\mathbf{J}\left(\boldsymbol{\Gamma}^{T} \boldsymbol{\Gamma}\right)^{-1} \mathbf{J}^{T}+\alpha^{2} \mathbf{I}\right)^{-1} \mathbf{y}
$$

Una posibilidad es elegir $\boldsymbol{\Gamma}=\mathbf{I}$, donde $\mathbf{I}$ es la matriz identidad, solución que aquí llamamos Tikhonov clásica o simplemente Tikhonov. Otra alternativa es elegir $\Gamma$ de manera que asegure cierta suavidad en la solución. En este capítulo utilizamos la matriz de suavidad de Laplace de tamaño $K \times K$, en donde cada valor de la diagonal $(i, i)$ es igual a la cantidad de elementos vecinos del elemento $i$, y cada ubicación $(i, j)$ (con $i \neq j)$ es un cero si los elementos no son vecinos o un -1 si los elementos $i$ y $j$ comparten una frontera. Esta regularización es una de las más simples y utilizadas en EIT, es llamada regularización de Laplace (Lionheart et al., 2004), y que en el contexto de este capítulo la llamamos Tikhonov-Laplace. Esta solución también es conocida como solución de Gauss-Newton con regularización de Laplace (Adler et al., 2009).

\subsubsection{Algoritmos sLORETA}

El algoritmo sLORETA se basa en agregar un coeficiente escalar a la solución de mínima norma que sea función de la ubicación para eliminar el sesgo. Para un elemento particular de la discretización $k$, la solución sLORETA se expresa a partir 
de la regularización con la matriz identidad de la Ec. (5.2) como:

$$
\widehat{\delta \boldsymbol{\sigma}_{k}}=\xi_{k} \mathbf{j}_{k}^{T} \mathbf{G}^{-1} \mathbf{y}
$$

donde $\boldsymbol{\xi}$ es un vector de $K \times 1$ coeficientes reales $\xi_{k}, \mathbf{j}_{k}$ es la $k$-ésima columna de $\mathbf{J}$, y $\mathbf{G}=\mathbf{J J}^{T}+\alpha^{2} \mathbf{I}$. El coeficiente $\xi_{k}$ se obtiene a partir de imponer la condición que para una sola fuente ubicada en $k$, la solución $\widehat{\delta \boldsymbol{\sigma}_{k}}$ sea máxima en $k$, es decir que $\widehat{\delta \boldsymbol{\sigma}_{k}}>\widehat{\delta \boldsymbol{\sigma}_{k^{\prime}}}$ para todo $k^{\prime} \neq k$. En Sekihara y Nagarajan (2008) se desarrolla esta idea, y finalmente el estimador sLORETA queda definido por:

$$
\widehat{\delta \boldsymbol{\sigma}_{k}}=\frac{\mathbf{j}_{k}^{T} \mathbf{G}^{-1} \mathbf{y}}{\sqrt{\mathbf{j}_{k}^{T} \mathbf{G}^{-1} \mathbf{j}_{k}}}
$$

A continuación mostramos además una variación de sLORETA donde se incluye la matriz de suavizado $\boldsymbol{\Gamma}$. La matriz identidad $\mathbf{I}$ en $\mathbf{G}$ es de $M(L-2) \times M(L-2)$, mientras que la matriz $\Gamma$ es de $K \times K$, donde $M$ es el número de pares de inyección, $K$ es el número total de elementos de la discretización y $l$ es el número de electrodos. Por eso es necesario reformular sLORETA para basarse en la solución (5.1) en vez de en la solución (5.2). Redefinimos la Ec. (5.7) como:

$$
\widehat{\delta \boldsymbol{\sigma}_{k}}=\xi_{k}\left[\mathbf{G}^{\prime}\right]_{k} \mathbf{J}^{T} \mathbf{y}
$$

donde el operador $[\cdot]_{k}$ indica la k-ésima fila de su argumento y $\mathbf{G}^{\prime}=\mathbf{J}^{T} \mathbf{J}+\alpha^{2} \boldsymbol{\Gamma}$. Siguiendo un procedimiento análogo al utilizado para definir $\xi_{k}$ en sLORETA obtenemos el siguiente estimador

$$
\widehat{\delta \boldsymbol{\sigma}_{k}}=\frac{\left[\mathbf{G}^{\prime-1}\right]_{k} \mathbf{J}^{T} \mathbf{y}}{\sqrt{\left[\mathbf{G}^{\prime-1}\right]_{k} \mathbf{J}^{T} \mathbf{j}_{k}}}
$$

que llamamos sLORETA-Laplace. 


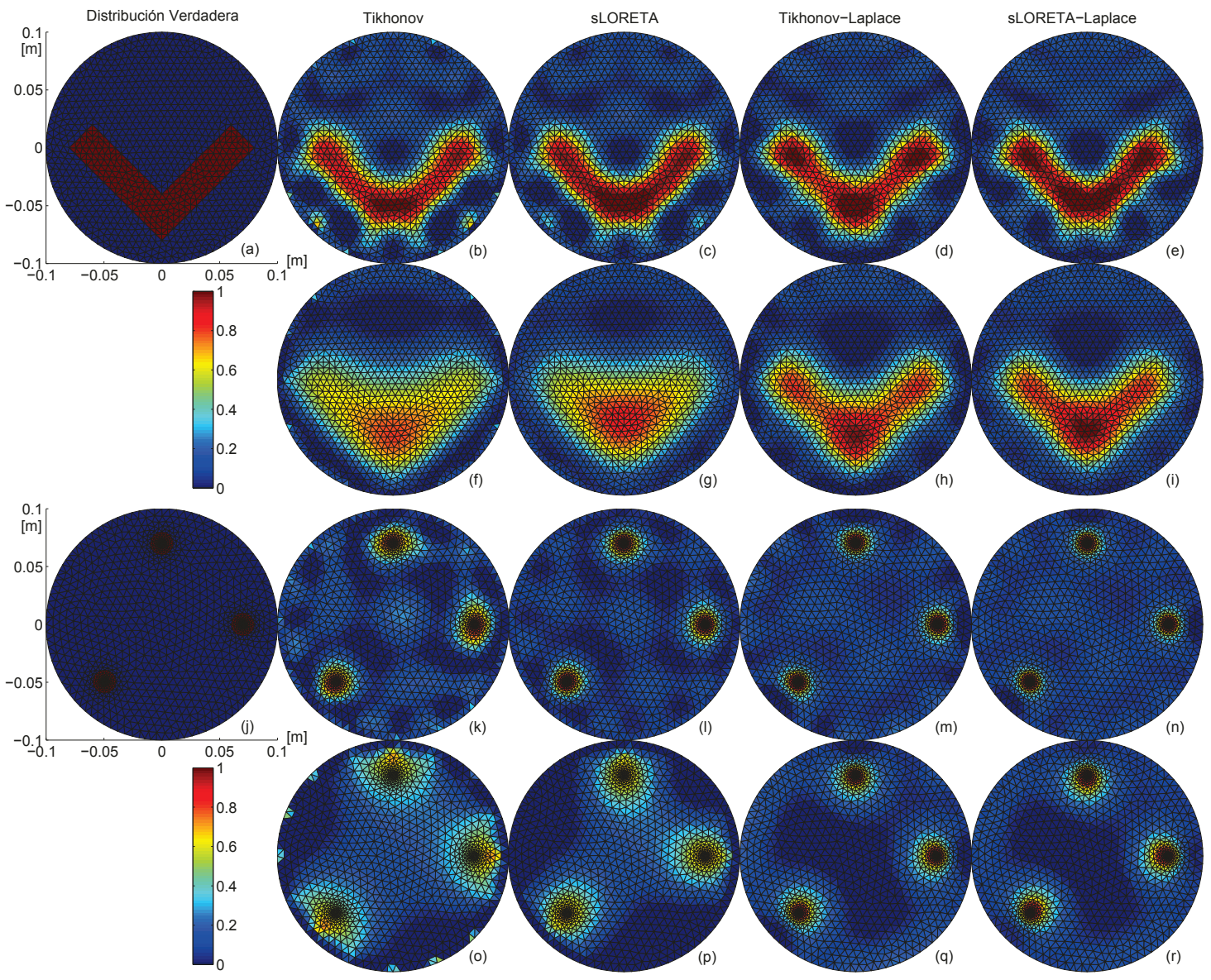

Figura 5.1: Mejores reconstrucciones de ambos fantomas para los cuatro algoritmos en dos condiciones de ruido: bajo ruido en la primer y tercer filas $\left(\sigma_{w}=1 n V\right)$, y alto ruido en la segunda y cuarta filas $\left(\sigma_{w}=10 \mu V\right)$

\subsection{Resultados}

\subsubsection{Simulaciones numéricas}

Como primera etapa para comparar los métodos se utilizaron dos fantomas simulados bidimensionales, circulares (de radio igual a $10 \mathrm{~cm}$ ), de aproximadamente 2000 elementos, con $L=16$ electrodos equiespaciados y con mapas de conductividad diferentes. Se simularon mediciones para el número máximo de pares de inyección no redundantes $(M=120)$. Para ambos fantomas se utilizó un mapa base homogé- 


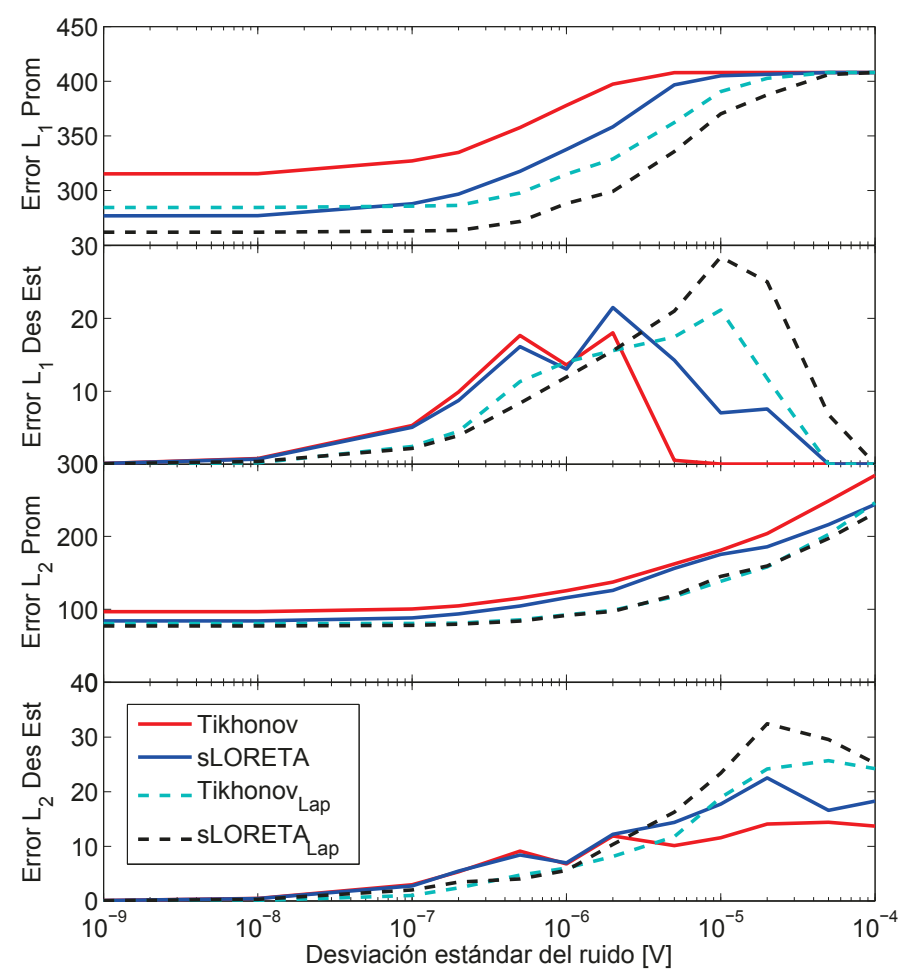

Figura 5.2: Error (normas L1 y L2) y desviación estándar de las reconstrucciones en función del nivel de ruido para el primer fantoma.

neo en todo el tanque con conductividad de $1 S / m$. Las diferencias de conductividad de cada mapa se localizaron en las zonas rojas de las Figs. 5.1(a) y 5.1(j), donde se adoptó un valor de conductividad de $1,5 \mathrm{~S} / \mathrm{m}$. Se adoptó un valor de $1 \mathrm{~mA}$ para la corriente de inyección y se utilizaron todos los posibles pares de inyección independientes, es decir, $M=L(L-1) / 2$.

Las mediciones se simularon resolviendo el problema directo utilizando FEM y adicionando ruido blanco gaussiano de media nula y desviación estándar $\sigma_{w}$ variable desde $1 n V$ a $0,1 m V(1 \mu V$ es generalmente apropiado para tener el cuenta el ruido electrónico de los amplificadores y el ruido de contacto). Se realizaron 20 simulaciones independientes para cada fantoma, y se calcularon el promedio y la desviación estándar del error de reconstrucción, definido como la norma de la diferencia entre el mapa verdadero y el mapa reconstruido. Se analizaron las normas $L 1$ y $L 2$ del error, que se grafican en la Fig. 5.2 para el primer fantoma. Para el segundo, los 


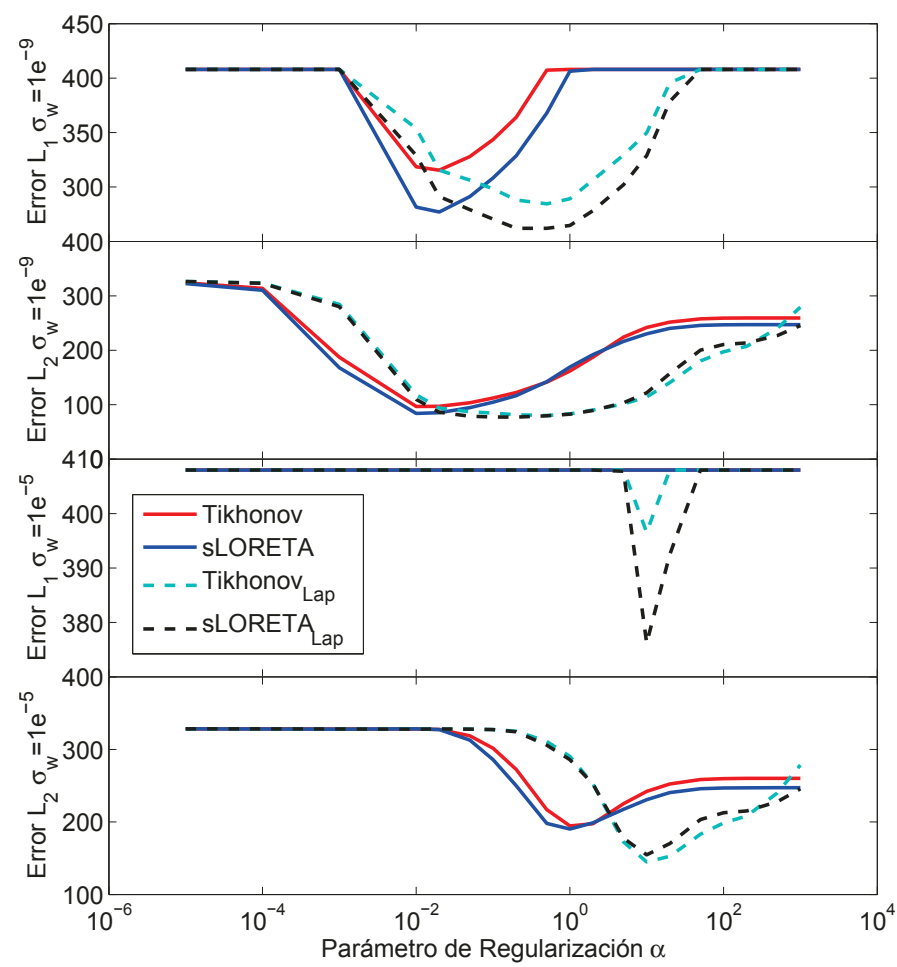

Figura 5.3: Error de reconstrucción (normas L1 y L2) del primer fantoma en función de $\alpha$, para niveles de ruido bajo $\left(\sigma_{w}=1 n V\right)$ y alto $\left(\sigma_{w}=10 \mu V\right)$.

resultados fueron muy similares. Para cada nivel de ruido se eligió el valor de $\alpha$ con menor error. Se calcularon también ambas normas del error en función del parámetro de regularización $\alpha$ en un rango desde $10^{-5}$ hasta $10^{3}$, y bajo dos condiciones de ruido (Figs. 5.3 y 5.4). Para analizar el sesgo, en la Fig. 5.5 se grafica la suma de la distancia entre los tres máximos de la solución y los tres centros verdaderos de las regiones con distinta conductividad del segundo fantoma. En la Fig. 5.1 se pueden ver las mejores reconstrucciones de ambos fantomas para los cuatro algoritmos y para dos niveles de ruido distintos.

\subsubsection{Mediciones en una maqueta experimental}

Para validar los métodos y comparar la calidad de las reconstrucciones se utilizaron mediciones reales de EIT obtenidas sobre un tanque experimental de $21 \mathrm{~cm}$ de diámetro lleno de agua salada conductora con un recipiente plástico cilíndrico no 
conductor de $8 \mathrm{~cm}$ de diámetro en su interior. El mismo se fue moviendo recorriendo dos veces el diámetro del tanque y luego dando una vuelta sobre el borde. El equipo de medición utilizado fue el IMPETOM C desarrollado por el Núcleo de Ingeniería Biomédica de la Universidad de la República, Montevideo, Uruguay descripto en el capítulo 2. Las mediciones fueron tomadas siguiendo el protocolo Sheffield de inyección y medición por pares adyacentes, aplicando una corriente de $5 m A$, y obteniendo un total de $L(L-2)$ mediciones para cada instantánea $(M=L)$. Se tomaron 300 instantáneas en 20 segundos (15 instantáneas por segundo). Debido a la relación entre el tamaño del recipiente y el del tanque, y al gran contraste entre la conductividad del agua salada y del plástico, consideramos que las mediciones poseen un SNR elevado. Esto permitió generar las mediciones faltantes para obtener el total de $M=L(L-1) / 2$ mediciones, como en los fantomas simulados. La Fig. 5.6 muestra para cada algoritmo la imagen reconstruida con el recipiente en cinco posiciones diferentes. Como en este caso la conductividad del objeto es menor que la conductividad base, se grafica $\widehat{\delta \boldsymbol{\sigma}}$ en lugar de $\widehat{\delta \boldsymbol{\sigma}}$. Para la reconstrucción, tanto de las simulaciones como de los datos reales, se utilizó un modelo de 1092 elementos y la matriz de sensibilidad se armó suponiendo una conductividad homogénea de $1 S / m$ en todo el tanque según el método alternativo desarrollado en el capítulo 2. Se probaron distintos parámetros de regularización eligiendo para cada algoritmo aquél que proporcionaba visualmente una mejor calidad de imagen y se mantuvo constante para reconstruir las distintas ubicaciones del recipiente.

\subsection{Discusión y conclusiones}

En el presente capítulo se mostró la adaptación del algoritmo sLORETA a EIT mostrando en general un mejor desempeño que el algoritmo Tikhonov clásico. Además, se realizó una pequeña modificación para poder incluir en sLORETA la matriz de regularización de Laplace, dando como resultado el algoritmo sLORETA-Laplace comparativamente de mejor desempeño que el algoritmo aquí llamado TikhonovLaplace. Los algoritmos fueron además aplicados a mediciones reales de EIT obtenidas sobre fantomas o maquetas experimentales. 


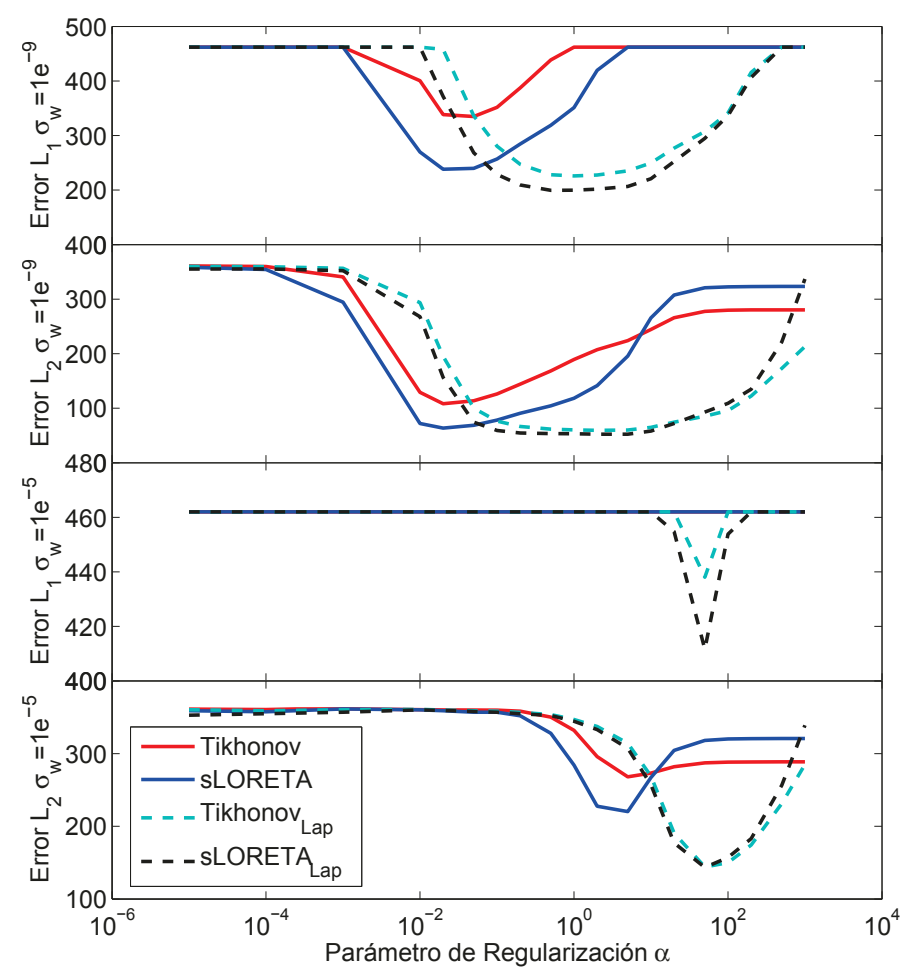

Figura 5.4: Error de reconstrucción (normas L1 y L2) del segundo fantoma en función de $\alpha$, para niveles de ruido bajo $\left(\sigma_{w}=1 n V\right)$ y alto $\left(\sigma_{w}=10 \mu V\right)$.

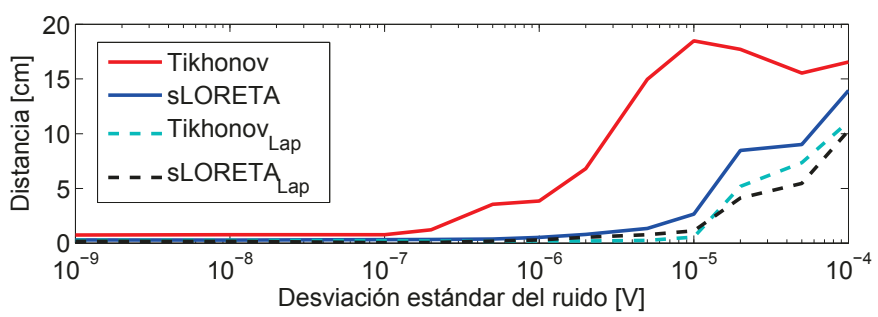

Figura 5.5: Sesgo para el segundo fantoma.

En la Fig. 5.2 se puede observar que al menos para estos ejemplos (las gráficas para el segundo fantoma fueron muy similares), utilizar la matriz $\boldsymbol{\Gamma}$ como la matriz de suavidad de Laplace presenta un menor error que con regularización con la matriz identidad, tanto en sLORETA como en Tikhonov, para todo el rango de ruido analizado. Además, se puede apreciar una mejora del sLORETA frente al Tikhonov clásico. Al comparar los dos algoritmos con regularización de Laplace ocurre 
lo mismo, aunque en menor grado ya que la mejora de sLORETA-Laplace frente a Tikhonov-Laplace es relativamente pequeña.

El análisis de las imágenes reconstruidas (Fig. 5.1) es absolutamente subjetivo. Sin embargo en el caso del primer fantoma, es posible observar que la zona con distinta conductividad es reconstruida más homogéneamente con el algoritmo sLORETA-Laplace que con el Tikhonov-Laplace. También si se comparan las reconstrucciones del fantoma real (Fig. 5.6), sLORETA-Laplace presenta levemente menor activación que Tikhonov-Laplace en los bordes del tanque donde no se encuentra el recipiente plástico.

En base a nuestras simulaciones, no encontramos que exista una diferencia entre los algoritmos frente a distintos niveles de ruido. Es decir, si un algoritmo presenta un menor error de reconstrucción que otro a bajos niveles de ruido, también presenta un menor error en condiciones más ruidosas.

En las Figs. 5.3 y 5.4 es posible observar que los algoritmos con la regularización de Laplace presentan bajos errores para un mayor rango de valores del parámetro de regularización (notar que en dichas figuras el eje de absisas está en escala logarítmica). Esto implica una menor sensibilidad de los algoritmos Tikhonov-Laplace y sLORETA-Laplace al parámetro de regularización, lo que constituye una ventaja adicional.

En la Fig. 5.5 es posible observar una notable reducción del sesgo al utilizar sLORETA en lugar de Tikhonov. Esto incluso se puede observar comparando la Fig. 5.1(o) con la Fig. 5.1(p). Sin embargo, era esperable además una mejora entre sLORETA y Tikhonov-Laplace, o una mejora mayor del sLORETA-Laplace frente al Tikhonov-Laplace, ya que sLORETA está específicamente diseñado para minimizar el sesgo. Una posible explicación de que esto no haya ocurrido es que la regularización basada en condiciones de suavidad implícitamente mejore el sesgo ya que tiene en cuenta la solución en los elementos vecinos. Otra posibilidad es que el sesgo no se evidencie en Tikhonov-Laplace si la disposición de los electrodos es simétrica, como en los fantomas utilizados en este trabajo donde los electrodos fueron dispuestos sobre la frontera de manera equiespaciada.

En resumen, los resultados de este trabajo sugieren la utilización de sLORETA 


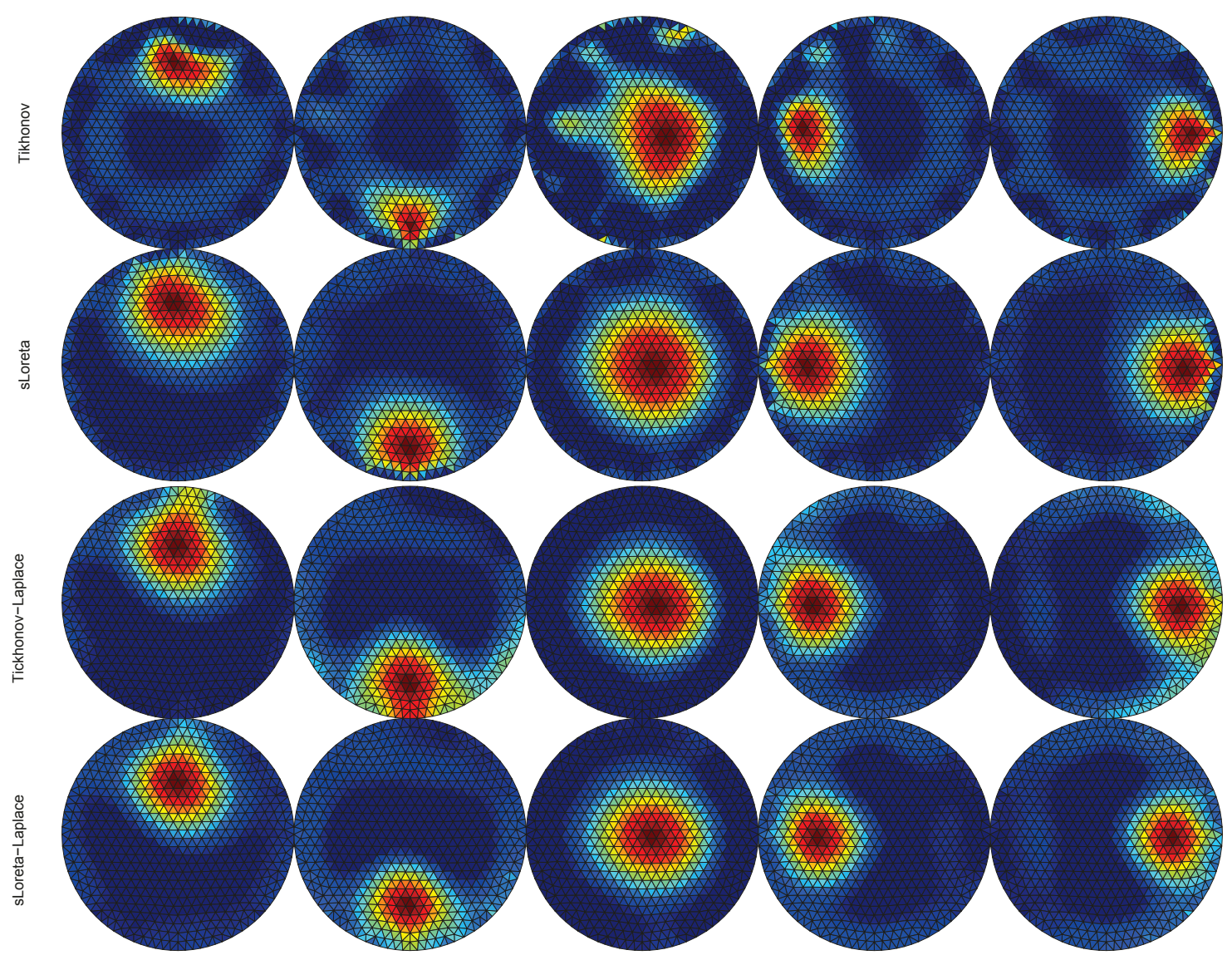

Figura 5.6: Reconstrucciones del fantoma real para los cuatro algoritmos y cinco posiciones diferentes del recipiente plástico. Cada imagen está normalizada respecto a su máximo.

en lugar del Tikhonov clásico y de sLORETA-Laplace en lugar del Tikhonov-Laplace para reconstrucción en EIT, teniendo en cuenta también que el incremento del costo computacional al utilizar sLORETA en lugar de Tikhonov es despreciable. 


\section{Capítulo 6}

\section{Filtrado espacial en EIT (EIT-SF)}

\subsection{Introducción}

En este capítulo se muestra la aplicación de técnicas de filtrado espacial (SF) para la localización de cambios de conductividad en EIT. Esta técnica combina las señales obtenidas con un arreglo de sensores de una manera particular para orientar la máxima ganancia hacia una ubicación espacial en concreto. En EEG/MEG generalmente se realiza un barrido virtual por toda la zona de interés obteniendo un mapa de activación neuronal. El filtro espacial lineal de mínima varianza con restricciones (LCMV) es un filtro adaptivo particular que se basa en la minimización de la varianza de la salida del filtro bajo algún tipo de restricción. La restricción más común es la de no-distorsión (van Been et al., 1997). Algunas variaciones para SF en EEG/MEG que tienen en cuenta la orientación de las fuentes han sido publicadas en Vrba y Robinson (2000); Chen et al. (2006); Sekihara y Nagarajan (2008).

Como ya se ha mostrado en el capítulo 5, la mayoría de los algoritmos de EIT más comunes están basados en métodos de reconstrucción en EIT en diferencias (Lionheart et al., 2004; Adler et al., 2009; Javaherian et al., 2013; Liu et al., 2013). En EIT en diferencias, una imagen de referencia es utilizada para comparar todas las demás instantáneas y se obtiene como resultado una imagen por cada instante de tiempo (o instantánea). Contrariamente, los filtros espaciales que se estudian en este capítulo generan un único mapa de activación que concentra la información de 
todo un intervalo temporal de interés.

En el presente capítulo se adapta el filtro LCMV a EIT, teniendo en cuenta algunas diferencias con EEG/MEG como ser la combinación de los distintos pares de electrodos para la inyección de corriente y los niveles de ruido. En primer lugar, se propone el uso de SF en EIT para localizar cambios de conductividad y estimar su variación temporal para tejidos en general, sin restringirse a aplicaciones en el cerebro. Para ello se realizan experimentos de simulación y reales sobre tanques cilíndricos experimentales, comparando el desempeño del método con el método clásico de Gauss-Newton con regularización de Laplace (también llamado Tikhonov con regularización de Laplace o simplemente Tikhonov-Laplace como en el capítulo anterior). Se muestra la aplicabilidad del método sobre dominios bidimensionales y tridimensionales y se incluye además la incorporación de restricciones adicionales de ganancia nula para mitigar el efecto de cambios de conductividad correlacionados. Se propone una alternativa si la forma de onda del cambio de conductividad de interés es conocida y se analiza además el efecto de tener errores en la ubicación de los electrodos.

Luego se analiza el uso de la técnica de filtrado espacial en EIT para aplicaciones específicas del cerebro humano. Primero se estudia el efecto de utilizar un distinto número de electrodos y distintos niveles de ruido a través de un estudio de simulación sobre geometrías de cabeza realistas. En estas primeras simulaciones se suponen sólo dos instantáneas, una antes y otra después de un cambio de conductividad asignado a una pequeña esfera ubicada en la unión de los lóbulos parietal y temporal. Después, se aplican las técnicas de filtrado espacial a simulaciones de EIT dinámico, es decir, con más de dos instantáneas, para localizar cambios de conductividad y estimar su variación temporal en el cerebro. Para ello se simulan cambios de conductividad en tres regiones distintas del cerebro, analizando distintos niveles de ruido y errores en la geometría de la cabeza.

Los resultados presentados en este capítulo sugieren que el filtrado espacial aplicado a EIT (EIT-SF) tiene un gran potencial para entender y caracterizar mejor cambios de conductividad que pueden ocurrir en el cerebro. Esto podría ayudar a la detección y caracterización temprana de accidentes cerebro-vasculares y a la locali- 
zación de regiones de activación neuronal. Estas aplicaciones se verían beneficiadas de la mejor resolución y menor carga computacional de los filtros espaciales comparados con las técnicas de reconstrucción más usuales de EIT. Más aún, la evolución temporal de los cambios de conductividad obtenida con EIT-SF es una potencial herramienta para el diagnóstico.

\subsection{Principios del filtrado espacial}

\subsubsection{Formulación}

A partir del modelo de señal linealizado de la Ec. (2.43) descripto en el capítulo 2, y suponiendo un cambio de conductividad $\delta \sigma_{k, t}$ en el elemento o posición $k$, el modelo de señal en diferencias se puede expresar como:

$$
\mathbf{y}_{t}=\mathbf{j}_{k} \delta \sigma_{k, t}+\delta \mathbf{n}_{t}
$$

ya que el $k$-ésimo elemento del vector $\delta \boldsymbol{\sigma}_{t}$ es el único elemento no nulo. Luego, las distintas instantáneas correspondientes a distintos instantes de tiempo $\mathbf{y}_{\mathbf{t}}$ se pueden agrupar en columnas formando una matriz de medición $\mathbf{Y}$, y las muestras de ruido de cada instante de tiempo $\delta \mathbf{n}_{t}$ también se pueden agrupar en una matriz de ruido $\delta \mathbf{N}$. El modelo de señal que tiene en cuenta los distintos instantes de tiempo resulta

$$
\mathbf{Y}=\mathbf{j}_{k} \delta \boldsymbol{\sigma}_{k}^{T}+\delta \mathbf{N}
$$

donde $\delta \boldsymbol{\sigma}_{k}$ es un vector que contiene las muestras temporales del cambio de conductividad en el elemento $k$. $\delta \mathbf{N}$ tiene en cuenta el ruido electrónico de los amplificadores y de los contactos modelizados como ruido blanco gaussiano (WGN), y a su vez incluye otros cambios de conductividad no deseados, que en general también se modelizan como WGN. A continuación se desarrolla la formulación del filtro LCMV de no-distorsión a partir del modelo de señal de la Ec. (6.2) basándose en las ideas de van Been et al. (1997); Vrba y Robinson (2000); Chen et al. (2006); Sekihara y Nagarajan (2008) en el contexto de EEG/MEG. 
El filtro espacial LCMV propone un vector de pesos $\mathbf{w}_{k}$ tal que $\mathbf{w}_{k}^{T} \mathbf{Y}$ es un estimador de mínima varianza del parámetro de interés en la posición $k$ y sujeto a restricciones particulares. En el contexto de EEG/MEG, los parámetros de interés son las características de las fuentes de actividad electromagnética mientras que en EIT son los cambios de conductividad $\delta \boldsymbol{\sigma}_{k}$. Es por eso que algunas veces en el contexto de EIT denominamos como "fuentes" a los cambios de conductividad, que si bien son perturbaciones electromagnéticas no son fuentes electromagnéticas en sí mismas. De acuerdo con el filtro LCMV de no-distorsión, los vectores de pesos $\mathbf{w}_{k}$ deben satisfacer

$$
\underset{\mathbf{w}_{k}}{\operatorname{argmin}}\left\{\mathbf{w}_{k}^{T} \mathbf{C}_{\mathbf{Y}} \mathbf{w}_{k}\right\} \text { sujeto a } \mathbf{w}_{k}^{T} \mathbf{j}_{k}=1,
$$

donde $\mathbf{C}_{\mathbf{Y}}=\mathbb{E}\left\{(\mathbf{Y}-\mathbb{E}\{\mathbf{Y}\})(\mathbf{Y}-\mathbb{E}\{\mathbf{Y}\})^{T}\right\}$ es la matriz de covarianza de $\mathbf{Y}$ y $\mathbb{E}$ significa esperanza (Sekihara y Nagarajan, 2008).

A continuación se desarrolla el procedimiento clásico para resolver el problema de minimización de la Ec. (6.3) que puede encontrarse en la literatura (van Been et al., 1997; Van Trees, 2002; Chen et al., 2006; Sekihara y Nagarajan, 2008). De (6.3) se desprende que el funcional a minimizar es:

$$
\mathcal{L}=\mathbb{E}\left\{\mathbf{w}_{k}^{T} \mathbf{C}_{\mathrm{Y}} \mathbf{w}_{k}\right\}+\lambda\left(\mathbf{w}_{k}^{T} \mathbf{j}_{k}-1\right)
$$

donde $\lambda$ es un parámetro que permite regular la importancia de la restricción de no-distorsión. La derivada de $\mathcal{L}$ respecto del vector de pesos resulta

$$
\frac{\partial \mathcal{L}}{\partial \mathbf{w}_{k}^{T}}=2 \mathbf{C}_{\mathbf{Y}} \mathbf{w}_{k}+\lambda \mathbf{j}_{k}=0
$$

de donde se puede despejar

$$
\mathbf{w}_{k}^{T}=-\lambda \mathbf{j}_{k}^{T} \mathbf{C}_{\mathrm{Y}}^{-1} / 2
$$

De la condición de no-distorsión de la Ec. (6.3) y de la Ec. (6.6) se obtiene que

$$
-\lambda \mathbf{j}_{k}^{T} \mathbf{C}_{\mathrm{Y}}{ }^{-1} \mathbf{j}_{k} / 2=1,
$$


resultando entonces

$$
-\lambda=\left(\mathbf{j}_{k}^{T} \mathbf{C}_{\mathrm{Y}}{ }^{-1} \mathbf{j}_{k}\right)^{-1} 2 .
$$

Luego, reemplazando la Ec. (6.8) en la Ec. (6.6), el vector de pesos para el filtro LCMV de no-distorsión es:

$$
\mathbf{w}_{k}^{T}=\left(\mathbf{j}_{k}^{T} \mathbf{C}_{\mathrm{Y}}{ }^{-1} \mathbf{j}_{k}\right)^{-1} \mathbf{j}_{k}^{T} \mathbf{C}_{\mathrm{Y}}{ }^{-1}
$$

Nótese que $\left(\mathbf{j}_{k}^{T} \mathbf{C}_{\mathrm{Y}}{ }^{-1} \mathbf{j}_{k}\right)$ es un escalar. La salida del filtro es un estimador del cambio de conductividad en la posición $k$,

$$
\widehat{\delta \boldsymbol{\sigma}_{k}^{T}}=\mathbf{w}_{k}^{T} \mathbf{Y}=\left(\mathbf{j}_{k}^{T} \mathbf{C}_{\mathbf{Y}}{ }^{-1} \mathbf{j}_{k}\right)^{-1} \mathbf{j}_{k}^{T} \mathbf{C}_{\mathbf{Y}}{ }^{-1} \mathbf{Y}
$$

Se puede mostrar que la salida del filtro es insesgada para una fuente localizada y que el filtro fuerza automáticamente ganancia nula en la posición de otras fuentes no correlacionadas basándose en la información de $\mathbf{C}_{Y}$ (Sekihara y Nagarajan, 2008). Si a $\mathbf{C}_{Y}$ se la estima a partir de los propios datos, el filtro LCMV de no-distorsión entra dentro de la categoría de filtros adaptivos, ya que utiliza las propias mediciones para construir el vector de pesos. Los algoritmos de reconstrucción mencionados en esta tesis como sLORETA o Gauss-Newton (GN) con regularización de Laplace son también llamados filtros no-adaptivos ya que no cambian en función de los datos.

\subsubsection{Matrices de covarianza y parámetro de regularización}

La sensibilidad del filtro LCMV decrece con la distancia a los electrodos, por lo que una medida absoluta no es lo más apropiado. En su lugar, se definió un índice para cada ubicación $k$ que normaliza la contribución del cambio de conductividad con respecto a una situación de sólo ruido, llamado indice de cambio de conductividad $(C C I)$. Este índice se basa en el índice de actividad neuronal de van Been et al. (1997); Chen et al. (2006), y su formulación es:

$$
C C I_{k}=\frac{\mathbf{w}_{k}^{T} \mathbf{C}_{\mathrm{a}} \mathbf{w}_{k}}{\mathbf{w}_{k}^{T} \mathbf{C}_{\mathrm{n}} \mathbf{w}_{k}}
$$


donde $\mathbf{C}_{\mathrm{a}}$ es la matriz de covarianza de la señal que contiene al cambio de conductividad de interés y $\mathbf{C}_{n}$ es la matriz de covarianza del ruido. El $C C I_{k}$ puede pensarse como la varianza de la salida del filtro de no-distorsión de la Ec.(6.10) normalizado por la varianza de la salida del filtro cuando sólo hay ruido. Reemplazando la expresión de la Ec.(6.9) en la Ec.(6.11) obtenemos:

$$
C C I_{k}=\frac{\mathbf{j}_{k}^{T} \mathbf{C}_{\mathrm{Y}}{ }^{-1} \mathbf{C}_{\mathrm{a}} \mathbf{C}_{\mathrm{Y}}{ }^{-1} \mathbf{j}_{k}}{\mathbf{j}_{k}^{T} \mathbf{C}_{\mathrm{Y}}{ }^{-1} \mathbf{C}_{\mathrm{n}} \mathbf{C}_{\mathrm{Y}}{ }^{-1} \mathbf{j}_{k}},
$$

que es equivalente al filtro de ganancia de ruido unitaria definido en Sekihara y Nagarajan (2008) cuando $\mathbf{C}_{\mathrm{n}}$ es la matriz identidad. El $C C I_{k}$ se puede computar para todos los $K$ elementos de la discretización resultando en un mapa de cambio de conductividad que llamamos mapa $C C I$.

Existen diversos métodos para estimar las matrices de covarianza $\mathbf{C}_{\mathrm{a}}, \mathbf{C}_{\mathrm{n}}$ y $\mathbf{C}_{\mathrm{Y}}$, lo cual es un aspecto no menor de las técnicas de filtrado espacial (van Been et al., 1997). El estimador más usual para $\mathbf{C}_{\mathrm{Y}}$ es la matriz de covarianza muestral $\mathbf{C}$

$$
\mathbf{C}=\frac{1}{T-1}(\mathbf{Y}-\overline{\boldsymbol{y}})(\mathbf{Y}-\overline{\boldsymbol{y}})^{T}
$$

donde $\overline{\boldsymbol{y}}$ es el promedio temporal de la matriz de datos Y, y $T$ es el número total de instantáneas. Las Ecs. (6.10) y (6.12) involucran la matriz inversa de $\mathbf{C}_{\mathrm{Y}}$ que generalmente es mal-condicionada, especialmente para un bajo número de instantáneas $T$. Si $T<M(L-2)$, directamente la matriz $\mathbf{C}$ es singular. La regularización de Tikhonov, también llamada carga diagonal, es una manera usual de mejorar el problema y consiste en definir $\mathbf{C}_{\mathrm{Y}}=\mathbf{C}+\alpha \mathbf{I}$, donde $\alpha$ es el parámetro de regularización e I es la matriz identidad. También se pueden aplicar otros métodos de regularización especialmente adecuados para $T<M(L-2)$ como el propuesto por Beltrachini et al. (2013).

Para la matriz de covarianza de la señal es común adoptar la aproximación de alta relación señal a ruido $(\mathrm{SNR}) \mathbf{C}_{\mathrm{a}}=\mathrm{C}$. La matriz de covarianza de ruido $\mathbf{C}_{\mathrm{n}}$ es típicamente estimada en condiciones de ausencia de señal, o elegida como la matriz identidad multiplicada por la varianza de ruido si se supone WGN espacial estacionario, como lo hacemos en el presente capítulo. 


\subsubsection{Variantes del filtro LCMV}

En esta sección se muestran dos posibles variaciones de los filtros LCMV: una es el agregado de restricciones adicionales de ganancia nula, y la otra es el aprovechamiento del conocimiento previo de la forma de onda del cambio de conductividad de interés. Estas técnicas permiten distinguir entre distintas fuentes.

Distinguir o separar fuentes correlacionadas es un problema conocido de los filtros LCMV (van Been et al., 1997). La capacidad de localizar entonces distintas fuentes depende del grado de correlación y de la distancia espacial entre las fuentes. Una alternativa para superar este efecto indeseado es forzar condiciones de ganancia nula en regiones particulares que contienen cambios de conductividad distintos a los de interés. Para poder aplicar esta técnica, las regiones con "interferencias" deben ser conocidas a-priori o estimadas previamente. Las condiciones de ganancia nula pueden ser incorporadas en los filtros espaciales aplicados a EIT como en cualquier otro filtro espacial. Supongamos que las condiciones de ganancia nula se quieren aplicar en las posiciones $k_{1}, k_{2}, \ldots, k_{l}$, y que $\mathbf{j}_{k_{1}}, \mathbf{j}_{k_{2}}, \ldots, \mathbf{j}_{k_{l}}$ son los vectores de sensibilidad correspondientes, el nuevo vector de pesos $\mathbf{w}^{\prime}{ }_{k}$ con condiciones de ganancia nula en las posiciones especificadas es:

$$
\mathbf{w}_{k}^{\prime T}=\mathbf{g}^{T}\left(\mathbf{J}_{l}^{T} \mathbf{C}_{\mathrm{Y}}{ }^{-1} \mathbf{J}_{l}\right)^{-1} \mathbf{J}_{l}^{T} \mathbf{C}_{\mathrm{Y}}{ }^{-1}
$$

donde $\mathbf{J}_{l}=\left[\mathbf{j}_{k}, \mathbf{j}_{k_{1}}, \mathbf{j}_{k_{2}}, \ldots, \mathbf{j}_{k_{l}}\right], \mathrm{y} \mathbf{g}=[1,0,0, \ldots, 0]^{T}$. Los costos de incorporar estas restricciones adicionales son que la SNR de la salida disminuye y que $\mathbf{J}_{l}^{T} \mathbf{C}_{\mathrm{Y}}{ }^{-1} \mathbf{J}_{l}$ se acerca a una matriz singular (Sekihara y Nagarajan, 2008).

En algunas aplicaciones la forma de onda de un cambio de conductividad particular podría ser conocida a partir de experimentos previos. Por ejemplo, Shi et al. (2008) muestra en un experimento con conejos anestesiados que la conductividad en un accidente cerebrovascular del tipo isquémico decrece aproximadamente de manera lineal. Entonces, el conocimiento de la dinámica o forma de onda específica podría ayudar a distinguir un cambio de conductividad particular. Suponiendo que la forma de onda normalizada y conocida de un cambio de conductividad de interés es $s(t)$, y que el vector $\mathbf{s}$ contiene las muestras temporales de $s(t), \delta \boldsymbol{\sigma}_{k}=\delta \sigma_{k} \mathbf{s}$ donde sólo 
el factor $\delta \sigma_{k}$ es desconocido. Un posible estimador puede obtenerse inmediatamente de la Ec.(6.10) como

$$
\widehat{\delta \sigma_{k}}=\frac{{\widehat{\delta \boldsymbol{\sigma}_{k}}}^{T} \mathbf{s}}{\|\mathbf{s}\|^{2}}=\frac{\mathbf{w}_{k}^{T} \mathbf{Y} \mathbf{s}}{\|\mathbf{s}\|^{2}} .
$$

Luego, el $C C I_{k}$ con forma de onda conocida resulta:

$$
C C I_{k}=\frac{\mathbf{j}_{k}^{T} \mathbf{C}_{\mathrm{Y}}{ }^{-1} \mathbf{C}_{\mathrm{s}} \mathbf{C}_{\mathrm{Y}}^{-1} \mathbf{j}_{k}}{\mathbf{j}_{k}^{T} \mathbf{C}_{\mathrm{Y}}{ }^{-1} \mathbf{C}_{\mathrm{n}} \mathbf{C}_{\mathrm{Y}}{ }^{-1} \mathbf{j}_{k}}
$$

donde $\mathbf{C}_{\mathrm{s}}=\frac{1}{T-1}(\mathbf{Y}-\overline{\boldsymbol{y}}) \mathbf{s s}^{T}(\mathbf{Y}-\overline{\boldsymbol{y}})^{T}$

\subsection{Resultados generales}

Para validar el método y analizar su desempeño para aplicaciones biomédicas en general, sin restringirse a aplicaciones en el cerebro humano, se realizaron experimentos en tanques cilíndricos simulados y experimentales. En primer lugar se muestran los resultados obtenidos con simulaciones en dominios bidimensionales, y se los contrasta con mediciones reales obtenidas con el IMPETOM C, de la Universidad de La República, Montevideo, Uruguay. Y en segundo lugar, se utilizan dominios tridimensionales para las simulaciones y para analizar los datos reales obtenidos con el equipo de EIT experimental AMP300 de Electrical Geodesics, Inc, Eugene, Oregon, Estados Unidos. Descripciones de ambos equipos se encuentran en el capítulo 2.

Los mapas de CCI fueron computados para estudiar el sesgo y la resolución espacial; y la salida del filtro fue también obtenida para estudiar la calidad en la estimación de la evolución de los cambios de conductividad. Se comparó también la calidad de la localización del método con respecto al método de reconstrucción clásico de Gauss-Newton con regularización espacial de Laplace (GN-Laplace) de la forma:

$$
\delta \boldsymbol{\sigma}_{t}^{\mathrm{GN}}=\left(\mathbf{J}^{T} \mathbf{J}+\lambda^{2} \boldsymbol{\Gamma}^{T} \boldsymbol{\Gamma}\right)^{-1} \mathbf{J}^{T} \mathbf{y}_{t}
$$

donde $\Gamma$ es el filtro discreto de Laplace, y $\lambda$ es el parámetro de regularización, el cual fue seleccionado ad-hoc para lograr el mejor desempeño. Aplicando el lema 
de inversión de matrices de Woodbury, puede mostrarse que la formulación de la Ec. (6.17) es equivalente a otro método utilizado, el filtro de Wiener (Sekihara y Nagarajan, 2008):

$$
\delta \boldsymbol{\sigma}_{t}^{\text {Wiener }}=\boldsymbol{\Sigma}_{m} \mathbf{J}^{T}\left(\mathbf{J} \boldsymbol{\Sigma}_{m} \mathbf{J}^{T}+\mathbf{C}_{\mathrm{n}}\right)^{-1} \mathbf{y}_{t}
$$

La equivalencia vale si se adopta $\left(\boldsymbol{\Gamma}^{T} \boldsymbol{\Gamma}\right)^{-1}$ como la matriz de covarianza de las fuentes $\boldsymbol{\Sigma}_{m}$ y $\mathbf{C}_{\mathrm{n}}=\lambda^{2} \mathbf{I}$

El método de GN-Laplace devuelve una imagen por instantánea, por lo que para compararlo con el filtro LCMV se tomó el cuadrado del valor cuadrático medio (RMS) de las $T$ imágenes individuales. Se puede observar que tanto el CCI como el RMS ${ }^{2}$ son cuadráticos. Debido a que se proponen utilizar las técnicas de filtrado espacial para localizar cambios de conductividad, pero no para reconstruir la forma geométrica de esos cambios, la comparación con el método de GN-Laplace se realiza utilizando sólo índices de desempeño relacionados con localización. En particular, se adoptaron como índices de desempeño el error de posición (PE) para cuantificar el sesgo, y la resolución (RES) para cuantificar la resolución espacial. Se definió el centro de gravedad (CoG) como:

$$
\mathrm{CoG}=\frac{\sum_{q=1}^{Q} \mathbf{c}_{q} x_{q}}{\sum_{q=1}^{Q} x_{q}}
$$

donde $Q$ es el número de elementos con un valor de imagen (CCI o $\mathrm{RMS}^{2}$ ) mayor a un cierto valor umbral, y donde $\mathbf{c}_{q} \mathrm{y} x_{q}$ son el centroide y el valor de la imagen del elemento $q$ respectivamente. El PE se obtuvo como la distancia Euclídea entre el punto central del cambio de conductividad verdadero y el CoG. El índice de desempeño de resolución (RES) se definió de igual manera que en Adler et al. (2009):

$$
\operatorname{RES}=\sqrt{\frac{Q}{K}}
$$

Puede observarse que para cambios de conductividad pequeños generalmente se desea un valor bajo de RES que indica una resolución alta. En esta tesis, los umbrales para determinar tanto el CoG como la RES fueron elegidos de manera ad-hoc 


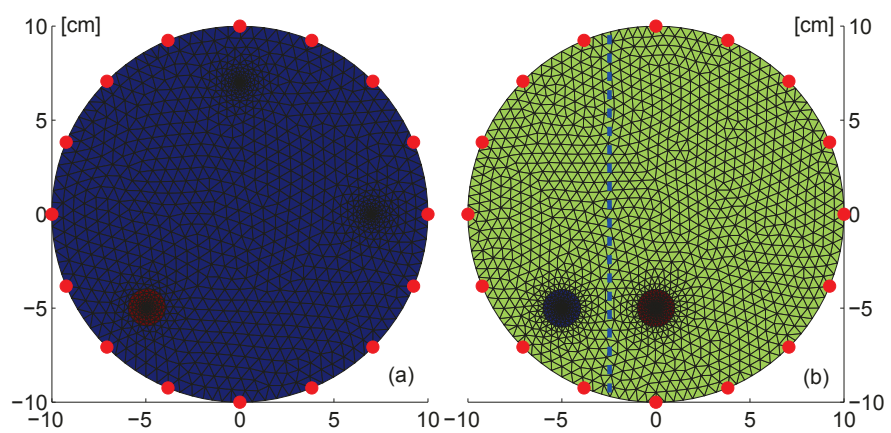

Figura 6.1: Discos virtuales utilizados para generar las señales con (a) un cambio de conductividad, y (b) dos cambios de conductividad. Los círculos "•" indican las ubicaciones de los electrodos, y la línea punteada indica la división de regiones para calcular los índices de desempeño de cada fuente.

buscando una buena representación entre los índices de desempeño y lo observado en las imágenes. Otra posibilidad sería determinar los umbrales a partir de un análisis estadístico utilizando algún tipo de test de hipótesis. En este caso igualmente habría que elegir un umbral estadístico (usualmente valor-p) de manera arbitraria.

Es importante resaltar que las discretizaciones (o mallas) utilizadas para generar las señales simuladas fueron diferentes a las utilizadas para calcular los mapas de CCI a fin de prevenir cualquier tipo de correlación indeseada inducida por usar las mismas mallas. Las mallas para generar las señales fueron en general mallas no uniformes, es decir con una mayor densidad de elementos en las regiones con cambios de conductividad, mientras que las mallas de reconstrucción fueron en general regulares, con elementos de similar tamaño en todo el dominio de análisis. Todas las mallas, tanto bidimensionales como tridimensionales fueron construidas con la ayuda del paquete de software iso2mesh (Fang y Boas, 2009).

En todos los experimentos, se adoptó $\mathbf{C}_{\mathrm{a}}=\mathbf{C}$, definiendo $\mathbf{C}$ como en la Ec.(6.13); $\mathbf{C}_{\mathrm{Y}}=\mathbf{C}+\alpha \mathbf{I} ;$ y para $\mathbf{C}_{\mathrm{n}}$ se adoptó la matriz identidad multiplicada por la varianza de ruido. 

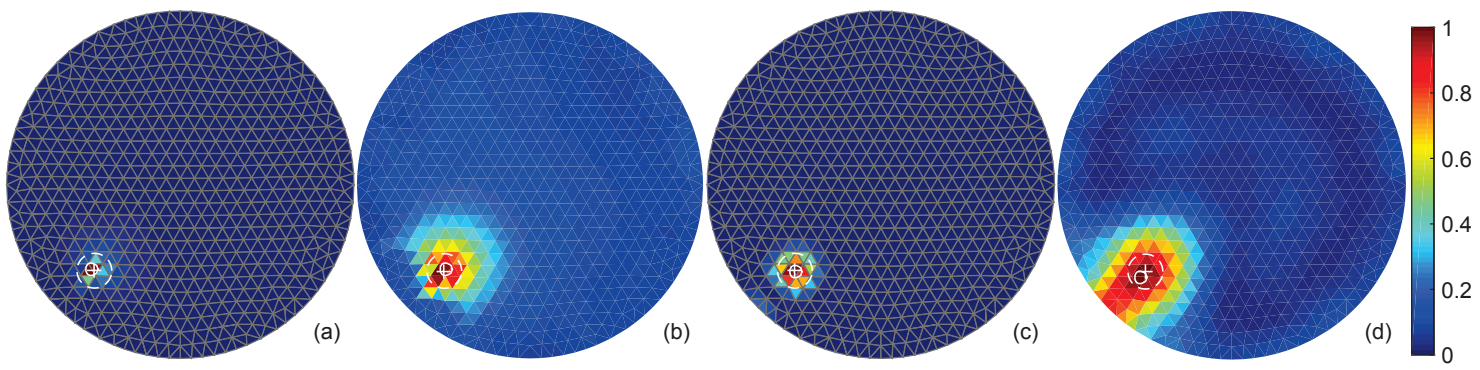

Figura 6.2: Simulación de un sólo cambio de conductividad. (a-b) Mapas normalizados de CCI obtenidos con el conjunto de datos (a) sin ruido y (b) con ruido $(\mathrm{SNR}=3)$. (c-d) $\mathrm{RMS}^{2}$ de las imágenes obtenidas con el método de GN-Laplace, para los mismos conjuntos de datos respectivamente. Los círculos punteados indican las regiones con conductividad dinámica y las marcas blancas "+" sus centros verdaderos. Los círculos blancos "o" indican los CoG obtenidos.

\subsubsection{Filtro espacial bidimensional en simulaciones}

Se construyó un disco virtual con conductividad de referencia homogénea e isótropa de $1 \mathrm{~S} / \mathrm{m}$, de $10 \mathrm{~cm}$ de radio y con 16 electrodos equiespaciados ubicados sobre su frontera. Cambios de conductividad dinámicos fueron asignados a una y a dos regiones circulares de $1 \mathrm{~cm}$ de radio cada una, como se muestra en la Fig. 6.1. En la misma figura también se muestra la posición de los electrodos y el mallado utilizado para generar las mediciones simuladas mediante el FEM. Se simularon las señales de los electrodos para todos los posibles pares de inyección de corriente, resultando en un total de 120 conjuntos de 14 mediciones simuladas cada uno, adoptando, para cada conjunto, una referencia de potencial eléctrico promedio. Se generaron además 120 instantáneas resultando entonces una matriz de datos $\mathbf{Y}$ de tamaño $1680 \times 120$. También se generaron dos conjuntos de datos con ruido, adicionando WGN para tener relaciones señal a ruido (SNR) igual a 3 e igual a 9. La SNR se definió como la relación de la potencia de la señal de máxima energía con respecto a la varianza de ruido. En EIT, valores de SNR entre 2 y 3 se esperan en casos de epilepsia (Fabrizi et al., 2006), valores entre 3 y 4 en respuestas visuales evocadas (Gilad et al., 2009), e incluso mayores valores en accidentes cerebro-vasculares del tipo isquémico, donde la impedancia puede llegar al $50 \%$ del valor de conductividad base (Hansen y Olsen, 1980; Holder, 1992; Horesh, 2006). 


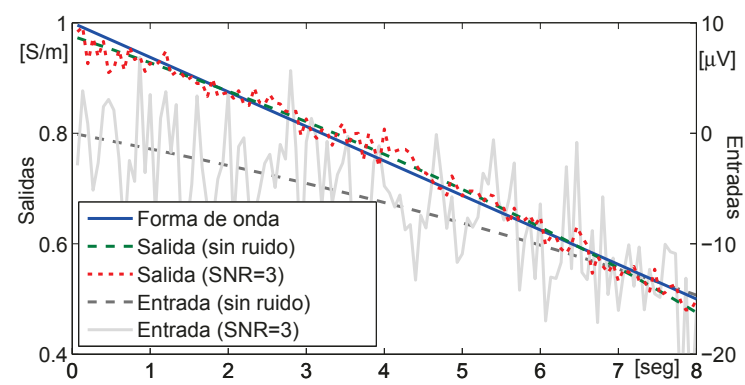

Figura 6.3: Variación temporal (o forma de onda) del cambio de conductividad [S/m] y las salidas del filtro LCMV normalizadas, con el filtro espacial orientado hacia el elemento de máximo CCI, y para los dos conjuntos de datos (sin ruido y con ruido tal que $\mathrm{SNR}=3$ ). Las mediciones simuladas en el electrodo más sensible para ambos conjuntos de datos también se muestran en el eje derecho $[\mu V]$.

Para definir el CoG y la RES de la imagen resultante normalizada según las Ecs.(6.19) y (6.20), se eligió un valor umbral de 0,5. Para dos cambios de conductividad simultáneos, las imágenes fueron divididas en dos secciones por una línea, como se muestra en la Fig. 6.1(b), y los índices PE y RES de cada fuente fueron calculados de manera independiente para cada sección.

\section{Un cambio de conductividad}

Se simuló un cambio de conductividad con dos formas de onda diferentes: un decrecimiento lineal hasta un $50 \%$ de la conductividad base y un período de sinusoide con picos de $\pm 50 \%$ de la conductividad base. La Fig. 6.2 muestra los mapas de CCI normalizados que se obtuvieron para el cambio de conductividad lineal utilizando tanto el conjunto de datos sin ruido como el conjunto con ruido. También se muestra el RMS ${ }^{2}$ de las imágenes obtenidas con el método GN-Laplace y en la Fig. 6.3 se muestran las salidas del filtro. Se puede observar que ambos métodos detectan las fuentes, incluso en el caso con ruido, y que el método de filtrado espacial presenta una mejor resolución. Además las salidas del filtro son coherentes con la dinámica del cambio de conductividad, incluso en el caso con ruido. Para el cambio de conductividad sinusoidal los resultados fueron muy similares. Para calcular los mapas de CCI, el parámetro de regularización fue elegido siguiendo el método de carga diagonal asimétrica de Sekihara y Nagarajan (2008): un valor entre el ma- 


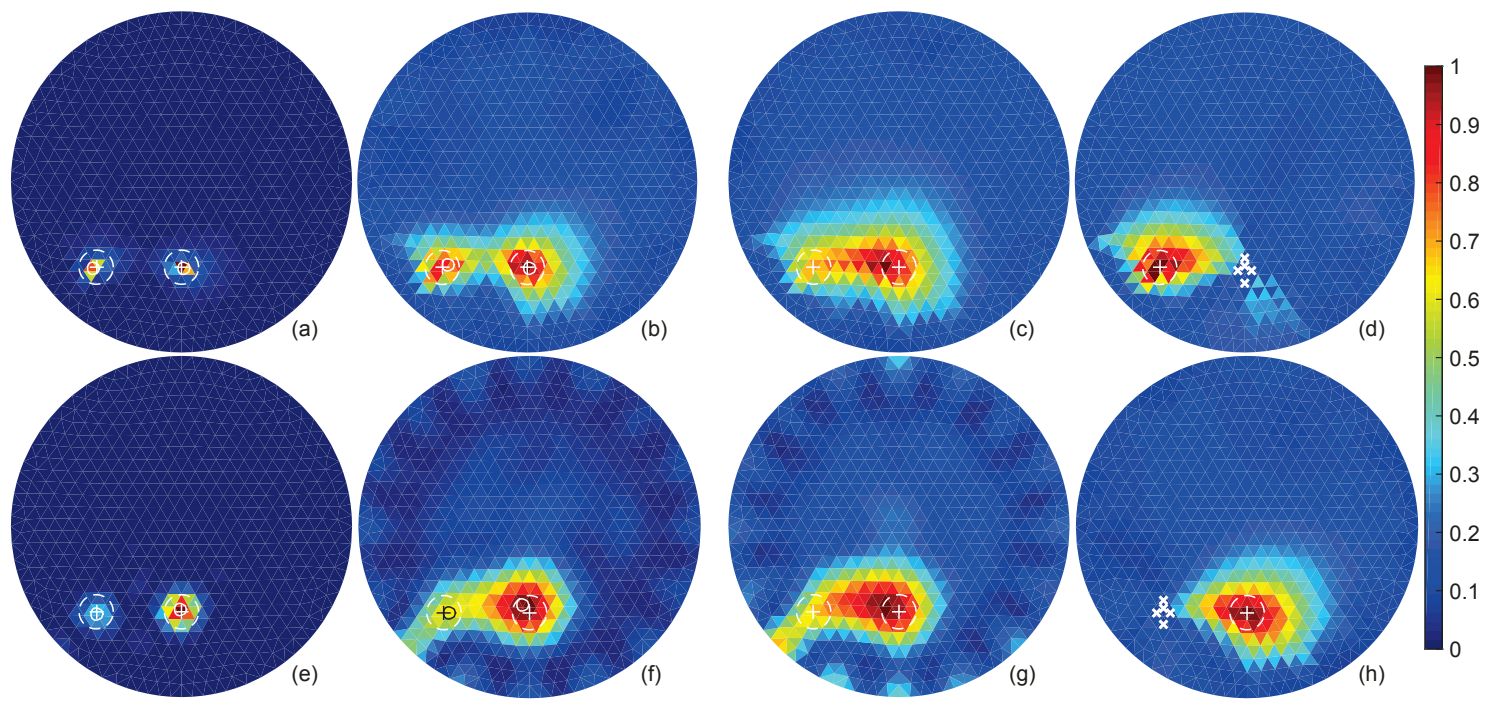

Figura 6.4: Simulación de dos cambios de conductividad simultáneos. (a-c) Mapas de CCI obtenidos con los conjuntos de datos (a) sin ruido, (b) con ruido aditivo y $\mathrm{SNR}=9$, y (c) con ruido aditivo y $\mathrm{SNR}=3$. (e-g) $\mathrm{RMS}^{2}$ de las imágenes obtenidas con el método GN-Laplace, para los mismos tres niveles de ruido respectivamente. (d) y (h), mapas de CCI con restricciones de ganancia nula aplicadas al conjunto de datos de $\mathrm{SNR}=3$ en las posiciones de las fuentes (d) derecha, y (h) izquierda. Los círculos punteados indican las regiones con conductividad dinámica y las cruces "+" sus centros verdaderos. Los círculos "o" indican los CoG obtenidos y las cruces blancas " $x$ " indican las posiciones de las restricciones de ganancia nula.

yor y el segundo mayor autovalor de $\mathbf{C}_{Y}, \lambda_{1}$ y $\lambda_{2}$, se eligió para el parámetro de regularización $\alpha_{n}$ de las matrices $\mathbf{C}_{\mathrm{Y}}{ }^{-1}$ del numerador de (6.12), mientras que un valor menor $\alpha_{d} \ll \lambda_{2}$ se eligió para las matrices $\mathbf{C}_{\mathrm{Y}}{ }^{-1}$ del denominador de (6.12) para mejorar la resolución (Sekihara y Nagarajan, 2008). Para calcular la salida del filtro espacial orientado hacia el elemento con máximo CCI se utilizó carga diagonal simétrica $\left(\alpha_{d}=\alpha_{n}=\alpha\right.$ ), eligiendo $\alpha=10 \lambda_{1}$ para mejorar la SNR de salida (ver Apéndice B). La Tablas 6.1 y 6.2 muestran el PE y la RES obtenidos con los dos métodos, para este caso bajo la columna "una sola fuente". 


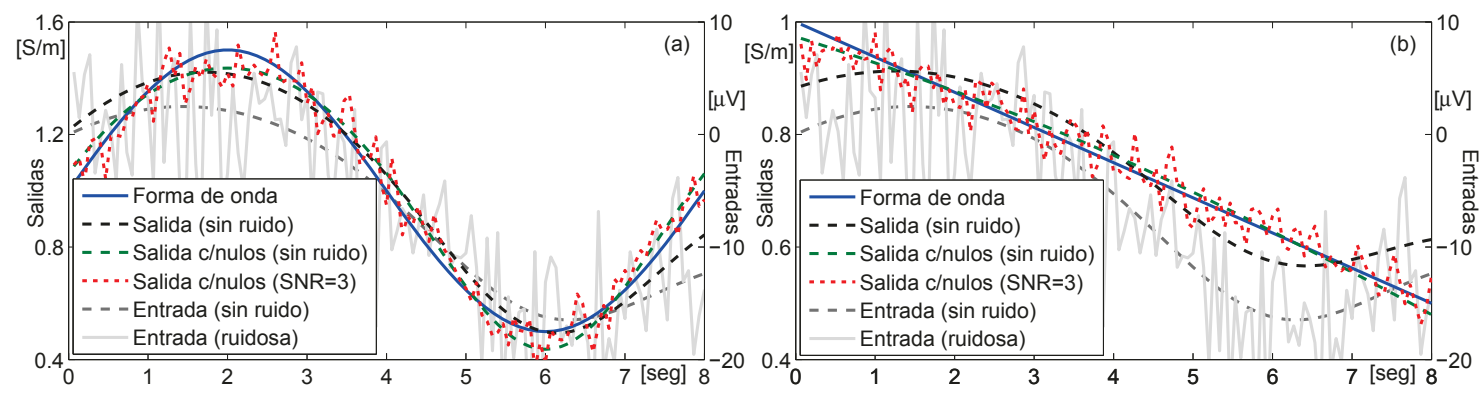

Figura 6.5: Formas de onda y salidas del filtro normalizadas para dos cambios de conductividad simultáneos asignados a la fuente de la izquierda (a) y a la de la derecha (b), tanto para el conjunto de datos sin ruido como para el conjunto de datos con ruido agregado $(\mathrm{SNR}=3$ ). Las mediciones simuladas en el electrodo más sensible para ambos conjuntos de datos también se muestran en el eje derecho $[\mu V]$.

Tabla 6.1: Error de Posición (PE) [mm].

\begin{tabular}{lcrrrrr}
\hline & \multicolumn{2}{c}{ Una sola fuente } & \multicolumn{4}{c}{ Dos fuentes simultáneas } \\
& & & \multicolumn{3}{c}{ SNR alto } & \multicolumn{3}{c}{ SNR=9 } \\
& SNR alto & SNR=3 & FD $^{\mathrm{a}}$ & $\mathrm{FF}^{\mathrm{b}}$ & $\mathrm{FD}^{\mathrm{a}}$ & $\mathrm{FF}^{\mathrm{b}}$ \\
\hline EIT-SF & 1,55 & 3,17 & 1,90 & 1,69 & 4,14 & 1,29 \\
GN-Laplace & 0,91 & 4,65 & 1,13 & 1,33 & 3,16 & 6,13 \\
\hline Diferencia & 0,64 & $-1,47$ & 0,77 & 0,36 & 0,98 & $-4,84$ \\
\hline
\end{tabular}

${ }^{a}$ Fuente Débil (izquierda). ${ }^{\mathrm{b}}$ Fuente Fuerte (derecha).

\section{Dos fuentes simultáneas}

Para dos fuentes en simultáneo, se simularon las señales utilizando el modelo virtual de la Fig. 6.1(b), asignando el cambio de conductividad lineal para la fuente de la región izquierda (azul), también llamada fuente débil, y el cambio de conductividad sinusoidal a la fuente de la región derecha (rojo), también llamada fuente fuerte. Los mapas de CCI que se obtuvieron con los datos sin ruido y con dos niveles de ruido adicionado se muestran en la Fig. 6.4, junto con las imágenes de RMS ${ }^{2}$ obtenidas con el método GN-Laplace. Obsérvese que con $S N R=9$, el método SF distingue ambas fuentes y el método de Laplace no, y que para $S N R=3$ ambos métodos detectan las dos fuentes como una sola. La misma figura también muestra los mapas de CCI que se obtuvieron al incorporar cinco restricciones de ganancia 
Tabla 6.2: Resolución (RES) $\left[\times 10^{-1}\right]$.

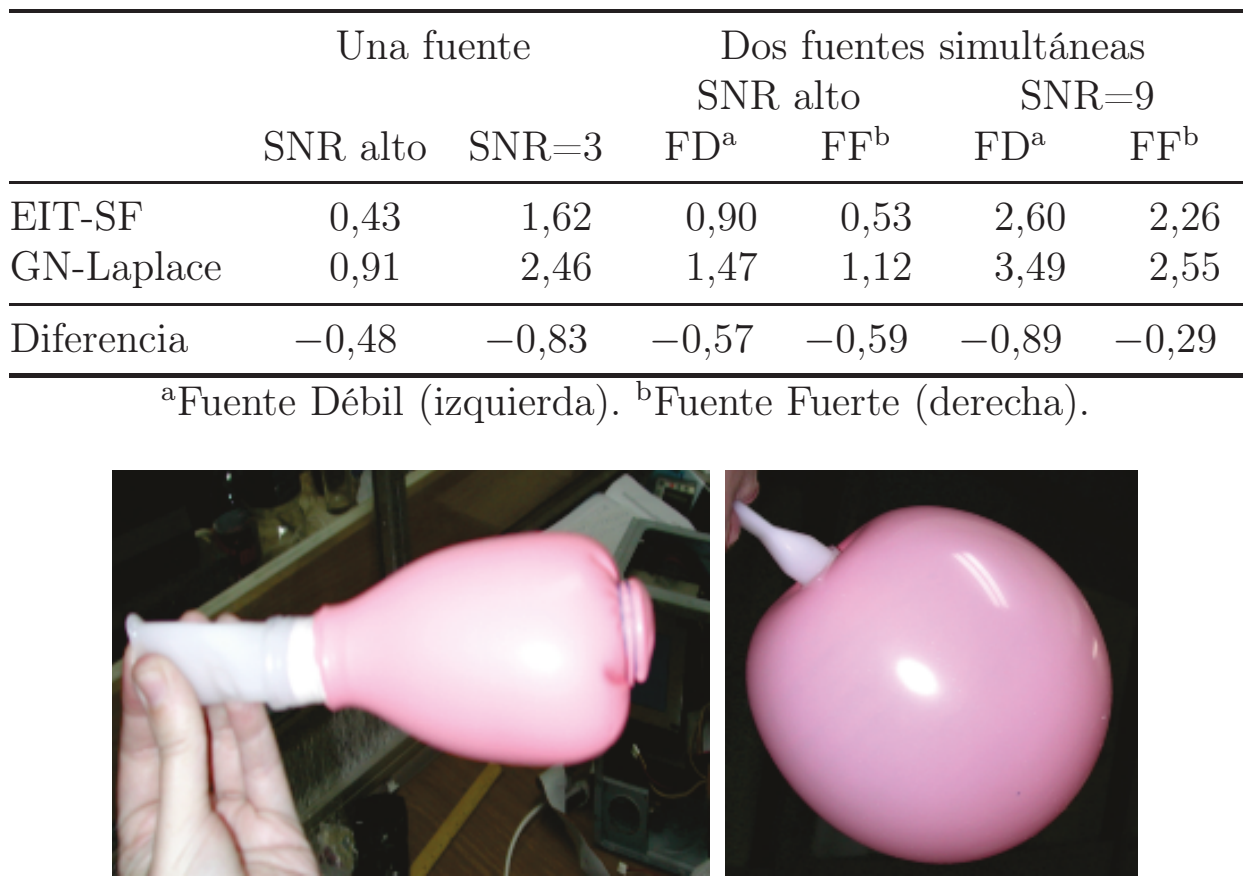

Figura 6.6: Fotos del globo en sus estados desinflado e inflado.

nula ubicadas sobre la posición de la fuente de la derecha. Esto permite mejorar la precisión en la detección de los cambios de conductividad. Los parámetros de regularización fueron elegidos de la misma manera que cuando se simuló un cambio de conductividad con la única diferencia que para el parámetro de regularización del numerador se eligió un valor entre el segundo y el tercer mayor autovalor de $\mathbf{C}_{\mathrm{Y}}$. La Fig. 6.5 muestra las salidas del filtro para cada cambio de conductividad donde también se observa la mejora en la calidad de las salidas cuando se utilizan restricciones de ganancia nulas. La Tablas 6.1 y 6.2 muestran el PE y la RES obtenidos con los dos métodos, para este caso bajo la columna "dos fuentes simultáneas".

\subsubsection{Filtro espacial bidimensional en mediciones reales}

Se probó el filtro espacial LCMV a mediciones reales de EIT tomadas sobre un tanque cilíndrico experimental de radio $11,5 \mathrm{~cm}$ lleno de agua salada. Se utilizó el globo de la Fig. 6.6 como objeto perturbador de la conductividad. Nótese que 

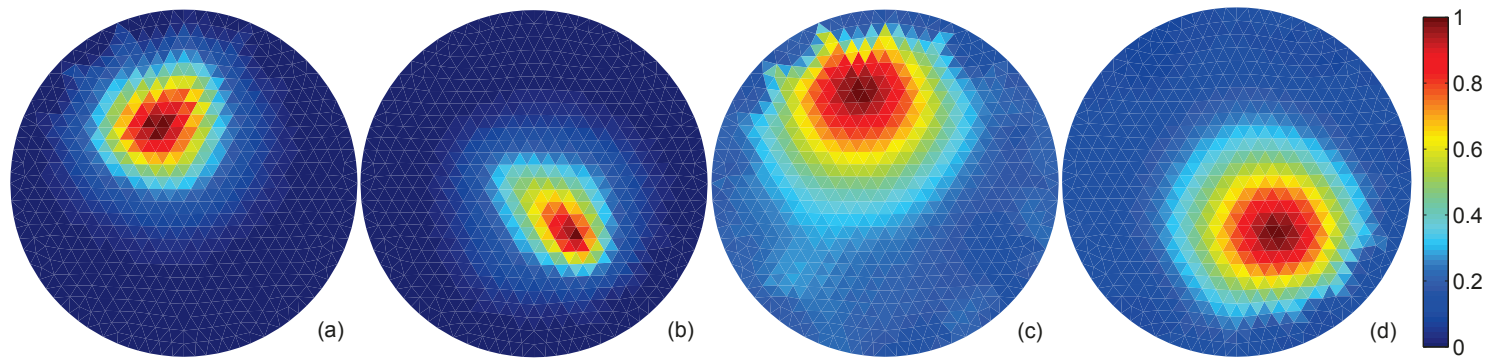

Figura 6.7: Mapas de CCI que se obtuvieron para el conjunto de datos reales con el objeto en dos posiciones diferentes: (a-b) señales sin ruido adicionado (SNR alto), y (c-d), señales con ruido adicionado $(\mathrm{SNR}=3)$

para simplificar la implementación de los experimentos, se utilizó un objeto de igual conductividad cambiando su tamaño, en lugar de un objeto de tamaño fijo y con cambios de conductividad como en las simulaciones. Esto es una aproximación y los resultados serían aún mejores con objetos de igual tamaño y diferente conductividad.

Las mediciones fueron adquiridas con el equipo de EIT experimental IMPETOM $C$. Se siguió el protocolo de pares de inyección y medición adyacentes Sheffield (Lionheart et al., 2004), utilizando una corriente de $1 \mathrm{~mA}$ pico. Se generaron un total de 16 conjuntos de 13 mediciones por instantánea. Debido a la gran diferencia entre la conductividad del objeto y la del agua salada, y debido también a la alta relación entre el diámetro del objeto y el del tanque, a las mediciones se las trató como señales sin ruido. Gracias a esta suposición, fue posible convertir el conjunto de datos Sheffield a un conjunto de datos completo con referencia de potencial eléctrico promedio y con 120 pares para la inyección de corriente.

Para estudiar un caso más realista, se generó un conjunto de datos con WGN aditivo con $S N R=3$. En todos los casos de cálculo de mapas de CCI y de estimación de la forma de onda se utilizó el mismo criterio para elegir los valores del parámetro de regularización que se utilizó con los datos simulados.

\section{Un cambio de conductividad}

Se midieron tres ciclos del objeto inflándose y desinflándose, para dos posiciones diferentes, a una velocidad de 15 instantáneas por segundo durante 20 segundos, 


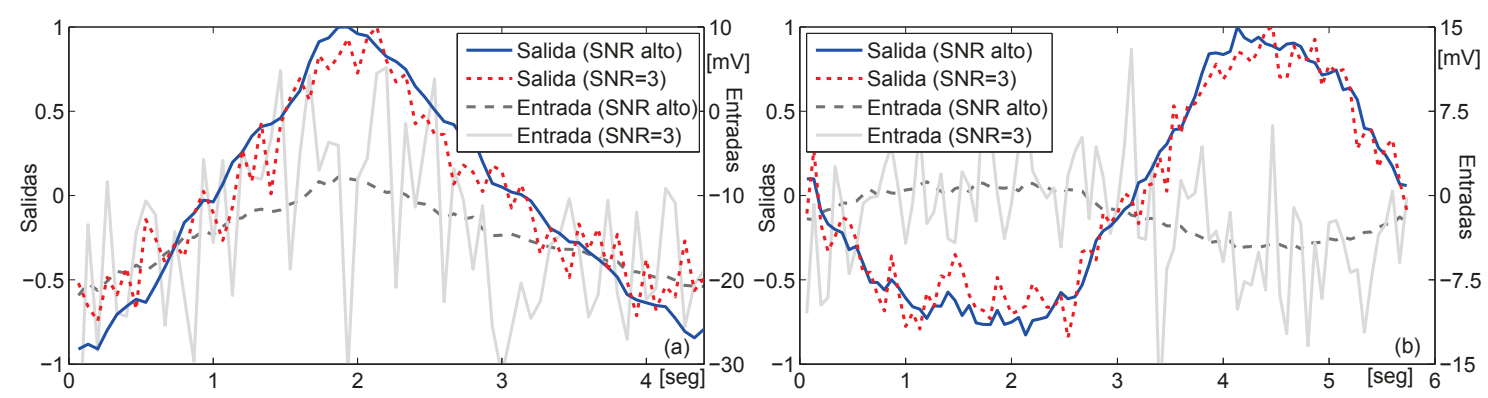

Figura 6.8: Salidas normalizadas del filtro espacial orientado hacia el elemento de máximo CCI, para las posiciones del objeto (a) arriba-izquierda y (b) abajo-derecha, y para alto y bajo SNR. También se muestra en la figura (eje derecho) el potencial eléctrico medido en el electrodo más sensible para ambos conjuntos de datos $[\mu V]$.

resultando en un total de 300 instantáneas por experimento. Los mapas de CCI se muestran en la Fig. 6.7 donde se puede observar la posición estimada del objeto. Para la posición de arriba a la izquierda (fuente más débil) se seleccionó una ventana de las mediciones donde el globo pasa de estar medianamente inflado a desinflado y a medianamente inflado nuevamente, y para la posición de abajo a la derecha (fuente más fuerte) se seleccionó un ciclo completo. Las estimaciones de los cambios de conductividad, es decir, las salidas del filtro para las señales con y sin ruido adicionado se muestran en la Fig. 6.8 para ambas posiciones. Se puede observar que las salidas son coherentes con las ventanas de los ciclos inflado-desinflado elegidas.

\subsubsection{Filtro espacial tridimensional en simulaciones}

Se simularon experimentos sobre un tanque cilíndrico virtual, emulando al tanque experimental de Electrical Geodesics Inc. para compararlos con los experimentos reales realizados sobre dicho tanque experimental. Tanto para las simulaciones como para los experimentos reales se utilizó un valor de corriente de $100 \mu V$ pico y se determinó el CoG según la Ec. (6.19) con un umbral de 0,95, mientras que para la RES se eligió un umbral de 0,75. Para el caso de dos fuentes simultáneas, se subdividió al dominio en dos regiones con un plano vertical como se muestra en la Fig. 6.9(c), y el PE y la RES de cada fuente fueron calculados independientemente en cada región. La malla utilizada para el problema inverso se muestra en la Fig. 6.10(a), 

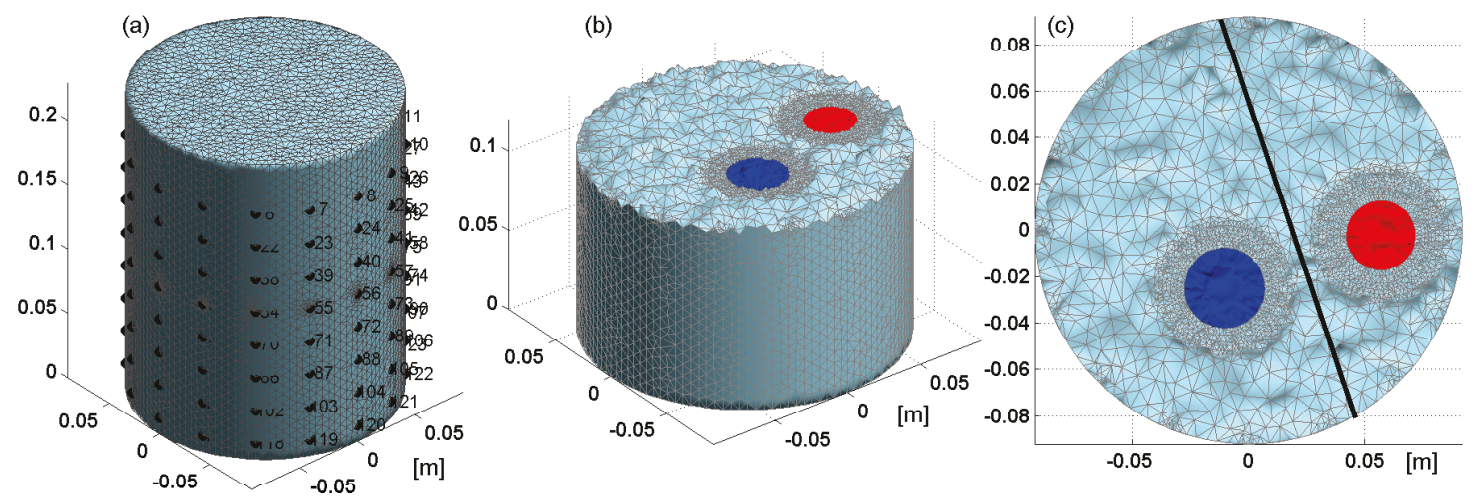

Figura 6.9: (a) Modelo virtual tridimensional del tanque cilíndrico utilizado para obtener las soluciones de EIT-SF y GN-Laplace. Los puntos "•" indican la ubicación de los electrodos. (b-c) Tanque virtual utilizado para generar las señales simuladas, cortado en $z=11 \mathrm{~cm}$. Las dos regiones esféricas con cambios de conductividad dinámicos se muestran en rojo (fuente del borde) y azul (fuente del centro). La línea recta en (c) indica el plano vertical divisorio que separa el dominio en dos para calcular los índices de desempeño de cada cambio de conductividad.

compuesta por aproximadamente 240000 tetraedros y con nodos en la ubicación de los electrodos.

Para generar las señales simuladas se construyó un modelo de elementos finitos de un tanque cilíndrico tridimensional de radio $9.2 \mathrm{~cm}$ y altura $22.85 \mathrm{~cm}$, con 128 electrodos en su frontera distribuidos en 8 anillos de 16 electrodos cada uno, y adoptando una conductividad base de $1,75 \mathrm{~S} / \mathrm{m}$. Se asignaron cambios dinámicos de conductividad a una y dos regiones esféricas (fuentes) de diámetro $3,5 \mathrm{~cm}$ como se muestra en la Fig. 6.9. Las señales se simularon para 88 combinaciones independientes de pares de inyección de corriente. La Fig. 6.9 también muestra la ubicación de los electrodos y la malla utilizada para generar las señales utilizando FEM. Se generaron 15 instantáneas para todas las señales simuladas, resultando en una matriz de datos $\mathbf{Y}$ de tamaño $11088 \times 15$. Se agregó WGN con desviación estándard $\sigma_{w}=0,2 \mu V$ para modelar mayormente el ruido electrónico de los amplificadores. Este valor de $\sigma_{w}$ se estimó de las mediciones obtenidas con el tanque experimental real. 

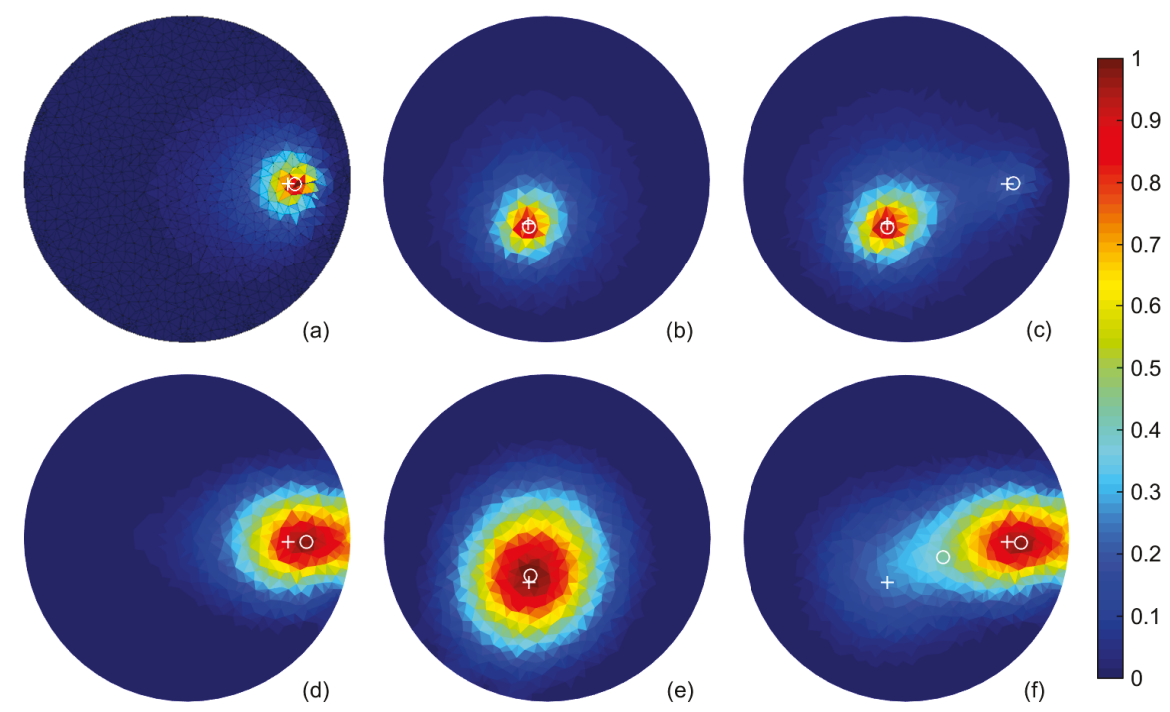

Figura 6.10: Mapas obtenidos con datos simulados: (a-c) mapas de CCI normalizados obtenidos con (a) la fuente del borde, (b) la fuente del centro, y (c) ambas fuentes en simultáneo. (d-f) RMS ${ }^{2}$ de las imágenes obtenidas con el método GN-Laplace para (d) la fuente del borde, (e) la fuente del centro y (f) ambas fuentes en simultáneo. Las cruces blancas "+" indican la posición central verdadera de los cambios de conductividad y los círculos blancos "o" indican los CoG obtenidos.
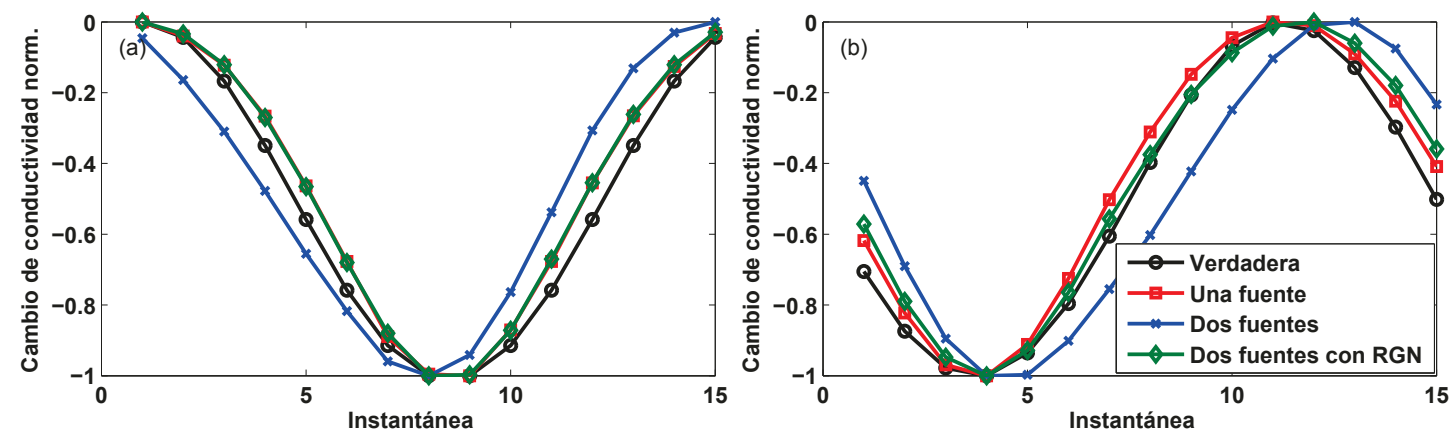

Figura 6.11: Salidas del filtro normalizadas para (a) la fuente del borde y (b) la fuente del centro. RGN significa "Restricciones de Ganancia Nula".

\section{Un cambio de conductividad}

Se simularon cambios de conductividad sinusoidales variando entre 1,75 S/m (conductividad base) y $0,08 \mathrm{~S} / \mathrm{m}$ (conductividad de los objetos utilizados en los experimentos reales) en dos ubicaciones diferentes: $(5,71,1,987 \pi, 11)$, aquí llamada fuente 
del borde, y $(2,71,1,375 \pi, 11)$ llamada fuente del centro. Nótese que las ubicaciones se expresan en coordenadas cilíndricas $(r[\mathrm{~cm}], \theta[\mathrm{rad}], z[\mathrm{~cm}])$. La Fig. 6.10(a,b,d,e) muestra los mapas de CCI normalizados y los $\mathrm{RMS}^{2}$ obtenidos con el método GNLaplace en un corte transversal. Se puede observar que ambos métodos detectan la fuente aunque EIT-SF lo hace con mejor resolución. La Fig. 6.11 muestra las salidas normalizadas del filtro espacial donde se observa la similitud entre la salida de una sola fuente y el cambio de conductividad verdadero. Para el parámetro de regularización tanto para computar el CCI como para calcular la salida del filtro se siguió el método de carga diagonal asimétrica (Sekihara y Nagarajan, 2008). Un valor entre el mayor y el segundo mayor autovalor de $\mathbf{C}_{\mathrm{Y}}, \lambda_{1}$ y $\lambda_{2}$, se eligió para el parámetro de regularización $\alpha_{n}$ de las matrices $\mathbf{C}_{\mathrm{Y}}{ }^{-1}$ del numerador de (6.12), mientras que un valor menor $\alpha_{d} \ll \lambda_{2}$ se eligió para las matrices $\mathbf{C}_{\mathrm{Y}}{ }^{-1}$ del denominador de (6.12). Las columnas "una fuente" bajo "datos simulados" de las Tablas 6.3 y 6.4 muestran el PE y la RES obtenidos. Para ambas fuentes tanto el PE como la RES son menores con EIT-SF que con GN-Laplace.

\section{Errores en la ubicación de los electrodos}

Se analizó el desempeño de la localización utilizando el método EIT-SF y el método GN-Laplace suponiendo ubicaciones de los electrodos aleatorias. Se generaron 10 conjuntos de datos diferentes para diez realizaciones en la ubicación de los electrodos suponiendo una distribución Normal con desviación estándar de $1 \mathrm{~mm}$ tanto en altura como en azimut. La Fig. 6.12 muestra las 10 realizaciones de la ubicación de los electrodos y los CoG obtenidos con ambos métodos para ambas fuentes. Allí se observa que el método EIT-SF presentó un menor PE aunque una mayor dispersión.

\section{Dos cambios de conductividad simultáneos}

También se simularon dos cambios de conductividad simultáneos en las regiones del centro (azul) y del borde (rojo) de la Fig. 6.9(b-c), asignando a cada uno una sinusoide con distinta fase. En la Fig 6.10(c) se muestra el mapa obtenido con EITSF y en la Fig. 6.10(f) se muestra la imagen de $\mathrm{RMS}^{2}$ obtenida con el método de GN-Laplace. Allí se observa que con EIT-SF se pueden distinguir ambas fuentes 

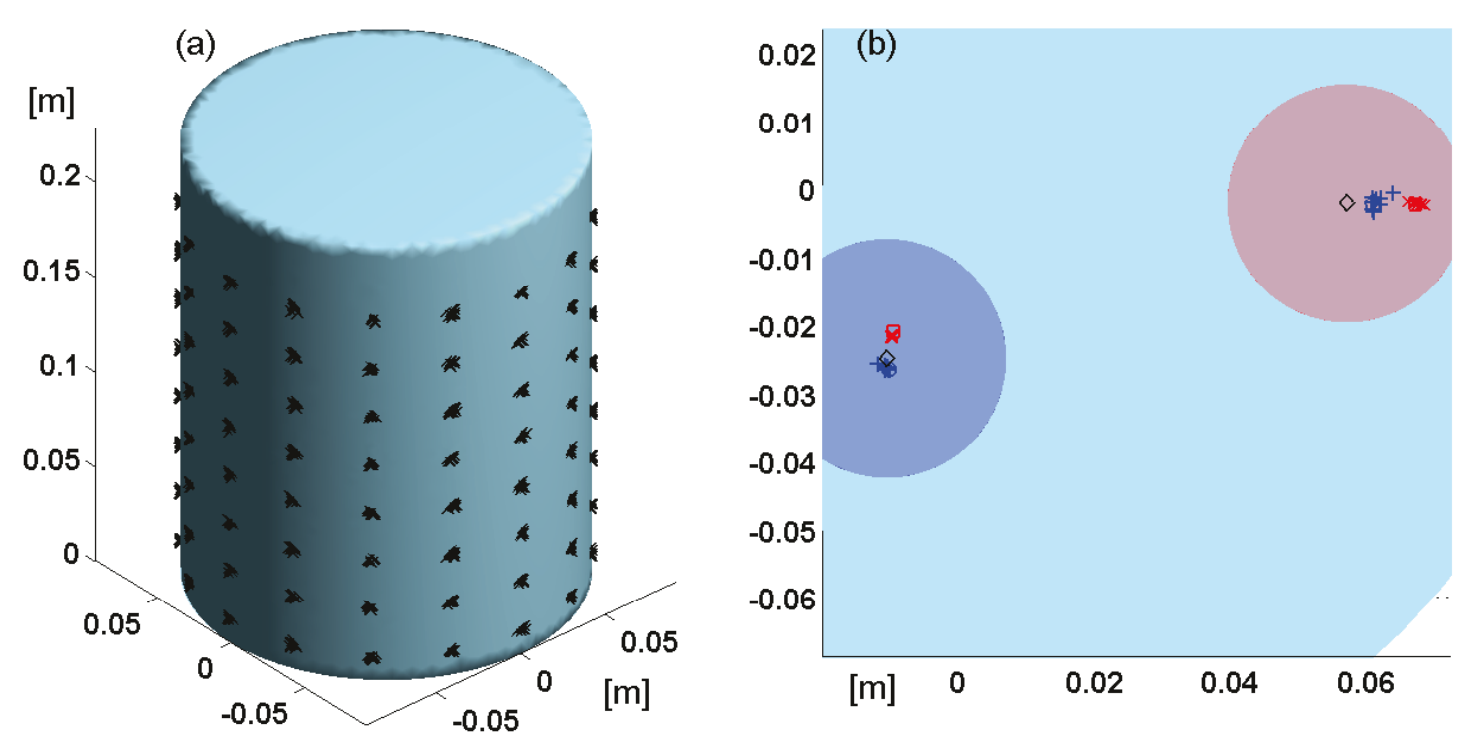

Figura 6.12: Simulaciones con ruido en la ubicación de los sensores. (a) Realizaciones de ubicación de los sensores utilizadas. (b) CoG obtenido con filtrado espacial ("+" azules) y con GN-Laplace ("X" rojas). Los círculos "o" y cuadrados " $\square$ " indican el CoG obtenido con filtrado espacial y GN-Laplace respectivamente sin considerar error en la ubicación de los sensores. Los rombos " $\diamond$ " indican el centro verdadero de las fuentes.
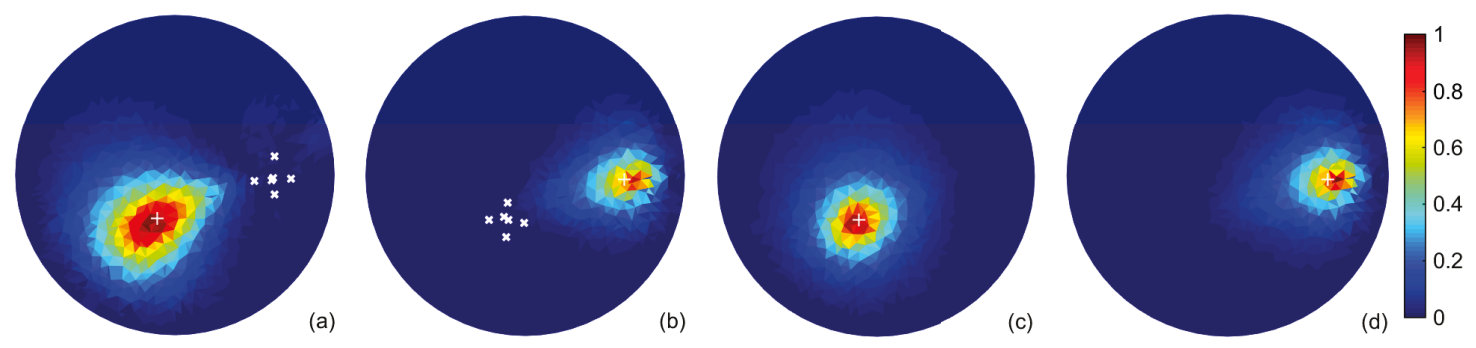

Figura 6.13: Resultados aplicando las variantes del filtro espacial LCMV. (a-b) Mapas de CCI con restricciones de ganancia nula. (c-d) Mapas de CCI con formas de onda de los cambios de conductividad conocidas. Las cruces blancas "+" señalan la posición central verdadera de las fuentes y las cruces blancas " $\times$ " indican las posiciones de las restricciones de ganancia nula.

mientras que con GN-Laplace no. La Fig. 6.13 muestra los mapas de CCI obtenidos con siete restricciones de ganancia nula colocadas en cada una de las fuentes y los 

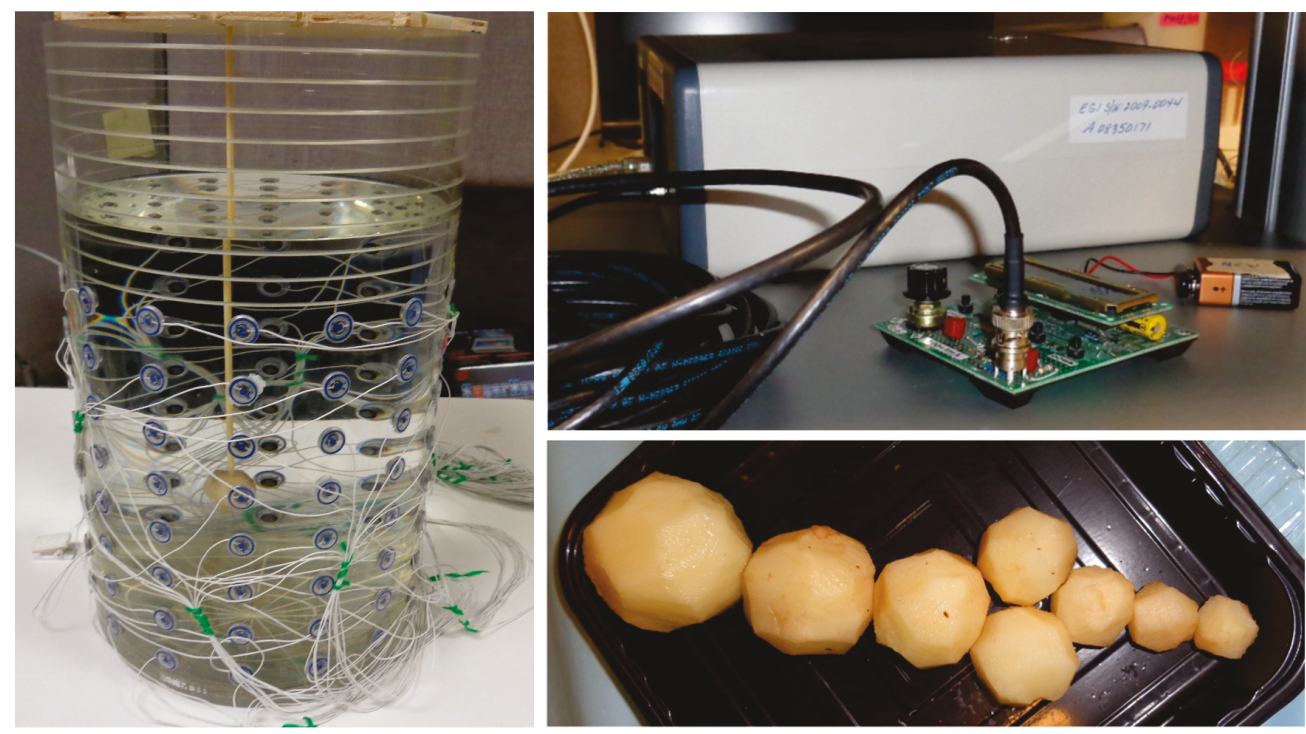

Figura 6.14: Tomógrafo de EIT experimental AMP300, de Electrical Geodesics Inc, Eugene, Oregon, Estados Unidos. (Izquierda) Tanque experimental. (Arriba a la derecha) Equipo de adquisición y selección de pares de inyección con una fuente de corriente externa. (Abajo a la derecha) Papas utilizadas en los experimentos.

mapas obtenidos suponiendo cambios de conductividad conocidos. La malla no se muestra para una mejor claridad de las imágenes. Se pueden observar las mejoras al utilizar estas variantes de LCMV en la detección y en la precisión de la localización. El parámetro de regularización se eligió de manera similar al caso de una sola fuente con la única diferencia que para el parámetro de regularización del numerador se eligió un valor entre el segundo y el tercer mayor autovalor de $\mathbf{C}_{\mathrm{Y}}$. Las salidas del filtro o estimaciones de las formas de onda se muestran en la Fig. 6.11 donde se observa la reducción de la interferencia o leakage de la otra fuente cuando se aplican restricciones de ganancia nulas. Las columnas "dos fuentes" bajo "datos simulados" de las Tablas 6.3 y 6.4 muestran los valores PE y RES obtenidos. Para ambas fuentes los valores tanto de PE como de RES son menores con EIT-SF que con GN-Laplace.

\subsubsection{Filtro espacial tridimensional en mediciones reales}

Se probó el filtro LCMV con mediciones reales de EIT obtenidas en un tanque cilíndrico experimental de radio $9,2 \mathrm{~cm}$ y altura $22,85 \mathrm{~cm}$ lleno con agua salada de 
Tabla 6.3: Error de Posición (PE) [mm].

\begin{tabular}{lcccccccc}
\hline & \multicolumn{3}{c}{ Datos simulados } & \multicolumn{4}{c}{ Datos reales } \\
& Una fuente & \multicolumn{2}{c}{ Dos fuentes } & \multicolumn{2}{c}{ Una fuente } & \multicolumn{2}{c}{ Dos fuentes } \\
& Borde & Centro & Borde & Centro & Borde & Centro & Borde & Centro \\
\hline EIT-SF & 3,89 & 2,05 & 4,42 & 2,15 & 8,51 & 7,28 & $N / D^{\text {a }}$ & 6,50 \\
GN-Laplace & 10,1 & 4,40 & 7,94 & $N / D^{\text {a }}$ & 12,1 & 7,71 & 10,8 & $N / D^{\text {a }}$ \\
\hline
\end{tabular}

${ }^{a} \mathrm{El} \mathrm{CoG} \mathrm{se} \mathrm{encuentra} \mathrm{sobre} \mathrm{el} \mathrm{plano} \mathrm{divisorio} \mathrm{entre} \mathrm{las} \mathrm{dos} \mathrm{fuentes.}$

conductividad 1,75S/m, y utilizando papas (conductividad de 0,08S/m según (Halden et al., 1990)) de diferentes tamaños (Fig. 6.14) como los objetos que perturban la conductividad base del agua salada. Los objetos colocaron en dos ubicaciones diferentes sosteniéndolos mediante un palillo de madera, en las siguientes coordenadas aproximadas: $(5,71,1,987 \pi, 11)$ para la fuente del borde y $(2,71,1,375 \pi, 11)$ para la fuente del centro (expresadas en coordenadas cilíndricas $(r[\mathrm{~cm}], \theta[\mathrm{rad}], z[\mathrm{~cm}]))$. Nótese que las ubicaciones son las mismas tanto para las simulaciones como para los experimentos reales. Se utilizaron siete objetos diferentes con diámetros aproximados de $2,2,5,3,3,5,4,4,5$ y $5 \mathrm{~cm}$. Las mediciones fueron realizadas con el equipo experimental de baja frecuencia AMP 300 descripto en la sección 2.3.5. El diseño del tanque experimental, el instrumental y el sistema de adquisición se describen en Esler et al. (2010), y el diseño para este experimento en particular se muestra en la Fig. 6.14. En la misma figura se pueden observar los electrodos estándar de EEG $(\mathrm{Ag} / \mathrm{AgCl})$ con anillos de goma colocados en los orificios de manera hermética. Son 128 electrodos organizados uniformemente sobre la superficie lateral en 8 filas y 16 columnas. Los electrodos se conectaron al equipo de EIT mediante cables estándar de EEG (Electric Geodesics, Inc.). Las mediciones se realizaron para 88 pares de inyección de corriente con niveles de corriente de $100 \mu \mathrm{V}$ (pico) y frecuencia $27 \mathrm{~Hz}$, utilizando un protocolo que involucra electrodos opuestos en la misma fila o filas adyacentes, generando entonces un total de 88 conjuntos de 126 mediciones de potencial por tamaño del objeto y por posición. Un sistema de lazo de enganche de fase permitió extraer la amplitud y fase de los datos de EIT crudos (Poolman et al., 2008). Para cada conjunto de mediciones se obtuvieron cuatro muestras de amplitud y fase promediando y grabando períodos de 4 segundos para cada par y utilizando 

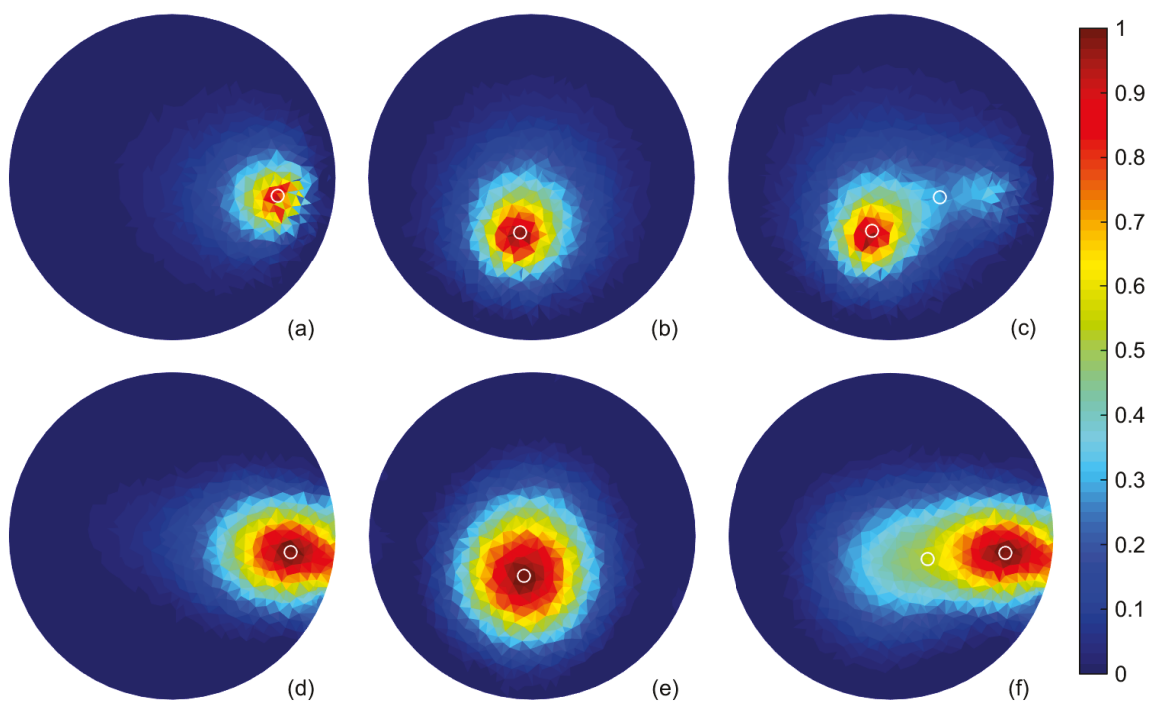

Figura 6.15: Mapas de CCI normalizados obtenidos con datos reales: (a) fuente del borde, (b) fuente del centro y (c) ambas fuentes en simultáneo. Imágenes de RMS ${ }^{2}$ normalizado obtenidas con el método de GN-Laplace para: (d) la fuente del borde, (e) la fuente del centro y (f) ambas fuentes en simultáneo. Los círculos blancos "o" señalan el CoG calculado.
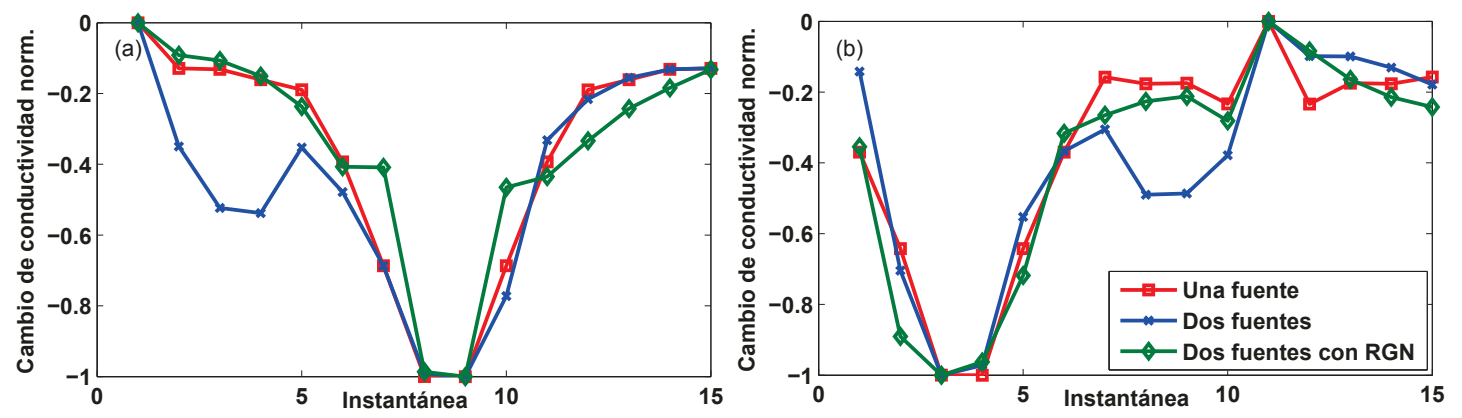

Figura 6.16: Salidas del filtro para los datos reales, para (a) la fuente del borde y (b) la fuente del centro. RGN significa "Restricciones de Ganancia Nula".

una ventana deslizante de 1 segundo.

\section{Un cambio de conductividad}

La dinámica temporal se construyó ordenando las mediciones de los objetos de distintos tamaños con los ordenamientos $0,1,2,3,4,5,6,7,7,6,5,4,3,2$, 1 у 
Tabla 6.4: Resolución (RES) $\left[\times 10^{-4}\right]$.

\begin{tabular}{|c|c|c|c|c|c|c|c|c|}
\hline & \multicolumn{4}{|c|}{ Datos simulados } & \multicolumn{4}{|c|}{ Datos reales } \\
\hline & \multicolumn{2}{|c|}{ Una fuente } & \multicolumn{2}{|c|}{ Dos fuentes } & \multicolumn{2}{|c|}{ Una fuente } & \multicolumn{2}{|c|}{ Dos fuentes } \\
\hline & Borde & Centro & Borde & Centro & Borde & Centro & Borde & Centro \\
\hline EIT-S & 2,10 & 3,67 & 5,30 & 4,88 & 5,55 & 23,8 & $N / D^{\mathrm{a}}$ & 17,2 \\
\hline GN-Laplace & 33,6 & 73,7 & 32,7 & $N / D^{\mathrm{a}}$ & 35,2 & 63,6 & 39,6 & $N / D^{\mathrm{a}}$ \\
\hline
\end{tabular}

${ }^{a} \mathrm{El} \mathrm{CoG} \mathrm{se} \mathrm{encuentra} \mathrm{sobre} \mathrm{el} \mathrm{plano} \mathrm{divisorio} \mathrm{entre} \mathrm{las} \mathrm{dos} \mathrm{fuentes.}$

$5,6,7,7,6,5,4,3,2,1,0,1,2,3,4$ para las posiciones del borde y del centro respectivamente. En los mencionados ordenamientos " 0 " significa que no hay objeto presente, "1" significa que está el objeto de menor tamaño y "7" significa la medición con el objeto de mayor tamaño. Se utilizaron distintas muestras de las 4 disponibles para una misma ubicación y tamaño de objeto. Los mapas de CCI y de $R M S^{2}$ obtenidos con ambos métodos se muestran en la Fig. 6.15(a,b,d,e), donde nuevamente se observa la detección de las fuentes y la mejor resolución de EIT-SF. Las salidas o evolución de los cambios de conductividad se muestran en la Fig. 6.16 para ambas ubicaciones y son en general coherentes con los ordenamientos utilizados salvo cuando los objetos son muy pequeños y se encuentran más lejos del borde del tanque. Las columnas "una fuente" bajo "datos reales" de las Tablas 6.3 y 6.4 muestran los valores de PE y RES obtenidos. Para ambas fuentes tanto el PE como la RES son menores con EIT-SF que con GN-Laplace.

\section{Dos cambios de conductividad}

El PD de EIT es teóricamente no lineal para cambios de conductividad simultáneos en diferentes posiciones. Sin embargo, para simplificar los experimentos, se estudió el efecto de sumar las mediciones de dos cambios de conductividad en distintas posiciones no simultáneos para imitar dos cambios de conductividad simultáneos. Para ello, se realizó una simulación con los dos objetos por separado y otra con los dos objetos en simultáneo. Los objetos se simularon como dos regiones de cambio de conductividad de tamaños cambiantes y conductividad fija igual a $0,08 \mathrm{~S} / \mathrm{m}$, en lugar de regiones con conductividad cambiante y tamaño fijo como en las simulaciones de 
la sección 6.3.3. Se obtuvieron dos conjuntos de datos, uno con los dos objetos en simultáneo (no linealidad) y otro sumando las mediciones simuladas considerando ambos objetos pero de a uno por vez (suposición lineal). Se encontró que el error al suponer linealidad era menor que el nivel de ruido de las mediciones. Explícitamente, la mayor diferencia entre las mediciones obtenidas con el modelo no lineal y las obtenidas suponiendo linealidad fue de $0,25 \mu \mathrm{V}$, menor que dos veces la desviación estándar de ruido, como se ve en la Fig. 6.17. Por ende, aunque no se realizaron mediciones reales en el tanque experimental con dos objetos en simultáneo, y basándose en el análisis previo, se construyó un conjunto de datos para dos objetos combinando los conjuntos de datos reales obtenidos para las dos posiciones de un solo objeto en el tanque.

La Fig. 6.15(c,e) muestra los mapas de CCI obtenidos con EIT-SF y con GNLaplace. En ambos casos se observa que una fuente es detectada con claridad mientras que la otra es apenas visible. La Fig. 6.18 muestra los mapas utilizando siete restricciones de ganancia nula en las regiones de las fuentes y los obtenidos con la suposición de formas de onda conocidas (obtenidas de los experimentos con una sola fuente). Se observa la mejora en la detección, sobre todo para la fuente que era apenas visible sin utilizar estas variantes de LCMV. En la Fig. 6.16 se muestran las salidas del filtro orientado hacia la posición central de las fuentes. Como en los datos simulados se puede observar que la utilización de restricciones de ganancia nulas disminuye la interferencia o leakage entre fuentes. Las columnas "dos fuentes" bajo "datos reales" de las Tablas 6.3 y 6.4 muestran los valores de PE y RES obtenidos para la fuente que se detectó con cada método.

\subsection{Resultados particulares con aplicaciones en el cerebro}

En esta sección se presentan resultados obtenidos al aplicar las técnicas de filtrado espacial en EIT a mediciones simuladas sobre modelos geométricos realistas de la cabeza humana. En primer lugar se realizó un estudio de simulación con sólo dos instantáneas (EIT estático) y con un sólo cambio de conductividad en una esfera 


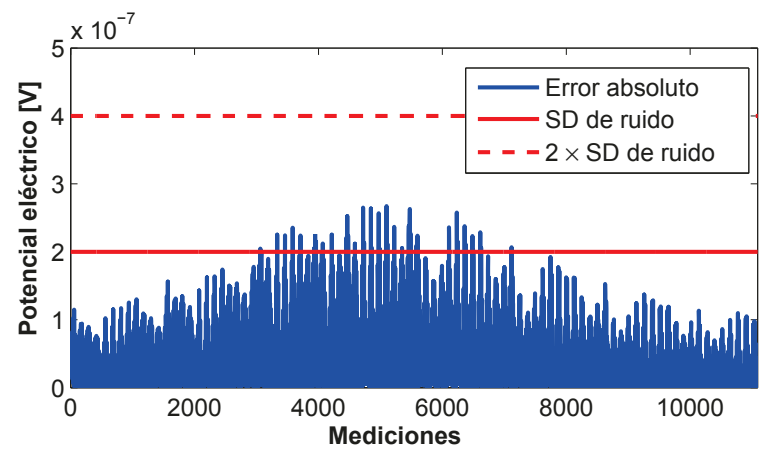

Figura 6.17: Para construir el conjunto de datos de mediciones reales con dos objetos en simultáneo se supuso linealidad en el problema. La línea azul muestra el error cometido al realizar esta suposición en una simulación imitando el escenario real. Se puede observar que el error es siempre menor que dos veces la desviación estándar de ruido estimada de las mediciones reales.
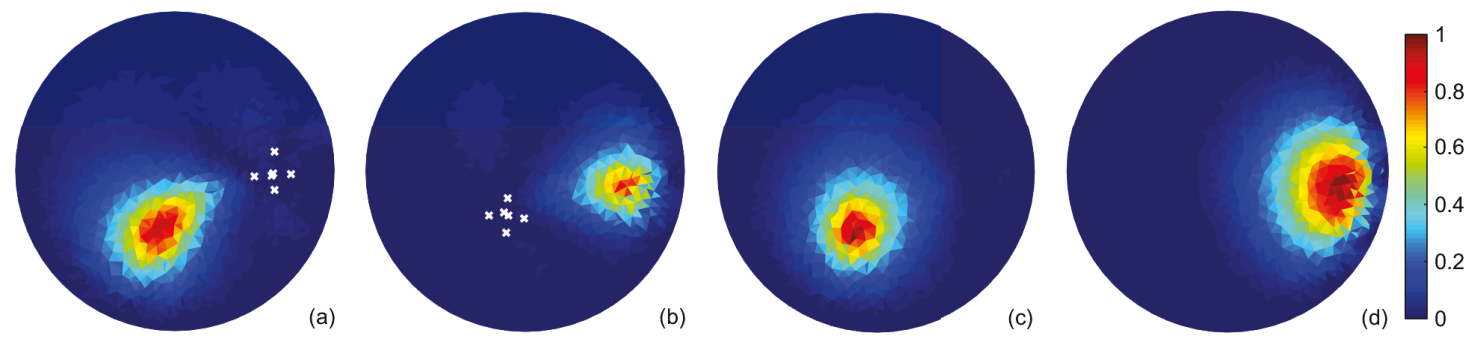

Figura 6.18: Variantes del filtro LCMV aplicadas a datos reales. (a-b) Mapas de CCI con restricciones de ganancia nula. (c-d) Mapas de CCI con conocimiento de la forma de onda de los cambios de conductividad. Las cruces " $\times$ " señalan la posición de las restricciones de ganancia nula.

ubicada entre el lóbulo temporal y el lóbulo frontal derechos. En este estudio se analizó el efecto de la varianza de ruido y del número de sensores. Luego se realizó otro estudio donde se incorporaron más instantáneas (EIT dinámico), en tres posiciones diferentes de la cabeza. En este estudio se estimaron las evoluciones de los cambios de conductividad en geometrías realistas y se analizó el efecto de utilizar geometrías diferentes para el proceso de localización. 


\subsubsection{Análisis de ruido y número de sensores}

Se realizó un estudio de simulación generando un incremento del $10 \%$ de la conductividad base en una pequeña esfera de radio 1cm ubicada sobre el lado derecho del cerebro en la unión del lóbulo parietal y frontal. Para generar las señales simuladas se utilizó un modelo de cabeza realista de tres capas. Se supuso un arreglo de 64 electrodos siguiendo el sistema de posicionamiento estándar de EEG 10 - 10. Como se supone la utilización de los mismos electrodos que en EEG, donde la superficie de los electrodos es mucho menor a la superficie exterior de la cabeza, los electrodos pueden ser modelados como puntuales sin superficie (Paulson et al., 1992). El problema directo de EIT se resolvió utilizando el FEM, tanto para la generación de las señales simuladas como para calcular el Jacobiano necesario para el problema inverso. Una vez más, se utilizó una discretización diferente, (regular, con 314798 tetraedros para el cerebro) para el problema inverso. Se adoptó un valor de $100 \mu \mathrm{A}$ pico para la corriente inyectada, valor máximo permitido según la norma IEC60601 (Gilad et al., 2007; IEC60601, 2005). Para el cuero cabelludo y para el cráneo se adoptaron valores de conductividad anisótropas y homogéneas con relaciones radial:tangencial de $1: 1.5(0,3$ y $0,45 \mathrm{~S} / \mathrm{m})$ y $1: 10(0,0015$ y $0,015 \mathrm{~S} / \mathrm{m})$ respectivamente (Rush y Driscoll, 1968; Horesh, 2006). Para el cerebro se adoptó una conductividad isótropa y homogénea con un valor de $0,4 \mathrm{~S} / \mathrm{m}$.

Se modeló al ruido electrónico debido a los amplificadores, al contacto electrodopiel y a otros posibles cambios de conductividad que no son de interés como ruido blanco gaussiano independiente entre canales. Otra fuente de ruido es la actividad eléctrica del cerebro, pero su efecto podría ser mitigado según se hace en Gonçalves et al. (2003), o siguiendo la metodología del capítulo 4.

Se eligió $\mathbf{C}_{n}=2 \sigma_{w}^{2} \mathbf{I}_{M(L-2)}$, donde $\sigma_{w}$ es la desviación estándar (SD) del ruido, el factor 2 es consecuencia de la diferencia entre $\mathbf{m}_{t} \mathrm{y} \mathbf{m}_{i}$ de EIT en diferencias (Ec. (2.43)), e $\mathbf{I}_{M(L-2)}$ es la matriz identidad de tamaño $M(L-2)$. Se realizaron simulaciones para tres niveles de ruido diferentes, con $\sigma_{w}$ igual a $1 \times 10^{-7} \mathrm{~V}, 1 \times 10^{-8} \mathrm{~V}$, y $1 \times 10^{-9} \mathrm{~V}$. Para estudiar la influencia del número de mediciones, se simularon dos

patrones de inyección de corriente, uno con 63 pares utilizando como un electrodo 


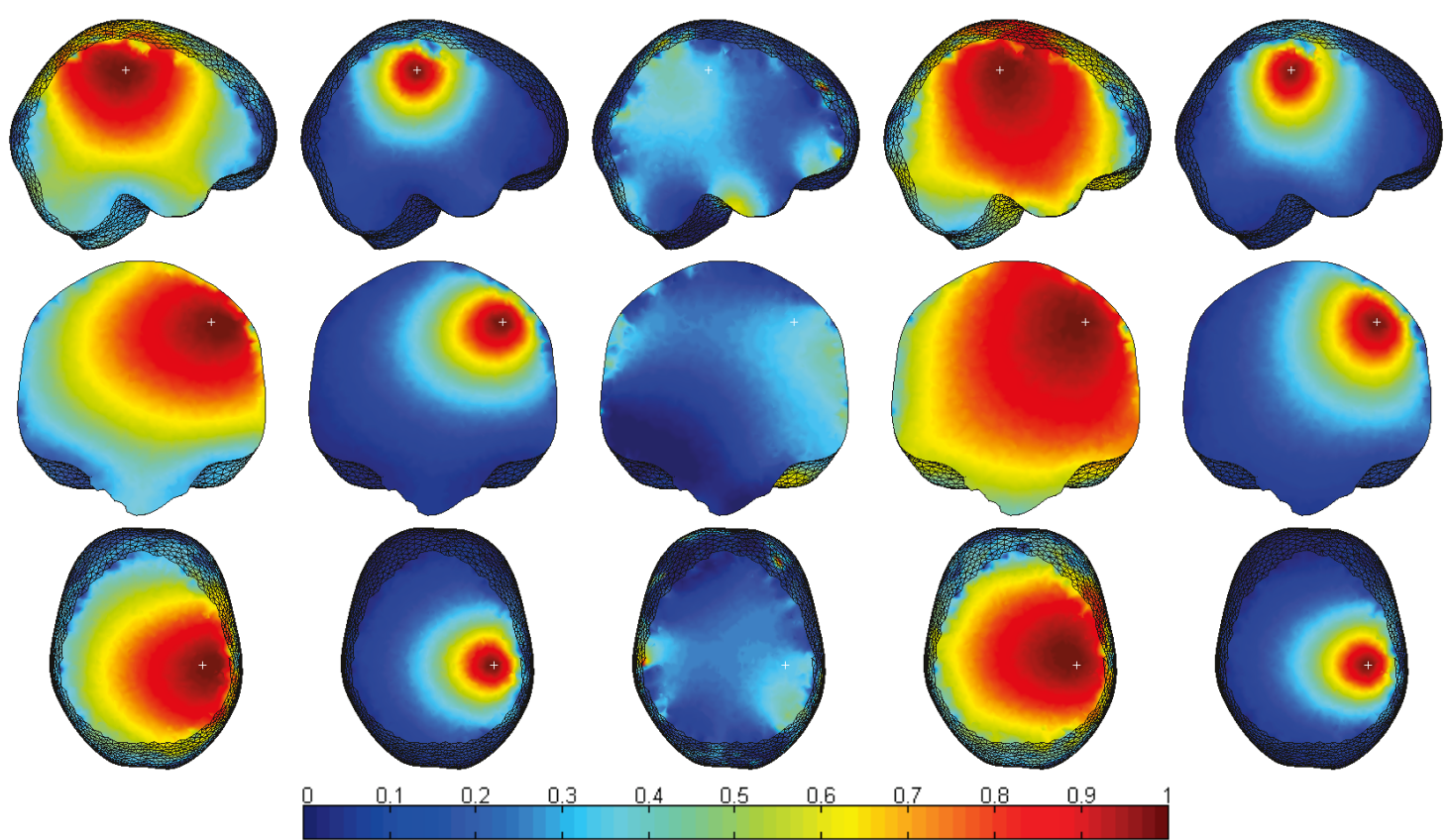

Figura 6.19: Secciones transversales de la cabeza ilustrando los mapas de CCI normalizados obtenidos con 63 (primeras dos columnas) y 125 (últimas tres columnas) pares de inyección y con SD de ruido $1 \times 10^{-7} \mathrm{~V}$ (tercera columna), $1 \times 10^{-8} \mathrm{~V}$ (primera y cuarta columnas), y $1 \times 10^{-9} \mathrm{~V}$ (segunda y última columnas). Las cruces blancas "+"señalan el centro verdadero de las regiones con cambio de conductividad.

siempre al electrodo $\mathrm{Cz}$, y otro con $M=125$ pares o combinaciones, utilizando a los electrodos Pz y Fz como uno de los electrodos de cada par. Los mapas de CCI fueron calculados para ambos patrones y para los tres niveles de ruido y se muestran en la Fig. 6.19.

Como indicador de desempeño se utilizó el Error de Posición (PE) con un umbral para el CoG de 0,95. Se simularon 20 realizaciones diferentes para cada patrón de inyección de corriente y para cada nivel de ruido. El PE se muestra en la Fig. 6.20, donde las simulaciones con $1 \times 10^{-7}$ de SD de ruido fueron excluidas para una mayor claridad. 


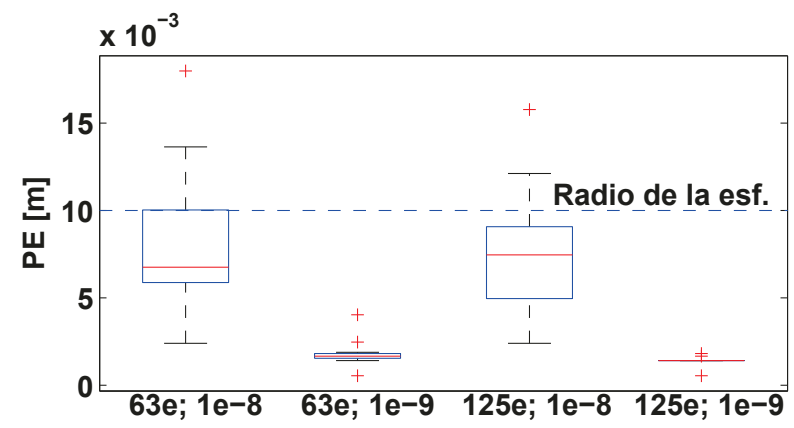

Figura 6.20: Error de Posición para 63 y 125 pares de inyección y para los tres niveles de ruido. La marca central es la media, los bordes son los percentiles 25 y 75 , y lo bigotes se extienden hasta los valores extremos no considerados atípicos. Las cruces rojas son valores considerados atípicos.

\subsubsection{Análisis de la dinámica y la geometría}

Se realizaron simulaciones sobre modelos de geometría realistas de tres capas, modelando tanto al cráneo como al cuero cabelludo de manera anisótropa y homogénea con relaciones de anisotropía 1 : 1,5 para el cuero cabelludo y 1 : 10 para el cráneo como en la sección anterior. El cerebro se modeló como un tejido isótropo y homogéneo de conductividad base $0,4 S / m$ salvo por una pequeña esfera de radio $1 \mathrm{~cm}$ a la que se le asignó un cambio de conductividad variable. Se simularon dos cambios de conductividad diferentes: un decrecimiento lineal hasta el $30 \%$ de la conductividad base (simulando un accidente cerebro-vascular isquémico (Horesh, 2006)) y un pulso de forma de campana gaussiana con un pico máximo de $10 \%$ de la conductividad base (simulado activación neuronal (Abascal et al., 2008)). La esfera con conductividad dinámica, de radio $1 \mathrm{~cm}$ y volumen aproximado $4,22 \mathrm{~cm}^{3}$ fue ubicada en tres posiciones diferentes: cerca de la corteza motora (P1), en la circunvolución temporal superior (P2), y próxima a la ínsula (P3). La geometría utilizada para generar las señales simuladas, las tres posiciones analizadas y las dos formas de onda se muestran en la Fig. 6.21.

Se simularon las señales suponiendo 64 electrodos y los 63 pares de inyección de corriente dejando el electrodo $\mathrm{Cz}$ fijo. Se generó entonces un vector de señales $\mathbf{Y}$ de 3906 elementos y 21 columnas correspondientes a los 21 instantes de tiempo simula- 

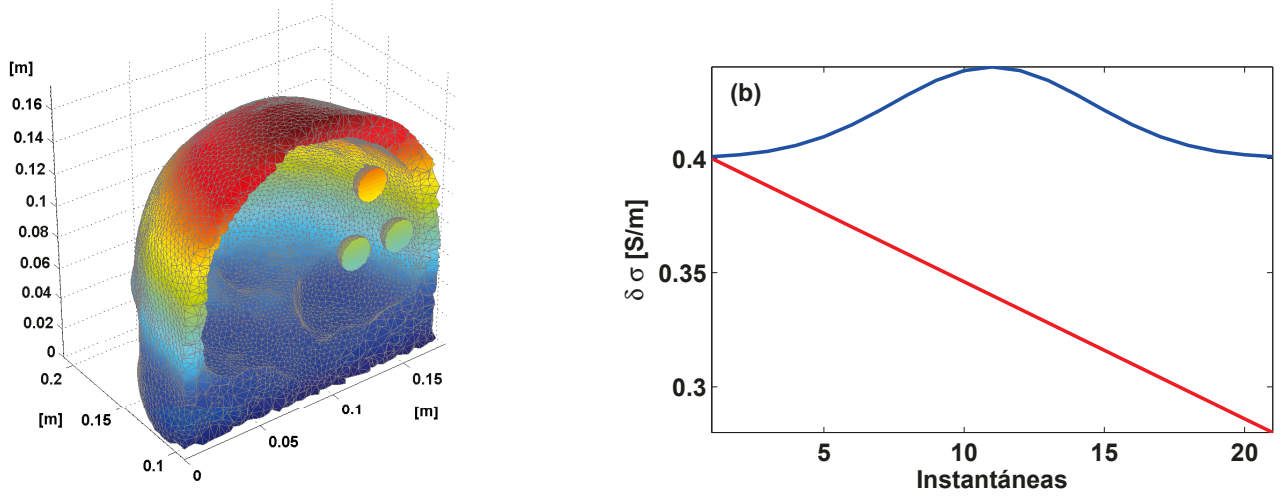

Figura 6.21: (a) Modelo utilizado para generar las señales simuladas con las tres ubicaciones de la esfera con conductividad dinámica. (b) Formas de onda de los cambios de conductividad simulados en cada una de las tres posiciones

dos. El problema directo se resolvió utilizando el FEM con un valor de corriente pico de $100 \mu \mathrm{A}$. Además se adicionó ruido blanco gaussiano con diferentes desviaciones estándar (SD).

De las señales simuladas se realizó la localización y estimación de la forma de onda con tres modelos de cabeza diferentes: propio del sujeto (M1), basado en el atlas ICBM 152 (Mazziotta et al., 2001) (M2), y modelo esférico de tres capas (M3). Los distintos modelos fueron corregistrados al modelo basado en atlas mediante una transformación afín (rotación, traslación y escala) utilizando la ubicación de los electrodos como los puntos fijos a registrar. En todos los casos se calculó el PE y la RES con un umbral de 0,8 .

En la Fig.6.22 se muestran tres ejemplos de los mapas de CCI obtenidos, para tres posiciones diferentes y tres niveles de ruido distintos. En la Fig. 6.23 se muestran los resultados de la localización utilizando el modelo específico del sujeto para las tres posiciones, las dos formas de onda y los distintos niveles de ruido analizados. Las tablas 6.5 y 6.6 resumen los valores de PE y de RES obtenidos.

En la Fig. 6.24 se muestran las salidas del filtro para los tres niveles de ruido y para ambas formas de onda, para la fuente ubicada en la circunvolución temporal superior y en la Fig. 6.25 se muestran los resultados para la localización con un modelo de cabeza diferente, para la forma de onda de pulso gaussiano sin ruido y 

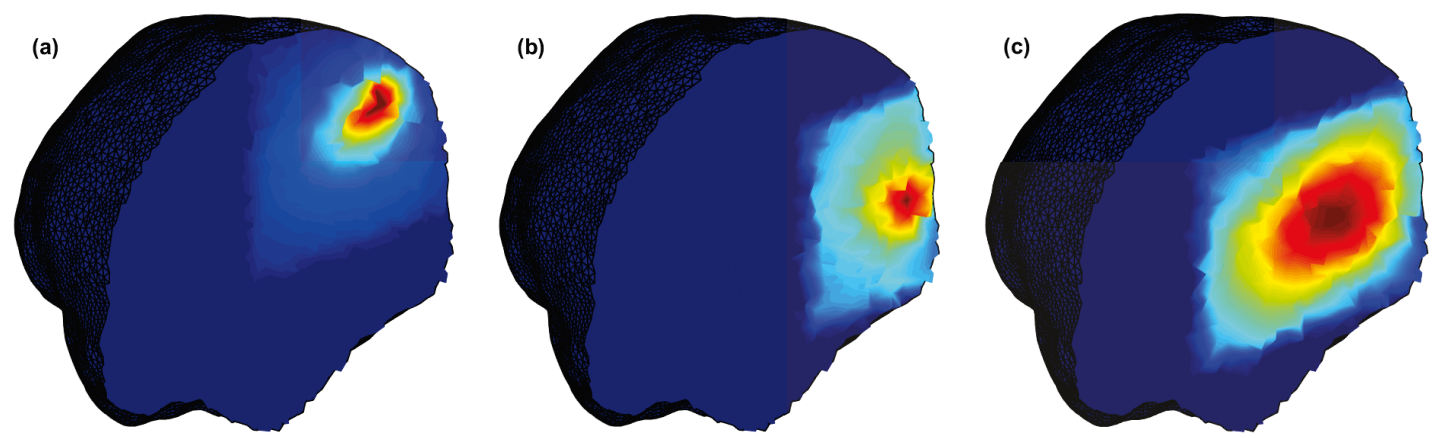

Figura 6.22: Mapas de CCI obtenidos para el decrecimiento lineal: (a) P1 (corteza motora) y sin ruido aditivo, (b) P2 (circunvolución temporal superior) con SD de ruido de $1 n V$, y (c) P3 (ínsula) con $\mathrm{SD}$ de ruido de $0,01 \mu V$. En todos los casos se muestra un corte coronal que pasa por el centro de la esfera con conductividad dinámica.
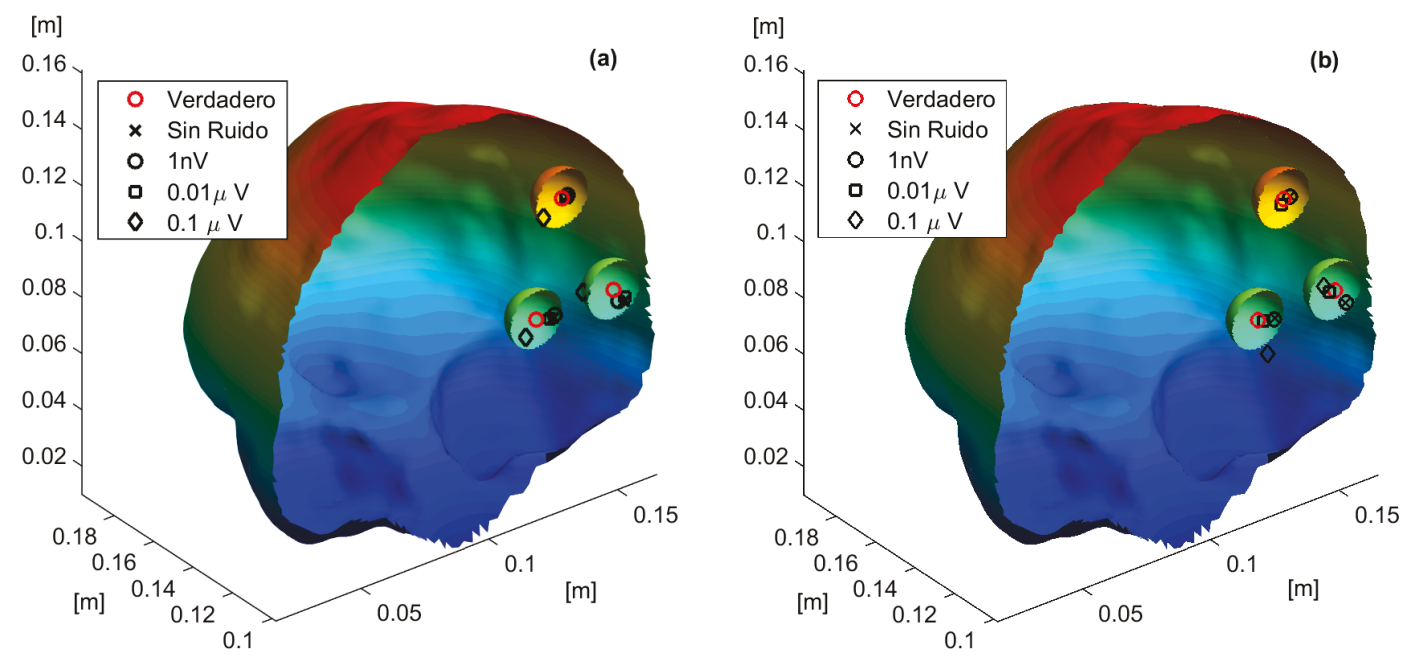

Figura 6.23: Centros de gravedad obtenidos para las tres posiciones y para los distintos niveles de ruido analizados para (a) el decrecimiento lineal y (b) el pulso gaussiano.

para el caso del decrecimiento lineal, con una SD de ruido de $0,01 \mu \mathrm{V}$. 
Tabla 6.5: Error de Posición (PE) $[\mathrm{mm}]$.

\begin{tabular}{lcccccccc}
\hline & \multicolumn{3}{c}{ Decrecimiento lineal } & \multicolumn{4}{c}{ Pulso gaussiano } \\
SD: & Sin ruido & $1 n V$ & $0,01 \mu V$ & $0,1 \mu V$ & Sin ruido & $1 n V$ & $0,01 \mu V$ & $0,1 \mu V$ \\
\hline P1 & 1,88 & 2,01 & 1,29 & 8,27 & 2,05 & 2,26 & 2,62 & 18,4 \\
P2 & 6,17 & 6,06 & 5,12 & 10,3 & 6,27 & 6,30 & 2,24 & 6,87 \\
P3 & 5,98 & 6,65 & 4,98 & 6,60 & 6,10 & 5,93 & 2,97 & 14,2 \\
\hline
\end{tabular}

P1: Corteza motora. P2: Circunvolución temporal superior. P3: Ínsula.

Tabla 6.6: Resolución $(\mathrm{RES}) \times 10^{-3}$.

\begin{tabular}{lcccccccc}
\hline & \multicolumn{3}{c}{ Decrecimiento lineal } & \multicolumn{5}{c}{ Pulso gaussiano } \\
SD: & Sin ruido & $1 n V$ & $0,01 \mu V$ & $0,1 \mu V$ & Sin ruido & $1 n V$ & $0,01 \mu V$ & $0,1 \mu V$ \\
\hline P1 & 10,9 & 12,4 & 45,5 & 199 & 11,2 & 15,7 & 131 & 188 \\
P2 & 19,6 & 24,6 & 34,4 & 192 & 18,9 & 20,9 & 113 & 179 \\
P3 & 26,6 & 31,1 & 85,4 & 263 & 26,9 & 34,2 & 197 & 225 \\
\hline
\end{tabular}

P1: Corteza motora. P2: Circunvolución temporal superior. P3: Ínsula.

\subsection{Discusión}

Aunque el modelo matemático de EIT en diferencias linealizado es equivalente al del problema de localización de fuentes en EEG, el uso de técnicas de filtrado espacial en EIT no es tan intuitivo ya que el filtrado espacial ha estado relacionado con problemas donde existen fuentes electromagnéticas reales como en las comunicaciones o en EEG/MEG. A continuación se discuten los resultados de aplicar el filtro espacial LCMV y sus variantes a problemas de localización de cambios de conductividad en EIT.

\subsubsection{Sesgo y resolución}

En las Figs. 6.2(a,b), 6.10(a,b), 6.19 y 6.22, y las tablas 6.1, 6.2, 6.3, 6.4, 6.5 y 6.6 se puede observar que la técnica de EIT-SF puede ser utilizada para localizar con bajo sesgo y buena resolución un cambio de conductividad localizado. Para datos simulados de una fuente, y en comparación con el método clásico de GN-Laplace, el filtro LCMV presentó siempre una mejor resolución y, en general, un mejor PE. Sólo 

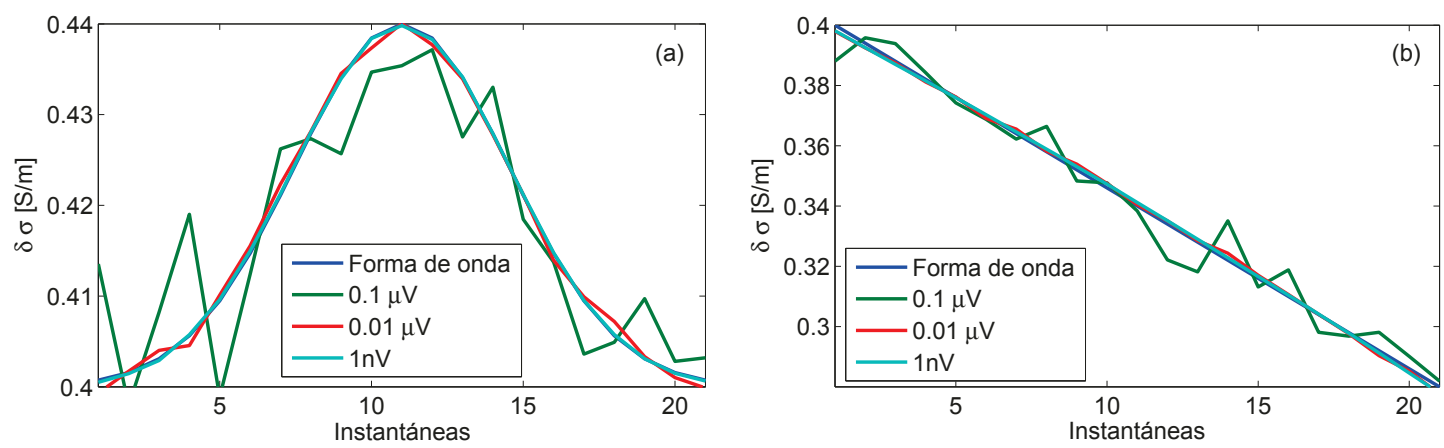

Figura 6.24: Formas de onda estimadas y normalizadas para los cambios de conductividad ubicados en la circunvolución temporal superior (P2), para (a) el decrecimiento lineal y (b) el pulso gaussiano.

en el caso de reconstrucciones bidimensionales y bajos niveles de ruido se encontró que el PE con el método GN-Laplace fue apenas menor.

Para el caso de datos reales obtenidos con el IMPETOM C, el sesgo fue difícil de determinar ya que no se consiguió la información de la posición real de los objetos durante los experimentos. Además, la posición central del objeto pudo haber cambiado durante los ciclos de inflado-desinflado. Lo que sí se pudo observar es un corrimiento del CoG estimado para la fuente más débil cuando se adicionó ruido blanco (Fig. 6.7). En cambio, para los experimentos realizados en EGI ("tridimensionales") la situación fue completamente diferente, ya que los experimentos fueron diseñados, armados, ejecutados y analizados íntegramente en favor de cumplir con los objetivos de esta tesis. Esto permitió medir a-priori la posición verdadera del centro de los objetos inmersos en el tanque cilíndrico. En la Fig.6.15(a,b,d,e) y en la Tabla 6.1 se puede observar que el PE fue menor con el filtro LCMV que con el método GN-Laplace. Nótese que el error fue ligeramente mayor que en las simulaciones, atribuible a la forma irregular de los objetos y a pequeñas incertezas en el posicionamiento de los objetos. La resolución espacial (RES) también fue ligeramente peor con datos reales que en las simulaciones debido al mayor tamaño de los objetos con respecto a las fuentes simuladas.

Para dos cambios de conductividad simulados, las Figs. 6.4(a) y 6.10(c) muestran que con el algoritmo LCMV fue posible localizar ambos cambios de conductividad, 

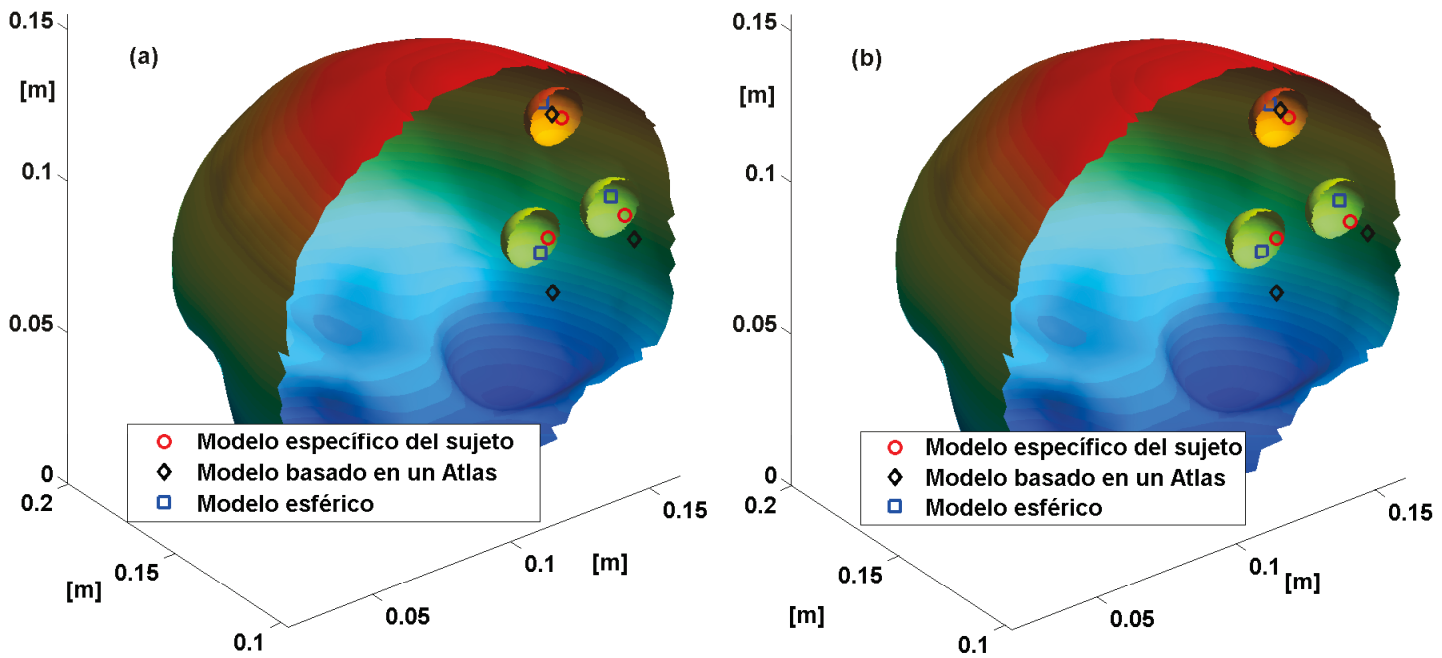

Figura 6.25: Localización utilizando un modelo de cabeza diferente. (a) Pulso gaussiano sin ruido. (b) Decrecimiento lineal con ruido. Todos los resultados fueron registrados hacia el modelo basado en atlas.

aunque una fuente se vea más débil, sobre todo para bajo SNR. Para dos cambios de conductividad reales, sólo se analizaron los experimentos obtenidos en EGI ya que para el caso de los datos tomados con el IMPETOM C, se encontró que el error de aproximación al suponer linealidad para armar el conjunto de datos con dos fuentes simultáneas a partir de los datos de las fuentes individuales no era despreciable frente al ruido, como sí ocurrió con el caso de los experimentos realizados en EGI. El pico del mapa de CCI de la Fig. 6.15(c) coincide con el punto medio de la fuente del centro de la Fig. 6.15(b), pero la fuente del borde se encuentra oscurecida.

El valor del parámetro de regularización es muy importante al computar los mapas de CCI. La utilización de la carga diagonal para la regularización funcionó de acuerdo a lo esperado tanto en las simulaciones como en los datos reales. Sólo en el caso de dos fuentes en simultáneo, una de las fuentes es apenas visible. Sin embargo, y como se discute más adelante, el uso de restricciones de ganancia nula, o del conocimiento de la forma de onda permitieron detectar con mayor claridad esas fuentes. 


\subsubsection{Estimación de la forma de onda}

Para los datos simulados de una sola fuente, el filtro pudo reconstruir la forma de onda del cambio de conductividad orientándolo hacia el elemento de máximo CCI, como se puede ver en las Figs. 6.3 y 6.11. Para los datos reales, las formas de onda reconstruidas en las Figs. 6.8 y 6.16 fueron coherentes con la dinámica de los objetos utilizados. Sólo en el caso de la fuente del centro con en los experimentos de EGI (más alejada de los sensores), el cambio de conductividad de los objetos más pequeños no siempre aumentó con el tamaño de los mismos, aunque el método pudo diferenciar entre un pequeño objeto presente y la ausencia del mismo.

Para dos cambios de conductividad, si se orienta al filtro hacia una fuente, el efecto de la otra fuente afecta o distorsiona la forma de onda. Esto se puede ver en las Figs. 6.5, 6.11 y aún más claramente en la Fig. 6.16. Como se explica a continuación, el uso de restricciones de ganancia nula permite neutralizar el efecto indeseado de interferencias correlacionadas.

\subsubsection{Variantes del filtro LCMV}

Una de las principales desventajas de los filtros espaciales es la imposibilidad de distinguir o separar fuentes completamente correlacionadas ("completamente correlacionadas" significa módulo del coeficiente de correlación igual a uno) (van Been et al., 1997). Si las fuentes no se encuentran completamente correlacionadas, el algoritmo puede distinguirlas como dos fuentes diferentes dependiendo de sus intensidades, del grado de correlación y de la distancia espacial entre ellas. La inclusión de restricciones de ganancia nula es una técnica muy utilizada en los filtros espaciales para suprimir interferencias correlacionadas, sobre todo en el ámbito de las comunicaciones donde la dirección de fuentes interferentes puede ser fija y conocida. Aunque la posibilidad de utilizar este tipo de restricciones se menciona en Sekihara y Nagarajan (2008), no fue posible encontrar en la literatura el uso de restricciones de ganancia nula en datos reales de EEG o MEG. En los experimentos se muestra que su utilización es completamente posible en el caso de EIT-SF. En las Figs. 6.4(d,h), $6.13(\mathrm{a}, \mathrm{b})$ y $6.18(\mathrm{a}, \mathrm{b})$ se puede observar que la fuente que era apenas visible aparece 
más claramente con el uso de restricciones de ganancia nula. Más aún, en las Figs. $6.5,6.16$ y 6.11 se puede ver que el uso de restricciones de ganancia nula elimina las distorsiones producidas por la otra fuente, mejorando notablemente la calidad de las formas de onda estimadas (nótese que las salidas de los filtros con restricciones de ganancia nulas son más parecidas a las salidas obtenidas con los datos de una sola fuente). A los fines prácticos es posible obtener un primer mapa de CCI sin utilizar restricciones de ganancia nula, y luego ir agregando este tipo de restricciones en las ubicaciones de las fuentes más fuertes para poder ver otras fuentes más débiles.

En las Figs. 6.13(c-d) y 6.18(c-d) se muestra que el conocimiento previo de la forma de onda también puede ser utilizado para detectar cambios de conductividad particulares, según el método simple de la Ec. (6.15). Un diccionario de formas de onda previamente elaborado permitiría mejorar la localización de cambios de conductividad relacionados con patologías específicas. Un diccionario de ese tipo podría ser construido utilizando EIT-SF en experimentos controlados.

\subsubsection{Error en la posición de los sensores}

En las simulaciones agregando variaciones en la ubicación de los sensores se encontró que, como se puede observar en la Fig. 6.12, en todos los casos el CoG obtenido con el filtro espacial LCMV está más cerca del centro verdadero que el CoG obtenido con el método GN-Laplace. Sin embargo, la varianza del CoG del método GN-Laplace es menor que la varianza obtenida con el filtro LCMV. Un análisis teórico sería posible utilizando la Cota de Cramér-Rao, de manera similar que en Beltrachini et al. (2011b). Los errores en la posición de los sensores pueden inducir errores en la localización, y algunos métodos que contemplan imprecisiones en la posición de los sensores han sido desarrollados (Dai et al., 2008; Dardé et al., 2012). Alternativamente, se han propuesto métodos para estimar la posición de los electrodos de manera más precisa, como en von Ellenrieder et al. (2013). 


\subsubsection{Potenciales aplicaciones de EIT-SF en el cerebro}

En accidentes cerebro-vasculares (ACV) de tipo isquémico, se espera encontrar un cambio de conductividad localizado y predominante. La potencialidad de EIT para la detección y caracterización temprana de accidentes cerebro-vasculares, basada principalmente en su portabilidad y relativo bajo costo, ha sido ampliamente señalada en la literatura (Clay y Ferree, 2002; Bayford, 2006; Horesh, 2006; Holder, 2008; Shi et al., 2008). En las Figs. 6.19, 6.20, 6.22 y 6.23, y en las Tablas 6.5 y 6.6 se muestra que el filtro LCMV también permite detectar y localizar un cambio de conductividad en el cerebro, con bajo error de posición y buena resolución, incluso para señales con un cierto nivel de ruido aditivo. Más aún, la forma de onda del cambio de conductividad también puede estimarse con EIT-SF, lo cual podría ser de utilidad para clasificar el tipo de ACV.

La localización de activación neuronal también podría beneficiarse de EIT-SF. Su mejor resolución comparada con los algoritmos de reconstrucción comúnmente utilizados en EIT, y la posibilidad de utilizar restricciones de ganancia nula para suprimir interferencias correlacionadas son características prometedoras para localizar regiones de alta actividad como en el caso de epilepsia o en el análisis de potenciales evocados. En las Figs. 6.24, 6.25 se muestra la localización para un pulso gaussiano emulando este tipo de cambios de conductividad, y en las Tablas 6.5 y 6.6 se puede observar el bajo error y la buena resolución en las estimaciones. Estas aplicaciones también podrían aprovechar la estimación de la forma de onda de los cambios de conductividad.

En las Figs. 6.19 y 6.20 se puede observar que para niveles de ruido iguales, utilizar 125 pares en lugar de 63 no parece mejorar el desempeño de la localización de manera significativa. Esto podría ser una consecuencia de que para esos experimentos de simulación, la región que cambia de conductividad se encuentra más cerca del electrodo $\mathrm{Cz}$ (electrodo fijo para 63 pares de inyección) que de los electrodos Fz y $\mathrm{Pz}$ (electrodos fijos para 125 pares de inyección).

Como en las primeras etapas de un ACV la geometría específica del paciente generalmente no está disponible, se estudió la utilización de modelos de cabeza 
promedio y modelos esféricos. La localización con otros modelos resultó satisfactoria, ya que como se observa en la Tabla 6.5, en la mayoría de los casos el PE fue menor a $1 \mathrm{~cm}$ que es el radio de la región con cambio de conductividad. A diferencia de lo esperado, se encontró que en varios casos el modelo basado en atlas presentó un PE mayor que el modelo esférico. Esto puede deberse a la geometría específica del sujeto y/o a que una mejor registración sea necesaria.

\subsection{Conclusiones}

En este capítulo se presentó el empleo del método de filtrado espacial en problemas de localización de cambios de conductividad en EIT. Se mostró que el método sirve para estimar la posición central de cambios de conductividad de manera precisa y con buena resolución, comparando su desempeño con el método clásico de reconstrucción GN-Laplace. La localización fue incluso posible utilizando geometrías realistas y adicionando niveles de ruido cercanos a los esperables en mediciones biomédicas reales.

La utilización de restricciones de ganancia nula y del conocimiento a-priori de las formas de onda facilitó la detección de fuentes más débiles y la supresión del efecto indeseado de otros cambios de conductividad correlacionados. Es importante resaltar que EIT-SF sólo usa un vector de sensibilidad a la vez, en lugar de utilizar la matriz de sensibilidad (Jacobiano) completa como ocurre en los métodos de reconstrucción estándar. Esto se vuelve ventajoso en términos computacionales cuando el número de elementos de la malla es elevado como en modelos tridimensionales detallados de la cabeza, que pueden requerir millones de elementos. A su vez, el método alternativo para generar la matriz de rigidez presentado en esta tesis en el capítulo 2 puede también ser utilizado para ahorrar memoria y tiempo de cómputo. También se describió un método directo para seleccionar el valor del parámetro de regularización, lo que se considera como otra ventaja de EIT-SF. Se mostró que el método permite además reconstruir la forma de onda de los cambios de conductividad en una región de interés particular. Debido a la alta resolución temporal de EIT y a su portabilidad, EIT-SF puede proporcionar nueva información acerca de la dinámica 
de los cambios de conductividad.

Los resultados obtenidos sobre tanques experimentales ilustraron el desempeño esperable de EIT-SF en sentido general, sin restringirse a aplicaciones de EIT en el cerebro humano. Luego, se mostró que utilizando modelos de cabeza realistas, EITSF puede ser utilizado satisfactoriamente para localizar un cambio de conductividad y para estimar su variación temporal, incluso sin utilizar la geometría específica del sujeto. En resumen, los resultados aquí presentados sugieren que la utilización de EIT-SF es prometedora para la detección temprana de ACVs en lugares de baja complejidad (como ambulancias) y para la detección de actividad neuronal, donde cambios de conductividad localizados son esperables. 


\section{Capítulo 7}

\section{Optimización en tDCS}

\subsection{Introducción}

La estimulación de corriente continua transcraneana (tDCS) surge principalmente como una alternativa a los psicofármacos para el tratamiento de desórdenes del comportamiento, enfermedad de Parkinson o aún en epilepsia (Boggio et al., 2006; Yook et al., 2011; Kalu et al., 2012). La tDCS consiste en aplicar una corriente continua por medio de electrodos colocados sobre el cuero cabelludo para modificar los umbrales de activación de las neuronas, aumentando o disminuyendo la tasa de disparos (Priori, 2003; Lang et al., 2005). La principal motivación de la tDCS es la posibilidad de direccionar el tratamiento hacia una región espacial particular del cerebro y no afectar a todo el cerebro como ocurre con los psicofármacos. En este sentido, es de interés diseñar patrones de inyección de corriente que optimicen la relación de compromiso de maximizar la densidad de corriente en la región de interés y minimizarla en el resto del cerebro. Si bien se han desarrollado algoritmos basados en soluciones de mínima norma (LS) o basados en filtros espaciales del tipo LCMV, estas soluciones son generalmente imprácticas y difíciles de implementar debido la complejidad del equipamiento requerido (Dmochowski et al., 2011; Sadleir et al., 2012). Es por esto que surge la necesidad de encontrar soluciones cuasi-óptimas pero más sencillas que tengan en cuenta restricciones de hardware y sean más fáciles de implementar en un equipo de bajo costo. Una manera de encontrar estas soluciones 
es basarse en el principio de reciprocidad, el cual relaciona el problema directo en EEG con el problema de optimización en tDCS.

En el presente capítulo se describe el principio de reciprocidad y se lo utiliza para encontrar patrones de inyección convenientes que consideran restricciones de hardware para su fácil implementación. Se realiza un análisis de desempeño de tres métodos basados en reciprocidad comparándolos con los métodos LS y LCMV. Dos de los métodos basados en reciprocidad son métodos "ad-hoc" y el restante es un algoritmo novedoso y simple que busca aprovechar las ventajas de los primeros dos. La comparación se realiza en términos de precisión (o sesgo), dispersión (o focalidad), intensidad y direccionalidad, utilizando arreglos de 128 y 256 electrodos. Se utilizan modelos de cabeza realistas, de siete capas (o tejidos) homogéneas e isótropas, aplicando el método FEM para resolver el problema directo en tDCS, es decir, determinar la distribución de la densidad de corriente sobre la corteza cerebral para un determinado patrón de inyección.

\subsection{Problema directo}

El problema directo (PD) consiste en calcular el potencial eléctrico en la cabeza, cuando se aplica una corriente sobre el cuero cabelludo. En particular, interesa el potencial eléctrico sobre la materia gris del cerebro. La solución al PD puede realizarse de igual manera que se resuelve el PD en EIT, ya que físicamente el problema es idéntico, es decir, debe satisfacer la ecuación de Laplace con condiciones de borde de Neumann, como en la Ec. (2.6). Por ende, el PD puede resolverse de manera analítica para geometrías de la cabeza esféricas o numérica para geometrías arbitrarias de la misma manera que se expone en el capítulo 2. En las simulaciones que se presentan en este capítulo se utilizaron modelos realistas, por lo que se discretizó el volumen y se empleó el método FEM lineal de la Ec. (2.37) que se resolvió utilizando el método del gradiente conjugado precondicionado de Barrett et al. (1994).

Cualquier patrón de inyección que puede generarse con $L$ electrodos, se puede descomponer en $L-1$ patrones de inyección independientes. Una posibilidad es generar un conjunto de patrones $\mathbf{f}_{i}$ donde $i$ es el electrodo de inyección de corriente 
con intensidad $I_{\text {MAX }}$ y los demás electrodos tienen una intensidad $-I_{M A X} /(L-$ 1). $I_{M A X}$ es la corriente máxima permitida. Se pueden utilizar otros conjuntos de patrones independientes que deberían llevar a los mismos resultados. Si se resuelve el PD para cada patrón, es posible calcular el gradiente del potencial eléctrico en cada elemento de la discretización resultando una matriz de transferencia $\mathbf{G}$ de tamaño $3 N_{e} \times(L-1)$. En $\mathbf{G}$, la columna $i$ corresponde a la solución del PD obtenida con $\mathbf{f}_{i}$. $N_{e}$ es el número total de elementos de la región de interés (típicamente toda la materia gris) y el 3 se debe a las tres componentes del gradiente.

\subsection{Algoritmos de optimización}

Supongamos un objetivo o blanco en los elementos $k_{1}, k_{2}, \ldots, k_{r}$ del mallado del carebro, con una densidad de corriente deseada según una orientación $\mathbf{u}$ de tamaño $3 \times 1$. Es posible armar un vector de selección de objetivo $\mathbf{s}$ de tamaño $N_{e} \times 1$ con "unos" en las posiciones $k_{1}, k_{2}, \ldots, k_{r} \mathrm{y}$ "ceros" en el resto. Luego, se puede construir el vector objetivo b de tamaño $3 N_{e} \times 1$ como: $\mathbf{b}=\mathbf{s} \otimes \mathbf{u}$, donde $\otimes$ representa el producto de Kronecker. Se plantea entonces el sistema lineal sobredeterminado:

$$
\mathrm{Gc}=\mathbf{b},
$$

donde $\mathbf{c}$ es el vector de coeficientes $c_{i}$ de la combinación lineal de los patrones base $\mathbf{f}_{i}$ para formar el patrón de inyección $\mathbf{f}$. Es decir,

$$
\mathbf{f}=\sum_{i}^{L-1} c_{i} \mathbf{f}_{i} .
$$

En otras palabras, se busca la combinación lineal de $\operatorname{los} \mathbf{f}_{i}$ que genere sobre la materia gris la "mejor" (con algún criterio apropiado) aproximación a la distribución de corriente deseada b. Al ser un sistema sobredeterminado, el problema de la Ec. (7.1) generalmente no tiene solución, ya que muy probablemente no exista combinación lineal de $\operatorname{los} \mathbf{f}_{i}$ que genere exactamente la distribución de densidad de corriente deseada b. Es por esto que generalmente se opta por buscar la solución de mínimos 
cuadrados (LS) o la solución que se basa en el filtro espacial LCMV, alternativas que se desarrollan a continuación.

\subsubsection{Mínimos cuadrados (LS)}

La solución de LS a la Ec. (7.1) es el vector de coeficientes c de tamaño $(L-1) \times 1$ que minimiza la norma al cuadrado de la diferencia entre Gc y b, es decir:

$$
\mathbf{c}_{L S}=\underset{\mathbf{c}}{\operatorname{argmin}}\left\{\|\mathbf{G} \mathbf{c}-\mathbf{b}\|^{2}\right\}=\left(\mathbf{G}^{T} \mathbf{G}\right)^{-1} \mathbf{G}^{T} \mathbf{b} .
$$

Luego, $\mathbf{f}_{L S}$ se forma a partir de $\mathbf{c}_{L S}$ según la Ec. (7.2) y se normaliza para que el total de la corriente inyectada sea igual a $I_{M A X}$.

\subsubsection{LCMV}

Otro criterio para determinar un par de inyección óptimo es utilizar el enfoque de LCMV, que fija una restricción de densidad de corriente deseada en un punto espacial $\vec{x}$ y minimiza la potencia total de la solución. La formulación matemática es:

$$
\mathbf{c}_{L C M V}=\underset{\mathbf{c}}{\operatorname{argmin}}\left\{\|\mathbf{G} \mathbf{c}\|^{2}\right\} \text { sujeto a } \widetilde{\mathbf{G}} \mathbf{c}=\mathbf{u},
$$

que se resuelve de manera similar al procedimiento descripto en la sección 6.2 de esta tesis y donde $\widetilde{\mathbf{G}}$ son las tres filas de $\mathbf{G}$ correspondientes al elemento del mallado que se encuentra en la ubicación $\vec{x}$. La solución entonces es similar a la de la Ec. (6.10) y viene dada por:

$$
\mathbf{c}_{L C M V}=\left(\mathbf{G}^{T} \mathbf{G}\right)^{-1} \widetilde{\mathbf{G}}^{T}\left(\widetilde{\mathbf{G}}\left(\mathbf{G}^{T} \mathbf{G}\right)^{-1} \widetilde{\mathbf{G}}^{T}\right)^{-1} \mathbf{u}
$$

Nuevamente $\mathbf{f}_{L C M V}$ se forma a partir de $\mathbf{c}_{L C M V}$ según la Ec. (7.2) y se normaliza para que el total de la corriente inyectada sea igual a $I_{M A X}$.

Nótese que estas dos versiones simples de LS y LCMV no tienen en cuenta otras restricciones como ser valores máximos en la corriente de cada electrodo individual, que sí se contemplan en las versiones de Dmochowski et al. (2011). Sin embargo, si se 
tienen en cuenta esas restricciones se requieren soluciones iterativas y computacionalmente costosas. Las versiones más simples de las Ecs. (7.3) y (7.5) no requieren soluciones iterativas y se utilizan principalmente en este capítulo como referencias de desempeño para evaluar los algoritmos basados en el principio de reciprocidad que sí consideran todas las restricciones de seguridad y las limitaciones del hardware.

\subsection{Principio de reciprocidad}

El teorema de reciprocidad (Malmivuo y Plonsey, 1995; Nunez y Srinivasan, 2006) enuncia que dado un dipolo eléctrico en la posición espacial $\vec{x}$ y con momento dipolar d, el potencial eléctrico $\Phi$ que se genera en el cuero cabelludo entre los puntos $A$ y $B$ puede calcularse a través de un simple producto escalar entre vectores:

$$
\Phi(A)-\Phi(B)=\mathbf{d}^{T} \cdot \frac{\vec{\nabla} \psi_{A B}(\vec{x})}{I_{A B}},
$$

donde $\psi_{A B}(\vec{x})$ es el potencial eléctrico resultante de aplicar una corriente eléctrica $I_{A B}$ en los puntos $A$ y $B$.

En base a este principio se puede mostrar que:

1. Si el gradiente del potencial eléctrico en $\vec{x}$ debido a la corriente $I_{A B}$ es igual a una orientación objetivo unitaria $\mathbf{u}$, entonces esto se logra eligiendo como $A$ y $B$ a los puntos sobre el cuero cabelludo con mayor diferencia de potencial eléctrico debido a un dipolo en $\vec{x}$ con momento $\mathbf{u}$. Matemáticamente:

$$
\text { Si: } \frac{\vec{\nabla} \psi_{A B}(\vec{x})}{\left\|\vec{\nabla} \psi_{A B}(\vec{x})\right\|}=\mathbf{u} \text { entonces }\{A, B\}=\underset{\mathbf{a}, \mathbf{b}}{\operatorname{argmax}}\{\Phi(a)-\Phi(b)\} .
$$

Demostración:

$$
\begin{aligned}
\underset{\mathbf{a}, \mathbf{b}}{\operatorname{argmax}}\{\Phi(a)-\Phi(b)\} & =\underset{\mathbf{a}, \mathbf{b}}{\operatorname{argmax}}\left\{\frac{\vec{\nabla} \psi_{a b}(\vec{x})^{T}}{I_{a b}} \cdot \mathbf{u}\right\} \\
& =\underset{\mathbf{a}, \mathbf{b}}{\operatorname{argmax}}\left\{\frac{\vec{\nabla} \psi_{a b}(\vec{x})^{T}}{I_{a b}} \cdot \frac{\vec{\nabla} \psi_{A B}(\vec{x})}{\left\|\vec{\nabla} \psi_{A B}(\vec{x})\right\|}\right\} .
\end{aligned}
$$


El máximo se alcanza cuando ambos vectores son colineales, es decir, el producto escalar de ambos vectores normalizados es igual a uno. Entonces la Ec. (7.8) se satisface cuando:

$$
\frac{\vec{\nabla} \psi_{a b}(\vec{x}) I_{a b}}{I_{a b}\left\|\vec{\nabla} \psi_{a b}(\vec{x})\right\|}=\frac{\vec{\nabla} \psi_{A B}(\vec{x})^{T}}{\left\|\vec{\nabla} \psi_{A B}(\vec{x})\right\|} \Rightarrow(a, b)=(A, B) .
$$

Sin embargo la recíproca no se satisface ya que no hay certeza de la existencia de un par de puntos $(A, B)$ tales que la corriente $I_{A B}$ genere un gradiente del potencial en $\vec{x}$ con la orientación arbitraria $\mathbf{u}$. Pero, se pude demostrar que:

2. Si se eligen como puntos $A$ y $B$ a los puntos con una mayor diferencia de potencial $\Phi$, generado por un dipolo en $\vec{x}$ y con momento $\mathbf{u}$, el gradiente del potencial $\vec{\nabla} \psi_{A B}(\vec{x})$ debido a una corriente inyectada $I_{A B}$ va a ser el de máxima colinealidad con $\mathbf{u}$. Matemáticamente:

$$
\text { Si: }(A, B)=\underset{a, b}{\operatorname{argmax}}\{\Phi(a)-\Phi(b)\} \text { entonces } \vec{\nabla} \psi_{A B}(\vec{x})^{T} \mathbf{u} \text { es máximo. }
$$

Demostración:

$$
\begin{aligned}
(A, B) & =\underset{a, b}{\operatorname{argmax}}\{\Phi(a)-\Phi(b)\}=\underset{a, b}{\operatorname{argmax}}\left\{\frac{\vec{\nabla} \psi_{a b}(\vec{x})^{T}}{I_{a b}} \cdot \mathbf{u}\right\} \\
& \Rightarrow \frac{\vec{\nabla} \psi_{A B}(\vec{x})^{T}}{I_{A B}} \cdot \mathbf{u} \text { es máximo. }
\end{aligned}
$$

Luego, $(A, B)$ es el par de puntos con los que se logra la mayor colinealidad entre el gradiente del potencial $\psi$ y la orientación objetivo $\mathbf{u}$ en $\vec{x}$.

En resumen, se puede aplicar el principio de reciprocidad simulando un dipolo en la posición espacial objetivo con un momento igual a la dirección deseada para elegir como puntos de inyección de corriente a los puntos sobre el cuero cabelludo con mayor diferencia de potencial. Sin embargo, en tDCS no interesa sólo la direccionalidad, sino también la focalidad, intensidad y sesgo. Además, la libertad de elección de puntos en el cuero cabelludo no es absoluta, ya que la ubicación de los electrodos 

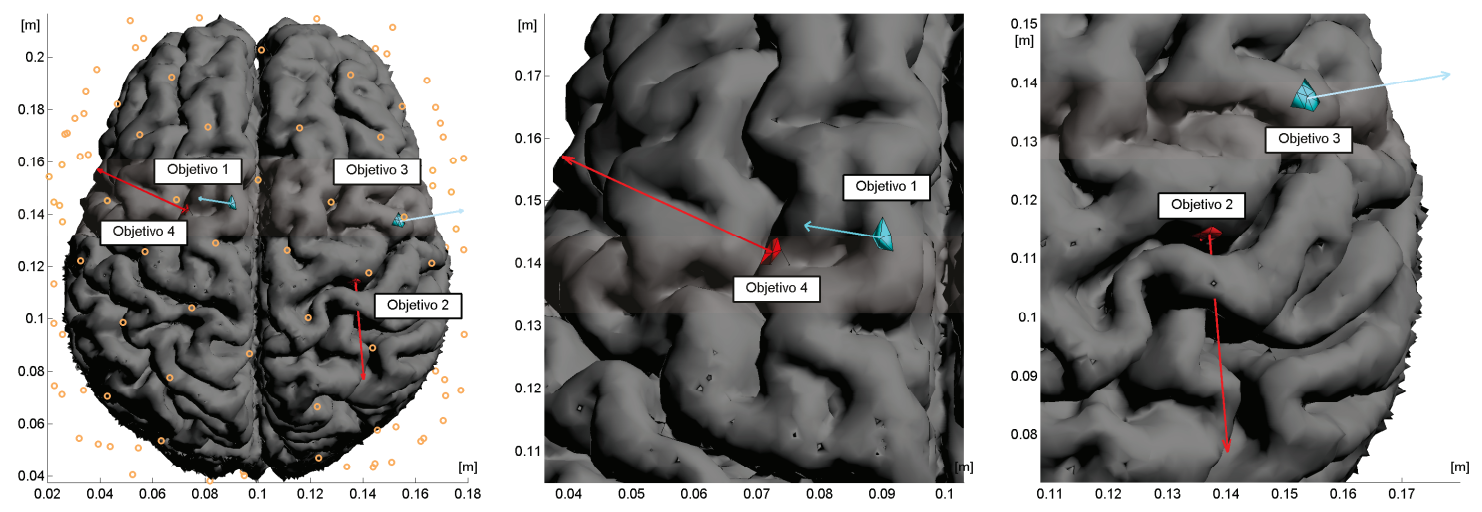

Figura 7.1: Cuatro objetivos o blancos analizados en este capítulo con sus respectivos vectores normales graficados con un largo de $5 \mathrm{~cm}$. Los objetivos 1 y 3 son mayormente perpendiculares y los objetivos 2 y 4 son mayormente tangenciales a la superficie exterior de la cabeza. Los cuatro objetivos son perpendiculares a la superficie exterior de la materia gris. Los círculos "o" indican la ubicación de los electrodos para la red de 128 electrodos. Los objetivos 3 y 4 tienen un electrodo muy cercano en la dirección de su normal, mientras que los objetivos 1 y 2 no.

se supone fija. Y en la práctica, también deben satisfacerse ciertas condiciones de seguridad y deben tenerse en cuenta restricciones de hardware.

\subsection{Patrones basados en reciprocidad}

En esta sección se presentan tres métodos para determinar patrones de inyección de corriente basados en el principio de reciprocidad. Los mismos consideran la restricción de seguridad que la intensidad de corriente en cada electrodo no supere $I_{M A X} / 10$ y la restricción de hardware de utilizar una sola fuente o generador de corriente (que puede dividirse en varios electrodos). Esta última restricción implica que $I_{M A X}$ se distribuye uniformemente en todos los electrodos que actúan como fuentes y que $-I_{M A X}$ se distribuye uniformemente entre todos los electrodos que actúan como sumideros de corriente.

Reciprocidad 1: Para un objetivo en la posición $\vec{x}$ con orientación deseada $\mathbf{u}$ saliente de la corteza cerebral (es decir, con orientación perpendicular a la superficie externa de la materia gris), se simula un dipolo eléctrico en $\vec{x}$ y con momento dipolar 
$\mathbf{d}=\mathbf{u}$ y se calcula el potencial eléctrico que se genera en los electrodos. Los 10 electrodos con mayor potencial eléctrico se eligen como las fuentes de corriente y los 30 electrodos con menor potencial eléctrico se eligen como los sumideros. Se eligen 30 y no 10 electrodos para la corriente negativa con la intención de dispersar la densidad de corriente cerca de los sumideros.

Reciprocidad 2: El método anterior basado completamente en reciprocidad mejora la direccionalidad, pero como se muestra más adelante en los resultados, no reduce la densidad de corriente en el resto del cerebro lo cual sería deseable. Entonces, para aumentar la focalidad, se analiza un segundo método. Las 10 fuentes se eligen de igual manera que en reciprocidad 1, pero para los sumideros se eligen los 10 sensores que rodean a las fuentes, de manera similar a la configuración tipo "anillo" de Dmochowski et al. (2011).

Reciprocidad 3: Como se ve más adelante en los resultados, en términos de sesgo o error de posición (PE), el método reciprocidad 1 es conveniente si la orientación objetivo es paralela a la superficie exterior del cuero cabelludo, y el método reciprocidad 2 es conveniente si la orientación objetivo es perpendicular a la superficie exterior del cuero cabelludo. Se desarrolló entonces un tercer método sencillo, también basado en reciprocidad, con la intención de combinar las ventajas de los dos métodos anteriores, de manera que sea similar a reciprocidad 1 si el objetivo es paralelo al cuero cabelludo y similar a reciprocidad 2 cuando es perpendicular. El algoritmo es el siguiente:

1. Tomar las 10 fuentes de igual manera que en reciprocidad 1 o reciprocidad 2.

2. Calcular la posición $\vec{x}_{m}$ como el promedio de las posiciones de las diez fuentes.

3. Calcular la distancia $d_{\vec{x}_{m} \vec{x}}$ entre $\vec{x}_{m}$ y $\vec{x}$.

4. Calcular una nueva posición $\vec{x}_{s}$ como $\vec{x}_{s}=\vec{x}-d_{\vec{x}_{m} \vec{x}} \mathbf{u}$. Recordar que $\mathbf{u}$ es unitario y con dirección saliente de la corteza.

5. Elegir como sumideros a los diez electrodos más cercanos a $\vec{x}_{s}$ que no sean fuentes. 

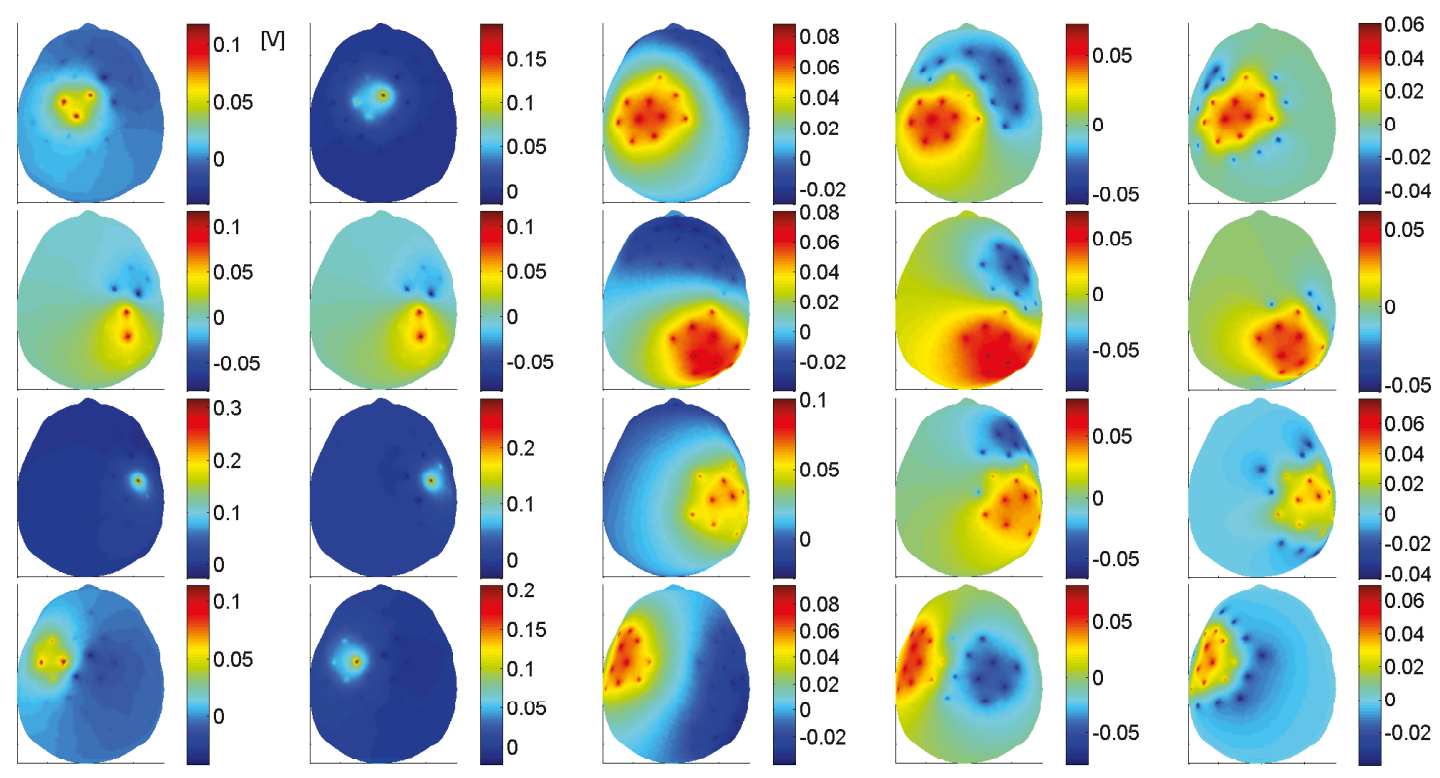

Figura 7.2: Potencial eléctrico sobre el cuero cabelludo para el arreglo de 128 electrodos. Las filas corresponden a cada uno de los cuatro objetivos y las columnas corresponden a los métodos $\mathrm{LS}$, LCMV, reciprocidad 1, reciprocidad 3 y reciprocidad 2 respectivamente. La barra de colores se expresa en Volts.

\subsection{Experimentos simulados}

Se utilizó el mismo modelo de cabeza realista detallado de la sección 3.6.1 con electrodos puntuales. Recordemos que el modelo se construyó a partir de imágenes de MR y CT, resultando un modelo de elementos finitos de aproximadamente 1,4 millones de elementos segmentado en 7 tejidos diferentes. Luego de la segmentación, dos redes de electrodos genéricas (Geodesic Sensor Net, EGI) de 128 y 256 electrodos se ajustaron a la superficie exterior del modelo y se obtuvieron las ubicaciones de los electrodos. Para el cráneo y el cuero cabelludo se adoptaron valores de conductividad cercanos a los obtenidos con bEIT para el mismo sujeto en la sección 3.6.1 para el modelo puntual, específicamente, $0,008 \mathrm{~S} / \mathrm{m}$ para el cráneo y $0,3 \mathrm{~S} / \mathrm{m}$ para el cuero cabelludo. En la Fig. 3.10 se muestra la malla de tetraedros, junto con la segmentación y la ubicación de los electrodos para la red de alta densidad de 128 electrodos. 

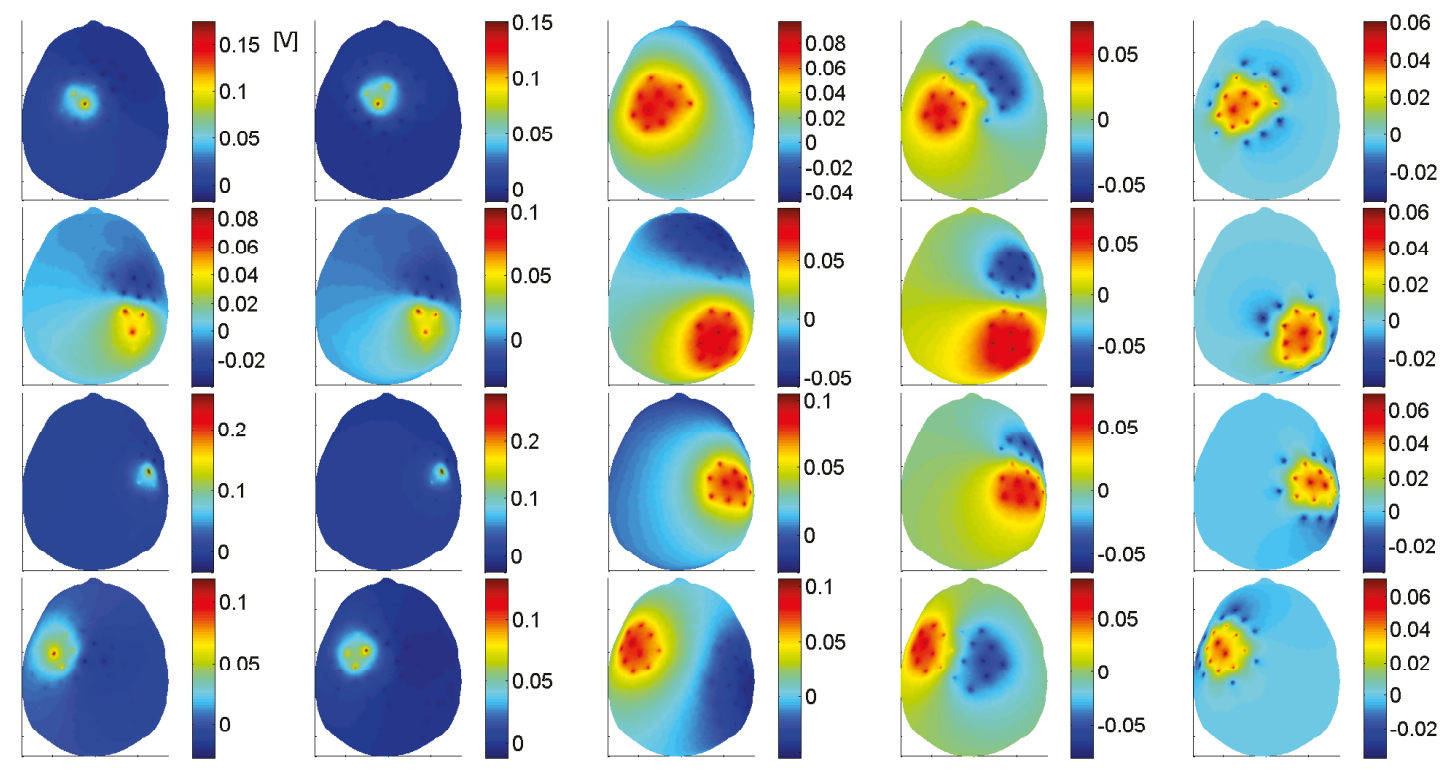

Figura 7.3: Potencial eléctrico sobre el cuero cabelludo para el arreglo de 256 electrodos. Las filas corresponden a cada uno de los cuatro objetivos y las columnas corresponden a los métodos LS, LCMV, reciprocidad 1, reciprocidad 3 y reciprocidad 2 respectivamente. La barra de colores se expresa en Volts.

\subsubsection{Resultados}

Se eligieron 4 objetivos o blancos en la materia gris con dirección saliente para probar y analizar el desempeño de los cinco métodos de elección del patrón de inyección de corriente descriptos anteriormente. Se eligieron dos objetivos en circunvoluciones donde la corteza es aproximadamente paralela a la superficie exterior del cuero cabelludo y en consecuencia el vector normal de esos blancos es perpendicular o radial (objetivos 1 y 3); y otros dos blancos en surcos, donde la corteza es aproximadamente perpendicular al cuero cabelludo por lo que su vector normal es paralelo o tangencial (objetivos 2 y 4). En cada caso se eligió un objetivo para que esté aproximadamente debajo (siguiendo la dirección de su vector normal) de un electrodo de la red de 128 sensores (objetivos 1 y 2), y otro para que esté entre electrodos (objetivos 3 y 4). Los objetivos se muestran en la Fig. 7.1. En las Figs. 7.2 y 7.3 se muestra el potencial eléctrico sobre el cuero cabelludo para los patrones de inyección de corriente obtenidos con los cinco métodos y para 128 y 256 electro- 


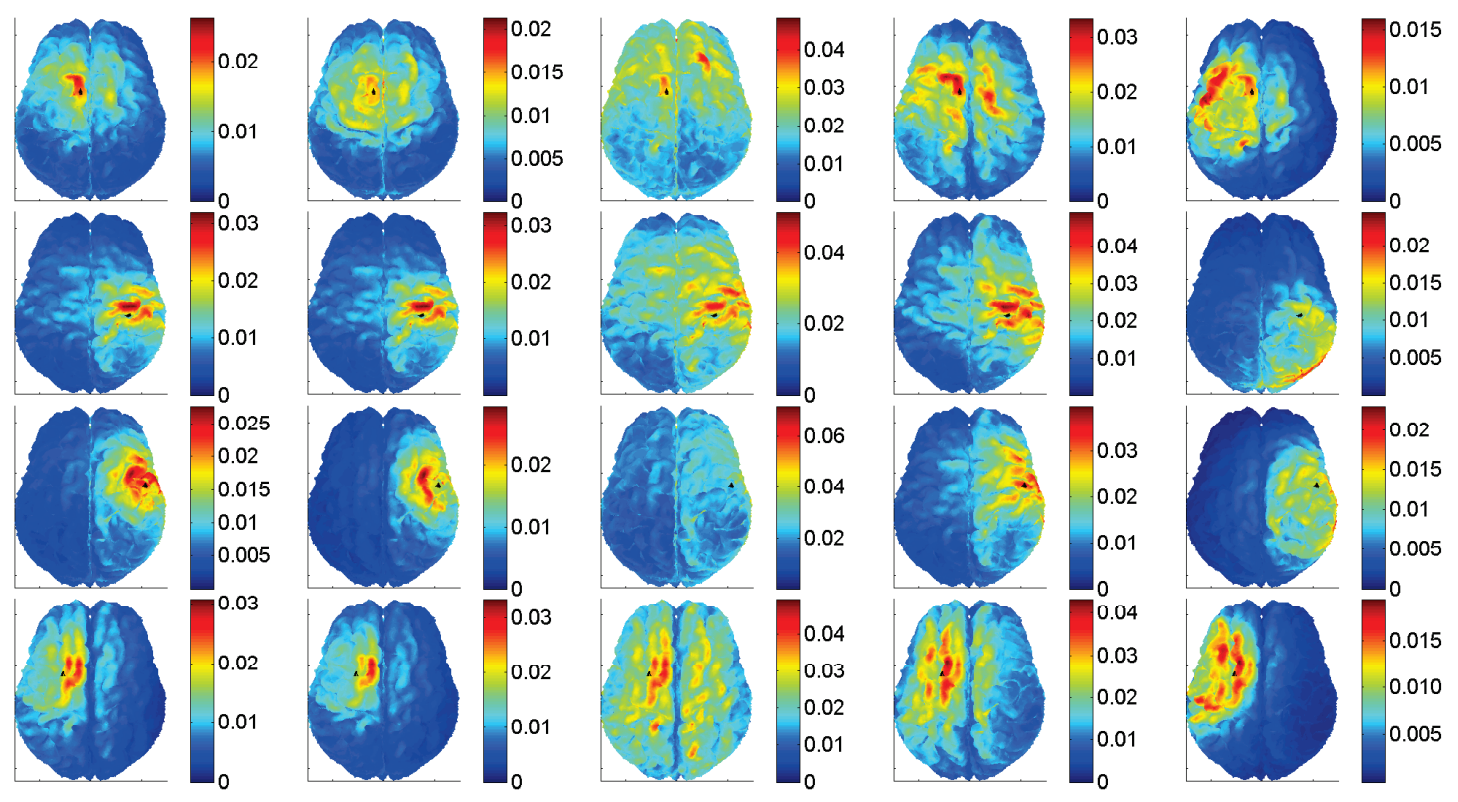

Figura 7.4: Módulo de la densidad de corriente sobre la corteza para 128 electrodos. Las filas corresponden a cada uno de los cuatro objetivos y las columnas corresponden a los métodos LS, LCMV, reciprocidad 1, reciprocidad 3 y reciprocidad 2 respectivamente. La barra de colores se expresa en $A / m^{2}$.

dos respectivamente. Las Figs. 7.4 y 7.5 muestran la densidad de corriente sobre la corteza obtenida con los cinco métodos para 128 y 256 electrodos respectivamente.

En la Fig. 7.6 se muestra la componente normal a la corteza de la densidad de corriente y en la Fig. 7.7 la componente tangencial. En ambos casos se muestra sólo lo obtenido con 256 electrodos, para 128 electrodos las imágenes resultan muy similares.

Para cada objetivo y cada método es de interés cuantificar de alguna manera el desempeño, en particular, la intensidad, la direccionalidad, el error de localización y la focalidad o dispersión. Para la intensidad se calculó el módulo de la densidad de corriente en el objetivo (Fig. 7.8(a)) y la componente de la densidad de corriente en la dirección objetivo (Fig. 7.8(b)). Para cuantificar direccionalidad, se calculó el producto escalar normalizado entre la dirección deseada $\mathbf{u}$ y la densidad de corriente en el objetivo, que se muestra en la Fig. 7.9(a).

Para el error de posición se definió el centro de gravedad ( $\mathrm{CoG}$ ) como en la Ec. 

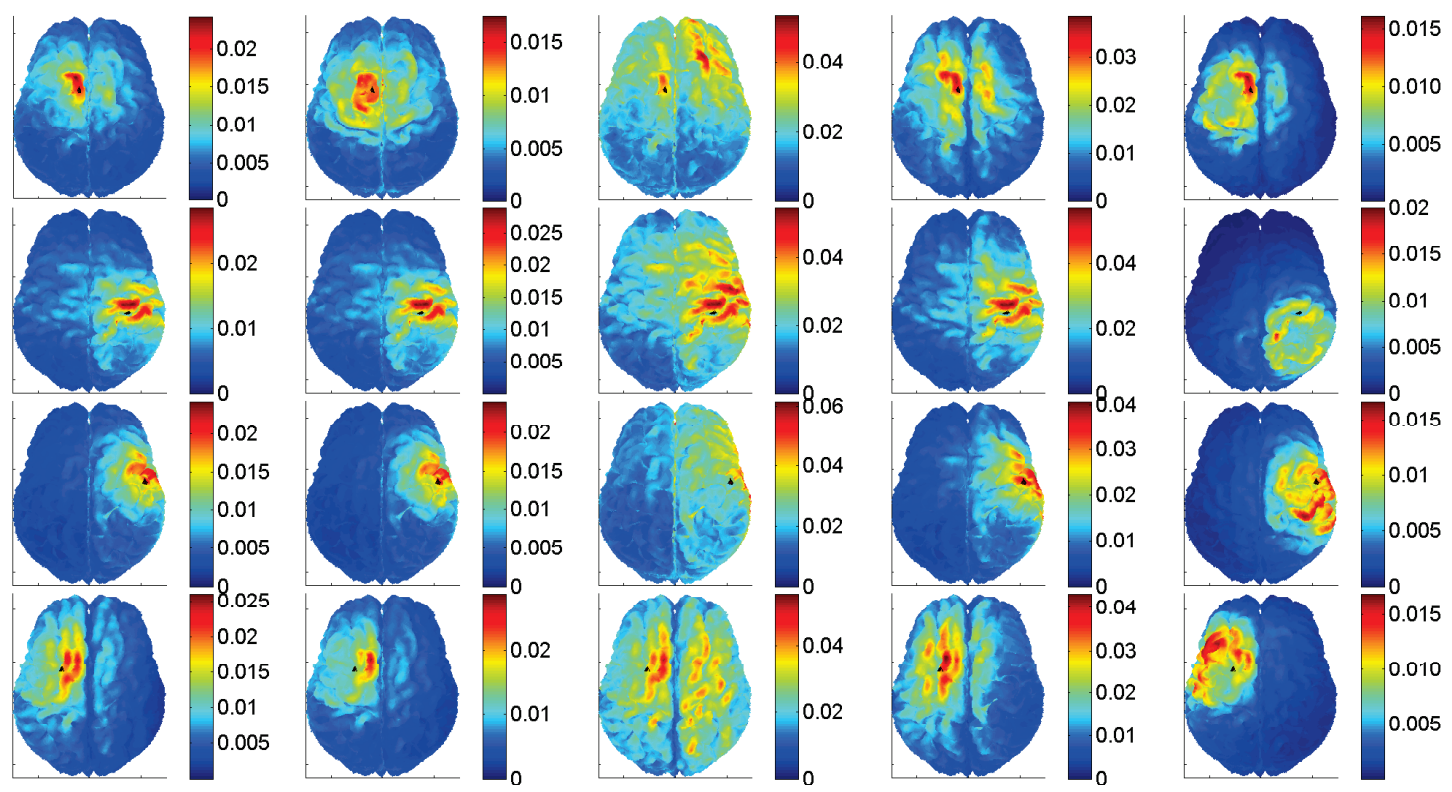

Figura 7.5: Módulo de la densidad de corriente sobre la corteza para 256 electrodos. Las filas corresponden a cada uno de los cuatro objetivos y las columnas corresponden a los métodos LS, LCMV, reciprocidad 1, reciprocidad 3 y reciprocidad 2 respectivamente. La barra de colores se expresa en $A / m^{2}$.

(6.19) a partir del módulo de la densidad de corriente con un umbral de 0,75 y luego se calculó el error de posición (PE) como la distancia euclídea entre el CoG y la ubicación objetivo verdadera. El PE se muestra en la Fig. 7.9(b). Para la focalidad o dispersión se calculó el índice RES de la Ec. (6.20) con un umbral de 0,25 siendo $K$ en este caso el número de elementos de la materia gris. Los índices RES calculados se muestran en la Fig. 7.10.

\subsection{Discusión}

En esta sección se analiza y discute el desempeño de los distintos métodos comparándolos entre sí en términos de error de posición, focalidad o dispersión, direccionalidad e intensidad.

\section{Error de posición:}

Entre los métodos LS y LCMV se observa un error de posición similar si el 


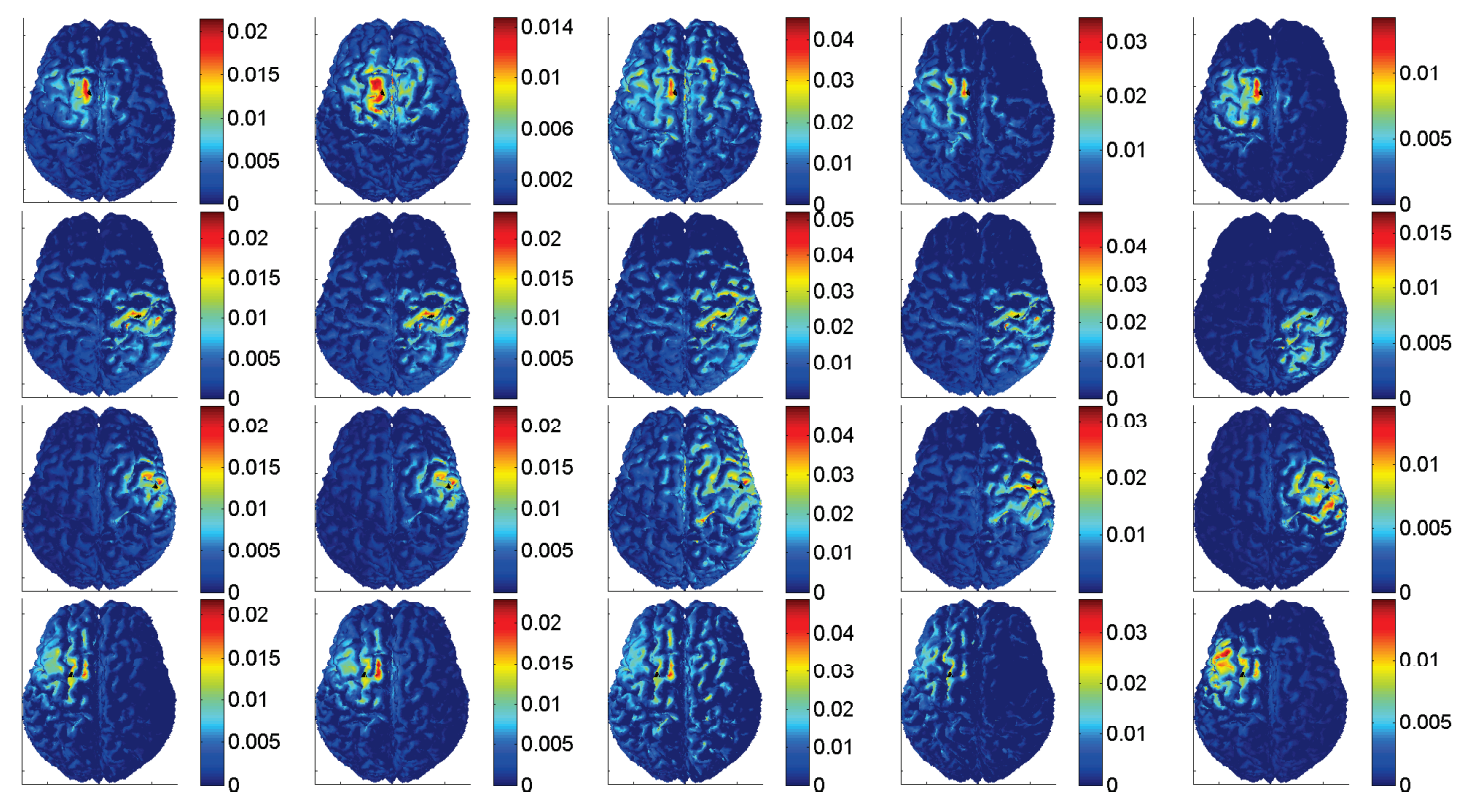

Figura 7.6: Componente normal a la corteza de la densidad de corriente para 256 electrodos. Las filas corresponden a cada uno de los cuatro objetivos y las columnas corresponden a los métodos LS, LCMV, reciprocidad 1, reciprocidad 3 y reciprocidad 2 respectivamente. La barra de colores se expresa en $A / m^{2}$.

objetivo se encuentra directamente debajo de algún electrodo, aunque para el caso de objetivos que no se encuentran directamente debajo de algún electrodo, el método LCMV presenta un mayor error, como se observa en la Fig. 7.9(b). Sin embargo, en la misma figura y comparando las Figs. 7.4 y 7.5 se puede observar que para 256 electrodos, el error de posición de LCMV mejora notablemente, sobre todo para el primer objetivo. Para 256 electrodos, el PE se encuentra en el orden del centímetro para ambos métodos.

En cuanto a los métodos de reciprocidad, puede observarse en las Figs. 7.9(b), 7.4 y 7.5 que el método propuesto (reciprocidad 3) presenta en general un menor error de posición que los otros métodos basados en reciprocidad, y es muy similar al error obtenido con los métodos de referencia LS y LCMV. Además no se encuentran grandes diferencias si el objetivo se encuentra directamente debajo de un electrodo o no, ni tampoco entre usar 128 o 256 electrodos. Como se había anticipado, también se observa un error de posición muy grande para el método reciprocidad 1 cuando 

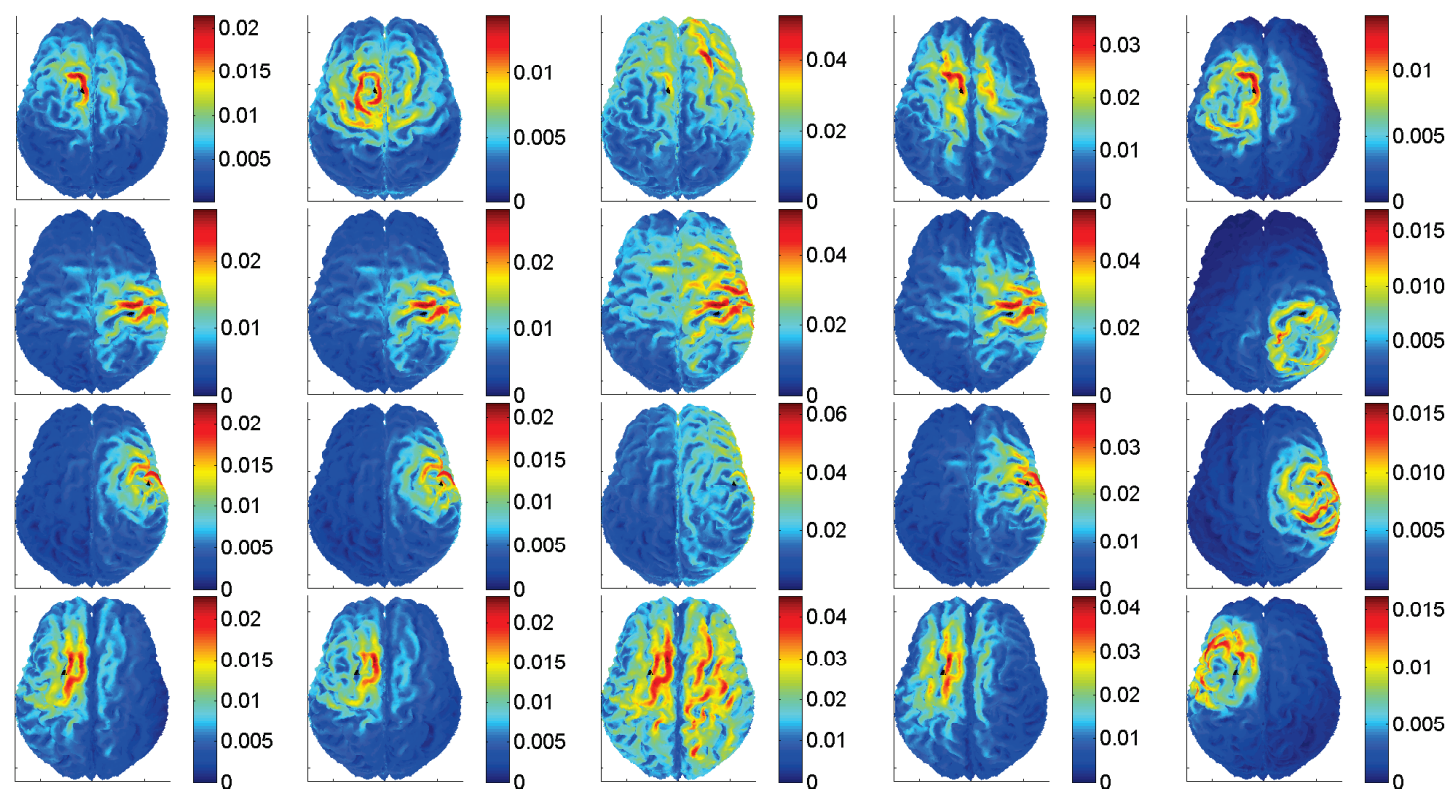

Figura 7.7: Componente tangencial a la corteza de la densidad de corriente para 256 electrodos. Las filas corresponden a cada uno de los cuatro objetivos y las columnas corresponden a los métodos LS, LCMV, reciprocidad 1, reciprocidad 3 y reciprocidad 2 respectivamente. La barra de colores se expresa en $A / m^{2}$.

el objetivo es radial (objetivos 1 y 3), y un error muy grande para reciprocidad 2 cuando el objetivo es tangencial (objetivos 2 y 4). Obsérvese también que el algoritmo más beneficiado con una mayor cantidad de electrodos es el reciprocidad 2 , y esto es razonable ya que una mayor densidad de electrodos permite formar mejor un "anillo" alrededor de las fuentes de corriente.

\section{Focalidad:}

Los métodos LS y LCMV presentan una focalidad similar, independientemente de la orientación y la ubicación del objetivo como se observa principalmente en las Figs. 7.5 y 7.10. Evidentemente el método reciprocidad 2 es el que mejor focalidad presenta, mientras que reciprocidad 1 es el de menor focalidad, tal como era de esperarse. En tanto, el método propuesto reciprocidad 3 presenta una focalidad intermedia del mismo orden a la obtenida con LS y LCMV. En la gran mayoría de los casos y métodos analizados, la focalidad mejora con 256 electrodos.

Si bien aún está en discusión, se cree que la componente más importante en 


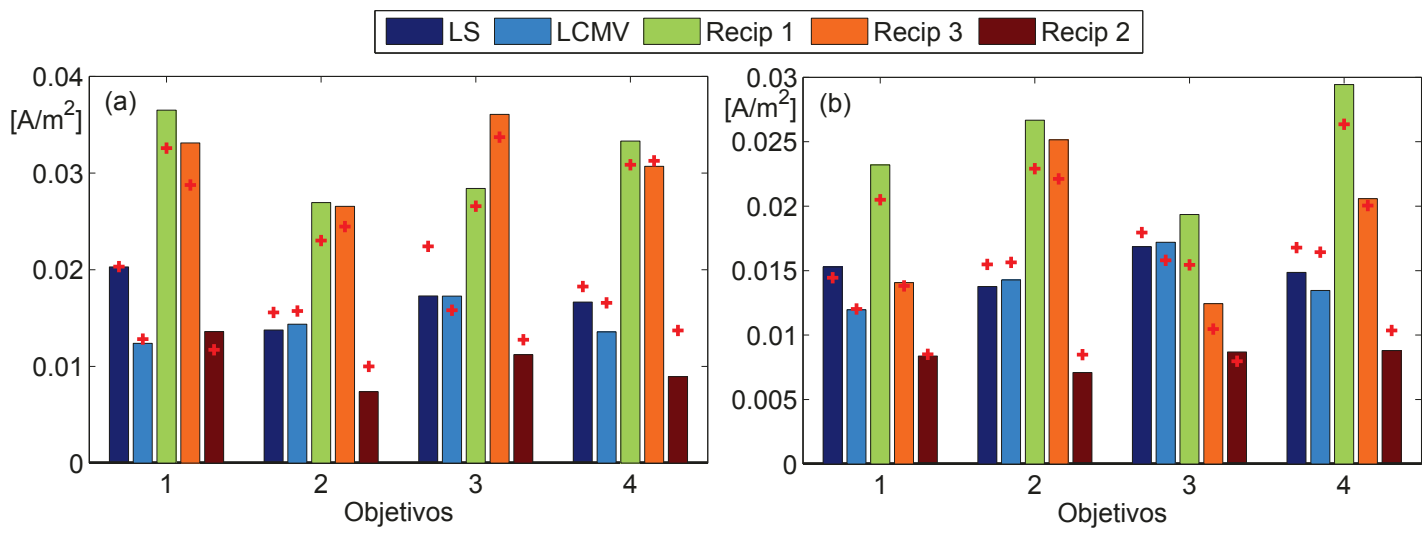

Figura 7.8: (a) Módulo de la densidad de corriente en el objetivo calculada con 256 electrodos (barras) y con 128 electrodos (cruces "+"). (b) Densidad de corriente en la ubicación objetivo y en la dirección buscada, calculada con 256 electrodos (barras) y con 128 electrodos (cruces "+").

tDCS es la componente normal a la superficie cortical ya que la corteza se encuentra mayormente estructurada en columnas de neuronas. Si se observa la Fig. 7.6, en donde sólo se muestra la componente perpendicular a la superficie cortical que es la deseada en los cuatro objetivos analizados, puede observarse más claramente la focalidad y precisión de los métodos propuestos. En la Fig. 7.7 se puede observar en qué regiones se disipa el resto de la corriente que en un principio no estaría estimulando la corteza cerebral por ser tangencial respecto a la alineación predominante de las neuronas en la materia gris.

\section{Direccionalidad:}

Entre los algoritmos LCMV y LS, el primero es el que alcanza una mejor direccionalidad como se ve en la Fig. 7.10(a). Esto es esperable ya que es la restricción dura de la formulación (7.4) y está en concordancia con los resultados de Dmochowski et al. (2011). En general, la direccionalidad de los algoritmos basados en reciprocidad resultó ser alta para los objetivos tangenciales y menor para objetivos radiales. El método propuesto presentó una direccionalidad inferior a la de los otros métodos, pero la intensidad de corriente en la dirección objetivo resultó ser mayor o del mismo orden de la obtenida con los métodos LCMV y LS, como se ve en la Fig. 7.8(b). En la misma figura puede observarse que, según lo esperado, el algoritmo 

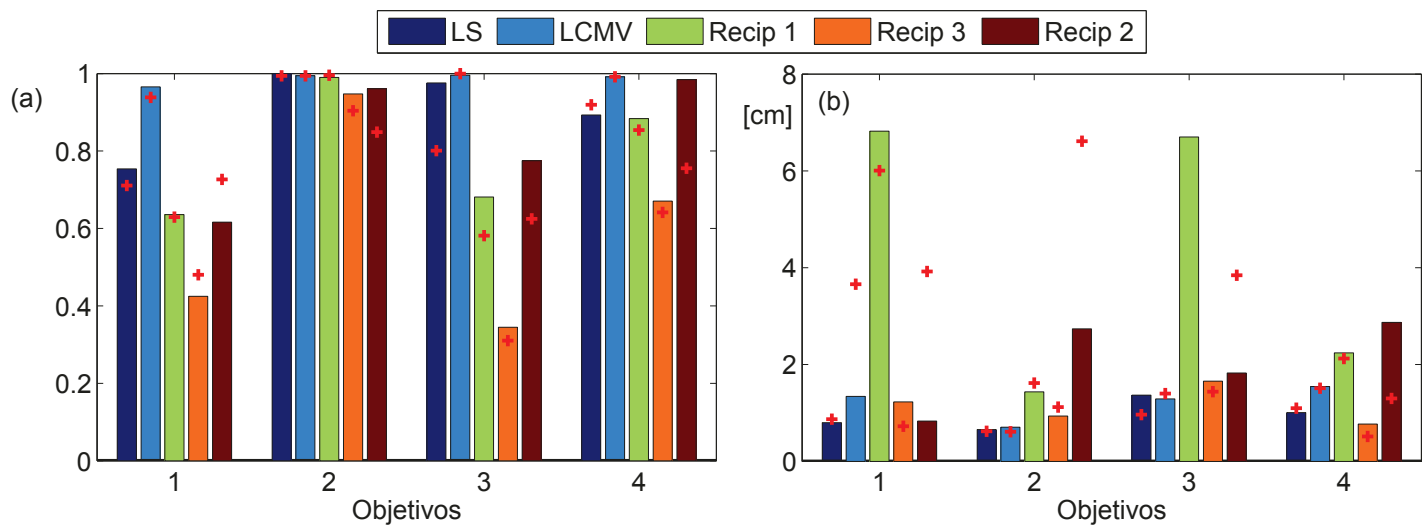

Figura 7.9: (a) Producto escalar normalizado entre la orientación deseada y la densidad de corriente en la ubicación del objetivo, calculado con 256 electrodos (barras) y con 128 electrodos (cruces "+"). (b) Error de posición (PE) como la distancia entre el CoG y la ubicación verdadera del objetivo, calculado con 256 electrodos (barras) y con 128 electrodos (cruces “+"), expresado en centímetros.

reciprocidad 1 es el que resulta en una mayor corriente en el objetivo en la dirección deseada.

\section{Intensidad:}

Tanto la intensidad total, como la intensidad en la orientación buscada son similares si se comparan los algoritmos LCMV y LS, como se observa principalmente en la Fig. 7.8, aunque también se visualiza en las escalas de las Figs. 7.4 y 7.5. En las mismas figuras se puede ver que los algoritmos reciprocidad 1 y reciprocidad 3 son los que resultan en una mayor intensidad de corriente total en el objetivo. A su vez, se observa claramente que el algoritmo reciprocidad 2 es el que menor densidad de corriente concentra en el objetivo debido a la cercanía entre las fuentes y los sumideros de corriente que hacen que una mayor densidad de corriente se concentre en el cuero cabelludo y el cráneo. Para el algoritmo reciprocidad 3, la intensidad en la dirección buscada disminuye considerablemente con respecto a la intensidad total, pero sin embargo, salvo para el objetivo 3, la intensidad en la orientación buscada es mayor o similar a los algoritmos de referencia. Por último, no se observan diferencias considerables en cuanto a intensidad si se utilizan 128 o 256 electrodos. 


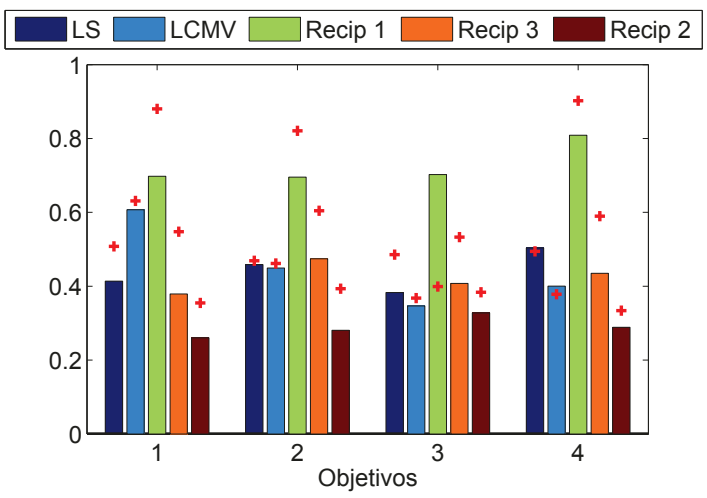

Figura 7.10: Focalidad o dispersión en términos del índice RES, calculado con 256 electrodos (barras) y con 128 electrodos (cruces "+").

\subsection{Conclusiones}

En este capítulo se mostró el desempeño de los métodos LS y LCMV y de tres métodos basados en el principio de reciprocidad y que incorporan más restricciones de hardware. Por un lado se pueden comparar entre sí los algoritmos LS y LCMV y por el otro se puede realizar una comparación entre estos algoritmos y los algoritmos basados en reciprocidad.

Si se comparan los dos métodos LS y LCMV para encontrar patrones de inyección óptima, ambos presentaron un desempeño similar, aunque pueden observarse pequeñas diferencias en direccionalidad, donde LCMV se desempeñó mejor y en sesgo, donde LS presentó un menor error de posición.

Si bien todos los algoritmos basados en reciprocidad presentaron en algunos casos un desempeño similar a LS o LCMV, el algoritmo desarrollado (reciprocidad 3) fue el de desempeño más parecido a los algoritmos LS y LCMV considerando todos los objetivos analizados. Fue el único algoritmo basado reciprocidad que mantuvo un error de posición similar o menor que los algoritmos de referencia en todos los objetivos analizados ya sea para 128 o 256 electrodos. Además presentó una resolución también similar a la de los algoritmos de referencia y lo mismo ocurrió con la intensidad de corriente en la dirección deseada. En el único punto que se desempeñó peor es en direccionalidad, aunque esto no significaría un problema grande en tDCS ya que 
en principio las corrientes tangenciales (perpendiculares al alineamiento promedio de las neuronas) no deberían afectar mayormente a las neuronas. Debe recordarse que los algoritmos LS y LCMV son óptimos en algún sentido y además cuentan con menos restricciones ya que cada electrodo puede suministrar una corriente arbitraria e independiente de los otros electrodos de inyección, lo que resalta el desempeño del método propuesto. En comparación con otras ideas más intuitivas de utilizar el principio de reciprocidad para elegir los electrodos de inyección de corriente, el algoritmo reciprocidad 3 presentó en general un mejor desempeño que se mantuvo para distintas orientaciones del objetivo.

Tanto del análisis teórico como de los resultados expuestos en este capítulo se desprende que utilizar el principio de reciprocidad para determinar patrones de inyección de corriente en tDCS es una alternativa que presenta un desempeño similar a LCMV o LS con mayores requerimientos de hardware. 


\section{Capítulo 8}

\section{Conclusiones}

Se presentaron distintos aportes relacionados con la tomografía de impedancia eléctrica (EIT), particularmente referidos a EIT paramétrico, al problema de reconstrucción en EIT y a la localización de cambios de conductividad en EIT. Además se desarrolló un método de procesamiento de señales para desafectar la actividad eléctrica propia del cerebro y se incursionó en métodos de generación de patrones de inyección de corriente convenientes para estimulación de corriente continua transcraneal.

En cuanto al problema directo en EIT se formuló su solución analítica para geometrías esféricas y su solución numérica para geometrías arbitrarias utilizando el método FEM. Se desarrolló un nuevo método para encontrar el potencial eléctrico que se espera en los electrodos en mediciones de EIT basándose en la solución del problema directo en electroencefalografía, el cual reduce la carga computacional.

Se analizó la técnica de EIT paramétrico para tejidos isótropos y anisótropos, y para un amplio rango de conductividades y factores de anisotropía del cráneo, evaluando sus límites de desempeño teóricos a través del cálculo de la cota de Cramér-Rao. La misma permitió además encontrar pares de inyección de corriente convenientes, resultando ser los que tienen mayor ángulo entre sí pero a su vez tienen varios electrodos de medición a su alrededor. Resultados en simulaciones permitieron determinar un comportamiento de forma aproximadamente exponencial decreciente en la varianza de las estimaciones en función del número de electrodos. Se propuso 
el estimador de máxima verosimilitud junto con el método de Gauss-Newton para resolver el problema y se lo utilizó para determinar satisfactoriamente la conductividad eléctrica equivalente del cráneo y del cuero cabelludo de sujetos a partir de mediciones simuladas y reales de EIT, y utilizando modelos de electrodos tanto puntuales como realistas.

Se desarrolló un tratamiento de las señales provenientes de mediciones de EIT para desafectar la actividad eléctrica propia del cerebro que actúa como ruido indeseado en EIT. Esto se realizó a través del cálculo del estimador de máxima verosimilitud para los llamados coeficientes de atenuación que relacionan la corriente inyectada con el potencial medido, y de la formulación de una forma de onda óptima. Se encontró que una sinusoide de alta frecuencia es muy similar a la forma de onda óptima por lo que es una buena elección como forma de onda para la corriente a inyectar en EIT. Además se mostró una manera de determinar el mínimo número de muestras necesario para desafectar las señales propias del cerebro para dos ejemplos de pacientes reales.

Para el problema de reconstrucción en EIT se comparó el método clásico de regularización en EIT, Tikhonov, con el método más usado en electroencefalografía sLORETA, gracias al paralelismo matemático que existe en el planteo de ambos problemas. Se encontró que sLORETA se puede aplicar a EIT manteniendo su principal ventaja de ser insesgado en tanto que el algoritmo de Tikhonov presenta un sesgo mayor hacia la ubicación de los electrodos. Además se reformuló sLORETA para poder incluir la regularización de Laplace y se mostró que la inclusión de esta regularización, tanto en Tikhonov como en sLORETA reconstruye mejor la distribución de conductividad verdadera y además brinda una mayor robustez frente a variaciones del parámetro de regularización.

Se logró adaptar satisfactoriamente la técnica de filtrado espacial a mediciones de EIT, para localizar cambios de conductividad de pequeño tamaño y para estimar su variación temporal. Se mostró el desempeño del filtro espacial LCMV de modo general basándose en mediciones reales y simuladas sobre tanques cilíndricos experimentales. Se analizó el desempeño de la técnica frente a distintos niveles de ruido aditivo, el efecto de otros cambios de conductividad con cierta correlación y errores 
en la ubicación de los electrodos. Se mostraron las ventajas de utilizar restricciones de ganancia nula para suprimir el efecto de cambios de conductividad no deseados y el aprovechamiento del conocimiento previo de la forma de onda. El algoritmo de filtrado espacial LCMV en EIT mostró tener mejor resolución que el algoritmo clásico de Tikhonov con regularización de Laplace muy usado en EIT. Luego se evaluó a partir de simulaciones numéricas la aplicación específica a la localización de cambios de conductividad dentro del cerebro analizando distintos niveles de ruido, distintas formas de onda y distintas geometrías de la cabeza. Se concluyó que la técnica de filtrado espacial en EIT presenta características prometedoras para la detección de ACVs y para la localización de fuentes de actividad neuronal.

Por último se realizó un análisis de simulación detallado de distintos métodos para determinar patrones de inyección de corriente convenientes para estimulación de corriente continua transcraneal. En particular se estudiaron nuevos métodos basados en el principio de reciprocidad, mostrando un desempeño similar a métodos óptimos como mínimos cuadrados o LCMV que requieren un hardware más complejo. Dentro de ellos se desarrolló un nuevo algoritmo con mejor desempeño que otros algoritmos "ad-hoc" basados en reciprocidad.

En cuanto a trabajos futuros, existen varias líneas de investigación que pueden continuarse a partir de los resultados presentados en esta tesis, involucrando nuevos desarrollos teóricos y una mayor cantidad de validaciones experimentales.

En EIT paramétrico se deben analizar con mayor profundidad los resultados obtenidos a partir de mediciones reales para determinar los motivos por los cuales las conductividades estimadas del cráneo y cuero cabelludo resultaron ser algo inferiores al rango reportado en la literatura. Luego se podría realizar la estimación suponiendo tejidos anisótropos como se mostró en los análisis de simulación. Más aún se pueden emplear modelos del cráneo más complejos con un mayor número de parámetros. Una posibilidad es relacionar la intensidad obtenida a partir de imágenes de CT con la conductividad no homogénea del cráneo y otra posibilidad es descomponer al mapa de conductividad del cráneo en armónicos esféricos lo que brindaría una solución no homogénea y suave.

Respecto a la localización de cambios de conductividad en EIT, resta aún validar 
los métodos con mediciones reales de EIT sobre humanos. Gracias a la colaboración con Electrical Geodesics Inc y en el NeuroInformatics Center de la Universidad de Oregon, Eugene, Estados Unidos se planean realizar dos experimentos, uno en animales y otro en humanos. El primero se basa en inducir un ACV del tipo hemorrágico en cerdos mientras al mismo tiempo se toman mediciones de EIT. El otro experimento consiste en estimular una pequeña región de la corteza cerebral a través de un estímulo sensorial en un dedo de la mano. Se realizarán varias repeticiones del experimento sobre un sujeto del cual se cuenta con buenos modelos eléctricos de la cabeza que incorporan la información de la CT y de DTI, como así también mediciones de EIT paramétrico. Este experimento servirá además para validar los métodos propuestos de forma de onda óptima para desafectar la actividad propia del cerebro en mediciones de EIT. Basándose en simulaciones del experimento y debido a la baja sensibilidad del método para cambios interiores al cráneo, la detección del cambio de conductividad de interés se encuentra muy cercana a los límites de detección para la resolución de los conversores disponibles y los niveles de ruido esperados. Debido a esta baja sensibilidad se planea utilizar la cota de Cramér-Rao para determinar límites teóricos de desempeño al aplicar EIT con electrodos colocados directamente sobre la corteza cerebral y cuantificar la mejora que implicaría evitar el cráneo.

En estimulación de corriente continua transcraneal también se planea probar el método propuesto en experimentos reales con humanos. Se seguirá trabajando para mejorar los algoritmos de generación de patrones de inyección basados en el principio de reciprocidad. Una línea más ambiciosa es tratar de explicar los efectos de la estimulación transcraneal, particularmente aplicada a epilepsia, a través de la modificación de modelos de poblaciones de neuronas fisiológicamente plausibles como los desarrollados en Wendling et al. (2000); Cosandier-Rimélé et al. (2008); Jacobacci et al. (2013). 


\section{Apéndice A}

\section{Resultados en EIT paramétrico deta- llados}

En este apéndice se detallan los resultados de la sección 3.6, obtenidos al aplicar la técnica de EIT paramétrico a mediciones reales sobre un sujeto masculino de aproximadamente 40 años de edad y de origen asiático. Las mediciones fueron íntegramente realizadas por Electrical Geodesics Inc. que luego nos proporcionaron los datos. Los resultados se obtuvieron utilizando un modelo de elementos finitos detallado, propio del sujeto y segmentado en siete tejidos o capas diferentes. Se utilizaron dos modelos diferentes para los electrodos: modelo puntual y modelo realista. En la siguiente tabla, $I+$ indica el electrodo de inyección e $I-$ el electrodo sumidero de corriente. La última columna es la diferencia entre el error obtenido con el modelo de electrodo puntual menos el error con el modelo realista con lo cual un signo positivo indica que el modelo de electrodo realista ajustó mejor a las mediciones que el modelo de electrodo puntual. Las estimaciones señaladas como "N/C" indican que el método no convergió adecuadamente, ya sea porque convergió a valores negativos o porque después de la décima iteración los valores no se estabilizaron con al menos cuatro dígitos significativos. El error se tomó como la norma L2 de la diferencia entre el potencial eléctrico en los electrodos medido y el potencial calculado en el modelo virtual utilizando las conductividades estimadas para el cráneo y el cuero cabelludo. 
Tabla A.1: Resultados de EIT paramétrico con datos reales para ambas modelizaciones de los electrodos. Las conductividades estimadas se expresan en $\mathrm{S} / \mathrm{m}$.

\begin{tabular}{|c|c|c|c|c|c|c|c|c|}
\hline \multicolumn{2}{|c|}{ Par } & \multicolumn{3}{|c|}{ Modelo puntual } & \multicolumn{3}{|c|}{ Mod. realista } & \multirow{2}{*}{$\begin{array}{c}\text { Comparación } \\
\text { Diferencia } \\
{\left[\times 10^{-4}\right]}\end{array}$} \\
\hline$I+$ & $I-$ & $\begin{array}{c}\sigma^{c c} \\
{\left[\times 10^{-1}\right]}\end{array}$ & $\begin{array}{c}\sigma^{c r} \\
{\left[\times 10^{-3}\right]}\end{array}$ & $\begin{array}{c}\text { Error } \\
{\left[\times 10^{-3}\right]}\end{array}$ & $\begin{array}{c}\sigma^{c c} \\
{\left[\times 10^{-1}\right]}\end{array}$ & $\begin{array}{c}\sigma^{c r} \\
{\left[\times 10^{-3}\right]}\end{array}$ & $\begin{array}{c}\text { Error } \\
{\left[\times 10^{-3}\right]}\end{array}$ & \\
\hline 2 & 60 & 3,66 & 5,56 & 1,43 & 2,20 & 9,60 & 1,40 & $-0,24$ \\
\hline 3 & 66 & 5,33 & 3,26 & 2,11 & 3,79 & 6,10 & 2,25 & 1,48 \\
\hline 4 & 70 & 3,19 & 4,69 & 1,69 & $\mathrm{~N} / \mathrm{C}$ & $\mathrm{N} / \mathrm{C}$ & - & \\
\hline 5 & 74 & 2,16 & 5,40 & 1,39 & $\mathrm{~N} / \mathrm{C}$ & $\mathrm{N} / \mathrm{C}$ & - & \\
\hline 6 & 81 & 1,90 & 10,0 & 5,28 & $\mathrm{~N} / \mathrm{C}$ & $\mathrm{N} / \mathrm{C}$ & - & \\
\hline 7 & 99 & $\mathrm{~N} / \mathrm{C}$ & $\mathrm{N} / \mathrm{C}$ & - & 4,29 & 16,1 & 8,80 & \\
\hline 9 & 67 & 4,49 & 4,79 & 1,44 & 2,73 & 8,90 & 1,52 & 0,77 \\
\hline 10 & 71 & 4,52 & 4,05 & 1,24 & 4,20 & 5,50 & 1,34 & 0,99 \\
\hline 11 & 75 & 2,58 & 5,80 & 0,86 & 2,13 & 6,40 & 1,24 & 3,78 \\
\hline 12 & 82 & 2,44 & 5,77 & 0,74 & 1,20 & 6,80 & 1,73 & 9,87 \\
\hline 13 & 88 & 2,17 & 7,01 & 1,03 & $\mathrm{~N} / \mathrm{C}$ & $\mathrm{N} / \mathrm{C}$ & - & \\
\hline 15 & 72 & 4,42 & 5,46 & 1,23 & 3,05 & 9,30 & 1,40 & 1,66 \\
\hline 16 & 76 & 6,55 & 1,35 & 2,10 & 3,51 & 5,90 & 2,38 & 2,76 \\
\hline 18 & 84 & 6,20 & 1,48 & 1,96 & 3,04 & 6,10 & 2,31 & 3,54 \\
\hline 19 & 83 & 3,69 & 3,96 & 0,87 & 3,28 & 5,50 & 1,02 & 1,46 \\
\hline 20 & 89 & 2,93 & 5,38 & 0,87 & 2,01 & 7,60 & 1,38 & 5,02 \\
\hline 22 & 77 & 4,36 & 4,64 & 1,25 & 2,89 & 8,00 & 1,29 & 0,46 \\
\hline 23 & 91 & 5,16 & 2,52 & 1,86 & 3,90 & 4,60 & 1,86 & 0,01 \\
\hline 24 & 90 & 3,92 & 3,70 & 0,85 & 3,25 & 5,40 & 1,06 & 2,03 \\
\hline 26 & 85 & 3,54 & 5,62 & 1,40 & 2,38 & 8,60 & 1,40 & $-0,01$ \\
\hline 27 & 97 & 3,80 & 3,70 & 1,17 & 4,15 & 3,90 & 1,25 & 0,79 \\
\hline 28 & 96 & 4,17 & 3,71 & 0,92 & 2,74 & 6,10 & 1,50 & 5,75 \\
\hline 29 & 95 & 3,24 & 5,12 & 0,97 & 1,68 & 7,50 & 1,80 & 8,29 \\
\hline 30 & 94 & 2,49 & 6,76 & 1,76 & $\mathrm{~N} / \mathrm{C}$ & $\mathrm{N} / \mathrm{C}$ & - & \\
\hline
\end{tabular}


Tabla A.1 - continúa de la página anterior

\begin{tabular}{|c|c|c|c|c|c|c|c|c|}
\hline \multicolumn{2}{|c|}{ Par } & \multicolumn{3}{|c|}{ Modelo realista } & \multicolumn{3}{|c|}{ Modelo puntual } & \multirow{2}{*}{$\begin{array}{c}\text { Comparación } \\
\text { Dif. } \\
{\left[\times 10^{-4}\right]}\end{array}$} \\
\hline$I+$ & $I-$ & $\begin{array}{c}\sigma^{c c} \\
{\left[\times 10^{-1}\right]}\end{array}$ & $\begin{array}{c}\sigma^{c r} \\
{\left[\times 10^{-3}\right]}\end{array}$ & $\begin{array}{c}\text { Error } \\
{\left[\times 10^{-3}\right]} \\
\end{array}$ & $\begin{array}{c}\sigma^{c c} \\
{\left[\times 10^{-1}\right]}\end{array}$ & $\begin{array}{c}\sigma^{c r} \\
{\left[\times 10^{-3}\right]}\end{array}$ & $\begin{array}{c}\text { Error } \\
{\left[\times 10^{-3}\right]}\end{array}$ & \\
\hline 31 & 107 & $\mathrm{~N} / \mathrm{C}$ & $\mathrm{N} / \mathrm{C}$ & - & $\mathrm{N} / \mathrm{C}$ & $\mathrm{N} / \mathrm{C}$ & - & \\
\hline 33 & 92 & 3,58 & 4,81 & 1,29 & 2,03 & 7,30 & 1,63 & 3,39 \\
\hline 35 & 101 & 4,26 & 3,16 & 1,31 & 3,23 & 5,80 & 1,53 & 2,20 \\
\hline 36 & 100 & 3,63 & 4,51 & 1,40 & 1,60 & 7,40 & 2,46 & 10,6 \\
\hline 37 & 125 & 6,95 & 2,89 & 2,41 & 1,62 & 10,2 & 3,73 & 13,2 \\
\hline 38 & 121 & 2,81 & 2,61 & 0,63 & $\mathrm{~N} / \mathrm{C}$ & $\mathrm{N} / \mathrm{C}$ & - & \\
\hline 39 & 98 & 3,45 & 3,98 & 1,27 & 2,84 & 6,40 & 1,46 & 1,91 \\
\hline 40 & 102 & 3,28 & 3,54 & 1,03 & $\mathrm{~N} / \mathrm{C}$ & $\mathrm{N} / \mathrm{C}$ & - & \\
\hline 41 & 108 & 3,35 & 4,56 & 1,59 & 2,49 & 6,80 & 1,59 & $-0,04$ \\
\hline 42 & 1 & 2,50 & 7,21 & 1,10 & $\mathrm{~N} / \mathrm{C}$ & $\mathrm{N} / \mathrm{C}$ & - & \\
\hline 43 & 120 & 2,57 & 2,22 & 0,65 & $\mathrm{~N} / \mathrm{C}$ & $\mathrm{N} / \mathrm{C}$ & - & \\
\hline 44 & 114 & 2,64 & 3,14 & 0,80 & $\mathrm{~N} / \mathrm{C}$ & $\mathrm{N} / \mathrm{C}$ & - & \\
\hline 48 & 102 & 2,96 & 4,35 & 1,25 & 2,83 & 7,60 & 1,40 & 1,48 \\
\hline 49 & 93 & 3,26 & 5,06 & 1,08 & 2,36 & 9,40 & 1,44 & 3,62 \\
\hline 53 & 8 & 3,54 & 5,96 & 1,31 & 1,93 & 9,60 & 1,51 & 2,08 \\
\hline 54 & 126 & 5,04 & 6,02 & 2,07 & 3,53 & 13,6 & 2,55 & 4,87 \\
\hline 55 & 113 & $\mathrm{~N} / \mathrm{C}$ & $\mathrm{N} / \mathrm{C}$ & - & 2,67 & 12,9 & 5,69 & \\
\hline 61 & 14 & 3,91 & 5,96 & 1,14 & 2,34 & 10,5 & 1,38 & 2,48 \\
\hline 78 & 21 & 3,85 & 5,33 & 1,08 & 2,42 & 9,50 & 1,49 & 4,10 \\
\hline 79 & 128 & 5,50 & 3,62 & 1,94 & 2,00 & 10,6 & 2,89 & 9,44 \\
\hline 80 & 56 & 6,92 & 2,97 & 3,68 & 1,96 & 9,40 & 8,75 & 50,7 \\
\hline 86 & 25 & 3,63 & 5,01 & 1,08 & 2,28 & 8,70 & 1,40 & 3,26 \\
\hline 87 & 127 & 2,92 & 6,16 & 0,66 & 2,16 & 10,1 & 1,15 & 4,85 \\
\hline 93 & 32 & 3,12 & 5,53 & 1,15 & 1,79 & 8,30 & 1,42 & 2,68 \\
\hline 103 & 45 & 3,02 & 4,00 & 1,19 & $\mathrm{~N} / \mathrm{C}$ & $\mathrm{N} / \mathrm{C}$ & - & \\
\hline 104 & 57 & 4,33 & 3,03 & 1,61 & 1,83 & 6,50 & 2,06 & 4,56 \\
\hline & & & & & & Cont & a en la 1 & óxima página \\
\hline
\end{tabular}


Tabla A.1 - continúa de la página anterior

\begin{tabular}{ccccccccc}
\hline \multicolumn{2}{c}{ Par } & \multicolumn{3}{c}{ Modelo realista } & \multicolumn{3}{c}{ Modelo puntual } & Comparación \\
$I+$ & $I-$ & $\sigma^{c c}$ & $\sigma^{c r}$ & Error & $\sigma^{c c}$ & $\sigma^{c r}$ & Error & Dif. \\
& & {$\left[\times 10^{-1}\right]$} & {$\left[\times 10^{-3}\right]$} & {$\left[\times 10^{-3}\right]$} & {$\left[\times 10^{-1}\right]$} & {$\left[\times 10^{-3}\right]$} & {$\left[\times 10^{-3}\right]$} & {$\left[\times 10^{-4}\right]$} \\
\hline 105 & 68 & 3,77 & 4,18 & 2,21 & $\mathrm{~N} / \mathrm{C}$ & $\mathrm{N} / \mathrm{C}$ & - & \\
106 & 63 & $\mathrm{~N} / \mathrm{C}$ & 3,49 & 7,39 & 2,12 & 9,80 & 7,09 & $-2,99$ \\
110 & 50 & 3,67 & 3,55 & 1,15 & $\mathrm{~N} / \mathrm{C}$ & $\mathrm{N} / \mathrm{C}$ & - & \\
111 & 64 & 3,33 & 4,76 & 1,59 & $\mathrm{~N} / \mathrm{C}$ & $\mathrm{N} / \mathrm{C}$ & - & \\
112 & 73 & 3,33 & 4,29 & 2,39 & 1,18 & 6,80 & 2,62 & 2,33 \\
115 & 47 & 3,15 & 4,50 & 1,19 & 2,04 & 7,30 & 1,59 & 3,97 \\
116 & 51 & 3,95 & 3,33 & 1,56 & 2,96 & 5,20 & 1,74 & 1,75 \\
117 & 58 & 4,19 & 3,62 & 1,37 & $\mathrm{~N} / \mathrm{C}$ & $\mathrm{N} / \mathrm{C}$ & - & \\
119 & 34 & 3,29 & 4,29 & 0,66 & 2,62 & 7,80 & 0,86 & 2,05 \\
122 & 52 & 6,47 & 2,24 & 2,12 & 2,27 & 7,80 & 3,05 & 9,25 \\
123 & 59 & 4,01 & 3,92 & 1,04 & 4,39 & 4,40 & 1,04 & 0,03 \\
124 & 65 & $\mathrm{~N} / \mathrm{C}$ & $\mathrm{N} / \mathrm{C}$ & - & $\mathrm{N} / \mathrm{C}$ & $\mathrm{N} / \mathrm{C}$ & - & \\
\hline Promedios: & & & & & & \\
\hline
\end{tabular}




\section{Apéndice B}

\section{Parámetro de regularización}

En este apéndice se muestra que la relación señal a ruido de la salida del filtro espacial LCMV de no-distorsión de la Ec. (6.10) aumenta si el parámetro de regularización $\alpha$ de $\mathbf{C}_{\mathbf{Y}}$ es grande. De acuerdo al modelo de señal de bajo rango, donde el número de fuentes $N_{f}$ no completamente correlacionadas es menor al número de mediciones independientes $N_{m}$, la matriz de covarianza muestral $\mathbf{C}$ se puede descomponer en un subespacio de señal y un subespacio de ruido (Sekihara y Nagarajan, 2008):

$$
\mathbf{C}=\mathbf{E}_{S} \Lambda_{S} \mathbf{E}_{S}^{T}+\mathbf{E}_{R} \Lambda_{R} \mathbf{E}_{R}^{T}
$$

donde $\mathbf{E}_{S}$ son los autovectores asociados a los mayores autovalores de $\mathbf{C}$ y $\mathbf{E}_{R}$ son los demás autovectores de C. $\Lambda_{S}$ es una matriz diagonal de tamaño $N_{f} \times N_{f}$ con los $N_{f}$ mayores autovalores de $\mathbf{C}$ y $\Lambda_{R}$ es también diagonal con el resto de los autovalores. Debido a la ortogonalidad entre $\mathbf{E}_{S}$ y $\mathbf{E}_{R}$, la inversa de $\mathbf{C}$ puede escribirse como:

$$
\mathbf{C}^{-1}=\mathbf{E}_{S} \Lambda_{S}^{-1} \mathbf{E}_{S}^{T}+\mathbf{E}_{R} \Lambda_{R}^{-1} \mathbf{E}_{R}^{T}
$$

Si la salida está normalizada, el denominador de la salida (6.10) no influye, por lo que:

$$
\widehat{\delta \boldsymbol{\sigma}_{k}^{T}} \propto \mathbf{j}_{k}^{T} \mathbf{C}_{\mathbf{Y}}{ }^{-1} \mathbf{Y}
$$

Como $\mathbf{C}_{\mathrm{Y}}=\mathbf{C}+\alpha \mathbf{I}, \alpha$ se suma a todos los autovalores de $\mathbf{C}$, ya que el producto 
matricial $\left[\mathbf{E}_{\mathbf{S}} \mathbf{E}_{\mathbf{R}}\right]\left[\mathbf{E}_{\mathbf{S}} \mathbf{E}_{\mathbf{R}}\right]^{T}=\mathbf{I}$. Luego, $\Lambda_{S}^{-1}=\operatorname{diag}\left[1 /\left(\lambda_{1}+\alpha\right) . ., 1 /\left(\lambda_{N_{f}}+\alpha\right)\right]$ y $\Lambda_{R}^{-1}=$ $\operatorname{diag}\left[1 /\left(\lambda_{N_{f}+1}+\alpha\right) . ., 1 /\left(\lambda_{N_{m}}+\alpha\right)\right]$, donde $\lambda_{i}$ son los autovalores de $\mathbf{C}$ ordenados de forma decreciente. Entonces para $\alpha$ grande, es decir, si $\alpha \gg \lambda_{1}$ :

$$
\widehat{\delta \boldsymbol{\sigma}_{k}^{T}} \stackrel{\sim}{\sim} \mathbf{j}_{k}^{T}\left(\mathbf{E}_{S} \mathbf{E}_{S}^{T}+\mathbf{E}_{R} \mathbf{E}_{R}^{T}\right) / \alpha \mathbf{Y}
$$

donde los subespacios de señal y de ruido están afectados por un mismo coeficiente. En cambio, si $\alpha \ll \lambda_{N_{p}}$, los elementos de $\Lambda_{S}^{-1}$ son menores que los elementos de $\Lambda_{R}^{-1}$, por lo que el término $\mathbf{E}_{S} \Lambda_{S}^{-1} \mathbf{E}_{S}^{T}$ se reduce frente al término $\mathbf{E}_{R} \Lambda_{R}^{-1} \mathbf{E}_{R}^{T}$, lo que explica una mayor presencia de ruido en la salida para valores de $\alpha$ chicos.

Ahora, valores de $\alpha$ grandes reducen también la resolución espacial del filtro y pueden incrementar la interferencia o leakage de fuentes espurias presentes en la señal, provenientes de otras ubicaciones espaciales distintas a la que se orienta el filtro (Sekihara y Nagarajan, 2008). Existe entonces una relación de compromiso entre la SNR de la salida y la resolución espacial o el leakage del filtro LCMV. 


\section{Bibliografía}

Abascal, J.-F. P., S. R. Arridge, D. Atkinson, R. Horesh, L. Fabrizi, M. D. Lucia, L. Horesh, R. H. Bayford, y D. S. Holder. Use of anisotropic modelling in electrical impedance tomography; description of method and preliminary assessment of utility in imaging brain function in the adult human head. NeuroImage, 43(2):258 - 268 (2008).

Abascal, J.-F. P. J., S. R. Arridge, W. R. B. Lionheart, R. H. Bayford, y D. S. Holder. Validation of a finite-element solution for electrical impedance tomography in an anisotropic medium. Physiol Meas, 28(7):S129-S140 (2007).

Adler, A., J. Arnold, R. Bayford, A. Borsic, B. Brown, P. Dixon, T. Faes, I. Frerichs, H. Gagnon, Y. Gärber, B. Grychtol, G. Hahn, W. Lionheart, A. Malik, R. Patterson, J. Stocks, A. Tizzard, N. Weiler, y G. Wolf. GREIT: A unified approach to 2D linear EIT reconstruction of lung images. Physiol Meas, 30(6):S35-S55 (2009).

Ahadzi, G., O. Gilad, L. Horesh, R. Bayford, y D. S. Holder. An EIT electrode protocol for obtaining optimal current density in the primary visual cortex. ICEBI'04 - V Electrical Impedance Tomography, págs. 621-624 (2004).

Bagshaw, A., A. Liston, R. Bayford, A. Tizzard, A. Gibson, A. Tidswell, M. Sparkes, H. Dehghani, C. Binnie, y D. Holder. Validation of reconstruction algorithms for electrical impedance tomography of human brain function. Neuroimage, 20:752764 (2003).

Barrett, R., M. Berry, T. F. Chan, J. Demmel, J. Donato, J. Dongarra, V. Eijkhout, R. Pozo, C. Romine, y H. V. der Vorst. Templates for the Solution of Linear Systems: Building Blocks for Iterative Methods, 2nd Edition. SIAM, Philadelphia, PA (1994). 
Bayford, R. Bioimpedance tomography (electrical impedance tomography). Annu. Rev. Biomed. Eng., 8:63-91 (2006).

Beltrachini, L., A. Blenkmann, N. Von Ellenrieder, A. Petroni, H. Urquina, F. Manes, A. Ibáñez, y C. Muravchik. Impact of head models in N170 component source imaging: Results in control subjects and ADHD patients. J Phys Conf Ser, 332(1) (2011a).

Beltrachini, L., N. von Ellenrieder, y C. Muravchik. Análisis del problema directo en EEG sobre medios anisótropos: formulación matemática y simulación mediante FEM. En Asociación Argentina de Mecánica Computacional, tomo 27, págs. 3267-3282 (2008).

Beltrachini, L., N. von Ellenrieder, y C. Muravchik. General bounds for electrode mislocation on the EEG inverse problem. Comput Meth Prog Bio, 103(1):1-9 (2011b). ISSN 0169-2607.

Beltrachini, L., N. von Ellenrieder, y C. Muravchik. Shrinkage approach for spatiotemporal EEG covariance matrix estimation. IEEE Trans. Signal Process., 61(7):1797-1808 (2013). ISSN 1053-587X.

Boggio, P., R. Ferrucci, S. Rigonatti, P. Covre, M. Nitsche, A. Pascual-Leone, y F. Fregni. Effects of transcranial direct current stimulation on working memory in patients with parkinson's disease. J Neurol Sci, 249(1):31-38 (2006).

Calderón, A. On an inverse boundary value problem. En Seminar on Numerical Analysis and its Applications to Continuum Physics, Sociedade Brasileira de Matematica, págs. 65 - 73. Rio de Janeiro (1980).

Chen, Y.-S., C.-Y. Cheng, J.-C. Hsieh, y L.-F. Chen. Maximum contrast beamformer for electromagnetic mapping of brain activity. IEEE Trans. Biomed. Eng., 53(9):1765-1774 (2006).

Clay, M. y T. Ferree. Weighted regularization in electrical impedance tomography with applications to acute cerebral stroke. IEEE Trans Med Imag, 21(6):629-638 (2002).

Clerc, M., G. Adde, J. Kybic, T. Papadopoulo, y J.-M. Badier. In vivo conductivity estimation with symmetric boundary elements. En NFSI2005: 5th International Conference on Bioelectromagnetism and 5th International Symposium on Nonin- 
vasive Functional Source Imaging, tomo 7. International Society for Bioelectromagnetism (2005).

Cosandier-Rimélé, D., I. Merlet, J. Badier, P. Chauvel, y F. Wendling. The neuronal sources of EEG: Modeling of simultaneous scalp and intracerebral recordings in epilepsy. NeuroImage, 42(1):135-146 (2008).

Dai, T., C. Gómez-Laberge, y A. Adler. Reconstruction of conductivity changes and electrode movements based on EIT temporal sequences. Physiol Meas, 29(6):S77 (2008).

Dalziel, C. Electric shock hazard. IEEE Spectr., 9(2):41-50 (1972).

Dannhauer, M., B. Lanfer, C. H. Wolters, y T. R. Knösche. Modeling of the human skull in EEG source analysis. Hum Brain Mapp, 32(9):1383-1399 (2011).

Dardé, J., H. Hakula, N. Hyvönen, y S. Staboulis. Fine-tuning electrode information in electrical impedance tomography. Inverse Probl Imag, 6(3):399-421 (2012).

De Munck, J., T. Faes, A. Hermans, y R. Heethaar. A parametric method to resolve the ill-posed nature of the EIT reconstruction problem: A simulation study. Annals of the New York Academy of Sciences, 873:440-453 (1999).

de Munck, J., H. Huizenga, L. Waldorp, y R. Heethaar. Estimating stationary dipoles from MEG/EEG data contaminated with spatially and temporally correlated background noise. IEEE Trans. Signal Process., 50(7):1565-1572 (2002). ISSN 1053-587X.

Dmochowski, J., A. Datta, M. Bikson, Y. Su, y L. Parra. Optimized multi-electrode stimulation increases focality and intensity at target. J Neural Eng, 8(4) (2011).

Dong, G., R. Bayford, H. Liu, Y. Zhou, y W. Yan. EIT images with improved spatial resolution using a realistic head model. En Conf. Proc. IEEE Eng. Med. Biol. Soc., págs. 1134-1137 (2006).

Dong, G., H. Liu, R. H. Bayford, R. Yerworth, P. H. Schimpf, y W. Yan. Spatial resolution improvement of 3D EIT images by the shrinking sLORETA-FOCUSS algorithm. Physiol Meas, 26(2):S199 (2005).

Eriksen, K. In vivo human head regional conductivity estimation using a threesphere model. En Proc. of the Annual Conf. on Engineering in Medicine and Biology, págs. 1494-1495 (1990). 
Esler, B., T. Lyons, S. Turovets, y D. Tucker. Instrumentation for low frequency EIT studies of the human head and its validation in phantom experiments. $J$ Phys Conf Ser, 224(1):012007 (2010).

Fabrizi, L., L. Horesh, A. McEwan, y D. Holder. A feasibility study for imaging of epileptic seizures by EIT using a realistic FEM of the head. En 14 ed. IFMBE, tomo 14, págs. 3874-3877. Seoul (2006).

Fang, Q. y D. A. Boas. Tetrahedral mesh generation from volumetric binary and gray-scale images. En Proceedings of the Sixth IEEE International Conference on Symposium on Biomedical Imaging: From Nano to Macro, ISBI'09, págs. 11421145. IEEE Press, Piscataway, NJ, USA (2009). ISBN 978-1-4244-3931-7.

Fernández-Corazza, M., L. Beltrachini, N. von Ellenrieder, y C. H. Muravchik. Tomografía de impedancia eléctrica y resonancia magnética como herramientas conjuntas para la estimación paramétrica de la conductividad eléctrica del cráneo y del cuero cabelludo. En XIV Reunión de Trabajo Procesamiento de la Información y Control RPIC 2011, págs. 845-850. Oro Verde, Argentina (2011a).

Fernández-Corazza, M., L. Beltrachini, N. von Ellenrieder, y C. H. Muravchik. Analysis of parametric estimation of head tissue conductivities using electrical impedance tomography. Biomed Signal Proces, 8(6):830-837 (2013a).

Fernández-Corazza, M., L. Beltrachini, N. von Ellenrieder, y C. H. Muravchik. Waveform selection for electrical impedance tomography. Lat Am Trans IEEE, 11(1):402-407 (2013b).

Fernández-Corazza, M., S. Turovets, P. Luu, y D. Tucker. Current pattern optimization in transcranial direct current stimulation based on the reciprocity principle. (2015a). Artículo en preparación.

Fernández-Corazza, M., S. Turovets, P. Luu, y D. Tucker. Optimization in transcranial electrical neuromodulation based on the reciprocity principle. Brain Stimulation, 8(2):403-403 (2015b). ISSN 1935-861X.

Fernández-Corazza, M., N. von Ellenrieder, y C. H. Muravchik. Estimation of electrical conductivity of a layered spherical head model using electrical impedance tomography. J Phys Conf Ser, 332(1) (2011b). Pp. 012022.

Fernández-Corazza, M., N. von Ellenrieder, y C. H. Muravchik. Spatial filtering in 
electrical impedance tomography. J Phys Conf Ser, 407(1) (2012). Pp. 012023.

Fernández-Corazza, M., N. von Ellenrieder, y C. H. Muravchik. sLORETA vs regularización de Tikhonov en reconstrucción de tomografía de impedancia eléctrica. En XV Reunión de Trabajo Procesamiento de la Información y Control RPIC 2013, págs. 283-288. Bariloche, Argentina (2013c).

Fernández-Corazza, M., N. von Ellenrieder, y C. H. Muravchik. EIT spatial filtering in realistically shaped head models. En 15th Int. Conf. on Biomed. App. of Electrical Impedance Tomography, págs. 31-31 (2014). ISBN 978-0-7709-0577-4.

Fernández-Corazza, M., N. von Ellenrieder, y C. H. Muravchik. Linearly constrained minimum variance spatial filtering for localization of conductivity changes in electrical impedance tomography. Int J Numer Method Biomed Eng, 31(2):n/a-n/a (2015c). ISSN 2040-7947.

Ferree, T., K. Eriksen, y D. Tucker. Regional head tissue conductivity estimation for improved EEG analysis. IEEE Trans Biomed Eng, 47(12):1584-1592 (2000).

Fletcher, R. Practical Methods of Optimization; (2nd Ed.). Wiley-Interscience, New York, NY, USA (1987). ISBN 0-471-91547-5.

Frank, E. Electric potential produced by two point current sources in a homogeneous conducting sphere. J. Appl. Phys., 23(11):1225-1228 (1952).

Geddes, L. y L. Baker. The specific resistance of biological materials - A compendium of data for the biomedical engineer and physiologist. Medical and biological engineering, 5(3):271-293 (1967). ISSN 0025-696X.

Geselowitz, D. B. On bioelectric potentials in an inhomogeneous volume conductor. Biophysical Journal, 7(1):1 - 11 (1967). ISSN 0006-3495.

Gilad, O., , y D. Holder. Impedance changes recorded with scalp electrodes during visual evoked responses: implications for electrical impedance tomography of fast neural activity. NeuroImage, 47:514-522 (2009).

Gilad, O., L. Horesh, y D. Holder. Design of electrodes and current limits for low frequency electrical impedance tomography of the brain. Med. Biol. Eng. Comput., 45:621-633 (2007).

Gonçalves, S., J. de Munck, J. Verbunt, F. Bijma, R. Heethaar, y F. L. da Silva. In vivo measurement of the brain and skul resistivities using an EIT-based method 
and realistic models for the head. IEEE Trans. Biomed. Eng., 50(6):754-767 (2003).

Gonçalves, S., J. C. de Munck, R. M. Heethaar, F. H. L. da Silva, y B. W. van Dijk. The application of electrical impedance tomography to reduce systematic errors in the EEG inverse problem - a simulation study. Physiol Meas, 21(3):379-393 (2000).

Halden, K., A. A. P. D. Alwis, y P. J. Fryer. Changes in the electrical conductivity of foods during ohmic heating. Int J Food Sci Tech, 25:9-25 (1990).

Hansen, A. J. y C. E. Olsen. Brain extracellular space during spreading depression and ischemia. Acta Physiologica Scandinavica, 108(4):355-365 (1980).

Hoekema, R., G. Wieneke, F. Leijten, C. van Veelen, P. van Rijen, G. Huiskamp, J. Ansems, y A. van Huffelen. Measurement of the conductivity of skull, temporarily removed during epilepsy surgery. Brain Topogr, 16:29-38 (2003). ISSN 0896-0267.

Holder, D. Electrical impedance tomography of brain function. En World Automation Congress. Hawaii (2008).

Holder, D. S. Detection of cerebral ischaemia in the anaesthetised rat by impedance measurement with scalp electrodes: implications for non-invasive imaging of stroke by electrical impedance tomography. Clin Phys and Physiol Meas, 13(1):63 (1992).

Horesh, L. Some Novel Approaches in Modelling and Image Reconstruction for Multi-Frequency Electrical Impedance Tomography of the Human Brain. Tesis Doctoral, University College London (2006).

IEC60601. Medical electrical equipment. part 1: general requirements for basic safety and essential performance. ed 3.0. International Electrotechnical Commission, Geneva (2005).

Isaacson, D., J. L. Mueller, J. C. Newell, y S. Siltanen. Reconstructions of chest phantoms by the d-bar method for electrical impedance tomography. IEEE Trans Med Imag, 23(7):821-828 (2004).

Jackson, J. D. Classical Electrodynamics Second Edition. John Wiley \& Sons, New York (1975).

Jacobacci, F., M. Sapir, S. Collavini, S. Kochen, y A. Blenkmann. Assessing effective 
connectivity in epileptogenic networks. a model-based simulation approach. $J$ Phys Conf Ser, 477(1):012037 (2013).

Javaherian, A., A. Movafeghi, y R. Faghihi. Reducing negative effects of quadratic norm regularization on image reconstruction in electrical impedance tomography. App Math Model, 37(8):5637-5652 (2013).

Kalu, U., C. Sexton, C. Loo, y K. Ebmeier. Transcranial direct current stimulation in the treatment of major depression: A meta-analysis. Psychol Med, 42(9):17911800 (2012).

Kay, S. M. Fundamentals of statistical signal processing: estimation theory. PrenticeHall, Inc., Upper Saddle River, NJ, USA (1993).

Kleinermann, F., N. Avis, y F. Alhargan. Analytical solution to the threedimensional electrical forward problem for a circular cylinder. Inverse Probl, 16(2):461-468 (2000).

Kunst, M. y P. Schaefer. Ischemic stroke. Radiol Clin N Am, 49(1):1-26 (2011).

Kwon, Y. W. y H. Bang. The Finite Element Method Using MATLAB (2Nd Ed.). CRC Press, Inc., Boca Raton, FL, USA (2000). ISBN 0-8493-0096-7.

Lagarias, J., J. Reeds, M. Wright, y P. Wright. Convergence properties of the NelderMead simplex method in low dimensions. SIAM J. Opt., 9(1):112-147 (1998).

Lai, Y., W. Van Drongelen, L. Ding, K. Hecox, V. Towle, D. Frim, y B. He. Estimation of in vivo human brain-to-skull conductivity ratio from simultaneous extraand intra-cranial electrical potential recordings. Clin Neurophysiol, 116(2):456465 (2005).

Lang, N., H. Siebner, N. Ward, L. Lee, M. Nitsche, W. Paulus, J. Rothwell, R. Lemon, y R. Frackowiak. How does transcranial DC stimulation of the primary motor cortex alter regional neuronal activity in the human brain? Eur J Neurosci, 22(2):495-504 (2005).

Li, K., A. D. Malony, y D. M. Tucker. Automatic brain MR image segmentation by relative thresholding and morphological image analysis. En VISAPP (1)'06, págs. 354-364 (2006).

Lionheart, W., N. Polydordes, y A. Borsic. En Holder, D. S., ed., Electrical Impedance Tomography: Methods, History and Applications, capítulo The reconstruction 
problem, págs. 3-64. Inst. Phys. (2004).

Liu, J., L. Lin, W. Zhang, y G. Li. A novel combined regularization algorithm of total variation and Tikhonov regularization for open electrical impedance tomography. Physiol Meas, 34(7):823-838 (2013).

Malmivuo, J. y R. Plonsey. Bioelectromagnetism: Principles and Applications of Bioelectric and Biomagnetic Fields. Oxford University Press (1995). ISBN 9780195058239.

Mazziotta, J., A. Toga, A. Evans, P. Fox, J. Lancaster, K. Zilles, R. Woods, T. Paus, G. Simpson, B. Pike, C. Holmes, L. Collins, P. Thompson, D. MacDonald, M. Iacoboni, T. Schormann, K. Amunts, N. Palomero-Gallagher, S. Geyer, L. Parsons, K. Narr, N. Kabani, G. L. Goualher, D. Boomsma, T. Cannon, R. Kawashima, y B. Mazoyer. A probabilistic atlas and reference system for the human brain: International consortium for brain mapping (ICBM). Philos. Trans. R. Soc. Lond. B Biol. Sci., 356(1412):1293-1322 (2001).

Mori, S., K. Oishi, H. Jiang, L. Jiang, X. Li, K. Akhter, K. Hua, A. V. Faria, A. Mahmood, R. Woods, A. W. Toga, G. B. Pike, P. R. Neto, A. Evans, J. Zhang, H. Huang, M. I. Miller, P. van Zijl, y J. Mazziotta. Stereotaxic white matter atlas based on diffusion tensor imaging in an ICBM template. NeuroImage, 40(2):570 - 582 (2008). ISSN 1053-8119.

Nentwich, L. M. y W. Veloz. Neuroimaging in acute stroke. Emerg Med Clin N Am, 30:659-680 (2012).

Niedermeyer, E. y F. L. da Silva. Electroencephalography: Basic Principles, Clinical Applications, and Related Fields. Lippincott Williams \& Wilkins, 5th edición (2004). ISBN 0781751268.

Nunez, P. y R. Srinivasan. Electric Fields of the Brain: The Neurophysics of EEG. Oxford University Press (2006). ISBN 9780195050387.

Oostendorp, T., J. Delbeke, y D. Stegeman. The conductivity of the human skull: results of in vivo and in vitro measurements. IEEE Trans Biomed Eng, 47(11):14871492 (2000). ISSN 0018-9294.

Ouypornkochagorn, T., N. Polydorides, y H. McCann. In vivo estimation of the scalp and skull conductivity. En 15th Int. Conf. on Biomed. App. of Electrical 
Impedance Tomography, págs. 10-10 (2014). ISBN 978-0-7709-0577-4.

Pascual-Marqui, R. Standardized low-resolution brain electromagnetic tomography (sLORETA): Technical details. Methods Find Exp Clin Pharmacol, 24(SUPPL. D):5-12 (2002).

Paulson, K. S., W. R. Breckon, y M. K. Pidcock. Electrode modelling in electrical impedance tomography. SIAM Journal of Applied Mathematics, 52:1012-1022 (1992).

Poolman, P., R. Frank, y S. Turovets. Modified lock-in detection for extraction of impressed EEG signals in low-frequency bounded-EIT studies of the human head. En Image and Signal Processing, 2008. CISP '08. Congress on, tomo 1, págs. 174-183 (2008).

Priori, A. Brain polarization in humans: A reappraisal of an old tool for prolonged non-invasive modulation of brain excitability. Clin Neurophysiol, 114(4):589-595 (2003).

Robinson, S. E. y D. F. Rose. Current source image estimation by spatially filtered MEG. En Excerpta Medica, págs. 761-765. Amsterdam (1992).

Rullmann, M., A. Anwander, M. Dannhauer, S. Warfield, F. Duffy, y C. Wolters. EEG source analysis of epileptiform activity using a $1 \mathrm{~mm}$ anisotropic hexahedra finite element head model. NeuroImage, 44(2):399 - 410 (2009). ISSN 1053-8119.

Rush, S. y D. Driscoll. Current distribution in the brain from surface electrodes. Anesth. Analg., 47(6):717-723 (1968).

Russell, G. S., K. J. Eriksen, P. Poolman, P. Luu, y D. M. Tucker. Geodesic photogrammetry for localizing sensor positions in dense-array EEG. Clin Neurophysiol, 116(5):1130 - 1140 (2005). ISSN 1388-2457.

Sadleir, R. y A. Argibay. Modeling skull electrical properties. Ann Biomed Eng, 35:1699-1712 (2007). ISSN 0090-6964.

Sadleir, R., T. D. Vannorsdall, D. J. Schretlen, y B. Gordon. Target optimization in tdcs. Front. Psychiatry, 3(90) (2012). ISSN 1664-0640.

Santos, E. y F. Simini. Electrical impedance tomography for pulmonary oedema extent monitoring: review and updated design. J Phys Conf Ser, 407(1):012024 (2012). 
Sekihara, K. y S. S. Nagarajan. Adaptive Spatial Filters for Electromagnetic Brain Imaging. Springer, Berlin (2008).

Shi, X., F. You, F. Fu, R. Liu, M. Dai, y X. Dong. Preliminary research on monitoring of cerebral ischemia using electrical impedance tomography technique. En 30th IEEE EMBS Conf, págs. 1188-1191. Vancouver (2008).

Silvester, P. y R. Ferrari. Finite Elements for Electrical Engineers. Cambridge University Press, Cambridge (1994).

Tang, C., F. You, G. Cheng, D. Gao, F. Fu, G. Yang, y X. Dong. Correlation between structure and resistivity variations of the live human skull. IEEE Trans Biomed Eng, 55(9):2286-2292 (2008).

Tizzard, A., L. Horesh, R. J. Yerworth, D. S. Holder, y R. H. Bayford. Generating accurate finite element meshes for the forward model of the human head in EIT. Physiol Meas, 26(2):S251 (2005).

Tuch, D., V. Wedeen, A. Dale, J. George, y J. Belliveau. Conductivity tensor mapping of the human brain using diffusion tensor mri. Proc Natl Acad Sci USA, 98(20):11697-11701 (2001).

Turovets, S., V. Volkov, A. Zherdetsky, A. Prakonina, y A. D. Malony. A 3D finitedifference BiCG iterative solver with the fourier-jacobi preconditioner for the anisotropic EIT/EEG forward problem. Comp. Math. Methods in Medicine, págs. $1-12$ (2014).

van Been, B. D., W. van Drongelen, M. Yuchtman, y A. Suzuki. Localization of brain electrical activity via linearly constrained minimum variance spatial filtering. IEEE Trans. Biomed. Eng., 44(9):867-880 (1997).

van der Vorst, H. BI-CGSTAB: A fast and smoothly converging variant of BI-CG for the solution of nonsymmetric linear systems. SIAM J. Sci. Stat. Comput., 13(2):631-644 (1992).

Van Trees, H. Detection, estimation, and modulation theory. PartIV: Optimum array processing. Wiley (2002).

Vauhkonen, M., P. Karjalainen, y J. Kaipio. A Kalman filter approach to track fast impedance changes in electrical impedance tomography. IEEE Trans Biomed Eng, 45(4):486-493 (1998). ISSN 0018-9294. 
von Ellenrieder, N., L. Beltrachini, A. Blenkmann, M. Fernández-Corazza, S. Kochen, y C. Muravchik. A low-cost and robust photogrammetry method for determining electrode positions. En 30th International Epilepsy Congress, tomo 54, págs. 358-358. Montreal, Canada (2013).

Vrba, J. y S. Robinson. Linearly constrained minimum variance beamformers, synthetic aperture magnetometry, and MUSIC in MEG applications. En Conference Record of the Thirty-Fourth Asilomar Conference on Signals, Systems and Computers, 2000., tomo 1, págs. 313-317 (2000).

Wendling, F., J. Bellanger, F. Bartolomei, y P. Chauvel. Relevance of nonlinear lumped-parameter models in the analysis of depth-EEG epileptic signals. Biol Cybern, 83(4):367-378 (2000).

Wolters, C., A. Anwander, X. Tricoche, D. Weinstein, M. Koch, y R. MacLeod. Influence of tissue conductivity anisotropy on EEG/MEG field and return current computation in a realistic head model: A simulation and visualization study using high-resolution finite element modeling. NeuroImage, 30(3):813 - 826 (2006).

Yook, S.-W., S.-H. Park, J.-H. Seo, S.-J. Kim, y M.-H. Ko. Suppression of seizure by cathodal transcranial direct current stimulation in an epileptic patient - a case report -. Ann Rehabil Med, 35(4):579 - 582 (2011).

Zhang, Y., W. van Drongelen, y B. He. Estimation of in vivo brain-to-skull conductivity ratio in humans. Appl Phys Lett, 89 (2006). 
